\title{
The beginning of the adaptive radiation of Theridomorpha (Rodentia) in Western Europe: morphological and phylogenetic analyses of early and middle Eocene taxa; implications for systematics
}

\author{
MONIQUE VIANEY-LIAUD* \& LAURENT MARIVAUX \\ Institut des Sciences de l'Évolution de Montpellier (ISEM, UMR 5554 CNRS/UM/IRD/EPHE), Université Montpellier, Place E. \\ Bataillon, 34095, Montpellier Cedex 5, France.
}

*corresponding author: monique.vianey-liaud@umontpellier.fr

\begin{abstract}
This paper provides a revision of the early and middle Eocene European rodents previously referred to as Ischyromyoidea, including taxa considered to be at the origin of the Theridomorpha. The use of an accurate dental terminology and a better understanding of the size and shape of their infra-orbital foramen (i.o.f.) led us to a substantial revision of this group, which allowed to better characterize them and to appreciate their variability. On these bases, phylogenetic analyses (cladistic and standard Bayesian approaches) of early Ypresian to late Priabonian European rodent species were undertaken in order to highlight the root of the early Theridomorpha and its content. The phylogeny was established based on 343 characters (338 dental) through 45 early Paleogene taxa. The ingroup included on one hand a few North American genera (Reithroparamys, Microparamys, and Acritoparamys) and European ones (Eogliravus, Ailuravus, Corbarimys, Meldimys, Euromys, Plesiarctomys, and Pseudoparamys) considered until now as being related with the North American superfamily Ischyromyoidea. On the other hand, it included genera close to the root of the Theridomorpha (Sparnacomys, Pantrogna, and Hartenbergeromys) and early Theridomyoidea (Masillamys, Protadelomys, and some Pseudosciuridae). The phylogenetic results obtained via the two distinct reconstruction approaches are consistent in virtually all relationships. The proposed systematics here derives from these phylogenetic results. This phylogenetic context led us to change the suprafamilial, familial, subfamilial or generic attribution of several species. Characters of Theridomorpha, like the obliquely developed postprotocristid allied with the occurrence of a metalophulid I, have been found in genera previously considered as Ischyromyidae (Pseudoparamys, Euromys, Sparnacomys, Meldimys, Pantrogna, and Hartenbergeromys) as well as the large i.o.f., when preserved (Pseudoparamys, Hartenbergeromys, and Masillamys). Based on these morphological observations and new phylogenetic considerations, the content of the Theridomorpha clade is here enlarged, thereby extending back the first theridomorph radiations to the early Eocene. Aside, a new taxon (Reinomys rhomboides gen. and sp. nov.) is described from Avenay. In addition, a new genus, Auroremys, is created for the species subita (Comte et al., 2012) from Chery-Chartreuve.
\end{abstract}

Keywords: Dental morphology, character analyses, variability, rodents, Eocene

Submitted 15 January 2020, Accepted 17 March 2021

Published Online 20 September 2021, doi: 10.18563/pv.44.2.e2

(C) Copyright Monique Vianey-Liaud September 2021

\section{INTRODUCTION}

The early Eocene rodents from Europe were long included in the Euramerican superfamily Ischyromyoidea (e.g., Escarguel, 1999). Among them, a genus, Hartenbergeromys was considered to be at the origin of the Theridomorpha, an endemic European group (Escarguel, 1999: 213-215; Marivaux et al., 2004), prior to the middle Eocene true Theridomyoidea, Protadelomys Stehlin \& Schaub, 1951. Based on the results of a comprehensive phylogenetic analysis, Hartenbergeromys Escarguel, 1999, and Pantrogna Hartenberger, 1971, are now no longer regarded as Ischyromyoidea, but placed in an indeterminate family within the Theridomorpha (see Vianey-Liaud \& Marivaux, 2017). In contrast, in the latter paper, an early Eocene genus, Sparnacomys, remained within the ischyromyoids, as the sister genus of the Theridomorpha, their sister group being the clade Pseudoparamys-Plesiarctomys (Vianey-Liaud \& Marivaux, 2017). Sharing some dental apomorphies with theridomorphs, Pantrogna and Hartenbergeromys were supposed to have retained a plesiomorphic infra-orbitary

region, i.e., protrogomorphous, whereas the Theridomyoidea (encompassing two families, Pseudosciuridae and Theridomyidae) are hystricomorphous. The genus Masillamys, defined by Tobien (1954) for three species (M. beegeri, M. krugi, and M. parvus) from Messel (Germany; early middle Eocene) was not included in our previous phylogenetic analysis, because Escarguel (1999: 214, 230), following Hartenberger (1993), placed the genus unequivocally within the Ischyromyoidea, in the tribe Microparamyini. Indeed, their infra-orbitary region was described as "sciuromorphous" since Tobien (1954), and not hystricomorphous as theridomorphs are. We have recently revised this material and shown that Masillamys is actually hystricomorphous, and shares many derived features with theridomorphs (Vianey-Liaud et al., 2019). The species, Masillamys parvus Tobien, 1954, was referred to Microparamys (Hartenberger, 1968), later to its sub-genus Sparnacomys (Hartenberger, 1971) and finally to Hartenbergeromys (Escarguel, 1999), but without a precise evaluation of the dental features. These changes of generic attributions reflect the difficulties in identifying the early Eocene species as either North American or European genera. 
The locality of Prémontré (late early Eocene, Bassin de Paris), from which the genus Hartenbergeromys (Escarguel, 1999) was originally defined, has also yielded the genus Pantrogna (P. marandati Escarguel, 1999). From this locality, fragmentary cranial remains are available, that would allow for a better evaluation of their infra-orbitary features. Numerous teeth of the two species have formerly been described (Escarguel, 1999: 196-207), without providing accurate differential diagnoses between the two genera. A revision of the different species from this locality has therefore proven to be necessary, as well as that from Avenay (early Eocene, Bassin de Paris), as the type species of Pantrogna is P. russelli (Michaux, 1968) from the latter. Finally, as for Pantrogna and Hartenbergeromys, the definition of several early Eocene species and genera, formerly included in the Ischyromyidae, requires a substantial update. This is the case of Sparnacomys chandoni Hartenberger, 1971, Pseudoparamys teilhardi (Wood, 1962), Plesiarctomys savagei (Michaux, 1964) and "Paramys" woodi Michaux, 1964, or among the genera considered as ailuravines like Meldimys louisi (Michaux, 1964), Euromys thaleri (Michaux, 1964) and 'Euromys' inexpectatus Escarguel, 1999, or the later Ailuravus subita Comte et al., 2012.

This paper intends to reconsider not only the infra-orbitary features of these taxa (when material is available) but also their dental features. A new evaluation of the latter, using an accurate terminology (allowing comparisons based on homologies) appeared to be essential. Indeed, the previous descriptions and diagnoses are difficult to use, the proposed criteria often correspond to overall shapes and morphologies, imprecise or very general, sometimes including weakly supported evolutionary hypotheses. The observation of all the dental material of these species from their type localities (Table 1) has led us to a better understanding of their variability, sometimes to highlight new taxa, or to change their generic attribution. In addition, two species from outside of the Bassin de Paris, one referred to Pseudoparamys (P. cezannei Hartenberger, in Godinot et al., 1987) from Palette (Southern France, Bouchesdu-Rhône), the other one referred to Meldimys (M. musak Rana et al., 2008) from Vastan (Gujarat, India), are also questioned. However, discussing all the early Eocene European rodents whether they were previously referred to Microparamys, Reithroparamys and Corbarimys, or suspected to be ascribed to Pseudoparamys, Sparnacomys or Pantrogna (e.g., Escarguel, 1999) is far beyond the scope of this paper.

On these bases, here we carried out phylogenetic analyses in order to formalize phylogenetic relationships and associated taxonomical inferences, as a means to better understand the early radiation of Eocene European rodents, including Theridomorpha and their relationships with Ischyromyoidea. In this context, we describe the origin and evolutionary changes of the specific characters defining the Theridomorpha clade.

\section{MATERIAL AND METHODS}

The table 1 list the species studied in detail in this paper.

The material from Avenay is listed in App. S1; the materials from Prémontré is in App. S2.

Collections. For the early Eocene species cited above, we have mainly revised the material from their type localities, previously studied by Michaux (1964, 1968), Hartenberger (1971) and Escarguel (1999), from the Bassin de Paris. The rodents from southern France (Palette, Rians, Mas-de-Gimel, Fordones, Fournes, and St. Maximin) and the Quercy (Vielase), some from the Bassin de Paris (Avenay, Mutigny, Condé-enBrie, and Saint Agnan) and from Bouxwiller are stored in the collections of the Université de Montpellier (UM-Collections). Among them, the fossil rodents from Prémontré, which have been collected primarily by Frédéric Hautefeuille (SLP29PR), Raoul Tété (SLP43PRPR), François Duchaussois (SLP27PR), David Zuccola (SLPZPR), Pierre Louis (PLPRE) and Maurice Sabatier (MSPRE) from the Société Laonnoise et Axonaise de Paléontologie, are stored at the Institut des Sciences de l'Evolution de Montpellier (ISE-M), located on the campus of the Université de Montpellier (Faculté des Sciences). Other material from Avenay and Mutigny (Coll. Teilhard) is stored in the collections of the Muséum national d'Histoire naturelle (MNHN) in Paris. The specimens of Masillamys from Messel are stored in the collections of the Senckenberg Museum in Frankfurt (SMF) and in the Hessisches Museum in Darmstadt (HMD) (Germany). The revised material of Protadelomys is stored in the collections of the Naturhistorisches Museum Basel (Switzerland; NHMB) for P. cartieri from Egerkingen localities; and in the collections of the Université de Lyon, and that of the Musée des Confluences in Lyon for P. lugdunensis from Lissieu (LIS). Pablo Peláez-Campomanes provided us casts of Protadelomys nievesae (Museo Nacional de Ciencias Naturales, Madrid, Spain).

Terminology and characters. We describe in detail the structures of teeth in order to encounter the morphological variability. We use the terminology proposed in Vianey-Liaud \& Marivaux (2017: fig. 4), with some modifications adapted to the material studied, to be consistent with the proposed hypotheses of homologies (Fig. 1). Further, in the text, we will describe separately the different elements of the tooth features. This is even more necessary as the general pattern of teeth of these ancient rodents is very close. It is worth noting that on the lower teeth, we recognized the position of the insertion of the buccal part of the metalophulid (it is generally median to the protoconid, at its apex, for the genera considered here), as well as the different paths for the attachments of its lingual part(s). We detailed the components of the "buccal wall" (Escarguel, 1999) between the protoconid and the hypoconid, distinguishing a postprotocristid and the anterior arm of the hypoconid (prehypocristid) from the ectolophid + mesoconid. The ectolophid is very short and lower than the mesoconid it bears. We can identify pre- and post-mesoconid spurs, swellings or ridges. On upper teeth, we paid attention to the attachment of the lingual protoloph with respect to the protocone and its arms, and the possible occurrence of a preparaconule. The term "cingulum lingual" as described by Escarguel (1999), was according to us not as precise as necessary for analysing upper tooth features: here we distinguish the lingual cusps (protocone and hypocone) from their arms (pre- and post-protocristae, preand post-hypocristae), and from the endoloph. The "antérolophe 2" of Escarguel (1999) is for us the free extremity of the preprotocrista, as also noted by Hooker (2010) for Sparnacomys georgei. The "crête descendant du protocône dans le trigone" sensu Escarguel (1999) is named here the protocrista. Finally, we also paid attention to the different components of the low ectocingulum: paraectocingulum developed buccal to the paracone, mesoectocingulum on either side of the mesostyle, metaectocingulum buccal to the metacone, and if the pre- and post-paracristae and pre- and post-metacristae take part in this ectocingulum (see Fig. 1). 
Table 1. List of taxa used for the phylogenetic analyses. Their systematics is that retained in this paper (Lit., literature; Obs, observed).

\begin{tabular}{|c|c|c|c|}
\hline \multicolumn{4}{|l|}{ GLIRES, RODENTIAFORMES, Wible et al ., 2007} \\
\hline \multicolumn{4}{|c|}{ ALAGOMYIDAE, Dasheveg, 1990} \\
\hline Tribosphenomys minutus & Meng, Wyss, Dawson and Zhai 1994 & Late Paleocene & Lit. \\
\hline \multicolumn{4}{|c|}{ ARCHETYPOMYIDAE, Meng, Li, Ni, Wang and Beard 2007} \\
\hline Archetypomys erlianensis & Meng, Li, Ni, Wang and Beard 2007 & Late Early Eocene & Lit. \\
\hline \multicolumn{4}{|l|}{ RODENTIA, Savage, 1951} \\
\hline \multicolumn{4}{|l|}{ CTENOHYSTRICA Huchon et al. 2002} \\
\hline Cocomys lingchaensis & (Li, Chiu, Yan and Hsieh 1979) & Early Eocene & Cast \\
\hline Tanquammys robustus & Li and Meng 2015 & Early Middle Eocene & Lit. \\
\hline \multicolumn{4}{|c|}{ ISCHYROMYIFORMES Marivaux, Vianey-Liaud and Jaeger, 2004} \\
\hline \multicolumn{4}{|c|}{$\begin{array}{l}\text { ISCHYROMYIDAE Alston, } 1876 \\
\end{array}$} \\
\hline Acritoparamys atavus & (Jepsen, 1937) & Late Paleocene & Cast \\
\hline Microparamys sambucus & Korth \& Emry, 1989 & Middle Eocene & Lit. \\
\hline Reithroparamys delicatissimus & (Leidy, 1871) & Late Early Eocene-Middle Eocene & Cast, Lit. \\
\hline \multicolumn{4}{|c|}{ GLIRIDAE Muirhead, 1819} \\
\hline Eogliravus wildi & Hartenberger, 1971 & Late Early Eocene-Middle Eocene & Obs \\
\hline Eogliravus hammeli & Thaler, 1966 & Late Early Eocene-Middle Eocene & Obs \\
\hline Eogliravus moltzeri & Peláez-Campomanes. 1995 & Late Early Eocene-Middle Eocene & Lit. \\
\hline \multicolumn{4}{|l|}{ Family indet. } \\
\hline Corbarimys hottingeri & Marandat, 1989 & Early Eocene & Obs \\
\hline Pseudoparamys $=$ Corbarimys cezannei new comb & Hartenberger, 1987 & Early Eocene & Obs \\
\hline \multicolumn{4}{|c|}{$\begin{array}{l}\text { AILURAVINAE Michaux, } 1968 \\
\end{array}$} \\
\hline Euromys = Ailuravus cardosoi new comb & (Estravis, 1992) & Early Eocene & Cast \\
\hline Euromys $=$ Ailuravus inexpectatus new comb & (Escarguel, 1999) & Early Eocene & Obs \\
\hline Ailuravus michauxi & Escarguel, 1999 & Early Eocene-Early Middle Eocene & Obs \\
\hline Ailuravus macrurus & Weitzel, 1949 & Early Middle Eocene & Lit. \\
\hline \multicolumn{4}{|c|}{ PLESIARCTOMYIDAE nov rank } \\
\hline Plesiarctomys savagei & Michaux, 1964 & Early Eocene & Obs \\
\hline Plesiarctomys hartenbergeri & Wood, 1970 & Early Eocene & Obs \\
\hline Plesiarctomys = Pseudoparamys lapicidinarum nov comb & (Escarguel, 1999) & Early Eocene & Obs \\
\hline Pseudoparamys teilhardi & (Wood, 1962) & Early Eocene & Obs \\
\hline \multicolumn{4}{|c|}{ INCERTAE sedis. } \\
\hline Meldimys musak & Rana et al, 2008 & Early Eocene & Lit. \\
\hline \multicolumn{4}{|l|}{ BASAL THERIDOMORPHA } \\
\hline \multicolumn{4}{|c|}{ EUROMYIDAE nov. } \\
\hline Meldimys louisi & Michaux, 1964 & Early Eocene & Obs \\
\hline Euromys thaleri & (Michaux, 1964) & Early Eocene & Obs \\
\hline 'Paramys' = Euromys woodi nov comb. & (Michaux, 1964) & Early Eocene & Obs \\
\hline \multicolumn{4}{|c|}{ Superfamily and Family indet. } \\
\hline Sparnacomys chandoni & Hartenberger, 1971 & Early Eocene & Obs \\
\hline Pantrogna russelli & Hartenberger, 1971 & Early Eocene & Obs \\
\hline Hartenbergeromys hautefeuillei & (Escarguel, 1999) & Late Early / Early Middle Eocene & Obs \\
\hline Pantrogna $=$ Hartenbergeromys marandat $i$ & (Escarguel, 1999) & Late Early / Early Middle Eocene & Obs \\
\hline MASILLAMYIDAE & & & \\
\hline Masillamys mattaueri & Hartenberger, 1975 & Early Middle Eocene & Obs \\
\hline Masillamys parvus & Tobien, 1954 & Early Middle Eocene & Obs \\
\hline Masillamys beegeri & Tobien, 1954 & Early Middle Eocene & Obs \\
\hline Masillamys krugi & Tobien, 1954 & Early Middle Eocene & Obs \\
\hline THERIDOMYOIDEA Als & n, 1876 & & \\
\hline Family indet & & & \\
\hline Protadelomys' nievesae & Peláez-Campomanes 1995 & Early Middle Eocene & Cast \\
\hline Protadelomys' maximini & Escarguel, 1998 & Middle Eocene & Obs \\
\hline Protadelomys' alsaticus & Hartenberger, 1969 & Middle Eocene & Obs \\
\hline Protadelomys cartieri & (Stehlin \& Schaub, 1951) & Early Late Eocene & Obs \\
\hline Protadelomys lugdunensis & Hartenberger, 1969 & Early Late Eocene & Obs \\
\hline Elfomys catalaunicus & Bonilla-Salomón et al. , 2016 & Early Late Eocene & Obs \\
\hline Paradelomys santjaumensis & Bonilla-Salomón et al., 2016 & Early Late Eocene & Obs \\
\hline Tardenomys chartreuvensis & Comte et al., 2012 & Early Late Eocene & Obs \\
\hline PSEUDOSCIURIDAE Z & el, 1893 & & \\
\hline Sciuroides rissonei & Hooker, 1986 & Early Late Eocene & Obs \\
\hline Treposciurus preecei & Hooker, 1986 & Early Late Eocene & Obs \\
\hline Tarnomys spelaeus & (Hartenberger, 1973b) & Late Late Eocene & Obs \\
\hline$=?$ Tarnomys quercyi, in Hooker \& Wiedmann 2000 & (Schlosser, 1884) & Quercy, old collections & Lit. \\
\hline Tarnomys helveticus & (Schmidt-Kittler, 1971) & Early Late Eocene & Obs \\
\hline Auremys nov. gen. subita & (Comte et al., 2012) & Early Late Eocene & Obs \\
\hline
\end{tabular}


For both lower and upper teeth, we noted constant position of some extra-ridges/wrinkles. Finally, in our terminology we did not use the "notches" introduced by Escarguel (1999: 116), i.e., the transverse valleys between the main alignments of cusps. The analyses of wear patterns and inferences on diets are outside the scope of this paper.

Some features have been described under various names: here we used anterostyle for the conule ending the anteroloph lingually (instead of the protostyle), because it is an extension of the anteroloph, not of the protocone. It is the same for the posterostyle (not hypostyle, as it is not closely related to the hypocone (Fig. 1).
Measurements. For all species, except that of the genus Masillamys, we used the tables of measurements provided by Escarguel (1999: 324-326), but the teeth were somewhat redistributed between the different loci and between the species, following new observations on their features. Some of the teeth were measured once more. In this case, the measurements were taken with a Nikon Measuroscope for the material stored in the UM-Collections. The holotypes and a few teeth available of the three species of Masillamys from Messel were measured from the pictures and drawings made by us in the Senckenberg (Frankfurt) and Hessisches (Darmstadt) museums (VianeyLiaud et al., 2019). We followed the same protocol for the teeth of rodents from Egerkingen, drawn at the Naturhistorische Museum (Basel).
A1

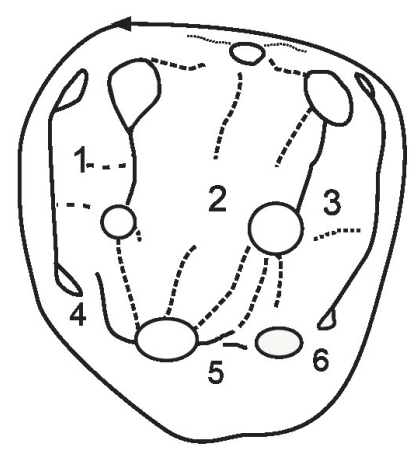

A2
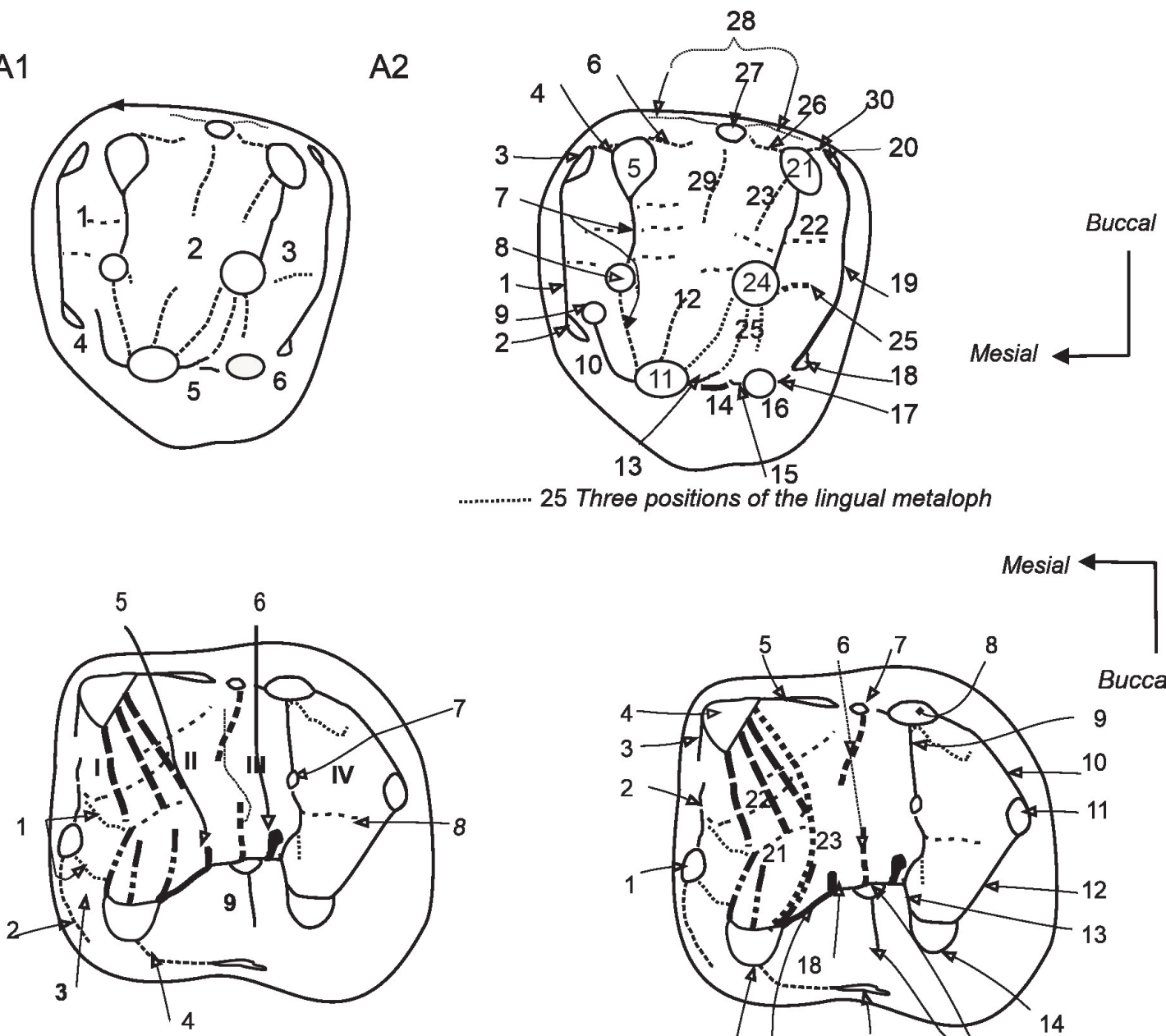

B1

$$
\begin{aligned}
& \text { 1-Two positions of the anterolophulid ........ } \\
& \text { I, II, III, IV = synclinids = flexids }
\end{aligned}
$$

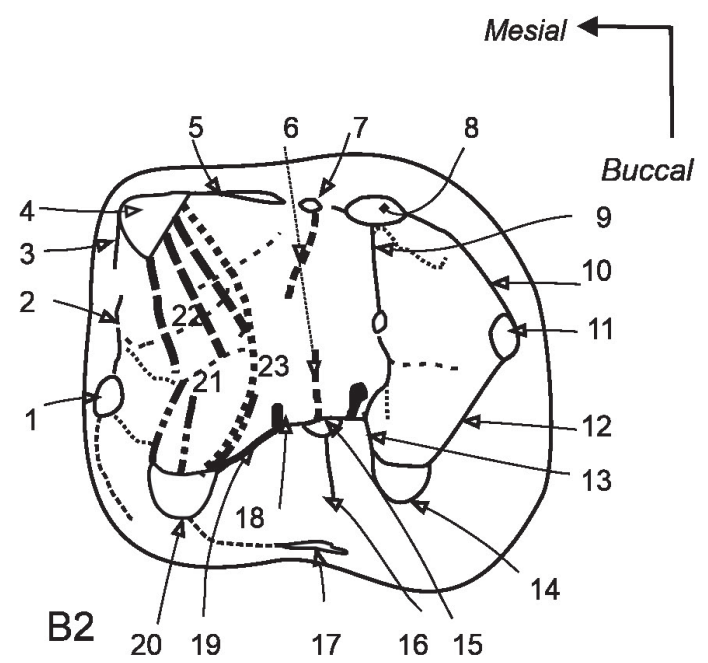

21 Three positions of the buccal metalophulid: . . . 22 Three positions of the lingual metalophulid:-

Figure 1. Dental terminology (modified after Vianey-Liaud et al., 2019). A. Upper molars. A1, name of flexi. 1, anteroflexus; 2, mesoflexus; 3, posteroflexus; 4, antesinus; 5, sinus; 6, posterosinus. A2, crests and cusps. 1, anteroloph; 2, anterostyle; 3, parastyle; 4, preparacrista; 5, paracone; 6, postparacrista; 7, protoloph (buccal+ lingual); 8, paraconule; 9, preparaconule; 10, preprotocrista; 11, protocone; 12, protocrista; 13, postprotocrista; 14, endoloph; 15, prehypocrista; 16, hypocone; 17, posthypocrista; 18, posterostyle ; 19: posteroloph; 20: metastyle; 21, metacone; 22, buccal metalophule II; 23, buccal metalophule I; 24, metaconule; 25, three positions of the lingual metaloph; 26, premetacrista; 27, mesostyle; 28, ectocingulum; 29, mesoloph (buccal) ; 30, postmetacrista. B. Lower molars. B1, crestids and cuspids. 1, two positions of the anterolophulid; 2, anterocingulid; 3, antesinusid; 4, protoconid spur; 5, premesoconid spur, or ridge or swelling; 6: postmesoconid spur, or ridge or swelling; 7, entoconulid; 8, extra-ridges; 9, sinusid. B2, other crestids and cuspids. 1, anteroconid; 2, anterolophid; 3, premetacristid; 4, metaconid; 5, postmetacristid; 6, mesolophid (lingual +buccal); 7, mesostylid; 8, entoconid; 9, entolophid (lingual + buccal); 10, posterolophid; 11, hypoconulid; 12 , posthypocristid; 13 , prehy p o ristid (= a n t e ri or arm of the h y p o c o n i d ) 14, hypoconid; 15, mesoconid; 16, ectomesolophid; 17, ectocingulid, ectostylid; 18, ectolophid; 19, postprotocristid; 20, protoconid; 21, different paths of the buccal metalophid: the most mesial and the medial one as buccal metalophid I; 22, different paths of the lingual metalophid I, and II for the most distal path; 23, path of the metalophid II, with buccal part made with the postprotocristid. Names of flexids: I, anteroflexid; II + III, mesoflexid; IV, posteroflexid. 
The teeth are brachydont or weakly to unilaterally hypsodont; the walls of the crowns are generally vertical, but sometimes curved, the corresponding cusp and cuspid walls showing bulging. Therefore, the dimensions slightly vary from top to base of the crown. Accordingly, as far as possible, we measured the maximum mesiodistal length and buccolingual width of crowns.

Morphological analyses. The occlusal surfaces, as well as the lingual and labial aspects of each tooth were drawn with a camera lucida to identify all structures, cusp(-id)s, ridges, extra-ridges and their possible connections. Such an approach using drawings, although somewhat time-consuming, has proven to be necessary, given the great resemblance of the dental morphologies at the beginning of this rodent adaptive radiation. The goal was to identify constants and significant variations that could support generic and specific distinctions. In the figures of the specimens throughout this article, the enamel ridges and apices of cusp(-id)s were delimited by solid continuous lines. The lower areas of the valleys were marked with dashed lines, and dashed lines surround the lower areas of equal depth.

During the analysis process, all the specimens were plotted on bivariate diagrams (Length $\mathrm{x}$ Width) in order to detect possible correlations between the morphological variability of the observed forms and the size.

The different localities considered here are referred to biochronological units (MP for Mammal Paleogene; e.g., Schmidt-Kittler et al., 1987; Aguilar et al., 1997), and stratigraphical ones in the Paleogene, with a radiometric date for Messel (Lenz et al., 2015).

Phylogenetic reconstructions. Phylogenetic analyses of late early Eocene to early late Eocene European rodent species were carried out in order to highlight the root of the early Theridomorpha and its content. These analyses were based on detailed morphological observations of several Eocene species of theridomorphs, "ischyromyoids" ailuravids and glirids. We employed several of the dental characters and character states listed in Vianey-Liaud \& Marivaux (2017). However, some characters were re-interpreted or added, in order to better describe the extent and variation of the character states across the taxonomic sample selected here. As in previous analyses, some multistate characters were considered as ordered if changes from one state to another required passing through intermediate states (Slowinski, 1993). With such an ad hoc assumption, character state assignments did not convey a priori judgments about character polarity (unconstrained parsimony). For some characters, multistate taxa were considered and characters were scored primarily as polymorphism $(0$ and $1[0+1])$ or as uncertain $(0$ or $1[0 / 1])$. Characters were polarized via the outgroup comparison method (Watrous \& Wheeler, 1981). We selected as out-groups a basal Glires (Tribosphenomys) and two stem Rodentia (Archetypomys and Cocomys), all three being recorded in the early Tertiary of Asia. Only one more species of Asian taxa was considered: Tanquammys robustus. The ingroup included on one hand a few North American genera and European ones so far considered as being related to the North American superfamily Ischyromyoidea (Ailuravinae, Plesiarctomyinae, and Gliridae). On the other hand, it included genera close to the root of Theridomorpha (Sparnacomys, Pantrogna, and Hartenbergeromys), early Theridomyoidea (e.g., Masillamys, Protadelomys, and some Pseudosciuridae)
(Table 1). The final matrix included 343 characters scored on 45 taxa (see App., S3, S4).

For estimating the relationships of the taxa, the final data matrix was subjected to both cladistic and Bayesian phylogenetic analyses.

Cladistic analyses. The phylogenetic reconstructions were performed with PAUP* 4.0b10 (Swofford, 2002). Polymorphic $(0+1 ;(01)$ under PAUP) versus uncertain $(0 / 1 ;\{01\}$ under PAUP) character states (multistate taxa) were considered and both treated distinctly by PAUP (options MSTaxa= Variable). Given the high number of selected taxa, analyses were carried out using the Heuristic search method (Hsearch), with a random step-wise addition (1,000 replications with randomized input order of taxa) and tree-bisection-reconnection (TBR) branch swapping options. The clade robustness was measured by the Bremer Index (Bremer, 1988) and Bootstrap percentages (BP) in equally weighted maximum-parsimony (after 1,000 iterations comprising two replications with randomized input order of taxa). The character-taxon matrix plus the assumptions (Nexus format) for the cladistic analyses are provided in the App. S4.

Bayesian analysis. The analysis was performed with MrBayes 3.2.6 (Ronquist et al., 2012), using the public resource CIPRES Science Gateway V. 3.3. (Miller et al., 2015; https://www. phylo.org/). For this analysis, we selected the conditional version of the Markov- $k$ model (Mkv; Lewis, 2001) for our total dataset, which included only morphological data, with the assumption of a gamma-distributed rate variation across characters (coding set to "variable"). Two independent runs were performed simultaneously with four Markov chain Monte Carlo (MCMC) chains for 25 million generations. Each run had one cold chain and three heated chains (temp $=0.02$ ). The chains were sampled every 1,000 generations and the first $25 \%$ of the trees were discarded as the "burn-in" period. An "allcompat" consensus tree was generated, summarizing all post-burn-in sampled trees. Convergence was assessed here by checking the effective sample sizes (ESSs) and the standard deviation of the mean of split frequencies in the final generation. The ESSs were checked using Tracer 1.7.1 (Rambaut et al., 2018). The character-taxon matrix and the command lines for this standard Bayesian analysis are provided in the App. S4.

\section{PHYLOGENETIC RESULTS}

For the cladistic analyses, heuristic searches have yielded four equally most parsimonious trees of 1042.46 steps each (Consistency Index, $\mathrm{CI}=0.373$; Retention Index, $\mathrm{RI}=0.637$ ). The cladogram presented in Figure 2 corresponds to a strict consensus tree of the four trees generated. For the standard Bayesian analysis, the "allcompat" consensus tree (majorityrule plus compatible groups) of 25,000 post-burn-in trees retained is provided in Figure 3. The resulting tree topologies obtained from these two distinct phylogenetic reconstruction approaches are congruent in almost all nodes. They differ mainly in the placement of the species "Ailuravus" subita Comte et al., 2012. In the results of the cladistic analyses, this species is placed among the Theridomyoidea (closely related to the pseudosciurids), whereas in the results of the Bayesian analysis it appears much more basal, being outside the Theridomorpha 


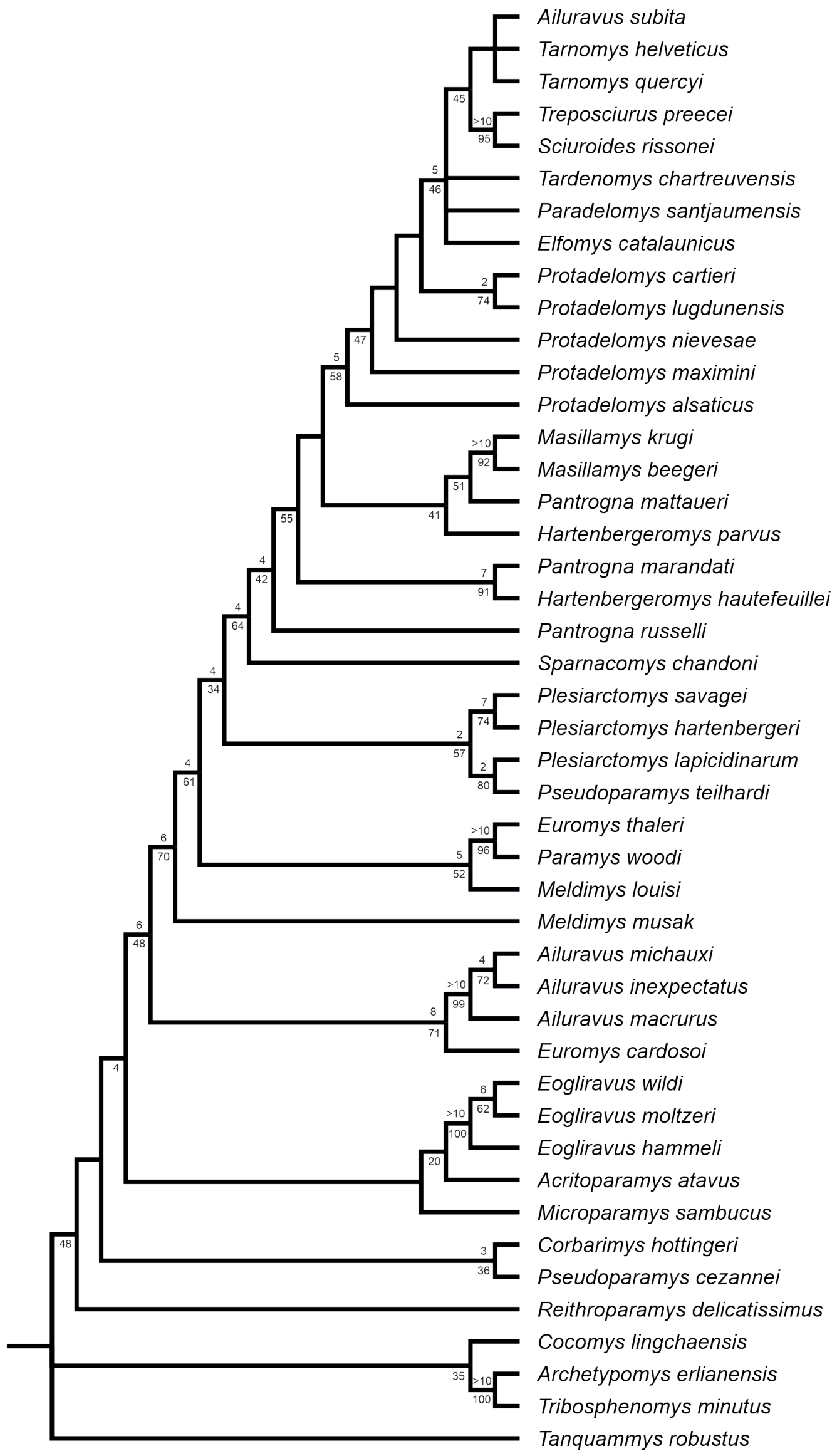

Figure 2. Results of the cladistic phylogenetic analyses of the 45 taxa considered (in- and out- groups). These taxa are reported with their original names. Strict consensus tree of four equally most parsimonious trees of 1042.6 steps (CI, 0.373; RI, 0.637). 
clade, and closely related to Euromys and Meldimys. However, whatever the phylogenetic results, this species is clearly set apart from the Ailuravinae (Ailuravus clade), a condition which entails a new generic attribution (see p.96)

In the following chapter, we propose a systematics that is adapted from the phylogenetic results obtained by the cladistic and Bayesian analyses (Figs. 2-3). The high-level taxonomic names used refer to the phylogenetic nodes (A-Q) labelled on the tree presented on the Figure 4.

\section{MORPHOLOGICAL ANALYSIS AND SYSTEMATICS}

Previous phylogenetic analyses (Vianey-Liaud \& Marivaux, 2017) have highlighted some dental features, critical to identify early theridomorphs, in addition to the hystricomorphous condition of the infraorbitary foramen (i.o.f.). On lower teeth, these features are the trigonid basin not much higher than the talonid basin, and a high buccomesial to distolingual oblique postprotocristid, descending from the apex of the protoconid, together with a short ectolophid sometimes very low or broken. The mesoconid is variably present; the metalophulid (at least its buccal half) is developed buccolingually from the apex (or the mesial part) of the protoconid, to the apex (or the mesial part) of the metaconid (= metalophulid I). On upper teeth, they are the presence of the well-developed hypocone, even if it is first smaller and lower than the protocone, and of the endoloph linking their two apices, then depressed linguobuccally by a more or less deep sinus and replaced by a mure, more buccal, in Theridomyidae. Based on these features, the genera Pantrogna and Hartenbergeromys were considered as basal Theridomorpha (among the earliest offshoots), even if their i.o.f. was so far not clearly characterized as hystricomorphous (Vianey-Liaud \& Marivaux, 2017; e.g. fig. 7a). We support here this inclusion and provide a more accurate description of their infra-orbitary region.

Moreover, our detailed dental morphology analysis (presented below) led us to reconsider the infra-ordinal attribution of Pseudoparamys, an early Eocene European genus so far included in the Pseudoparamyinae, a subfamily of Ischyromyoidea. Our previous analyses placed this taxon as a close sister group of the roots of the Theridomorpha. Pseudoparamys Michaux, 1964, is here placed within the basal Theridomorpha (Figs. 2-4), based on characters of lower molars cited above, seen on the teeth of the type-assemblage from Mutigny, and found on teeth from Avenay. Besides, the characters of the i.o.f. given in Michaux (1968), described this cranial structure as widely open at its base ("large rayon de courbure"), wider than on paramyids, a configuration which substantiates our current attribution $(\mathrm{Mu} 6023$ in Michaux, 1968: 152, fig. 2). Plesiarctomys, its i.o.f. being defined as protrogomorphous (e.g., Wood, 1970), was so far considered as a member of the ischyromyoids. However, the fragment of maxillary SLPZPR-185 of Plesiarctomys savagei (Michaux, 1964) from Prémontré displays a moderately enlarged i.o.f. (Plate 1), different from the classical protrogomorphous condition. To rule on the taxonomic position of Plesiarctomys, it would be necessary to revise the other species of this genus. For the present analysis, we have only considered the two early Eocene species previously referred as to Plesiarctomys: $P$. savagei from Prémontré and P. lapicidinarum (Escarguel, 1999) from Condé-en-Brie. Our results resolved Plesisarctomys and Pseudoparamys as forming a clade, sister of the large
Theridomorpha clade (Figs. 2-4).

Similarly, other early Eocene species and genera (Meldimys louisi and "Paramys" woodi) so far included in the Ischyromyoidea, actually display theridomorph features. For example, the dental features of M. louisi and "Paramys" woodi (Paramyinae, Michaux, 1968) defined from Avenay, are not so different from those of Pseudoparamys or that of typical Euromys thaleri, even the postprotocristid is more oblique posteriorly and longer for Meldimys than for Pseudoparamys and Euromys, but their i.o.f. is unknown. Until now, Meldimys was included in the paramyids Ailuravinae (Michaux, 1968), as well as Euromys (Escarguel, 1999) and Ailuravus (Rütimeyer, 1891). This is discussed below, but from our phylogenetic results Meldimys louisi and "Paramys" woodi appear as the sister-clade of the Plesiarctomyidae.

The following systematics takes into account our phylogenetic results. This has led us to propose a revision of the suprafamilial, familial, subfamilial or generic attributions of several species.

\section{Clade ISCHYROMYIFORMES Marivaux, Vianey-Liaud \& Jaeger, 2004}

Until now, the superfamily Ischyromyoidea Alston, 1876, only included the family Ischyromyidae (= Paramyidae) and five sub-families (Paramyinae, Reithroparamyinae, Ailuravinae, and Ischyromyinae; e.g., Anderson, 2008). The objective of this work was to identify among the Eocene rodents from Europe, those species that are potentially at the origin of the Theridomorpha. Thus, we have selected a few genera among the reithroparamyines and microparamyines, like Reithroparamys or Microparamys or even Acritoparamys atavus that have been often related to European Eocene rodents like the Ailuravinae and Gliridae (Escarguel, 1999; Marivaux et al., 2004; VianeyLiaud \& Marivaux, 2017). Here, Eogliravus is resolved as closely related to Acritoparamys and Microparamys, the three genera forming a clade, following the clade of the European Corbarimys (node C, Fig. 4). Corbarimys had been first established as a subgenus of Microparamys (Marandat, 1989), then raised to genus rank (Escarguel, 1999: 251). We discuss this genus below, because in our phylogenetic tree, a species previously named Pseudoparamys cezannei, is far from the pseudoparamyines within the ischyromyoids (node A, Fig. 4), making in fact a clade (node B, Fig. 4) with Corbarimys hottingeri. As a result, we refer the species cezannei to the genus Corbarimys.

Family indet.

\section{Genus Corbarimys Marandat, 1989}

Type species. Corbarimys hottingeri Marandat, 1989.

Type locality. Fordones (early Eocene, France, Corbières; younger than MP7, and older than MP8-9; cf. Yans et al., 2014).

Original diagnosis. Very small size; strong metaconule, mainly on M1, sometimes double on M2. Hypocone massive, lingual and separated from the protocone; short anterior cingulum. On p4 and m1-2, hypoconulid generally present and scarcely stretched transversely.

Emended diagnosis. Ischyromyoid rodents of small to very small size. Upper teeth: trapezoidal D4 smaller than molars, 


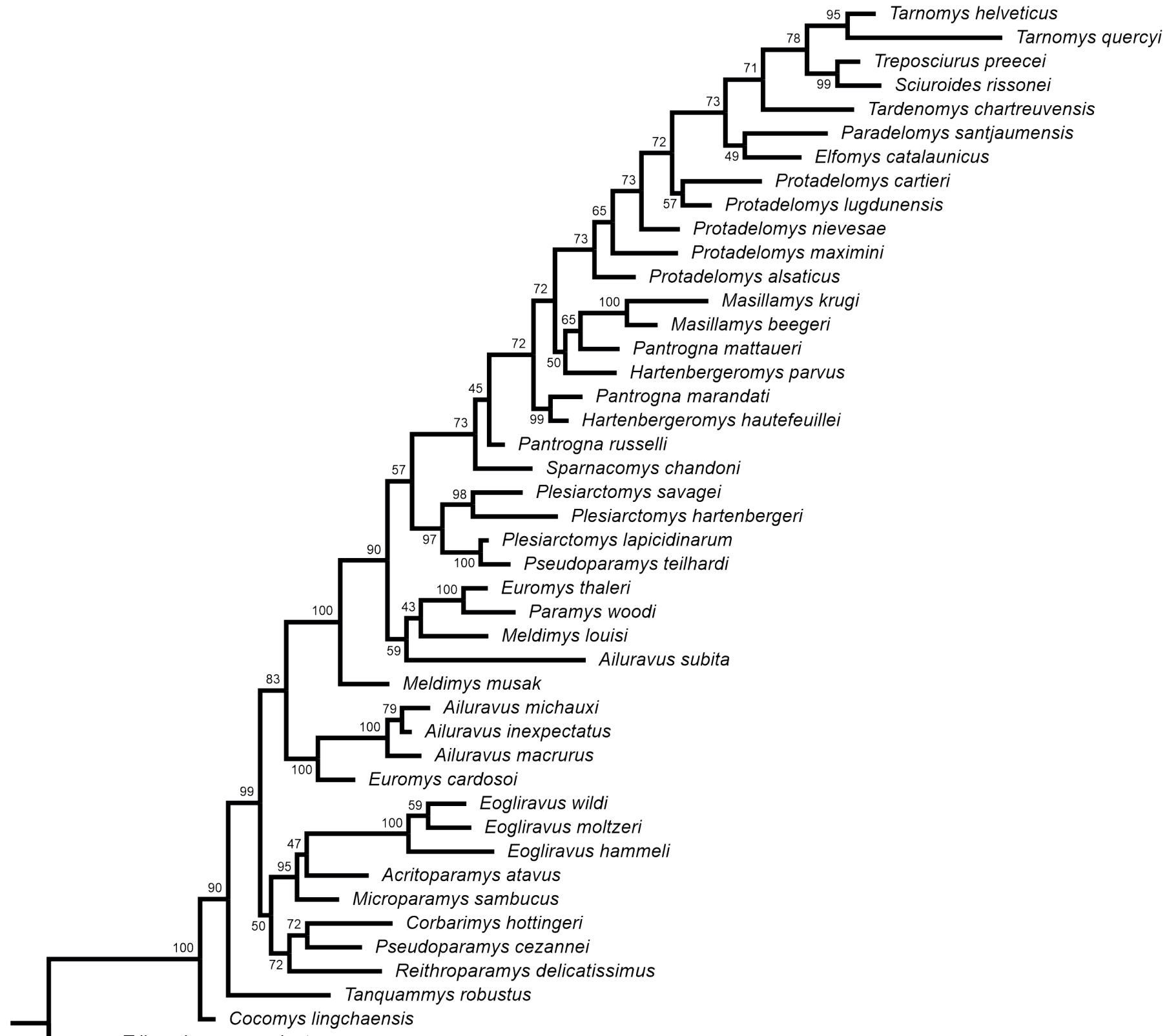

Tribosphenomys minutus

Archetypomys erlianensis

Figure 3. Results of the Bayesian phylogenetic analysis. Allcompat consensus tree (majority-rule plus compatible groups) of 25000 post-burn-in trees retained by the Bayesian analysis. Numbers at nodes represent posterior probabilities (PP; in per cent).

with ectocingulum; P4, D4 and M1-2 with small swollen hypocone, lingual on M1 more buccal on M2; on molars, endoloph variably absent to present; protoloph and metaloph more or less developed; paraconule and metaconule present. Lower teeth: $\mathrm{p} 4$ with high and strong metaconid, and protoconid absent; concave talonid basin on lower molars; metalophulid poorly developed, mainly buccal metalophulid II, lingual metalophulid II short to absent; absence of thick mesiobuccal to distolingual oblique postprotocristid, but short thin and low mesiodistal cristid present, sloping from the transverse postprotocristid (= buccal metalophulid II) to the level of the short and low mesial ectolophid; swollen mesoconid, followed by a very short and low distal ectolophid; entolophid weak to absent; hypoconulid stretched transversely, more or less prominent.
Corbarimys hottingeri Marandat, 1989

Remarks on the previous description (Marandat, 1989). It is worth noting that the features supposed to relate Corbarimys to Cocomys or Tanquammys (Marandat, 1989: 103-104), such as "the occurrence of a large metaconule on P4 and molars, or a well-developed hypocone separated from the protocone by a furrow on molars or a cuspate entoconid, and a distinct hypoconulid", are not unique ctenodactyloid characters. They are also found in ischyromyoids.

Emended diagnosis. Small Corbarimys, with pre- and postprotocristae making a $\mathrm{V}$ with the protocone apex, and endoloph often absent. D4 triangular. 

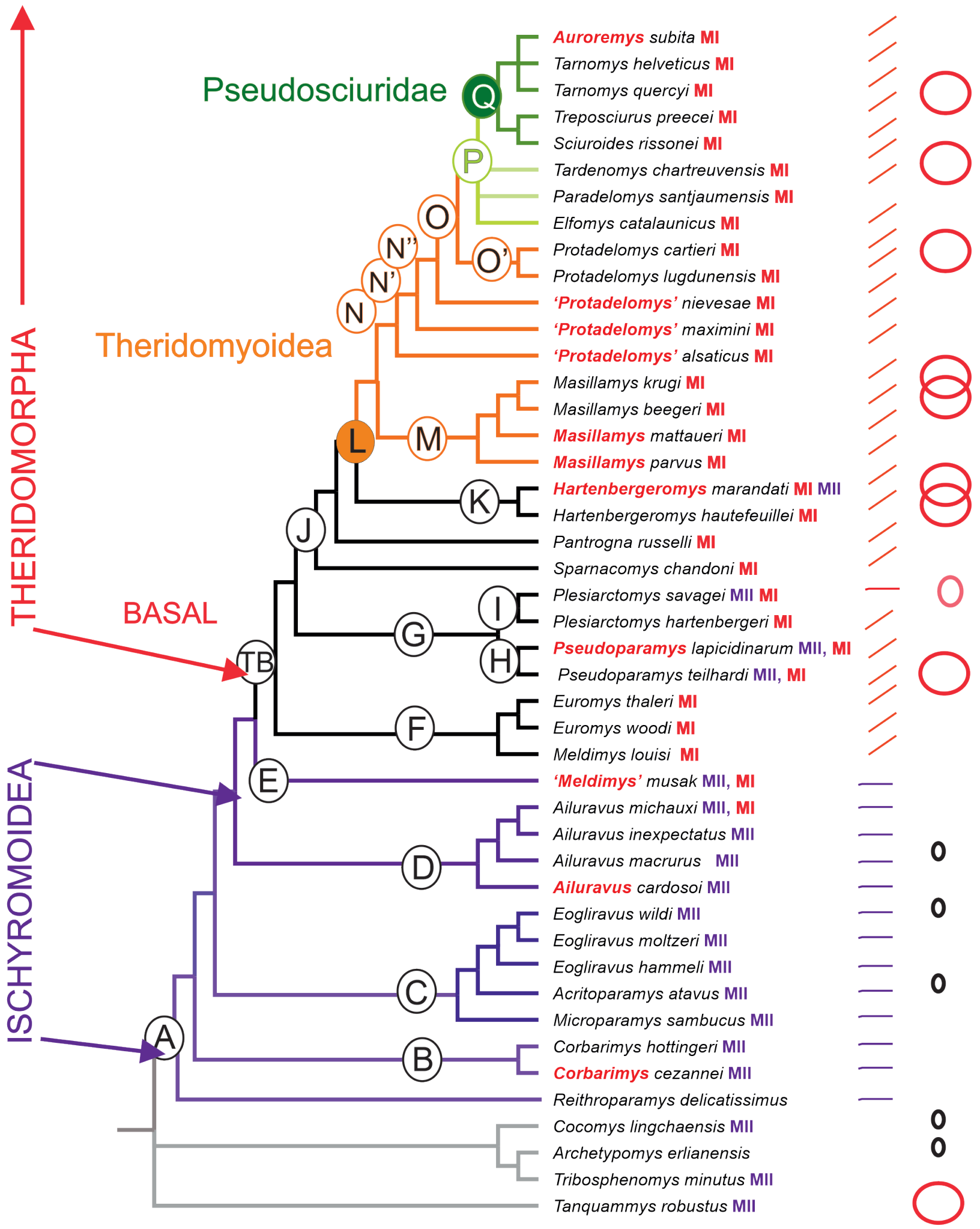

O Small i.o.f

I.o.f. Moderately enlarged

Large i.o.f.

- Mesiodistal sloping ridge from the postprotocristid

— More or less mesiodistal sloping postprotocristid

Oblique postprotocristid

MII: Metalophid II on lower molars MI: Metalophid I on lower molars

Figure 4. Tree of figure 2, labelled with the taxa of supra specific rank, reported from the node that marks their emergence. The new generic attributions of species are red- coloured. Some drawings indicate a few critical characters: the size of the infra-orbitary foramen, the orientation of the distal postprotocristid (bearing a mesiodistal sloping ridge or an oblique sloping ridge), the occurrence of metalophulid II or/and metalophulid I. 
Corbarimys cezannei (Hartenberger, 1987), new comb.

Figures 5-6.

Pseudoparamys cezannei Hartenberger in Godinot et al. 1987: 280, Pl. 2, figs. a-e.

Pseudoparamys cezannei Hartenberger; in Marandat, 1991: 104-105, Pl. 3, figs. 3-5.

Remarks. This species was first included in the genus Pseudoparamys (Hartenberger, 1987). If C. cezannei has relatively high-crowned upper teeth, an arcuate posterocingulum and the pre- and post-protocristae nearly aligned, like Pseudoparamys, there are more and clear differences with this genus (cf. differential diagnosis).

Holotype. PAT-20, left P4.

Type locality. Palette (Aix basin, early Eocene, MP7).

Original diagnosis (Hartenberger, 1987: 280; translation from French). "Small sized Pseudoparamys, smaller than $P$. teilhardi; $\mathrm{p} 4$ less reduced than this species; upper molars with bulging protocone and metaconule developed; mesoconid strongly reduced on lower molars."

Emended diagnosis. Small sized Corbarimys (p4: $1.28 \mathrm{~mm} \mathrm{x}$ $1.75 \mathrm{~mm}$ ), larger than Corbarimys hottingeri (M1: $1.04 \mathrm{~mm}$ x $1.22 \mathrm{~mm}$ ). Differs from the latter in the more bulging main cusps, the higher lingual wall on upper teeth with pre- and postprotocristae aligned and the high short endoloph, in the variable occurrence of entolophid elements and possible wrinkles on the enamel of flexi and flexids.

Differential diagnosis. Differs from Pseudoparamys teilhardi:

- On upper teeth: in more bulging cusps, narrowing the bases of flexi, lower and shorter "lingual" wall, with smaller anterostyle and lower hypocone, the latter more lingual on D4, P4 larger compared with M1, mesoloph absent, M3 with strong protocrista.

- On lower teeth: protoconid absent on $\mathrm{p} 4$; talonid basin less deep; incomplete metalophulid, reduced to buccal metalophulid II (= transversely oriented postprotocristid); absence of thick mesiobuccal to distolingual oblique postprotocristid but short thin and low mesiodistal cristid present, sloping from the buccal metalophulid II to the level of the short and low mesial ectolophid; elements of the entolophid present (postmesoconid part + lingual entolophid part.

\section{Description and comparisons.}

\section{Upper teeth. (Fig. 5)}

D4. The only D4 (PAT-29) displays a continuous ectocingulum, extending from the parastyle to the posteroloph through the mesostyle. The hypocone is strong but less than the protocone; it is slightly more buccal than the protocone, the endoloph is low (marked by an interruption of the connection postprotocrista hypocone), and the sinus is shallow but quite distinct. This tooth differs from that of Pseudoparamys teilhardi in its stronger hypocone, weaker mesiodistal ridge preprotocrista-protoconepostprotocrista. It differs from Plesiarctomys savagei in its larger and lower hypocone, and less obliquely stretched lingual wall.

P4. The previous description of the $\mathrm{P} 4$ reported that there is no mesial wear facet on this tooth, thereby precluding the presence of a (D)P3. The observation of M1 does not show us any mesial contact wear facet, but the $\mathrm{P} 4$ is certainly present. The absence (or presence) of (D)P3 cannot be demonstrated by this means.
The anteroloph is long and thin, but low and attached along the mesial flank of the tooth. The paracone bears a well-defined postparacrista, which is slightly notched buccally before its junction with the small mesostyle. The paraconule is swollen and protruding, adjacent to the anteroloph; it attaches to the mesial extremity of the preprotocrista through the low lingual protoloph. The premetacrista is indistinct; the metacone is slightly smaller than the paracone, and the buccal metaloph thicker than the buccal protoloph. The metaconule is bulging and strong, doubled lingually in a weak conule poorly distinguished from the lingual metaloph. The latter joins the postprotocrista between the endoloph and the apex of the protocone. Pre- and postprotocristae, sloping along the bulging protocone, make a widely open $\mathrm{V}$. The short endoloph links the postprotocrista to the reduced and low hypocone, which extends buccally through a low posteroloph.

A few faint extra-ridges descend from the distal flank of the paracone and from the mesial slopes of the metaconules, to the floor of the narrow mesoflexus.

M1-M2. The cusps are weakly salient around the crown, and the lingual wall is higher than the buccal one. They show features similar to those described for P4, notably for their paracone/ postparacrista and premetacrista/metacone areas. However, the

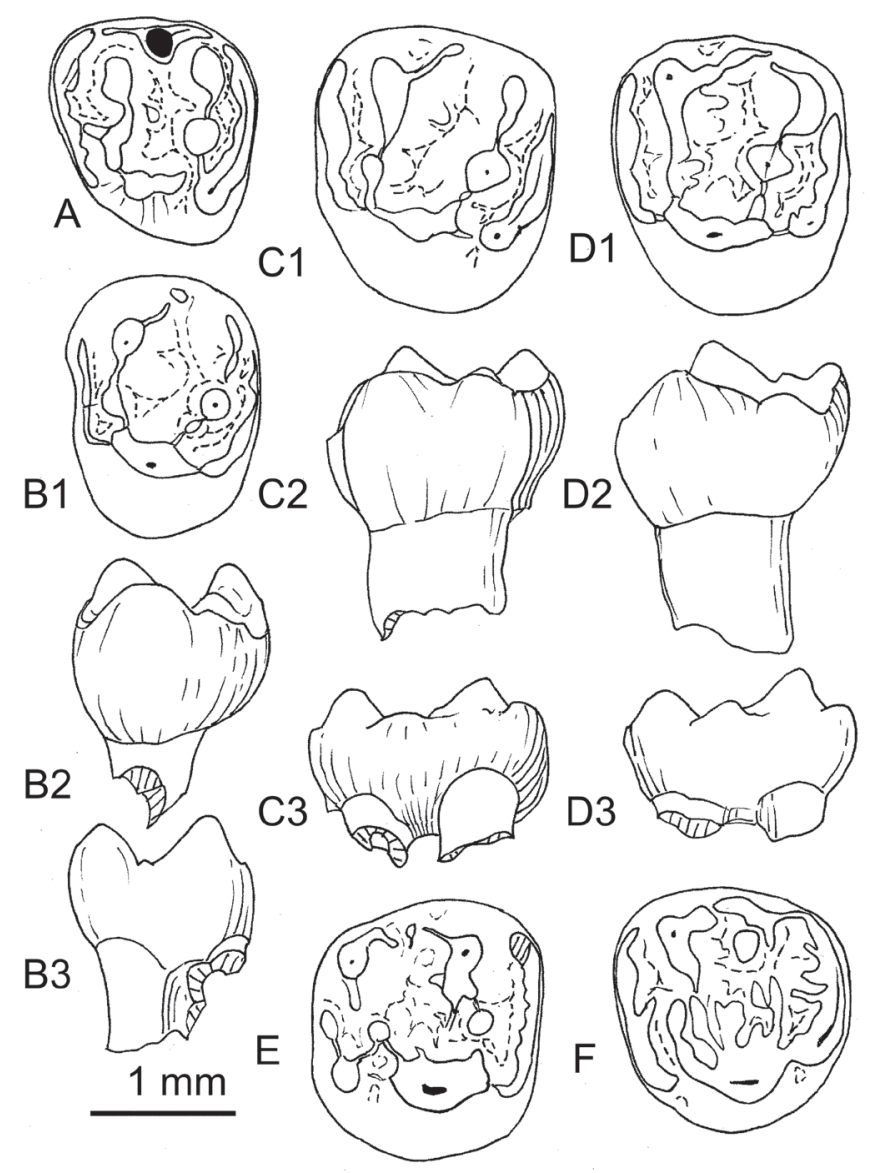

Figure 5. Upper teeth of Corbarimys cezannei (Hartenberger, 1987) from Palette (Bouches-du-Rhône; MP7?). A. UM-PAT 29, left D4, occlusal view. B. UM-PAT 20; B1, occlusal view, B2, lingual aspect, B3, buccal aspect. C. UM-PAT 21, left M1; C1, occlusal view, C2, lingual aspect, C3, buccal aspect. D. UM-PAT 22, left M2; D1, occlusal view, D2, lingual aspect, D3, buccal aspect. E. PAT 23, right M2, occlusal view. F. UM-PAT 31, left M3, occlusal view. Scale bar, $1 \mathrm{~mm}$. 
mesostyle is longer, with the buccal notch of the postparacrista deeper, and the mesoflexus is longer. M2 differs from M1 in having a hypocone smaller and more buccal (same level as the anterostyle), and the metacone more lingual in position, involving a relatively shorter posteroloph (the shortest for PAT-23). The pre- and post-protocristae are more mesiodistally aligned on M2 than on M1. The premetacrista is well defined on PAT-22. The paraconule is smaller than the metaconule, as on P4, for the PAT-21 M1 and the PAT-22 M2; the PAT 23 M2 has its paraconule larger than the metaconule. The hypocone is well defined. Faint extra-ridges are visible not only from the lophs in the mesoflexus but also in the anteroflexus. These molars differ from those of $P$. teilhardi, apart from their smaller size, in their more bulbous cusps, less crestiform and less mesiodistally aligned elements of the "lingual wall", in the absence of enamel wrinkle, a hypocone larger with respect to the protocone, a shorter posteroflexus, and a shorter posteroloph.

M3. The PAT-31 M3 shows a plane wear surface on its postparacone area. On this specimen, the buccal protoloph is weakly connected both to the preprotocrista through a long paraconule - lingual protoloph ridge, and to the equally long protocrista. The stretched mesostyle attaches to the crestiform-arched metacone; this connects to the very short posteroloph, the lingual end of which barely enlarges as a slightly distinct hypocone. There is a central low isolated conule (metaconule?), close to a ridge (lingual metaloph?), which joins the postprotocrista. Three short extra-ridges run distomesially from the arched metacone.

\section{Lower teeth. (Fig. 6)}

p4. The $\mathrm{p} 4$ differs from that of $P$. teilhardi in the absence of a protoconid. The trigonid is reduced to a high and strong metaconid, which is mesiolingual in position. The postmetacristid slopes to the wide mesoflexid opening, which opens at the same level as the floor of the talonid. One faint ridge, hardly distinct, runs from the apex of the metaconid to the floor of the talonid. More buccally, there is only one ridge, slightly stronger and shorter than the previous one. This might be a metalophulid extended distally by the protocristid. This reaches the level of the mesoconid from which a shallow break makes a separation. A short and low ectocingulid is present below, before reaching the mesial border of the sinusid. The mesoconid + distal ectolophid are slightly obliquely oriented, and connected more distally to the prehypocristid. The oblique mesiobuccal- to linguodistal posthypocristid attaches to the buccolingually stretched hypoconulid. The latter is faintly salient; it continues as far as a short and scarcely swollen posterolophid, connected to the buccal flank of the entoconid. The two roots of $\mathrm{p} 4$ merge below the crown cervix and separate more ventrally.

$\boldsymbol{m} 1$. The enamel is corroded and digested on the unique $\mathrm{m} 1$ available (PAT-28). The metaconid appears particularly more worn than the other main cuspids. There is a short anterolophid connected buccally to the mesial flank of the protoconid. The buccal metalophulid is transverse and short from the midapex of the protoconid; it ends nearly at the contact with the worn, weak and short lingual metalophulid. A thin and short mesiodistal ridge slopes from the distal flank of the protoconid to the mesial ectolophid. The latter is short and low, ending at the level of a break, in front of the swollen but small mesoconid. Distally, it bears a short and thick postmesoconid ridge, directed to a faint and short lingual entolophid. The distal ectolophid joins the prehypocristid. The oblique posthypocristid joins the relatively low and buccolingually stretched hypoconulid.

$\boldsymbol{m} 2$. Features similar to those of $\mathrm{m} 1$ are observed on the better preserved $\mathrm{m} 2$ PAT-24, on which the metaconid is salient, the trigonid basin more visible and narrow, and the postmetacristid moderately sloping to the mesoflexid opening, which overlies the concave talonid basin. Enamel wrinkles can occur on the talonid surface.

$\boldsymbol{m} 3$. On the two m3 (PAT-26 and PAT-30), the anterolophid is connected to a mesial metalophulid (premetacristid). There is no lingual metalophulid aside the premetacristid, and the buccal metalophulid is short; therefore, the trigonid basin remains open distally. The other features are similar as those observed on $\mathrm{m} 1-\mathrm{m} 2$, as the concave basin is fringed with thin and faint wrinkles, and has a mesiodistal mesial ectolophid, a rounded mesoconid, a more lingual distal ectolophid, and a continuous posterior lophid. They differ from $\mathrm{m} 1$ and $\mathrm{m} 2$ in having a lower trigonid, a lower hypoconulid not overlying the posterior lophid, and in the absence of entolophid extraridges. The posterior lobe is only slightly narrower than the anterior one. On PAT-26, the mesiodistal cristid in front of the mesoconid is more clearly distinguishable: it is relatively high and long, as high as the mesoconid, from which it separates through a short and shallow break that reaches about $1 / 3$ height

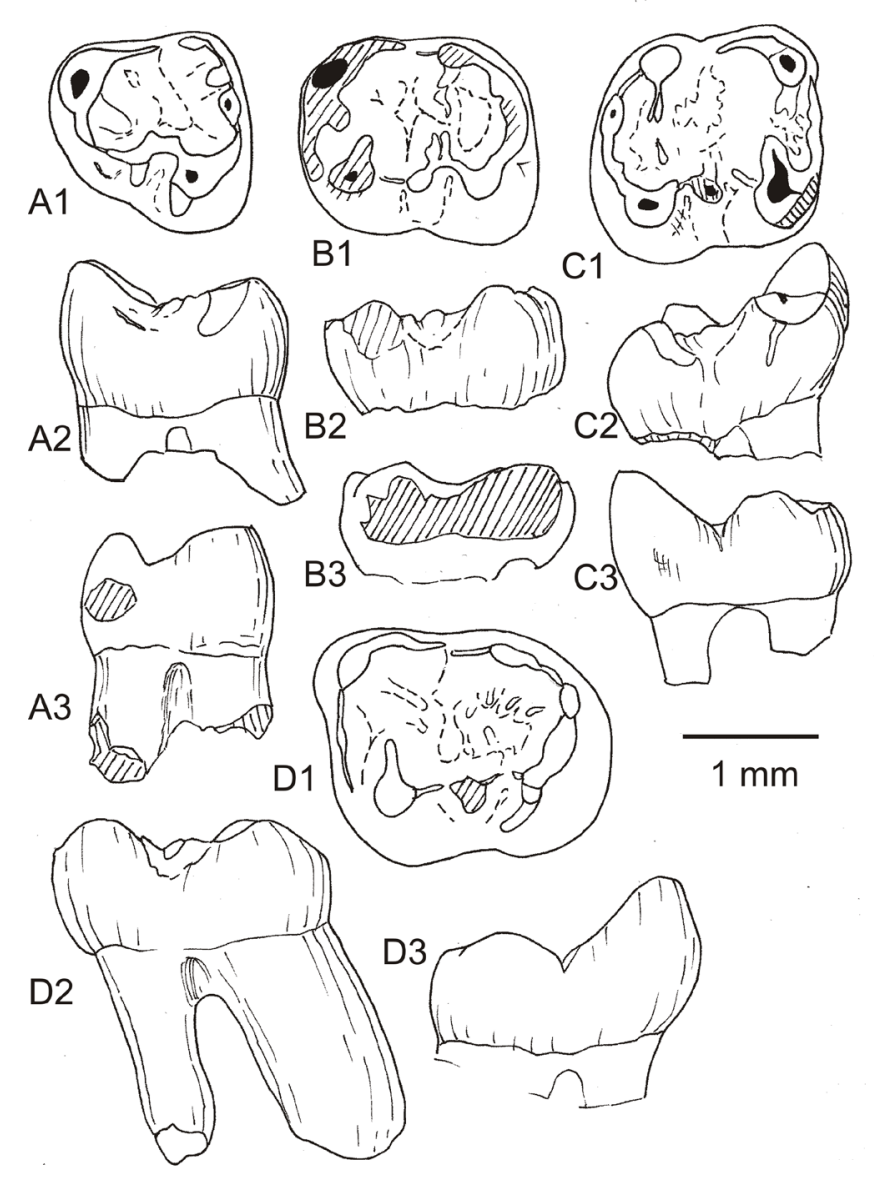

Figure 6. Lower teeth of Corbarimys cezannei (Hartenberger, 1987) from Palette (Bouches-du-Rhône; MP7?). A. UM-PAT 27, left p4; A1, occlusal view, A2, buccal aspect, A3, lingual aspect. B. UM-PAT 28, left m1, B1, occlusal view, B2, buccal aspect, B3, lingual aspect. C. UM-PAT 24, right $\mathrm{m} 1, \mathrm{C} 1$, occlusal view, C2, buccal aspect, C3, lingual aspect. D. UM-PAT 30, left m3, D1, occlusal view, D2, buccal aspect, D3, lingual aspect. Scale bar, $1 \mathrm{~mm}$. 
of the distal flank of the protoconid. This is different from Pseudoparamys, on which there is a true thick postprotocristid, which slopes slighly mesiobuccally to distolingually from the apex of the protoconid; there, it looks more like a high ectolophid ascending the lower $1 / 3$ of the distal flank of the protoconid. We observed such a condition on some $\mathrm{m} 3$ of Plesiarctomys savagei (PR-1186).

\section{Sub-family AILUravinae Michaux, 1968}

Remarks. The five described species of Ailuravus, including also cardosoi originally named Meldimys, form a wellsupported clade (node D; Fig. 4), a group not very far from the basal Theridomorpha (node TB; Fig. 4). Until now the taxon Ailuravinae was a sub-family of the Ischyromyidae, and included the North-American genera Eohaplomys and Mytonomys (Korth, 1988; Anderson, 2008). Later, these taxa were included in the family Alagomyidae (Hartenberger, 1995, followed by Escarguel, 1999). This grouping was supported by a phylogenetic analysis ( 7 taxa and 27 characters). Some of the characters and their polarities are questionable. It is the case for $\mathrm{n}^{\circ} 5$ (molarized P4) and $\mathrm{n}^{\circ} 6$ (shape of $\mathrm{P} 4$, cordiform or triangular). However, the P4 of Alagomys, considered to be molarized, is actually narrow bucco-lingually, short, not molarized, with only two cusps (paracone and protocone), which is closer to the condition found in basal Ctenohystrica like Cocomys (Vianey-Liaud, Gomes Rodrigues and Marivaux, 2010: 540-541). We have not found relationships between Ailuravus and Cocomys or Tamquammys (Marivaux et al., 2004; Vianey-Liaud \& Marivaux, 2017, and this paper).

As our analysis is already extensive and the objective being to analyze the early radiations at the origin of theridomorphs, we have not included prosciurines, aplodontines or the genera Eohaplomys and Mytonomys. Untangling the relationships between North American rodents is another subject, outside the scope of the present paper.

Among European Eocene rodents, the species of Ailuravus differs from the basal Theridomorpha in the absence of the strong oblique postprotocristid, found in other large European Eocene rodents like the large Plesiarctomyidae Plesiarctomys. They share with the latter dental features found together on upper and lower teeth. The ectocingulum is more or less developed on upper teeth, and together on lower teeth, there is the development of a mesiodistal ridge sloping from the buccodistal flank of the protoconid to the very short and low mesial ectolophid in front of the mesoconid. However, the evolutionary trajectories of the large Plesiarctomyidae and Ailuravinae diverged, each showing probably different chewing motions and dietary adaptations, Ailuravus being more brachydont, with acute protruding $\operatorname{cusp}(-\mathrm{id}) \mathrm{s}$, with groove on lower teeth allowing oblique movements during matication, whereas well-developed unilateral hypsodonty and the presence of mesiodistal buccal and lingual ridges in Plesiarctomys evoke mesiodistal movements.

\section{Genus Ailuravus Rütimeyer, 1891}

Remarks. Wood (1976) revised and clarified the systematics of the genus Ailuravus, considering three species of the middle Eocene. The first is A. macrurus from Messel (MP11, now dated as slightly younger than the late early Eocene, at the beginning of the middle Eocene; Lenz et al., 2015); the second is the type species $A$. picteti from Egerkingen (early middle Eocene, MP14), and A. stehlinschaubi from late middle Eocene localities (Mormont-Eclepens, Robiac Nord, MP16). The diagnoses of the Ailuravinae proposed by Wood (1976) were mainly based on these three species of the genus Ailuravus, but also on the Ypresian Meldimys louisi (Michaux, 1968), which brought to him a few primitive characters.

"Large paramyids; hypocone progressively enlarged but small in primitive forms such as Meldimys; protostyle (= anterostyle) large, sometimes approaching hypocone in size; M3 unusually like M 1.2; (D)P3 usually present, with well-developed pattern; conules progressively elongate anteroposteriorly; entoconid generally isolated from large, rounded hypoconulid; large mesoconid in a strong ectolophid, sometimes isolated from buccal margin of crown; incisors proportionately small, both in cross section and in length, with thin enamel; cross section of lower incisors ovate, narrow end forward; lower incisors progressively end beneath $\mathrm{m} 2$; arboreal, at least some forms with a long, hairy prehensile tail; fore-limbs proportionately long; scaphoid and lunar not fused (adapted from Wood's diagnosis, 1976: 123-124)."

Later (Escarguel, 1999) included in the Ailuravinae his proposed new genus Euromys, with three species: Euromys thaleri from Mutigny and Avenay (mid-early Eocene, MP89), Euromys inexpectatus from Prémontré (late early Eocene, MP10), and Euromys cardosoi from Silveirinha (early Ypresian, MP7). The genus Euromys was defined by Escarguel for the material previously described by Michaux (1964) as Reithroparamys thaleri, then to an indetermined Genus A (Michaux, 1968), mainly from Mutigny and Avenay. We will show that Euromys thaleri shares more features with the species "Paramys" woodi than with Euromys inexpectatus. These features are strikingly mainly depicted on lower teeth. They are the paths of the buccal metalophulid I (transversely connected to the apex of the protoconid, not to its posterior arm) and the oblique (mesiobuccal- to distolingual) postprotocristid, more or less long, sloping from the protoconid apex along its distal flank to join the short and low mesial ectolophid. The species inexpectatus has to be included within the genus Ailuravus, whereas we refer $P$. woodi to Euromys. We have found these shared features in Pseudoparamys, Meldimys, but also in Sparnacomys, Pantrogna and Hartenbergeromys. This arrangement is different from that found in the species of Ailuravus in which the postprotocristid is the buccal component of the metalophulid II, whereas the longer ectolophid starts at the junction between the posterior arm of the protoconid and the lingual metalophulid, and directed mesiodistally to the mesoconid (see below). We cannot use some characters of the upper molars, such as the development of ectocingulum elements: these exist in varying degrees in numerous genera like Meldimys, Pseudoparamys, Sparnacomys, Pantrogna and Masillamys, or even in Pseudosciuridae, Aplodontoidea or Sciuroidea.

More recently, a late middle Eocene species was described as Ailuravus (A. subita Comte et al., 2012; from ChéryChartreuve, Bassin de Paris, "MP15"). Based on our character analyses, it appears that it does not share the typical features of Ailuravus; therefore, we erect a new genus, Auroremys, likely excluded from the Ailuravinae.

Therefore, we reconsider the characteristics of the Ailuravinae, which include the features of $A$. inexpectatus, and exclude those of Meldimys and Euromys. We discuss the species "Euromys" cardosoi from Silveirinha (Estravis, 1992), and "Ailuravus" mitchelli from Abbey Wood (Hooker, 2010). From 
our phylogenetic results, this clade (node D; Fig. 4) appears as among the closest outgroup of the basal Theridomorpha (node TB; Fig. 4), branching after the ischyromyid clade Microparamys-Gliridae (node C; Fig. 4).

Type species. Ailuravus picteti Rütimeyer, 1891.

Lectotype. Basel Em 3 b, isolated left M3 selected by Wood (1962, p. 238).

Type locality. Egerkingen, fissure not precised (Solothurn, Switzerland; MP14).

Referred species. Ailuravus inexpectatus (Escarguel, 1999), originally referred to as Euromys; A. michauxi Escarguel, 1999; A. macrurus Weitzel, 1949; A. stehlinschaubi Wood, 1975; A. mitchelli Hooker, 2010; "Ailuravus" cardosoi (Estravis, 1992), originally referred to as Meldimys then as Euromys (Escarguel, 1999).

Original diagnosis of Ailuravus (Wood, 1976). "Large paramyid, about the size of a marmot; cheek teeth with fundamental paramyid pattern, but progressively develops numerous accessory ridges with over-deepening of many valleys in deep, narrow trenches. (D)P3 primitively present and complex. P4 progressively large and massive. Hypocone and protostyle of subequal size, both progressively enlarging and both derived from cingulum. Hypocone progressively set off from protocone by a lingual valley. M3 unusually molariform, but hypocone often small. Wear retaining the acute shape of the cusps mainly from the paracone, metacone to the protocone. Ectolophid of lower cheek teeth strong. Mesoconid and hypoconulid progressively large and distinct. Entoconid large, conical, and usually isolated from posterior cingulum. $\mathrm{m} 3$ the largest lower tooth; p4 usually the next largest. Upper cheek teeth with three roots, lowers with two. Lower incisor with thin enamel, rounded anterior face, and egg-shaped cross section, narrow end forward; lower incisor very short, ending in the genotype below the posterior part of $\mathrm{m} 2$. Main mental foramen in front of $\mathrm{p} 4$ often with one or more accessory foramina; symphysis highly convolute, permitting no motion between rami. Tail long, with about 40 caudal vertebrae, apparently prehensile; humerus, ulna and tibia subequal in length and only slightly shorter than femur; scaphoid and lunar separate bones; claws long."

Diagnosis (emended from Wood (italics), for osteological features and new dental features). Rodent of relatively large size. "Lower incisor with thin enamel, rounded anterior face, and egg-shaped cross section, narrow end forward; lower incisor very short, ending in the genotype below the posterior part of m2. Main mental foramen in front of 44 often with one or more accessory foramina; symphysis highly convolute, permitting no motion between rami. Tail long, with about 40 caudal vertebrae, apparently prehensile; humerus, ulna and tibia subequal in length, and only slightly shorter than femur; scaphoid and lunar separate bones; claws long."

Lower masseteric crest weak to absent on lower jaws. Enamel of teeth rough, to strongly wrinkled; granules and fine wrinkles, rare in the flexi; cusps and conules conical, slender in the earliest species, stockier on the latest ones.

Upper teeth. Wear retaining acute mesiodistal profile mainly for the paracone, metacone and protocone. (D)P3 present, and relatively well developed, compared to (D)P3 of theridomorphs. P4 smaller than to nearly as long as M1. M2 narrower than M1. M3 narrower and shorter than M2. D4 narrower than P4, with lingual wall shorter. Hypocone clearly slightly smaller and lower than the protocone, the bases of both lingual cusps being adjacent on the main part of their height, the endoloph being hardly distinct and short; sinus short linguobuccally and narrow; hypocone more developed on D4 than on P4, and placed more lingual than the protocone; anterostyle on M3 reduced in size. Ectocingulum (para-, meso-, and meta-) developed on D4; para-ectocingulum more or less developed; and metaectocingulum absent on P4 and M1, absent or very short on M2 and M3; large mesostyle; mesoloph absent; strong parastyle on M1, less on M2; paraconule strongly protruding mesially from the protoloph. Main metaconule bearing a mesiodistal ridge more pronounced on the latest species; lingual metaloph low to very low, connecting the protocone or the postprotocrista; mesoflexus trench deep and narrow.

Lower teeth. d4 distinctly smaller than p4. p4 smaller to nearly equal in size to $\mathrm{m} 1$, then molars increasing in length from $\mathrm{m} 1$ to $\mathrm{m} 3$. Trigonid from markedly higher than talonid on $\mathrm{p} 4$ and $\mathrm{d} 4$, to progressively weakly higher, to as low, from $\mathrm{m} 1$ to $\mathrm{m} 3$. Protoconid present on $\mathrm{p} 4$. Metaconid markedly to slightly higher than the other cuspids, with metalophulid I (a transverse buccal metalophulid from the protoconid apex joining the lingual metalophulid) rarely present or incomplete, metalophulid II (postprotocristid joining the lingual metalophulid) incomplete to complete. Mesiodistal ridge sloping from the posterior arm of the protoconid, ending at the level of a short and broken mesial ectolophid, in front of the strong mesoconid and short distal ectolophid. Sinusid buccolingually wide, reaching midwidth of the teeth on the latest species. Mesolophid and transverse entolophid generally absent, but arched short lingual entolophid (joining the entoconid and hypoconulid) frequent. Hypolophid (short buccolingual ridge stretching/ extending the lingual side of the hypoconid), connected both to the prehypocristid and posthypocristid. Salient hypoconulid, framed by two buccolingual diving ridges, and separated from the entoconid and hypoconid; separation from the entoconid less deep than with the hypoconid. Main groove from the mesoflexid lingual opening, to the notch between the hypoconulid and the hypoconid.

\section{Ailuravus cardosoi (Estravis, 1992) new comb.}

Meldimys cardosoi Estravis, 1992: 115-127, Pl. 12, figs. 1-20. Euromys cardosoi (Estravis, 1992) in Escarguel, 1999: 142143.

Original diagnosis. (see Estravis, 1992: 115-116).

Modified diagnosis. (see Escarguel, 1999: 141-142).

Holotype. SV3-342, fragment of left maxillary bearing P4-M3, figured in Estravis (1992: PI.12; fig. 7a-b).

Type locality. Silveirinha (type population; early Eocene, $\sim$ MP7, Portugal).

Measurements and description (Estravis, 1992: p. 116-120; tabl. 3; figs.14-16).

Remarks. This species was formerly referred successively to Meldimys (Estravis, 1992) then to Euromys (Escarguel, 1999). From the results of our phylogenetic analyses, this species falls within the Ailuravus clade, and is resolved as the earliest offshoot of this clade.

Discussion. This species differs from Euromys mainly in its lower teeth, lacking theridomorph apomorphies (cf. beginning of the section "Morphological analysis and systematics"). It has a transverse posterior arm of the protoconid, directed - 
connected to the lingual metalophulid, disposition defined as a metalophulid II: there is no buccal transverse metalophulid from the apex of the protoconid (metalophulid I). A strong and oblique postprotocristid found in Euromys and other theridomorphs is absent here. Based on our phylogenetic results, the species cardosoi can be included in the genus Ailuravus (A. cardosoi).

Ailuravus inexpectatus (Escarguel, 1999) and Ailuravus cf. michauxi Hartenberger, 1975

App., S. 2; Figures 7-15

Remarks. The species Ailuravus michauxi has been defined on a few specimens from Grauves (Hartenberger, 1975: 790, pl.1; six specimens) together with Ailuravus remensis (o.c.; two specimens). The features provided in the original diagnosis can be applied to a wide number of Eocene species. Following Hooker (1986), Escarguel (1999) synonymized A. remensis with $A$. michauxi, based on his analysis of a more abundant assemblage of Ailuravus from Prémontré, a locality he considered as contemporaneous with Grauves. A reevaluation of the small assemblage from Grauves would be necessary to ascertain, first the synomymy A. michauxi- remensis, second the similarity of its Ailuravus with that of Prémontré. Therefore, and in the meantime, the species of Prémontré will be cautiously synonymised with $A$. michauxi.

Then, as we transfer the species inexpectatus from the genus Euromys to the genus Ailuravus (see p.xx), we consider that at least two species of Ailuravus are present in Prémontré. We propose below their joint original diagnoses, the analyses of their morphology and size distribution. This is necessary, in order to highlight their differential characteristics, and which features justify their attribution to the same genus. It is significant that, in the original diagnosis of the species inexpectatus - which was included in the genus Euromys - its morphology was compared only with $A$. michauxi, whereas in the diagnosis of $A$. michauxi, the latter is compared with inexpectatus (Escarguel, 1999: 122-123; 147).

Holotype of Ailuravus michauxi. GR 7735, right 44.

Type locality. Grauves (Bassin de Paris, MP10).

Original diagnosis of Ailuravus michauxi. (Hartenberger, 1975: 780; translation from French). "Small sized species; upper teeth with double metaconule; hypocone weakly developed. P4 rather short; mesoconid strongly developed".

Emended diagnosis in Escarguel (1999: 122-123; translation from French). "Middle sized Ailuravus, significantly larger than Euromys inexpectatus. Cheek teeth more robust than for E. inexpectatus. Enamel surface rough. Heart-shaped D4, with marked and lingually positioned hypocone; protoconule (= paraconule) faintly smaller than the metaconule, mesostyle absent. P4 with developed antero- and postero-cingula; hypocone - as a swelling of the posterior cingulum - reduced and rarely absent; protoconule present. M1-2 with protoconule (= paraconule) generally double lingually. M1 with marked sinus and hypocone; massive metaconule rarely double. Posterior part of M2 less reduced compared to M1 than for $E$. inexpectatus; well-developed hypocone, lingual sinus and protoconule (= paraconule); metacone and metaconule sub-equal; mesostyle weak to absent. M3 of similar size as M2, with sinus and hypocone reduced but present; strong metaconule, with metacone - metaconule connection wellmarked. M1-3 with ridge sloping from the protocone in the trigon (= protocrista) stronger than in E. inexpectatus. Trigonid developed on $\mathrm{d} 4$ - anteroconid present -and sometimes closed distally. p4 large, wider than $\mathrm{m} 1$; massive trigonid, sometimes closed distally, with sketch of metalophulid I. On m1-3, trigonid closed distally by a well-developed metalophulid II; metalophulid I generally present; massive lingual cristid from the metaconid (= postmetacristid), more lengthened than in E. inexpectatus; ectolophid and mesoconid well-developed; massive hypoconid and hypoconulid, better developed than in E. inexpectatus, weakly connected to the entoconid by a double link with a marked centrat notch, as seen on Plesispermophilus. $\mathrm{m} 3$ rather long; trigonid basin open distally."

Holotype of Ailuravus inexpectatus. MNHN-PLPRE-I011, right M1 in Escarguel, 1999: P1. 6, figs. k-1.

Type locality. Prémontré (Aisne, Bassin de Paris, late early Eocene, MP10).

Original diagnosis of Ailuravus inexpectatus. (Escarguel, 1999: 147; translation from French). "Middle sized Ailuravinae, between sizes of Euromys thaleri and Ailuravus michauxi. Cheek teeth overall less molarized, slender, with lower cusps and ridges less developed than in A. michauxi. Enamel surface smooth to having a weak shagreen-like pattern. Triple mental foramen. d4 relatively narrow; trigonid poorly developed rare anteroconid - and always open distally; d4 and p4 with protoconid well-developed, nearly as high as the metaconid on 4 ; p4 compressed anteroposteriorly; reduced trigonid rare anteroconid - and open distally. Trigonid of m1-3 open distally; metalophulid I weak to absent; complete ectolophid and mesoconid rather poorly developed; hypoconulid less isolated than in $A$. michauxi. $\mathrm{m} 3$ with a frequent incipient hypolophid. D4 heart-shaped, with hypocone extremely lingual; reduced protoconule; mesostyle present. P4 narrow mesiodistally; reduced anterior and posterior cingula; hypocone and protoconule absent to much reduced. M1 with small hypocone, sinus, conules, parastyle and mesostyle less developed than in A. michauxi. M2 with weak hypocone and lingual sinus; reduced metacone and metaconule; mesostyle very weak to absent. M3 reduced, without hypocone; reduced protoconule; low metacone extremely lingual. M1-3 with ridge sloping in the trigon, less distinct than in A. michauxi; tendancy to protoconule doubling."

\section{New diagnosis (differential, between $A$. michauxi and $A$. inexpectatus).}

Middle sized species of Ailuravus, A. michauxi (M1: L mean x W mean: $3.55 \mathrm{~mm}$ x $4.39 \mathrm{~mm}$ ) larger than $A$. inexpectatus (M1: L mean x W mean: $3.15 \mathrm{~mm}$ x $3.96 \mathrm{~mm}$ ). High cusps, slenderer than in more recent species; stronger and more acute for $A$. michauxi, slender for $A$. inexpectatus. Surface of enamel smooth to finely striated on $A$. inexpectatus, wrinkles or granules more visible on $A$. michauxi.

Relative size of teeth: $\mathrm{d} 4$ much smaller than $\mathrm{p} 4$, which is narrower and slightly shorter than $\mathrm{m} 1$, shorter than $\mathrm{m} 2$, shorter than m3; D4 much smaller than P4, which is shorter than M1, M2 longer and narrower than M1, M3 shorter and narrower than M2 (less for A. michauxi, but few M3 of A. inexpectatus).

Upper teeth. For both species, anterostyle present, less developed on D4 and P4; more buccal than the protocone and at same level as the hypocone on M2, more lingual and more distinct than the reduced hypocone on M3; hypocone lower and smaller than the protocone on molars, with endoloph scarcely distinct. Hypocone reduced (cingular) on P4. Sinus shallow and narrow. 
Both species with similar morphological pattern and variation. D4 and molars: buccal slope with various developments of the mesostyle and ectocingulum, of the parastyle + mesiobuccal corner of the paracone more or less bulging and projected mesiobuccally, giving a more cordiform shape to the D4 and strong asymmetry of the M1. Mesoloph absent. Variable number of paraconules and metaconules; mesiodistal extra-ridge from the metaconule variably present; on both, more or less mesial attachment of the lingual protoloph on the preprotocrista.

On P4, morphological variation mainly concerning the parastyle and mesostyle areas, influencing the length of the tooth. P4 of $A$. inexpectatus narrower with paracone and metacone slenderer than on A. michauxi. Shallow ectoflexus and stretched mesostyle connected to the para-ectocingulum when present on $A$. inexpectatus and para-ectocingulum absent on $A$. michauxi.

Lower teeth. $\mathrm{d} 4$ and $\mathrm{p} 4$ with low anteroconid and anterocingulid variably present, distomesial premetacristid and preprotocristid. On $\mathrm{p} 4$ of $A$. michauxi only, mesiodistal extra-ridge descending on the middle of the distal flank of the trigonid, to the talonid. Short and low anterolophid on molars, aligned with the linguobuccal premetacristid; metalophulid I and II variably present, incomplete or complete on $A$. michauxi, buccal metalophulids being better marked and stronger in $A$. michauxi than in A. inexpectatus; metalophulid II more often incomplete and buccal metalophulid I rarely present on $A$. inexpectatus. Arched lingual entolophid between entoconid and hypoconulid (often delimiting a posterolingual islet) variably present on both; rarely a very low entolophid attached to the distal ectolophid or to the hypolophid on A. michauxi only.

Material and measurements. (App. S. 2, Figs. 7A-B; Table 2) A few teeth are redistributed. In both species, upper D4 and $\mathrm{P} 4$ are not numerous, and D4 appear distinctly smaller than P4-M1-M2. Among the five specimens referred to as D4 of inexpectatus, one (SLP29PE-65) is a M3 bud (the angle between pre- and post-protocristae is wider and the cusps lower than on D4). PLPRE-1005, previously identified as a M3 of $A$. inexpectatus, is a worn D4 of Plesiarctomys savagei.
The stronger D4 referred to as A. michauxi (SLP29PE-85), although worn, could be referred to another species (see below). One tooth previously referred to as a M3 of $A$. inexpectatus is a D4 of this species. P4 are shorter than M1, which are shorter than M2; M3 are much narrower than P4M1-M2 for A. inexpectatus, and less so for A. michauxi. Two M3 of the latter are longer (PLPRE-214 and SLP29PE-974). Several teeth of $A$. inexpectatus previously considered as M1 are $\mathrm{M} 2$, and several teeth of $A$. michauxi previously considered as M2 are M1. Two M3 previously referred to $A$. michauxi belong to $A$. inexpectatus (SLP29PR-325 and -1440), one M3 (PLPRE-1041), previously referred to $A$. inexpectatus is an M3 of Plesiarctomys savagei. Among the M3 previously referred to Plesiarctomys savagei, one belongs to A. michauxi (SLP27281) and two to A. inexpectatus (SM 052 and SLP29PR-264).

In both species, the $\mathrm{d} 4$ are distinctly smaller than $\mathrm{p} 4$; $\mathrm{p} 4$ are only slightly smaller than $\mathrm{m} 1$ (or nearly the same size as for A. inexpectatus), which are smaller than $\mathrm{m} 2 ; \mathrm{m} 3$ are distinctly longer than $\mathrm{m} 1-\mathrm{m} 2$. The teeth of $A$. inexpectatus are smaller than those of $A$. michauxi. The PLPRE-w $\mathrm{m} 3$ of $A$. inexpectatus (Pl.6, fig. e; Escarguel, 1999) is much shorter than the other $\mathrm{m} 3$. The SM- $817 \mathrm{~m} 3$ is distinctly narrower than the other $\mathrm{m} 3$ of A. michauxi. The SLP43PR-94 $\mathrm{m} 2$ is wider and slightly longer than the other $\mathrm{m} 2$ of $A$. inexpectatus. Finally, the large SM-3 tooth is not a $\mathrm{m} 1$ of $A$. michauxi, but a p4 (see below).

\section{Description.}

Upper teeth. (Figs. 8-10). The enamel is not strongly ornamented: the surface on the enamel flanks of $A$. inexpectatus is rough or with blunt wrinkles, which are more visible on $A$. michauxi (when the teeth are not too worn or coated with glue). The protocone-hypocone width is much shorter than the buccal width on D4 and M1; the difference is less pronounced on P4 and $\mathrm{M} 2$.

D4. Ailuravus inexpectatus and A. michauxi. As far as we can appreciate with such scarce material, the morphological variation is similar for $A$. inexpectatus and $A$. michauxi; their main difference is in size (Fig. 7A). Their degree of "molarization" is not so different; the hypocone is present
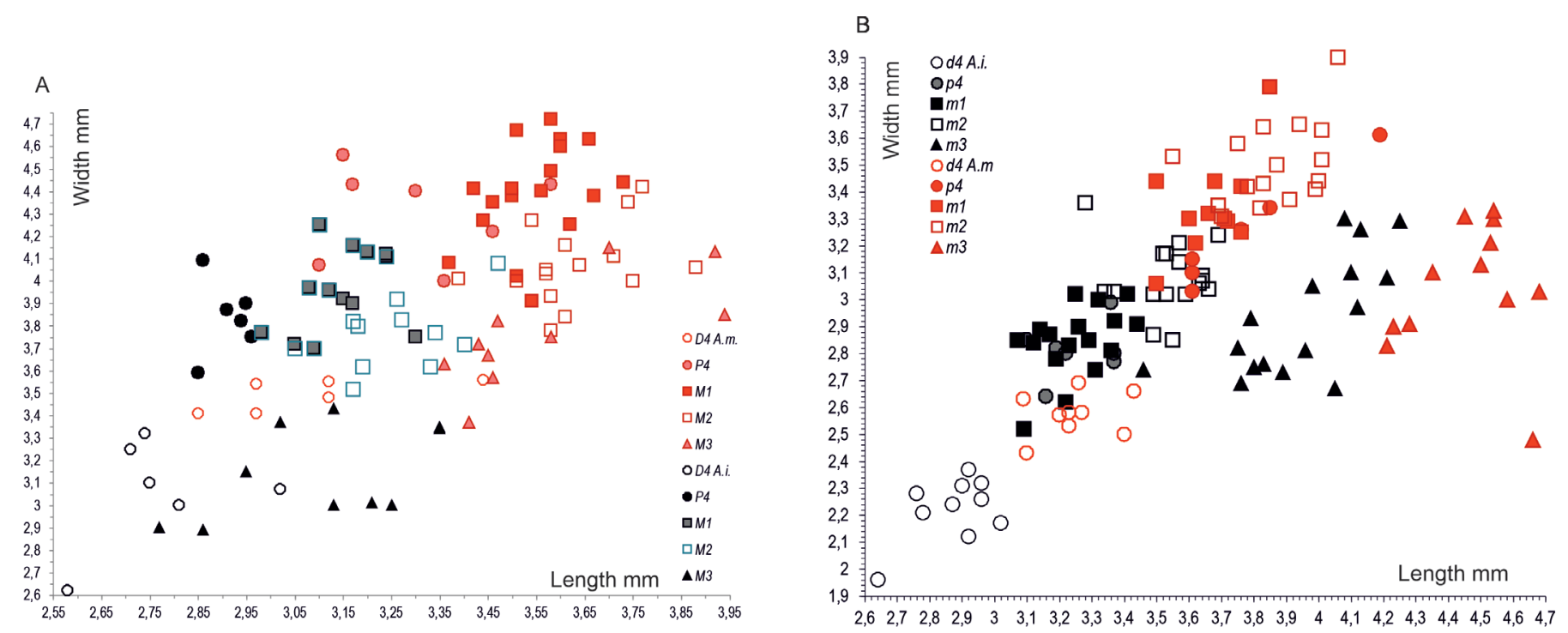

Figure 7. Bivariate graphs (Length x Width) of upper teeth (A) and lower teeth (B) of the two species of Ailuravus (A. michauxi Hartenberger, 1975 and A. inexpectatus Escarguel, 1999) from Prémontré (Late Ypresian, MP10, Bassin de Paris). Graduations in millimetres. 


\begin{tabular}{|c|c|c|c|c|c|}
\hline \multirow[b]{3}{*}{ Loci } & \multicolumn{5}{|c|}{$\begin{array}{l}\text { Ailuravus inexpectatus } \\
\text { (Escarguel, 1999) }\end{array}$} \\
\hline & & \multicolumn{4}{|c|}{ Length } \\
\hline & $\mathrm{n}$ & $\min -\max$ & $\mathrm{m} \pm \mathrm{Sm}$ & sd & $\mathrm{v}$ \\
\hline D4 & 6 & $2.58-3.02$ & $2.768 \pm 0.059$ & 0.1450 & 5.24 \\
\hline $\mathrm{P} 4$ & 6 & $2.85-2.96$ & $2.912 \pm 0.019$ & 0.0471 & 1.62 \\
\hline M1 & 13 & $2.98-3.24$ & $3.145 \pm 0.024$ & 0.0878 & 2.79 \\
\hline M2 & 19 & $2.98-3.47$ & $3.200 \pm 0.028$ & 0.1239 & 3.87 \\
\hline M3 & 10 & $2.77-3.35$ & $3.101 \pm 0.062$ & 0.1977 & 6.42 \\
\hline $\mathrm{d} 4$ & 10 & $2.64-3.02$ & $2.873 \pm 0.036$ & 0.1143 & 3.98 \\
\hline $\mathrm{p} 4$ & 7 & $3.10-3.37$ & $3.252 \pm 0.042$ & 0.1125 & 3.46 \\
\hline $\mathrm{ml}$ & 17 & $3.09-3.44$ & $3.249 \pm 0.026$ & 0.1109 & 3.41 \\
\hline $\mathrm{m} 2$ & 17 & $3.28-3.69$ & $3.534 \pm 0.027$ & 0.1148 & 3.25 \\
\hline \multirow[t]{2}{*}{$\mathrm{m} 3$} & 16 & $3.46-4.25$ & $3.947 \pm 0.52$ & 0.2084 & 5.28 \\
\hline & & \multicolumn{4}{|c|}{ Width } \\
\hline Loci & $\mathrm{n}$ & $\min -\max$ & $\mathrm{m} \pm \mathrm{Sm}$ & sd & $\mathrm{v}$ \\
\hline D4 & 6 & $2.62-3.32$ & $3.060 \pm 0.100$ & 0.2460 & 8 \\
\hline P4 & 6 & $3.59-4.09$ & $2.910 \pm 0.019$ & 0.1661 & 4.33 \\
\hline M1 & 13 & $3.72-4.25$ & $3.958 \pm 0.051$ & 0.1852 & 4.68 \\
\hline M2 & 19 & $3.52-4.25$ & $3.865 \pm 0.047$ & 0.2075 & 5.37 \\
\hline M3 & 10 & $2.89-3.43$ & $3.144 \pm 0.066$ & 0.2101 & 6.68 \\
\hline $\mathrm{d} 4$ & 10 & $1.96-2.37$ & $2.224 \pm 0.037$ & 0.1184 & 5.32 \\
\hline $\mathrm{p} 4$ & 7 & $2.64-2.99$ & $2.810 \pm 0.039$ & 0.1039 & 3.70 \\
\hline $\mathrm{m} 1$ & 17 & $2.52-3.02$ & $2.845 \pm 0.031$ & 0.1308 & 4.60 \\
\hline $\mathrm{m} 2$ & 17 & $2.85-3.36$ & $3.081 \pm 0.030$ & 0.1264 & 4.10 \\
\hline $\mathrm{m} 3$ & 16 & $2.67-3.30$ & $2.933 \pm 0.055$ & 0.2208 & 7.53 \\
\hline
\end{tabular}

Table 2. Size variations of the different loci of teeth of Ailuravus michauxi (Escarguel, 1999) and Ailuravus inexpectatus (Escarguel, 1999) from Prémontré (MP 10; Bassin de Paris). Comparisons of the size (Length $x$ Width) of the different loci of teeth between these two species through ANOVAs, in association with a test $\mathrm{F}$ of significance $(\mathrm{P}<0.01)$. on both, clearly smaller and lower than the protocone (e.g., unworn SLP29PR-2211, for A. michauxi and unworn PLPRE-S for $A$. inexpectatus). The main cusps are conical and acute. On unworn or weakly worn teeth, the paracone is stronger than the metacone. Both are framed by their sloping anterior and posterior arms being more or less aligned mesiodistally, and joining at the buccal opening of the mesoflexus. The development of a paraectocingulum - connected to the parastyle - and of a metaectocingulum - connected to the posteroloph buccal extremity - is variable on both. Thus, there are "cordiform" specimens in both species (e.g., PLPRE-s or SLP29PE-407 for A. inexpectatus; SLP29PE-1540 or -1017 for $A$. michauxi, Figs $8 \mathrm{~A} 1$ and $\mathrm{F} 1$ ). In these cases, the paraectocingulum and meta-ectocingulum are protruding buccally, and separated by a kind of ectoflexus in the mesostylar area; this ectoflexus may be more or less deep buccolingually. In both species, the para-ectocingulum may be absent or weak, whereas the meta-ectocingulum is always stronger. A kind of mesostyle ends the meta-ectocingulum mesially: it is not located between the paracone and the metacone. The mesoloph is absent. The anteroloph and posteroloph are low; the former ends in a weak anterostyle on the mesial flank of the protocone, the latter joining the descending posterior arm of the hypoconid. A short low endoloph joins the mesial flank of the hypocone (of which the anterior arm is absent) and the distal extremity of the postprotocrista. A short, shallow and narrow sinus is present, and the crown at the contact of the anteroloph on the mesial flank of the protocone is weakly concave.

The protoloph bears a single paraconule on the three observed specimens of $A$. inexpectatus; it is single or double on $3 / 7$ of $A$. michauxi. The lingual protoloph often reaches the extremity of the preprotocrista $(1 / 3 \mathrm{~A}$. inexpectatus; $5 / 7$ A. michauxi.), on the others its attaches a little more distally on this arm, leaving its extremity free in the anteroflexus. The metaloph bears generally one metaconule (in one case two, aligned buccolingually: A. inexpectatus PLPRE-725), which is higher to a greater or lesser extent than the paraconule. The metaloph reaches either the apex of the protocone, or more distally on its posterior arm. There is a weak thickening in the position of the protocrista, sloping along the buccal flank of the protocone to the narrow floor of the mesoflexus.

P4. Ailuravus michauxi. Of the eight P4 of this species, two are damaged or eroded. The main cusps are slightly stockier than those of $A$. inexpectatus. There are some variations in the morphological features, but none displays a para-ectocingulum. The morphological variations mainly concern the parastyle and mesostyle areas, which influence the length of the tooth. The ectoflexus is always present, even if the mesostyle is strong and stretched; in these cases, the ectoflexus deepens in front of the mesostyle. Among the shortest P4, SLP29PR-1993 is heavily rolled and worn. One can distinguish only one small paraconule, one strong metaconule, and the hypocone is nearly absent. On MSPRE-42, the mesostyle is reduced to a short low ridge buccal of the mesoflexus opening, or of a small conule on SLP29PR-1390, -767and MSPRE-101; it is longer on SLP29PR-1363 and -955. On the longest P4, the parastyle is swollen and protrudes mesially (SLP29PR-955,-1363, and MSPRE-101), but not on the others. Moreover, SLP29PR-955 also has the strongest mesostyle, extended lingually by a low and short mesoloph, which widen the floor of the mesoflexus; whereas it is narrow on the others.

The paraconule and metaconule are double on two and four teeth, respectively. The connections of the protoloph and metaloph with the protocone are as in $A$. inexpectatus. The hypocone is well defined, lower and smaller than the protocone in one case (SLP29PR-1390); it is more often reduced (SLP29PR-767, -955,-1363, MSPRE-42, and -101) at the lingual extremity of the posteroloph.

Ailuravus inexpectatus. The six $\mathrm{P} 4$ of $A$. inexpectatus are narrower than those of $A$. michauxi. All have a shallow ectoflexus on their buccal wall. On the unworn SLP29PR-1080, this wall is nearly flat, the mesostyle filling the ectoflexus area. The mesostyle connects to the para-ectocingulum, which joins the anteroloph, making a buccomesial cingulum. A paraectocingulum is also present on the worn SLP29PR-1260, on which the mesostyle extends a little along the buccodistal flank of the paracone. The para-ectocingulum is absent on two (SLP29PR-92 and -1007), but the others are too damaged to decide. The parastyle is present (and worn) on SLP29PR-1260, 
and very small and thin on SLP29PR-92. Paracone and metacone are slenderer than on $A$. michauxi, but only one unworn tooth is known. A weak preparacrista connects to the buccomesial corner of the cingulum. The postparacrista is not individualized. The protoloph descends to join the small paraconule, linked to the extremity of the preprotocrista. The protocrista is faintly swollen in A. michauxi, and not visible on the few $\mathrm{P} 4$ of $A$. inexpectatus.

The premetacrista slopes to the narrow groove, which separates it from the mesostyle. The postmetacrista joins the buccal corner of the posteroloph. One high crista links the metacone to the posteroloph, as a metaloph II. The buccal metaloph connects to a small metaconule, buccal of the main strong metaconule. The other P4 have only one strong metaconule. This connects to the protocone apex. A postprotocrista slopes distally, and stops in front of the shallow valley, thereby isolating the hypocone. This is smaller and lower than the protocone, and in continuity with the low posteroloph.
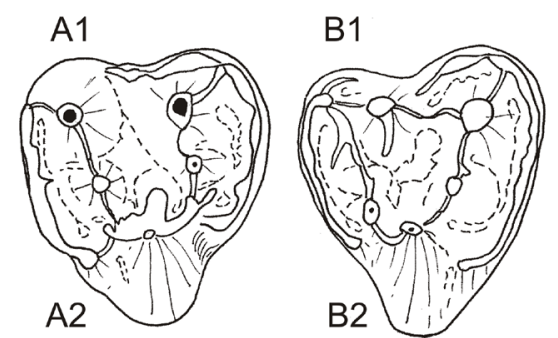

$\mathrm{C} 1$
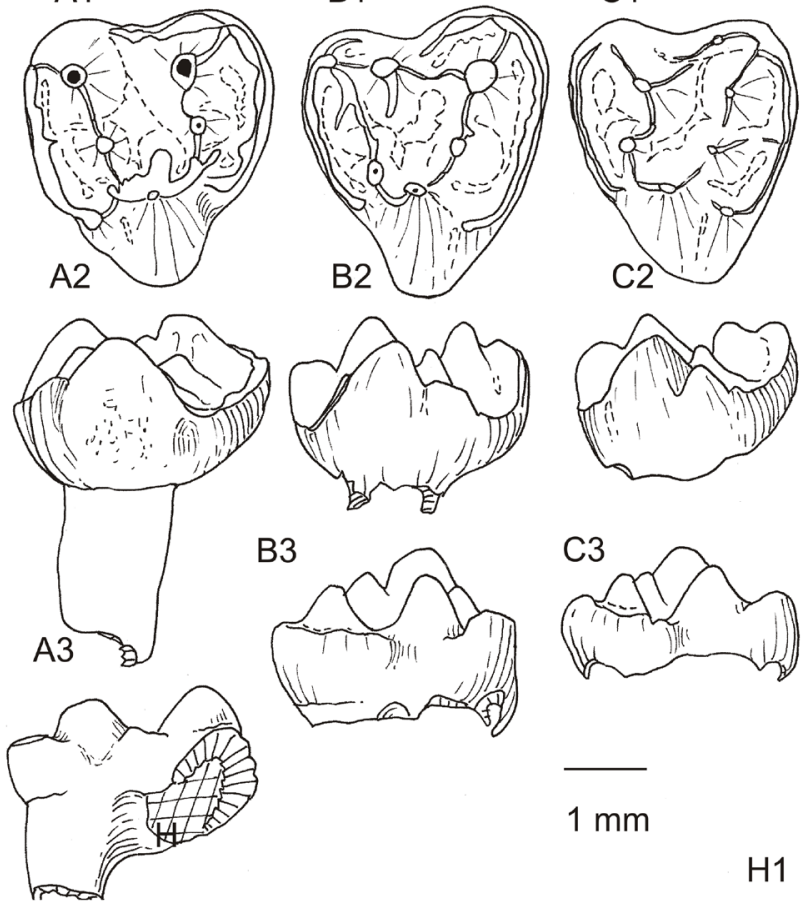

B3
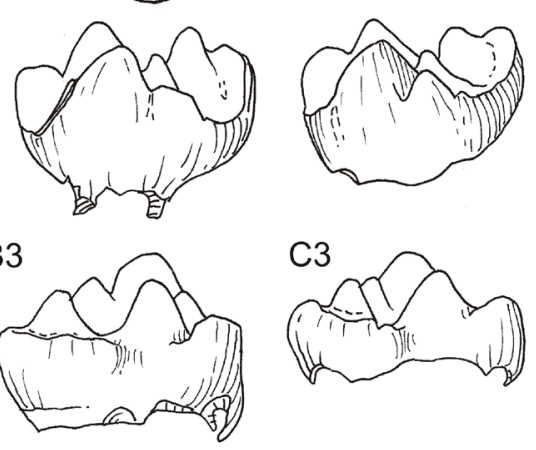

C3

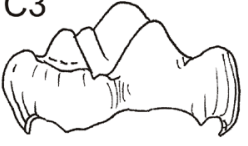

F1
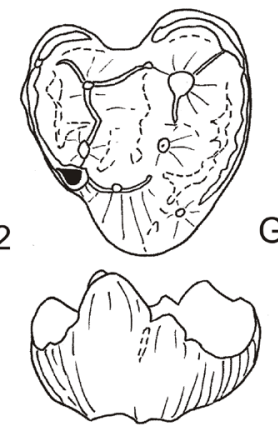

F3

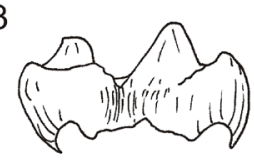

G1

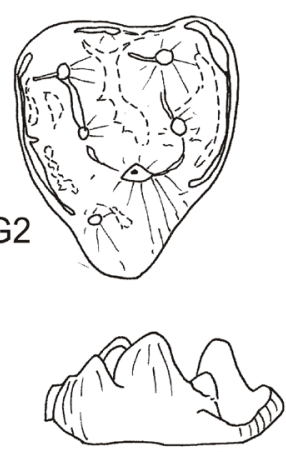

G3

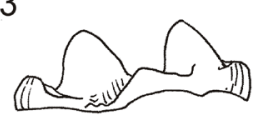

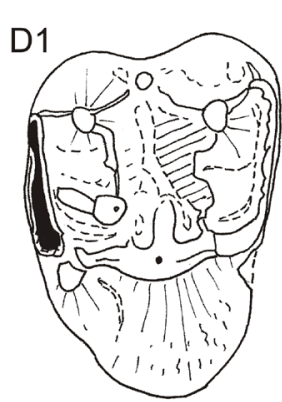

E1
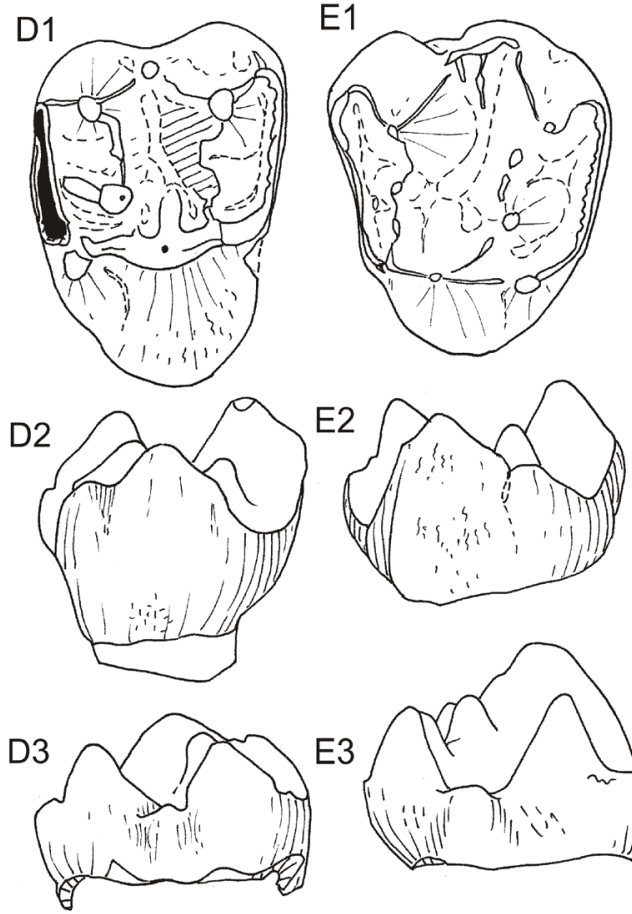

E3

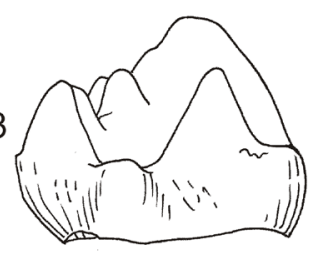

H1

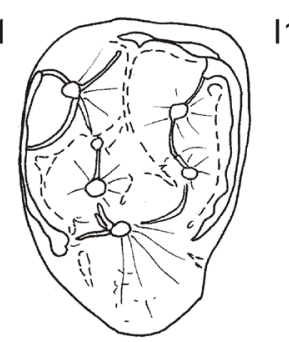

11

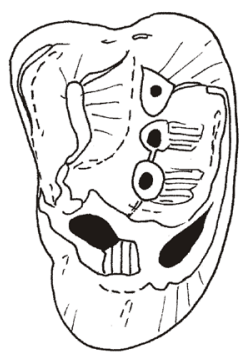

$\mathrm{H} 2$
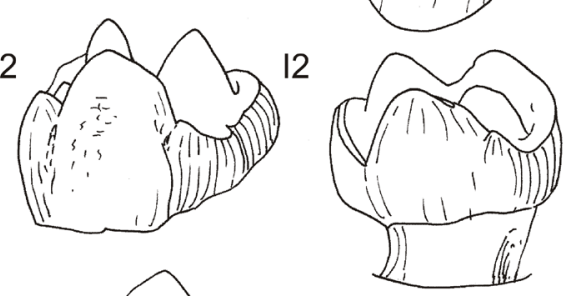

H3

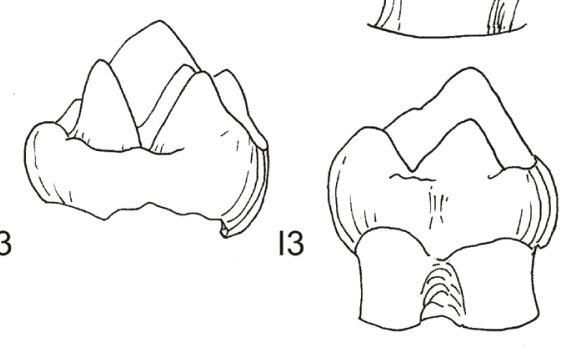

Figure 8. Upper D4 and P4 of Ailuravus (A. michauxi Hartenberger, 1975; A, B, C. D4; D, E. P4 and A. inexpectatus Escarguel, 1999; F, G. D4; H, I. P4) from Prémontré (Late Ypresian, MP10, Bassin de Paris). A. SLP29PR-1540, B. SLP29PR-1017; C. SLP29PR-2211; D. SLP29PR-1390; E. SLP29PR-955; F. PLPRE-s; G. SLP29PR-407, H. SLP29PR-1080; I. SLP29PR-92. For all: 1, occlusal view; 2, lingual aspect; 3, buccal aspect. Scale bar, 1 mm. 
M1-M2. Ailuravus inexpectatus and A. michauxi. The M1 are less numerous in the collection than the M2; the contour of M1 is more slender and asymmetrical than that of M2. Both species have similar morphological pattern and variation. As for D4, the variation concerns the buccal side, with various developments of the mesostyle and ectocingulum, the parastyle + mesiobuccal corner of the paracone is more or less projected mesiobuccally, the number of paraconules varies, and the attachment of the lingual protoloph is more or less mesial. Ailuravus michauxi is definitely not "more molarized" than $A$. inexpectatus; the hypocone is lower and smaller than the protocone in both, and not more so in $A$. inexpectatus. On unworn teeth, the cusps appear conical and acute. Comparison of the height of the cusps and crowns of the two species is not easy, owing to various degrees of wear, and incomplete preservation of the base of the crowns and roots; in any case, they are about the same height (Fig. 9). The extra-ridges are rare, and the enamel surface surrounding the crowns is generally weakly wrinkled, or smooth.

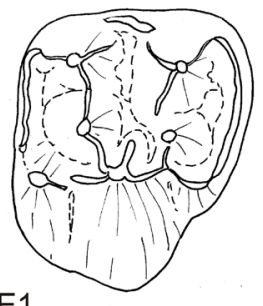

E1

B1
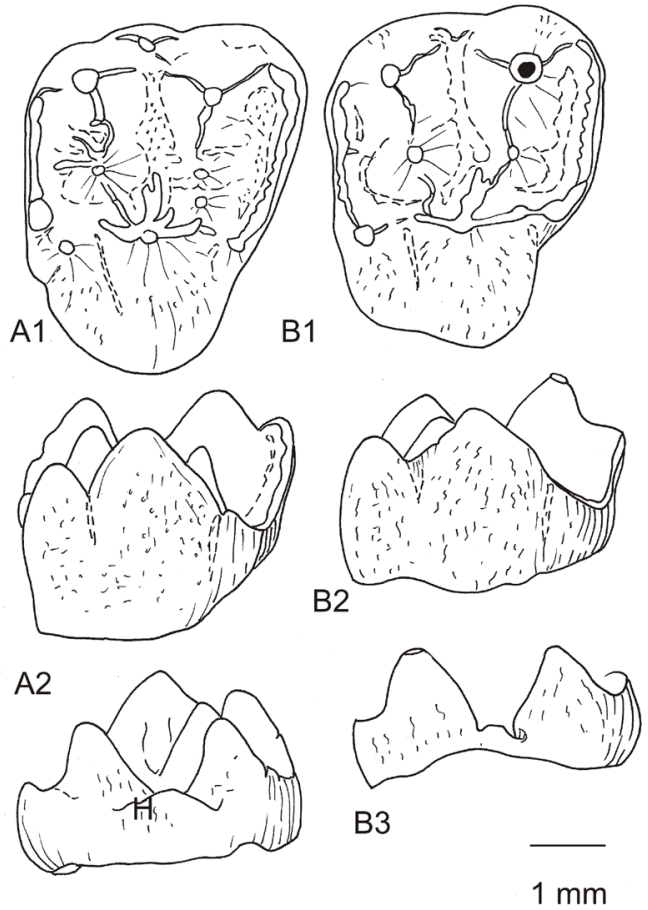

A3
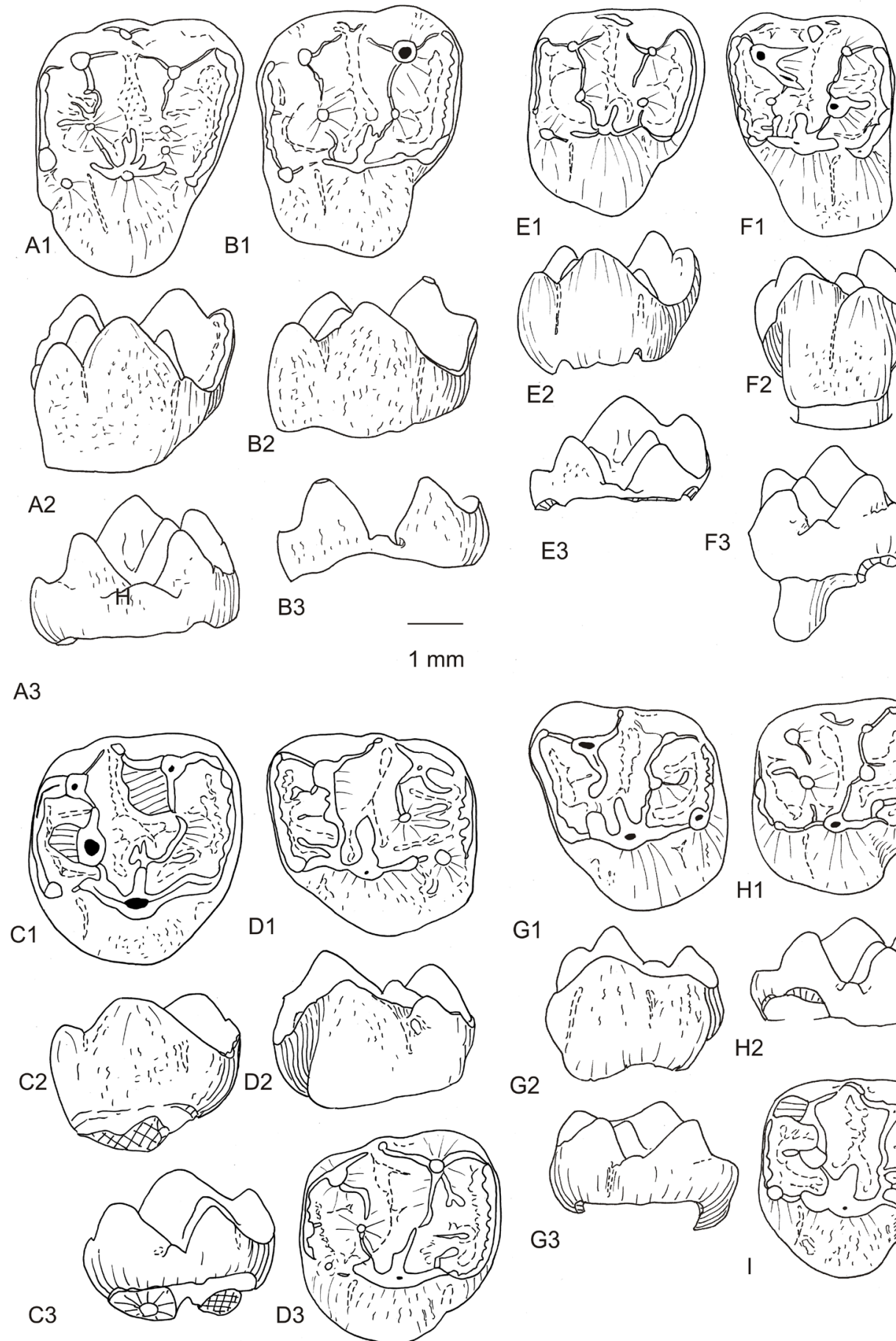

E3
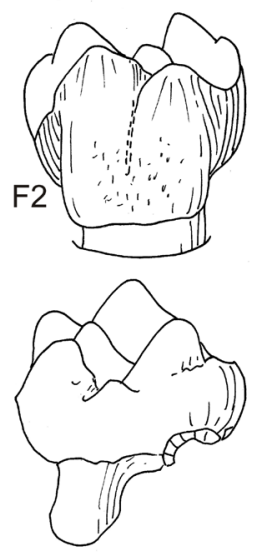

G1

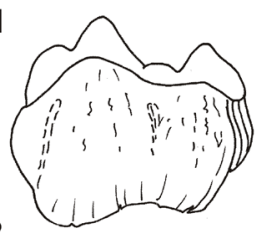

H1

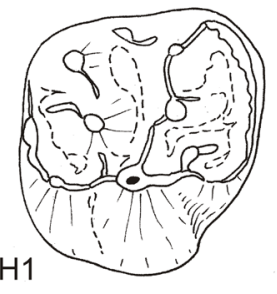

G2

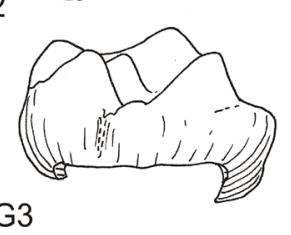

$\mathrm{H} 2$
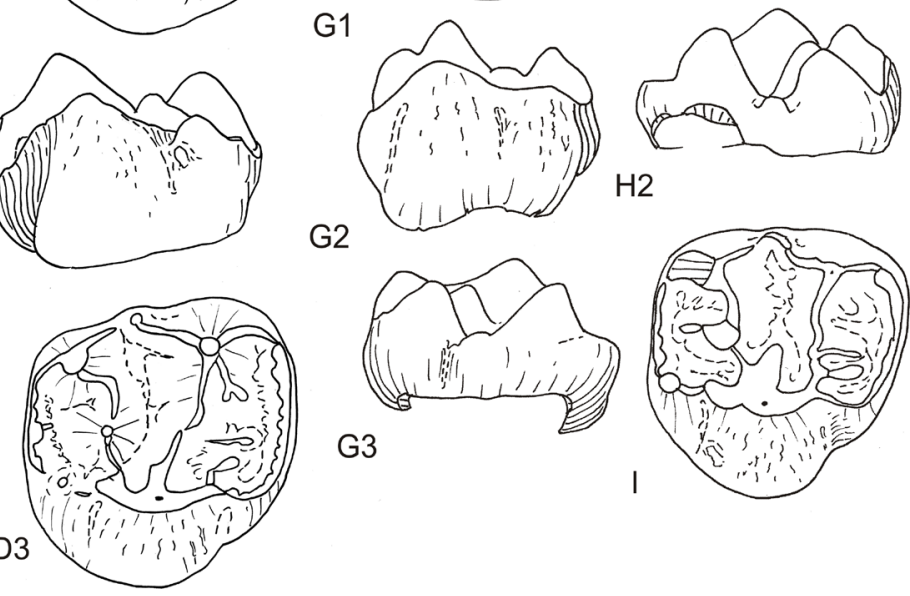

G3

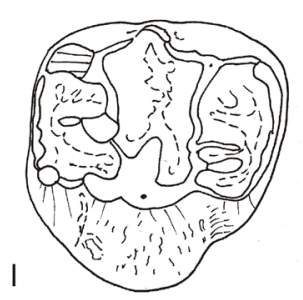

Figure 9. Upper M1 and M2 of Ailuravus (A. michauxi Hartenberger, 1975; A, B. M1, C, D. M2 and A. inexpectatus Escarguel, 1999; E, F. M1; G, H, I. M2) from Prémontré (Late Ypresian, MP10, Bassin de Paris). A. PLPRE-753, B. SLP43PR-305; C. PLPRE-1008; D. SLP29PR-1523; E. PLPRE-1011, Holotype; F. SLP29PR-1049; G. SLP29PR-799; H. SLPZ-319; I. PLPRE-u. For all: 1, occlusal view; 2, lingual aspect; 3, buccal aspect. Scale bar, 1 mm. 
M1. The parastylar area is slightly swollen and faintly projected buccomesially (9/16), moderately (4/16) or strongly (3/16) for $A$. michauxi. The type of $A$. inexpectatus is among the less asymmetrical of the M1 of this species. Its parastyle is not swollen, the anteroloph is thin and somewhat curved; it is not the case for all the other M1 of this species, on which the parastyle area is more or less protruding, and the anteroloph is straight transversely to the anterostyle. The mesostyle, buccal
A1

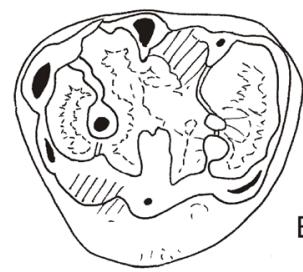

B1

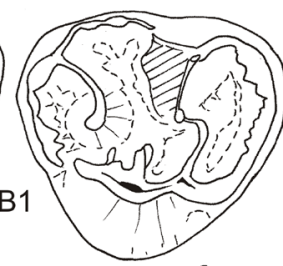

A2

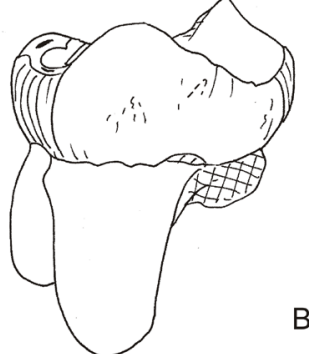

B2

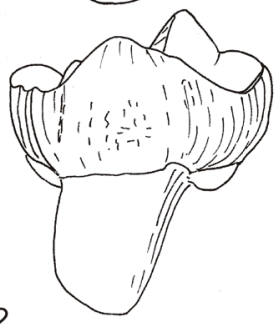

A3
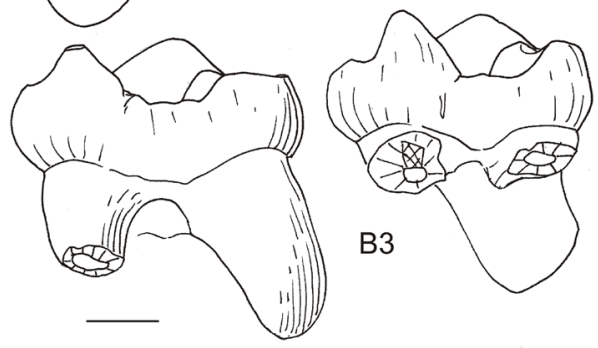

$1 \mathrm{~mm}$

C1

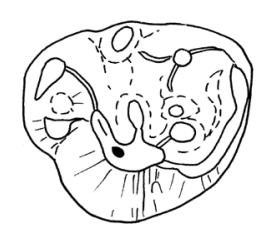

D1

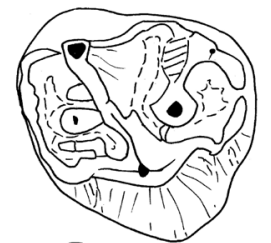

$\mathrm{C} 2$

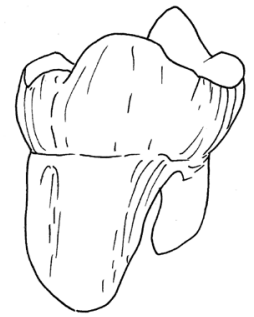

C3

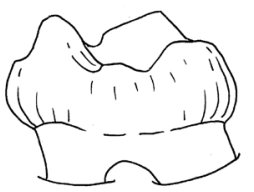

D2

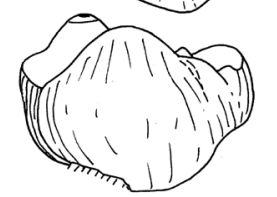

D3

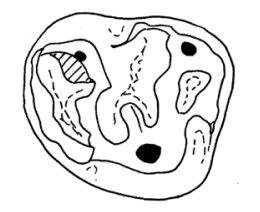

Figure 10. Upper M3 of Ailuravus (A. michauxi Hartenberger, 1975; A, B and A. inexpectatus Escarguel, 1999; C, D, E) from Prémontré (Late Ypresian, MP10, Bassin de Paris). A. SLP29PR-974, right M3; A1, occlusal view, A2, lingual aspect, A3, buccal aspect. B. SLP29PR-94, left M3; B1, occlusal view, B2, lingual aspect, B3, buccal aspect. C. SLP29PR-1501, right M3; C1, occlusal view, C2, lingual aspect, C3, buccal aspect. D. SLPZ327, left M3; D1, occlusal view, D2, lingual aspect. E. MSPRE-052, left M3. Scale bar, $1 \mathrm{~mm}$. of the paracone - metacone alignment, is small (5/16), a little enlarged by short mesiodistal ridges $(6 / 10)$, attached to a weak para-ectocingulum (3/16) for $A$. michauxi; an incomplete paraectocingulum and a meta-ectocingulum extending the mesostyle ridges are present on one; the ectocingulum is complete on one. On A. inexpectatus, the mesostyle is weak and stretched in its mesiodistal low ridges on the type and the greater number of the specimens, more isolated on one (PL1193). Incomplete para- and meta-ectocingulum are present on three M1 of $A$. inexpectatus, an incomplete weak meta-ectocingulum on one, and an incomplete weak para-ectocingulum on another. Pre- and post-paracristae are aligned mesiodistally, as are preand post-metacristae. The postparacrista joins the mesostyle, whereas the premetacrista is separated by a cleft. Paracone and metacone are pyramidal, the anterior and posterior slopes (along the pre- and post- cristae) being maintained at least until moderate wear. The anteroloph is lower than the posteroloph, slender and long, ending in a tiny anterostyle (distinct on unworn). A short ridge connects to the mesial slope of the preprotocrista, closing the anteroflexus lingually. The wall below is concave forming a pronounced antesinus. The two arms of the protocone (pre- and post- protocristae) are nearly aligned mesiodistally, and follow the slopes of the conical cusp. The protoloph bears one (A. michauxi: 10/16; $A$. inexpectatus. $8 / 12$ ) or two (A. michauxi: $6 / 16 ; A$. inexpectatus. $4 / 12$ ) paraconules, the more lingual the smaller. They rarely extend mesially in short distomesial ridges (A. michauxi: $2 / 16$; A. inexpectatus: 1/12). The protoloph joins the extremity of the preprotocrista (A. michauxi: $7 / 16 ;$ A. inexpectatus: 12/12), and the preprotocrista is closer to the apex of the protocone $(A$. michauxi: $3 / 16$ ) or the protocrista (A. michauxi: $3 / 16)$. In this case, a crest extends the preprotocrista free in the anteroflexus. The thick protocrista slopes to the middle of the mesoflexus along the buccal slope of the protocone.

The protocone and hypocone are at the same lingual level or the hypocone is a little more lingual. They are attached relatively high, and there the endoloph is rarely distinct. The sinus is narrow, and relatively deep; its base reaches about $1 / 3$ to $1 / 2$ of the crown height $(13 / 16)$ or reaches the base of the crown (3/16) for A. michauxi; about half of the crown height for $A$. inexpectatus. The metaconule is stronger than the paraconule and single; it is edged buccally with a mesiodistal ridge in two cases on $A$. michauxi; three extra-ridges diverge from its summit on two other M1 of A. michauxi, and one mesiodistally. On three M1 of $A$. inexpectatus, a short extraridge descends distally from the metaconule to the posteroloph. The metaconule is connected by the weak lingual metaloph nearly to the apex of the protocone, or slightly more distally on the postprotocrista. The posteroloph reaches the buccal corner of the postmetacrista.

M2. As for M1, the parastyle area is slightly swollen and scarcely projected buccomesially (A. inexpectatus: 4/19; A. michauxi: 5/17), moderately (A. inexpectatus: 6/19; $A$. michauxi: 9/17), or more (A. inexpectatus: $6 / 19 ; A$. michauxi: $3 / 17)$. On both species: when not or only moderately projected, the occlusal outline is more symmetrical. The hypocone, smaller and lower than the protocone, is relatively less developed than on M1; the antesinus is as developed as the sinus. The hypocone and anterostyle are on the same lingual level as the protocone or slightly more buccal; this appears clearly on the most symmetrical and unworn teeth. The mesostyle is reduced, smaller than on M1; a faint para-ectocingulum is present on one specimen of $A$. inexpectatus (SLP29PR-799), and a faint metaectocingulum on PLPRE-393 (A. inexpectatus) and PLPRE-t 
and PLPRE-221 (A. michauxi). The mesoflexus trench is narrow on all, except on one (MSPRE-59) of $A$. michauxi on which it is a little wider in its buccal part, owing to a larger mesostyle. The features of the paracone and metacone, and their cristae are the same as on M1.

The protoloph bears one (A. michauxi: $8 / 17$; A. inexpectatus: $7 / 19$ ) or two paraconules, the more lingual the smaller; the latter is often developed as a ridge directed distomesially. As seen on little worn teeth, the protoloph joins the extremity of the preprotocrista (A. michauxi: $7 / 14 ; A$. inexpectatus: $7 / 15)$, the preprotocrista is closer to the apex of the protocone $(A$. michauxi: $3 / 14 ; A$. inexpectatus: $5 / 15)$ or to the protocrista $(A$. michaux: $4 / 14 ;$ A. inexpectatus: $3 / 15)$. In this latter case, the lingual paraconule (when present) joins the extremity of the preprotocrista. The other features are as on M1.

M3. The M3 are less numerous in the collection than the M1M2; the occlusal outline of M3 is triangular, the hypocone and posteroloph being much reduced. Both species have similar morphological pattern and variation. The paracone is the highest cusp, the metacone the lowest but it is always swollen and protruding; it connects to the generally well-defined metaconule on the metaloph, which attaches generally to the distal extremity of the postprotocrista, or a little more mesially. The small mesostyle may be slightly stretched mesiodistally; the faint wrinkles are more frequent than on M1-M2.

The PLPRE-1041 M3, smaller than the other M3 previously referred to as $A$. inexpectatus, has quite a different pattern. Its distal part is flatter, with a lower and crestiform metacone; and a longer and heavily crested mesostyle area, with numerous extra-ridges. It would better correspond to Plesiarctomys savagei. Among the M3 previously considered as belonging to $P$. savagei, two can be referred to $A$. inexpectatus (SLP29PR-264 and 2100), and one to A. michauxi (SLP27-281).

Lower teeth. (Figs. 7B, 11-14) The surface of the enamel appears smooth or finely striated; small reliefs can be discernible on the floor of the talonid basin and on the sinusid walls, mainly of the largest teeth, that of $A$. michauxi. The cuspids are conical, and the posterior ones are somewhat hooked. The talonid is much lower than the trigonid on $\mathrm{d} 4$ and $\mathrm{p} 4$, only a little lower on $\mathrm{m} 1$ and $\mathrm{m} 2$; nearly at the same level on $\mathrm{m} 3$.

d4. Only nine $\mathrm{d} 4 \mathrm{of} A$. michauxi and nine of $A$. inexpectatus are present from Prémontré, and they display similar morphological variation around the same common pattern. The main difference between the two taxa is their size (Fig. 7B). Ailuravus inexpectatus is smaller and a little narrower than $A$. michauxi, two teeth of $A$. inexpectatus being substantially narrower (SLP29PE-545 and PLPRE-b), but these are strongly eroded. For Escarguel (1999), the d4 of A. michauxi differs from $A$. inexpectatus in their more developed trigonid (anteroconid present), which is sometimes closed posteriorly, whereas the anteroconid is rare in $A$. inexpectatus, and the trigonid always opens posteriorly. These criteria cannot be used as they are similarly variable in both taxa.

In both species, the main cuspids are hooked and slender, emerging from a relatively high basal wall of the crown, as seen on unworn and weakly worn teeth. The metaconid is only a little higher than the protoconid and hypoconid; the entoconid is lower than the hypoconid. The trigonid basin (anteroflexid) is narrow, as the protoconid and metaconid are close buccolingually, and it is more or less long mesiodistally, according to the development of the premetacristid and preprotocristid, and of the anteroconid. There is rarely a small conulid (anteroconid), more or less mesial or closer to the metaconid (A. michauxi: $2 / 9 ;$ A. inexpectatus: $2 / 9$ ). It is either isolated or included in the preprotocristid or premetacristid. These ridges descend from the mesial flanks of the metaconid and protoconid, not joining on a few teeth (therefore the trigonid makes a shallow distomesial valley open mesially), or turning to form a low and very short anterolophid, sometimes slightly extended on the mesial flank of the protoconid as a cingulid. These variations occur in both species.

The postmetacristid slopes gently to the long flat lingual border of the mesoflexid opening, on which the mesostylid is always absent. Metalophulid I (junction mid-protoconid to mid-metaconid) is generally absent, or faintly represented, interrupted at the base of the trigonid valley. Metalophulid II is generally present but much affected by wear, rarely incomplete, in both species. The two elements of metalophulid II, buccal as the postprotocristid, and lingual from the metaconid, converge at the middle of the sloping distal flank of the trigonid. A sloping mesiodistal ridge begins at this junction, and lowers to a very short mesial ectolophid in front of the mesoconid. The latter is weakly to moderately swollen. The distal ectolophid joins the base of the hypoconid. The ectolophid + mesoconid are about the $2 / 5$ of the tooth width, whilst the sinusid depth is less than half the height of the crown. The floor of the sinusid is flat and sometimes bordered buccally by a more or less strong ectocingulid. On PLPRE- 589 (A. inexpectatus.), small conulids may be present.

The hypoconid lies at the buccal end of a short hypolophid, which is followed by the posthypocristid, sloping to the valley that separates the hypoconid from the hypoconulid.
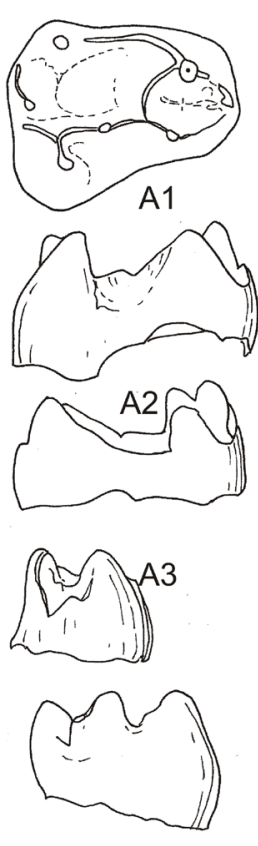

A4

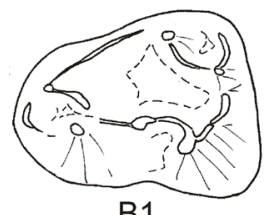

B1
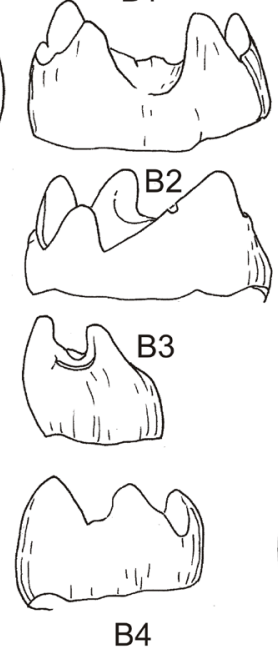

$2 \mathrm{~mm}$
C1
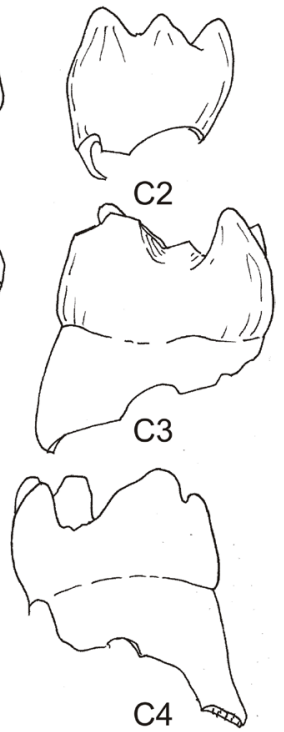

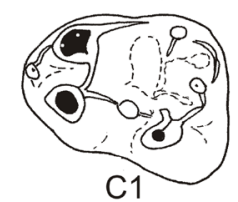

Figure 11. Lower d4 of Ailuravus (A. michauxi Hartenberger, 1975; A, B and A. inexpectatus Escarguel, 1999; C) from Prémontré (Late Ypresian, MP10, Bassin de Paris). A. PLPRE-a; A1, occlusal view, A2, buccal aspect, A3, lingual aspect, A4, mesial aspect, A5, distal aspect. B. SLP29PR-964; B1, occlusal view, B2, buccal aspect, B3, lingual aspect, B4, mesial aspect, B5, distal aspect. C. SLP29PR-1448; C1, occlusal view, C2, mesial aspect, C3, buccal aspect, $\mathrm{C} 4$, lingual aspect. Scale bar, $2 \mathrm{~mm}$. 

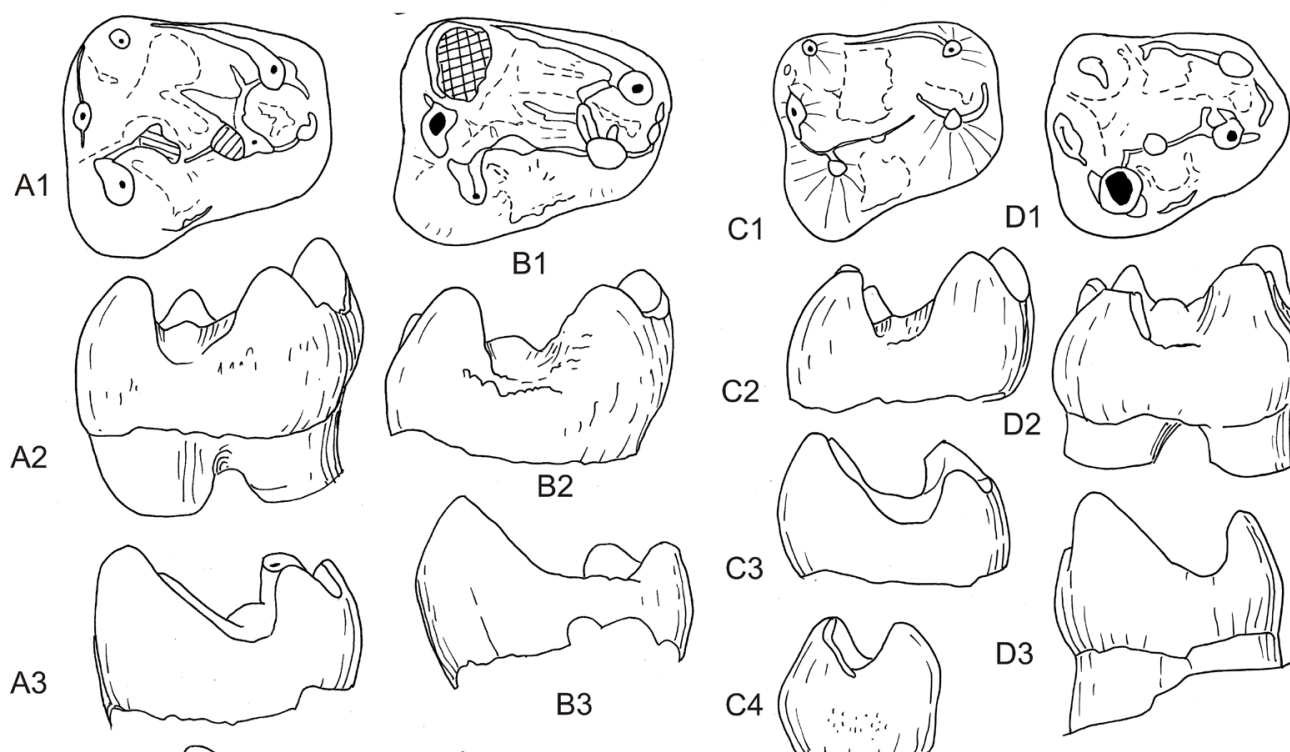

$\mathrm{D} 2$

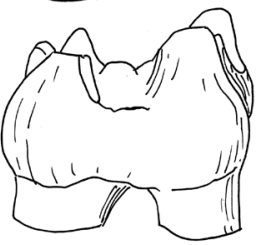

C3
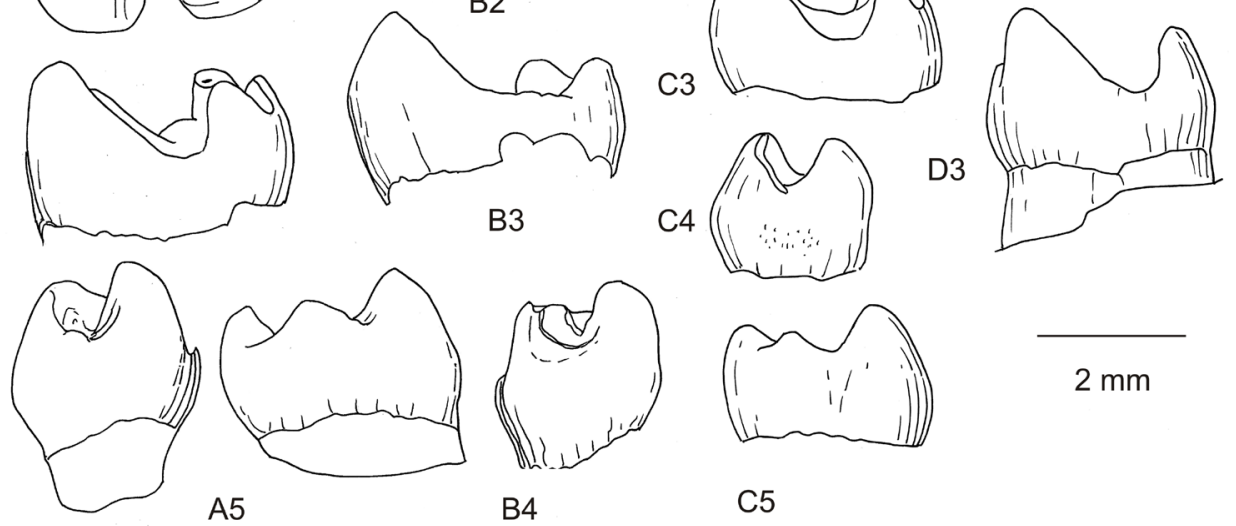

$2 \mathrm{~mm}$

Figure 12. Lower p4 of Ailuravus (A. michauxi Hartenberger, 1975; A, B and A. inexpectatus Escarguel, 1999; C, D) from Prémontré (Late Ypresian, MP10, Bassin de Paris). A. SLP29PR-934; A1, occlusal view, A2, buccal aspect, A3, lingual aspect, A4, mesial aspect, A5, distal aspect. B. SLP29PR-777; B1, occlusal view, B2, buccal aspect, B3, lingual aspect, B4, mesial aspect. C. SLP29PR-102; C1, occlusal view, C2, buccal aspect, C3, lingual aspect, C4, mesial aspect, C5, distal aspect. D. PLPRE-a, on a right lower jaw; D1, occlusal view, D2, buccal aspect, D3, lingual aspect. Scale bar, $2 \mathrm{~mm}$.

The high conical hypoconulid is isolated and often bears a lingual thin ridge, sometimes a buccal thin ridge, in both species. Its separation from the entoconid is less deep than from the hypoconid. An arched lingual entolophid sometimes joins the mesial flanks of the entoconid and hypoconulid $(A$. inexpectatus: PLPRE-463; A. michauxi: SLP29PR-68, -642,PLPRE-964, and MSPRE-155).

p4. Ailuravus michauxi. Only five p4 are referred to this species. They differ from $\mathrm{p} 4$ of $A$. inexpectatus mainly in their larger size (Fig. 7B, 12). The anterolophid is variably present as for $A$. inexpectatus. The metalophulid is complete (but low) on the p4 figured by Escarguel (1999: pl.1, fig. k); it is incomplete or absent lingually on the others. In both species, the protoconid is acute and always well developed, nearly as high as the metaconid. A difference with $A$. inexpectatus is the length of the mesiodistal ridge sloping from the posterior arm of the protoconid along the distal flank of the trigonid to the floor of the talonid basin. As this flank is longer distally than in $A$. inexpectatus, the mesoconid appears more distal, closer to the hypoconid, and the mesial ectolophid is longer. The arched short entolophid is present in one specimen.

Ailuravus inexpectatus. The metaconid is slightly higher than on $\mathrm{d} 4$, but not much higher than the protoconid. The short anterolophid is low to very low, closing the narrow trigonid basin. The anteroconid is small in two cases (SLP29PR-441 and -2095). It is absent on one, on which there is only the descending preprotocristid, and no premetacristid. The trigonid is limited distally by the postprotocristid; one can distinguish a faint wrinkle at the place of the buccal metalophulid from the protoconid apex. The lingual metalophulid is absent. The postmetacristid slopes relatively abruptly to the long flat mesostylid area, which obstructs the mesoflexid aperture. The mesiodistal ridge sloping from the postprotocristid appears weaker than in A. michauxi. The mesoconid is joined on each side by two mesiodistal ridges in line with the ectolophid, whilst its base is swollen. Therefore, it appears stronger when worn. The distal ectolophid is short and joins the short prehypocristid. The ectolophid-mesoconid is situated about $2 / 5$ the width of the tooth. The sinusid is wide, flat at its buccal base, and the ectocingulid weakly marked.

The features of the hypoconid, hypoconulid and entoconid are as on $\mathrm{d} 4$. The bases of the entoconid and hypoconulid are separate on PRE PLPRE-a, -102 or -1477, but connect mesially to a weak arched hypoconulid on the others.

$\boldsymbol{m} 1-\boldsymbol{m} 2$. The $\mathrm{m} 1$ differ from the $\mathrm{m} 2$ in their narrower trigonid (although much less than on p4), but the trigonid is narrower than the talonid at both loci. It is less high than the floor of the talonid on $\mathrm{m} 2$ than on $\mathrm{m} 1$. In both species, the metaconid is nearly facing the protoconid, and the entoconid is slightly more mesial than the hypoconid, but without reaching the mesoconid level. On weakly worn teeth, the wrinkles that affect the buccal surface of the enamel are fine and blunt on A. inexpectatus, whereas they are often blunt but more numerous and thicker on A. michauxi. On unworn teeth, there are granules on the enamel of the flexi only for $A$. michauxi; they are hardly visible with wear.

\section{Ailuravus inexpectatus.}

m1. The mesial arm of the metaconid, which starts lower than its apex, is preceded by a more lingual swelling, as a small 
lingual "anteroconulid", on two specimens (SLP PRE-465 and -1353). Then, the short anterolophid often swells as a buccal anteroconid. The anterolophid fuses with the lingual extremity of the preprotocristid, which is always present. The metaconid is only a little higher than the protoconid. Its postmetacristid descends relatively abruptly to the flat long mesostylid area, closing the mesoflexid opening, and delimiting the talonid basin. The short trigonid basin - closed mesially by the anterolophid - is partly closed distally by the postprotocristid (buccal metalophulid II). On a few teeth (SLP29PR-51, -112, and -1230), the groove of the trigonid is open distally. On more specimens (SLP29PR-592, -756, -1025, -1192, -1353, -1456, and -1705), this buccal metalophulid II joins the weak lingual metalophulid, descending along the metaconid flank. Together with metalophulid II, a weaker metalophulid I is rarely present, complete or buccal only (SLP29PR-1705, -1905, and -2255). In any case, the trigonid is much higher than the floor of the talonid. The mesiodistal ridge starts from the junction of the two parts of metalophulid II, and descends to the break (low mesial ectolophid) preceding the mesial flank of the bulging mesoconid. There is a kind of ectomesolophid on a few teeth (SLP29PR-1025, -1230, -1353, and -1905). As seen on unworn teeth, a weak ectocingulid outlines the flat floor of the sinusid. As the hypoconid is extended lingually by a short and welldefined buccal hypolophid on unworn or weakly worn teeth, the distal ectolophid is seen to be linked to it $(11 / 17)$, as is the sloping buccal arm of the hypoconulid. Between this arm and the salient hypoconulid, a narrow notch is distinct on unworn teeth. The hypoconulid is nearly as strong as the hypoconid, and stronger than the entoconid. The lingual ridge descending buccolingually from the hypoconulid reaches the middle of the distal flank of the entoconid. When the arched lingual entolophid is present, at mid height of the lingual flank of the entoconid-hypoconulid, a shallow posterolingual islet is isolated (14/17).

$\boldsymbol{m} 2$. The features are same as those of $\mathrm{m} 1$, except some variations in the paths of the metalophulid and entolophid. A lingual metalophulid I is rarely present (4/14); a low entolophid reaches the distal ectolophid on two (SLP29PR-1934 and -945), or an arched lingual entolophid and a short buccal entolophid are both present. In one case (SLP29PR-1), the hypoconulid has a mesial extra-conulid, nearly as high as it does. The ectomesolophid ridge is more visible and frequent (10/14).

\section{Ailuravus michauxi.}

$\boldsymbol{m} 1$. They display the same variations as $\mathrm{m} 1$ of $A$. inexpectatus, but they are larger, their cuspids stronger and more acute when unworn. A few differences can be emphasized. Buccal metalophulid I is stronger and well marked, as well as buccal metalophulid II. The latter is complete on 5/10, and interrupted (or nearly absent in one case) in the others. The mesoconid is somewhat stronger. A cluster of granules is more visible on the surfaces of the flexi. The arched lingual entolophid is less frequent $(3 / 10)$.

$\boldsymbol{m} 2$. These are more numerous (19) in the collection than m1 (10). The enamel is ornamented, more strongly than in $A$. inexpectatus. The features are as those of $\mathrm{m} 1$, except some

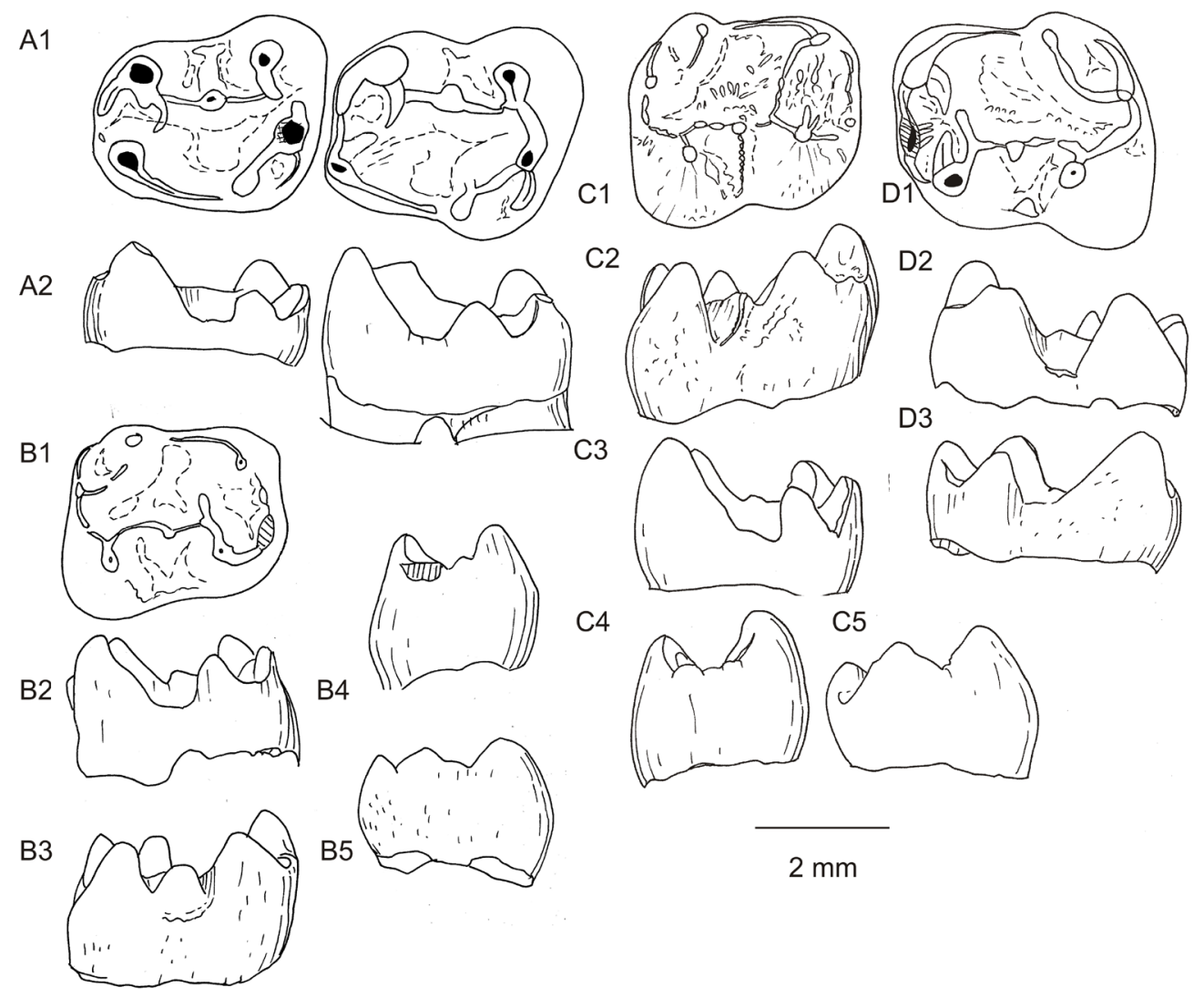

Figure 13. Lower $\mathrm{m} 1$ and $\mathrm{m} 2$ of Ailuravus (A. inexpectatus Escarguel, 1999; A, B and A. michauxi Hartenberger, 1975; C, D) from Prémontré (Late Ypresian, MP10, Bassin de Paris). A. SLP29PR-563, $\mathrm{m} 1$ and $\mathrm{m} 2$ on a right lower jaw; A1, occlusal view, A2, lingual aspect. B. SLP29PR-1197, right m2; B1, occlusal view, B2, lingual aspect, B3, buccal aspect. C. SLP29PR-1035, right m1; C1, occlusal view, C2, buccal aspect, C3 lingual aspect, C4, mesial aspect, C5, distal aspect. D. SLP29PR-75, left m2; D1, occlusal view, D2, buccal aspect, D3, lingual aspect. Scale bar, 2 mm. 
variations in the paths of the metalophulid and entolophid. The arched lingual entolophid is frequent (16/19). There is rarely a very low incomplete (PLPRE k, SLP29PR-101) or complete (SLP29PR-1330) entolophid, connected to the hypolophid or to the distal ectolophid.

m3. Ailuravus michauxi. (Fig. 14A-B) The m3 are more elongated, and relatively narrower posteriorly than in $A$. inexpectatus with the base of the metaconid larger, the entoconid and hypoconulid slightly less important. The morphological variation is similar (e.g., SLP29PR-861, with the strong swollen ectolophid at the mesial base of the hypoconid). The low linguobuccal entolophid is generally long, even if discontinuous (11/15), doubled by the arched lingual entolophid (3/13) or absent $(1 / 15)$.

Ailuravus inexpectatus. (Fig. 14C-D) The m3 are elongate, mainly due to the enlargement of the hypoconid, which becomes the strongest cuspid. The mesial width is equal to shorter than the distal width. The anterolophid is longer than on $\mathrm{m} 2$ as the protoconid is more distal. The trigonid basin is short, its floor inclined posteriorly towards the talonid; it remains higher than the latter. The cuspids are lower than on $\mathrm{m} 1-\mathrm{m} 2$. The postprotocristid is blocked more or less closely against the buccal base of the metaconid: the more the trigonid is closed, the less the trigonid is open distally. The mesiodistal ridge from the metalophulid II and the ectolophid are like on $\mathrm{m} 1-\mathrm{m} 2$. The linguobuccal entolophid is more frequent than on $\mathrm{m} 2$. It connects to the junction prehypocristid-distal ectolophid $(11 / 16)$, or both this and to the hypoconulid (2/16) (the others are too much worn). Only one (SLP29PR-646) displays the arched lingual entolophid, but its buccal half is strongly damaged: it could be a m2. On one specimen (SLP29PR-891), there is a strong conulid at the junction of the ectocingulid with the mesial base of the hypoconid.

Remarks and discussion. Size is the more striking difference between these two species. Differences in size between the teeth are statistically significant when the number of teeth is enough, like for upper and lower first and second molars, as shown with ANOVA analyses (Table 2, $\mathrm{P}$ values $<0.01$ ). This difference in size support the morphological ones: The cusps are high for both, but stronger and more acute for $A$. michauxi, slender for $A$. inexpectatus. The wrinkles or granules are more visible on $A$. michauxi than on $A$. inexpectatus. $\mathrm{P} 4$ of $A$. inexpectatus is narrower with paracone and metacone slenderer than on A. michauxi. The shallow ectoflexus and stretched mesostyle connects to the para-ectocingulum when present on $A$. inexpectatus. The para-ectocingulum is absent on $A$. michauxi. On 4 of $A$. michauxi only, mesiodistal extra-ridge descending on the middle of the distal flank of the trigonid, to the talonid. The buccal metalophulids are better marked and stronger in $A$.

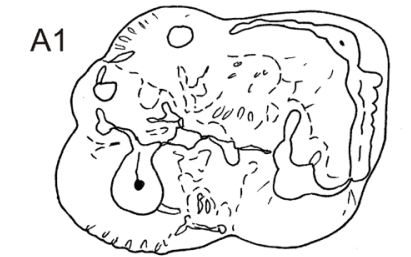

A2

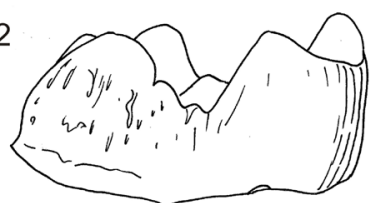

A3

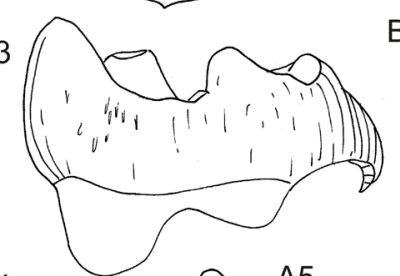

A4
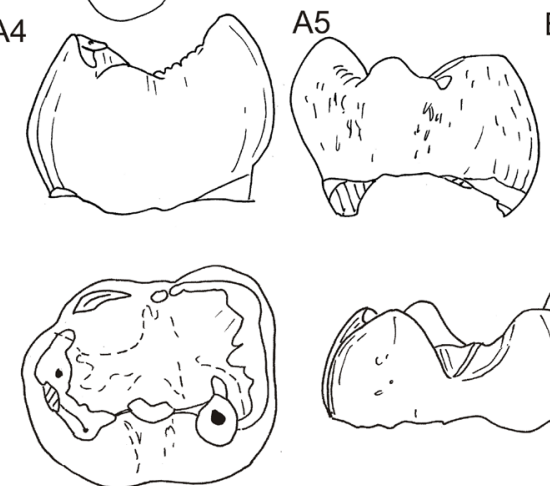

D1

D2
B1

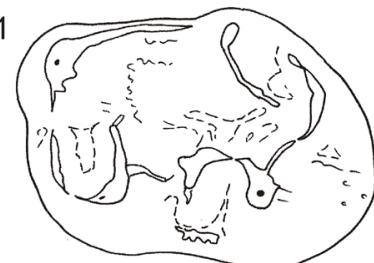

$\mathrm{B} 2$

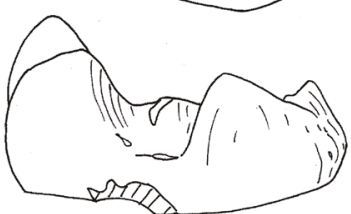

B3

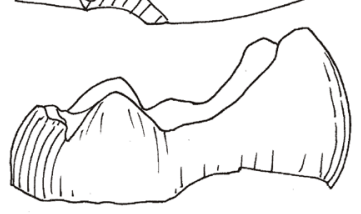

B4
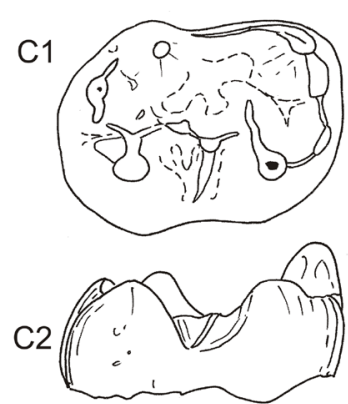

C3

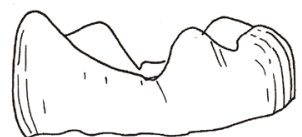

C4

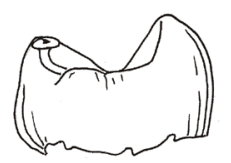

C5
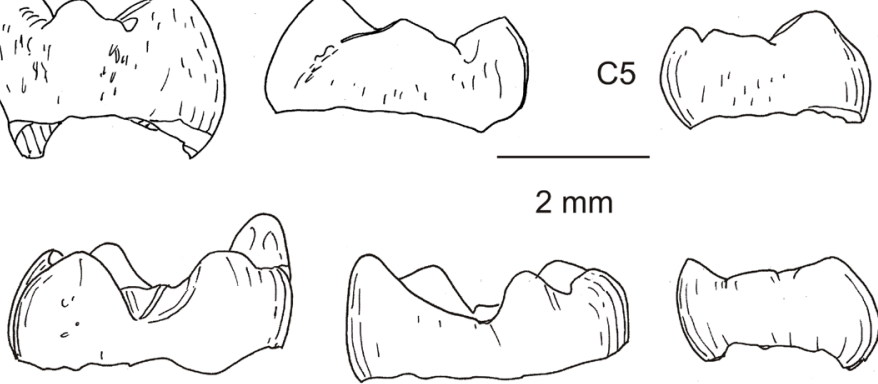

$2 \mathrm{~mm}$
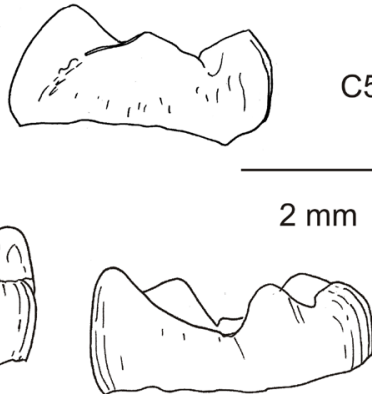

D3

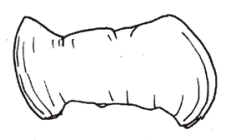

D4

Figure 14. Lower m3 of Ailuravus (A. michauxi Hartenberger, 1975; A, B and A. inexpectatus Escarguel, 1999; C, D) from Prémontré (Late Ypresian, MP10, Bassin de Paris). A. SLP29PR-861; A1, occlusal view, A2, buccal aspect, A3, lingual aspect, A4, mesial aspect, A5, distal aspect. B. SLP29PR-1212; B1, occlusal view, B2, buccal aspect, B3, lingual aspect, B4, distal aspect. C. SLP29PR-1832; C1, occlusal view, C2, buccal aspect, C3, lingual aspect, C4, mesial aspect, C5, distal aspect. D. PLPRE-w; D1, occlusal view, D2, buccal aspect, D3, lingual aspect, D4, distal aspect. Scale bar, $2 \mathrm{~mm}$. 
michauxi than in A. inexpectatus. The metalophulid II is more often incomplete and the buccal metalophulid I rarely present on $A$. inexpectatus. A very low entolophid attached to the distal ectolophid or to the hypolophid is rarely present, on $A$. michauxi only.

A few specimens differ from $A$. inexpectatus and A. michauxi, in their size or morphology and are described below.

?AILURAVINAE sp. indet 1: The SLP29PE-85 D4 is the largest one. Although somewhat eroded and digested, the cusps appear stockier than on the two species of Ailuravus. It is "cordiform" like the others, with strong para-ectocingulum and metaectocingulum joined to the anteroloph and posteroloph. It differs from them in the attachment of the lingual protoloph and metaloph, which is closer to the protocone apex, in the long free extremity of the preprotocrista, and in the stronger connection of the premetacrista to the more central mesostyle.

Ailuravus sp. indet. 2. The tooth MSPRE-3 (Fig. 15A) has been formerly described and figured as a $\mathrm{m} 1$ (Escarguel, 1999: pl. 1, fig. n). It could be a p4, larger than the others are, with an anterolophid stronger than on the other $\mathrm{p} 4$, being of same height as the metalophulid. The trigonid is reduced buccolingually and mesiodistally; its posterior slope descends to half-length of the tooth; like for the $\mathrm{p} 4$ of $A$. michauxi. It differs from the latter in its quite larger size, the longer and slender low anterolophid, the mesoconid doubled, the deeper distal notch between hypoconid and hypoconulid, the stronger arched entolophid, bearing a conule just mesial to the hypoconulid; and finally, the enamel of the buccal flank of the teeth is strongly wrinkled.

The tooth SLP29PR-947 (Fig. 15B), previously recognized as a $\mathrm{m} 2$, shows a buccolingually short trigonid: it is probably a m1. It looks like MSPRE-3. Despite the trigonid is short buccolingually, it is probably not a p4, because the trigonid posterior flank is steeper: it does not dive distally to halflength of the tooth. There is a strong high anterolophid closing the trigonid mesially, a reduced metalophulid I, and a strong metalophulid II, closing the trigonid distally, whereas it is weaker on true A. michauxi. The postmetacristid descends to the flat mesostylid area. The mesiodistal ridge from the junction of buccal and lingual parts of metalophulid II stops at the low mesial ectolophid. The strong mesoconid bears an ectomesolophid. The deep sinusid is edged buccally by the ectocingulid. There are blunt thick wrinkles and granules in the basin, the sinusid and on the buccal flanks. There is a strong arched lingual entolophid, which, together with the buccolingual ridge descending from the hypoconulid, close distally a well-developed islet.

Genus and species indet. (Fig. 15C). A mandible bearing only the first tooth (SLP29PR-1371) and showing the alveoli of the $\mathrm{m} 1$ to $\mathrm{m} 3$ has been previously identified as a juvenile of $A$. inexpectatus. In this context, the single tooth was identified as a d4 (Escarguel, 1999: 149). This tooth cannot be a d4, because the alveoli of all molars are present showing that the $\mathrm{m} 3$ was erupted. Moreover, the salient part of the cuspids is not limited, buccally, at the upperpart of the crown, and the sinusid is deeper: it is probably a $\mathrm{p} 4$. In addition, the two long roots are not divergent as they are on $\mathrm{d} 4$, whereas they are parallel, here, like on p4. Like on the two species of Ailuravus, the mesial preprotocristid and premetacristid descend to the anterolophid, which closes the mesial border of the moderately developed trigonid basin. The trigonid gutter is short and open distally, because buccal metalophulid II runs distally along the slope of the trigonid to the center of the tooth. There is no other metalophulid ridge. The long postmetacristid slopes moderately to the short mesostylid area. The long mesiodistal
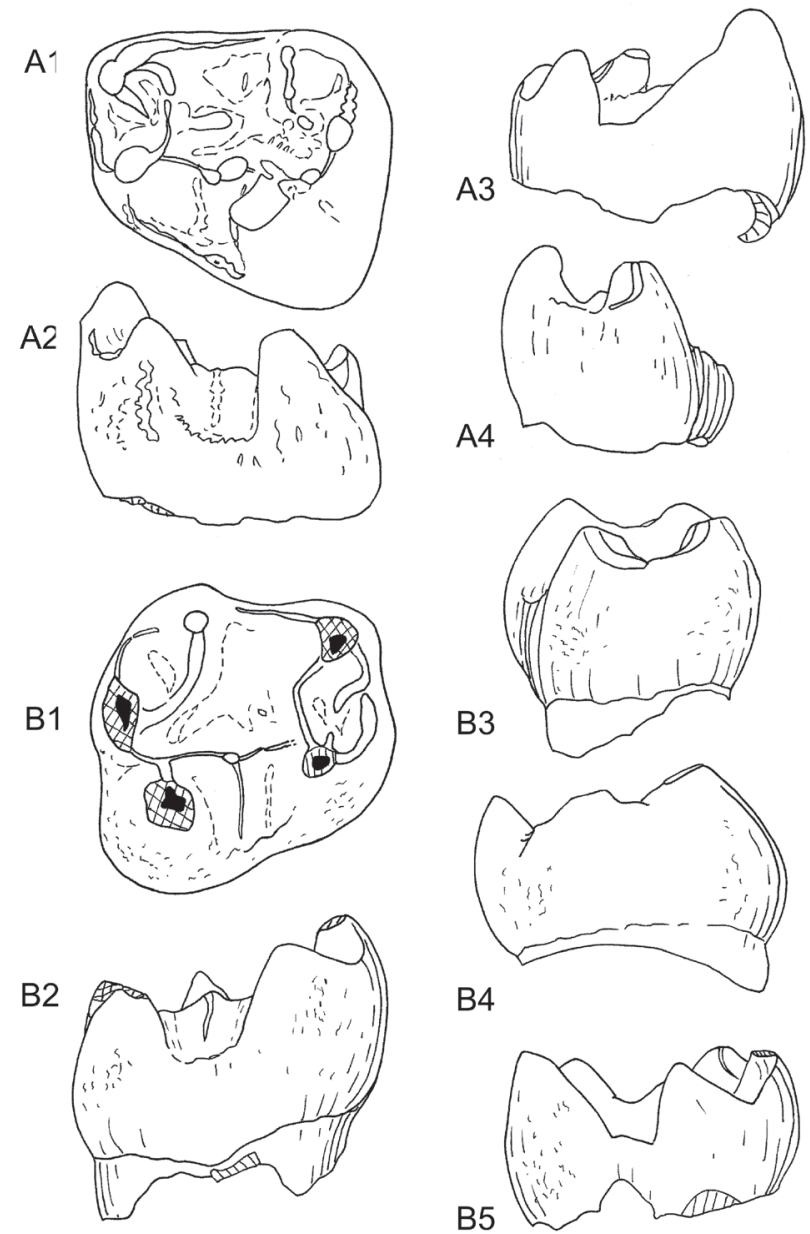

B4

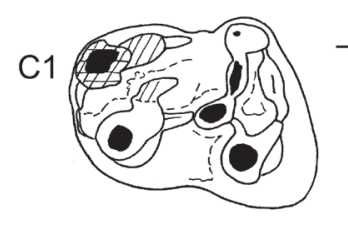

B5

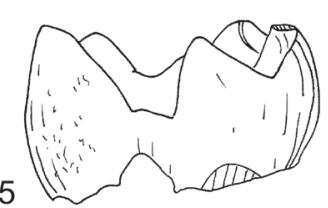

C2

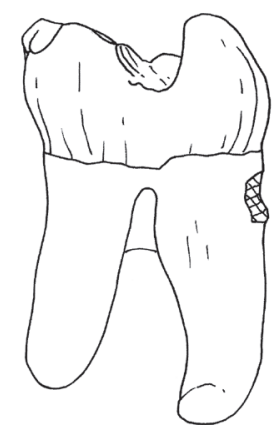

C3

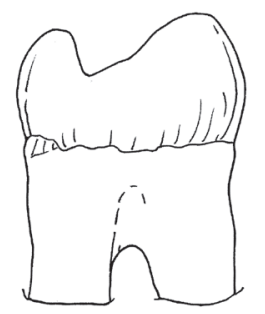

C4

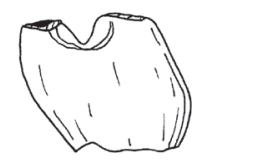

C5

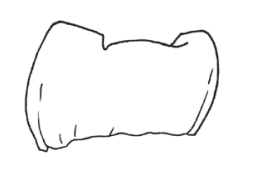

Figure 15. Two taxa indet. from Prémontré (Late Ypresian, MP10, Bassin de Paris). Ailuravus sp. indet. (A, B). A. MSPRE-3, left p4; A1, occlusal view, A2, buccal aspect, A3, lingual aspect, A4, distal aspect. B. SLP29PR-947, right $\mathrm{m} 1$; B1, occlusal view, B2, buccal aspect, B3, mesial aspect, B4, distal aspect, B5, lingual aspect. Genus and species indet. C. SLP29PR-1371, left p4; $\mathrm{C} 1$, occlusal view, $\mathrm{C} 2$, buccal aspect showing the roots typical for a premolar (not a d4), C3, lingual aspect, C4 mesial aspect, C5, distal aspect. Scale bar, $2 \mathrm{~mm}$. 
ridge descends to the cleft at the place of the very short mesial ectolophid, followed by the bulged mesoconid. A long and low entolophid joins the entoconid to the mesoconid. The hypoconulid is not salient, but stretched buccolingually; it attaches to the poshypocristid and the postentocristid.

The morphology of this tooth is different of that of the d4 of the two species A. inexpectatus and A.michauxi. The trigonid is not less reduced buccolingually and the anterolophid not protruding. The mesoconid is more central, the hypoconulid stretched buccolingually, the entolophid between the mesoconid and the entoconid is present though low. We think the morphology and proportion of this tooth better match that of a permanent $\mathrm{p} 4$ and the jaw does not belong to any of these two species of Ailuravus.

\section{“Ailuravus” mitchelli Hooker, 2010}

\section{Holotype. Left M1, M31909.}

Type locality. Abbey Wood (Blackheath Formation, early Eocene, around 55 My, Hooker, 2010).

Original diagnosis. Hooker (2010: 26).

Emended diagnosis. Small Ailuravus. Cheek teeth lack enamel wrinkling. P4 with low anteroloph; buccal flank convex, at the mesostyle level; hypocone indistinct. M1 with continuous ectocingulum, relatively weak paraconule and metaconule; protoloph joining the extremity of the preprotocrista; metaloph attached to the protocone; pre- and post- protocristae making a relatively narrow $\mathrm{V}$; low and short endoloph; hypocone small and lower than the protocone. p4 with connate-cuspate protoconid and metaconid. Lower molars lacking entolophid (from the entoconid) and hypolophid (from the hypoconid); lingual metalophulid reduced and weak on $\mathrm{m} 1$, nearly missing on $\mathrm{m} 3$; well-developed buccal metalophulid II (= posterior arm of the protoconid); short mesiodistal ridge from the buccal metalophulid II, directed to the short interrupted mesial ectolophid.

Remarks and discussion. Hooker (1986) has precisely described this material; we will add a few comments, as we have included the species inexpectatus in the genus Ailuravus, and used a more detailed terminology. This small species shares some features with Ailuravus, but the occlusal surfaces do not show the typical wear pattern of this genus. This could be related to its small size, likely associated with a different mode of chewing and/or diet. Hooker remarked that lower molars of $A$. mitchelli, "although smaller, have considerable morphological similarities with the species cardosoi, but P4 of the latter species has a hypocone like Ailuravus."

The P4 of $A$. michauxi has a prominent parastyle, which is less developed in A. inexpectatus; the hypocone is present on both species. In these species, the buccal tooth margin displays an ectoflexus, between the bulged buccal flanks of the paracone and metacone in $A$. michauxi, less pronounced in $A$. inexpectatus; it is absent on the species mitchelli, in which this area is in constrat salient, like in Corbarimys hottingeri, Plesiarctomys savagei or in Pseudoparamys. The ectocingulum rarely develops on M1 of $A$. michauxi, more often on $A$. inexpectatus and $A$. cardosoi. The two M1 of the species mitchelli have a continuous ectocingulum. It is also the case for Plesiarctomys and rarely for Meldimys. It is absent on the upper molars of Corbarimys. The cusps are less bulged and salient than on the two above species of Ailuravus, not strongly framed by pre- and post- paracristae, pre- and post- metacristae.
On lower d4, p4 and molars, the metalophulid is incomplete; limited on $\mathrm{m} 1$ and $\mathrm{m} 3$ to a short posterior arm of the protoconid directed lingually (buccal metalophulid II, like for Corbarimys). This structure is similarly developed on molars of $A$. inexpectatus, and some of A. michauxi, when other molars have better developed metalophulid II, and sometimes a metalophulid I. Like in larger Ailuravus, but also in Corbarimys, or also in early Eocene species of Plesiarctomys, there is a relatively long mesiodistal ridge from the buccal metalophulid II, descending to the short and broken mesial ectolophid. The distal ectolophid is also weakly broken behind the mesoconid. The latter is moderately bulging. If $A$. mitchelli shows a valley between the entoconid and hypoconulid, as in other species of Ailuravus, and in Corbarimys, the molars figured do not show the typical trench, between the entoconid and the hypoconulid. However, it seems that there is a break between the posthypocristid and the hypoconulid on the p4 (Hooker, 2010, fig. 11a), but this is also seen in some specimens of Meldimys or some of Euromys thaleri. The entoconid is crested, whilst it is conical, high and isolated on the larger Ailuravus. Moreover, in the larger Ailuravus, as well as in Corbarimys, an arched entolophid is variably present between the entoconid and hypoconulid, which is absent here. It is present once in $A$. cardosoi. The hypoconid is not stretched lingually to make the hypolophid as seen on the larger Ailuravus. This hypolophid is absent in Corbarimys. Therefore, this species mitchelli displays some differences with larger species of Ailuravus, but also with Corbarimys, and much more with Meldimys or Euromys. Therefore, its attribution to the genus Ailuravus is not certain.

\section{THERIDOMORPHA}

Remarks. At the base of the Theridomorpha clade (node TB, Fig. 4), two clades are successively differentiated after that of the ailuravines (node D, Fig. 4): the Meldimys-Euromys clade (node F, Fig. 4) and then the Pseudoparamys-Pleiarctomys clade (node G, Fig. 4). The Meldimys-Euromys clade is resolved here, at the base of the Theridomorpha, only based on the dental morphology. They share teeth features with Theridomorpha, like the unilateral hypsodonty, the height of the main cusps above the top surface of the lophs lower than the height below to the base of the crown, the lingual aspect of the crown being substantially higher than the buccal one, this being a sign of a certain degree of unilateral hypsodonty of the teeth; like also the occurrence of metalophulid I only, and the strong oblique postprotocristid, the well-developed hypocone and high endoloph. For the second clade (node G, Fig. 4), if Pseudoparamys (node H, Fig. 4) is clearly hystricomorphous, and its lower teeth display a thick and oblique postprotocristid, both apomorphies of the Theridomorpha, it is not the case of Plesiarctomys (node I, Fig. 4), in which the i.o.f. is only moderately or weakly enlarged. Concerning the postprotocristid, in this genus it takes part of the metalophulid II and attaches to a mesiodistal crestid sloping to the short low and broken mesial ectolophid. Additionaly, Pseudoparamys and Plesiarctomys differ from the subsequent theridomorph taxa arranged from the node J (Fig. 4), in their protoconid well present on $\mathrm{p} 4$ and $\mathrm{d} 4$, whereas it is absent from $\mathrm{J}$ to at least $\mathrm{M}$ (Masillamys), reduced to a mesiodistally stretched protocristid.

\section{Family EuROMYIDAE Family nov.}

Type genus. Euromys Escarguel, 1999. 
Referred genus. Meldimys Michaux, 1968.

Remarks. From our phylogenetic results, this family corresponds to the clade differentiated at the node F (Fig. 4). Meldimys and Euromys, making the first offshoot of the Theridomorpha. The species previously identified as Meldimys musak (Rana et al., 2008) from Vastan (Gujarat, India) takes place in our phylogeny as the sister species of the basal Theridomorpha (or as the earliest offshoot of the Theridomorpha clade). It is not closely related to the type species of the genus (Meldimys louisi), and as such it likely represents a new genus (a South Asian branch of the European theridomorph radiation).

Diagnosis. Middle-sized basal Theridomorpha; smaller than the Plesiarctomyidae (weak unilateral hypsodonty; occurrence of metalophulid I only; strong oblique postprotocristid; welldeveloped hypocone; high endoloph on molars). Enamel surfaces often wrinkled and rough. On upper teeth, parastyle and ectocingulum variably developed on P4, more on D4, rarely on molars; Paracone with oblique linguobuccally preand post- paracristae; Mesoloph generally present, more or less long. On lower teeth, metalophulid I only present; Entolophid generally absent or incomplete and low. Differs from the Plesiarctomyidae in the presence of protoconid on $\mathrm{d} 4$ and $\mathrm{p} 4$.

\section{Genus Meldimys Michaux, 1968}

Type species. Meldimys louisi (Michaux, 1964).

Type locality. Avenay (Marne, Bassin de Paris; mid-early Eocene, MP8-9).

Original diagnosis of Reithroparamys louisi. (Michaux, 1964: 153; translation from French). "Protoconid from which starts three ridges nearly transverse, the anterior joins the anterolophid, the second limits the trigonid basin, the third descends in the talonid basin, and is separated from the mesoconid; posterolophid weakly differentiated; distinct ridge (mesolophid?) in the talonid basin".

Original diagnosis of Meldimys (Michaux, 1968: 155; translation from French): "Ailuravinae; p4 with relatively strong protoconid; m1-2 with sketch of a connection between the hypoconulid and the entoconid in the talonid basin; hypoconulid well-defined from the hypoconid. M1-2 with hypocone still weakly developed, and not well-separated from the protocone".

Emended diagnosis. (Escarguel, 1999; translation from French). "Ailuravinae. Cheek teeth with circular contours, with noticeable increase in enamel wrinkles, from front to back of the dental row. D4 molarized and cordiform, of reduced size; P4 globular and wide, with mesostyle projected labially and hypocone very reduced; Ml-2 with reduced hypocone and massive pyramidal paracone; ridge descending from the protocone in the marked trigone; M3 slightly reduced, with small hypocone, lingual sinus marked and massive metaconule. Lower $\mathrm{p} 4$ elongated and arched. $\mathrm{p} 4-\mathrm{m} 3$ with massive metaconid having a broad and plane distolingual flank; mesoconid separated from the protoconid but connected to the hypoconid; hypoconid of $\mathrm{m} 3$ projected backwards. Trigon marked on upper molars"

Remarks on a revised diagnosis (Rana et al., 2008: 3). This revised diagnosis of the genus only deals with the differences from the other Ailuravinae, as the genus was considered as such. These differences correspond to similarities with basal Theridomorpha. It is the case of features of the paracone and its lophs and cristae (see new diagnosis), giving the pyramidal, "tetrahedral" paracone of Escarguel (1999) and Rana et al. (2008), which are not unique to Meldimys but also found in some Ailuravus, and also in Euromys, Sparnacomys, Pantrogna, Hartenbergeromys, and Masillamys. It is also the case for most of features of the lower teeth.

Emended diagnosis (new). Middle-sized rodents ( M1: L mean x W mean, $2.233 \mathrm{~mm}$ x $2.774 \mathrm{~mm}$ ): smaller than Plesiarctomys and Ailuravus and larger than Sparnacomys, Pantrogna and Hartenbergeromys.

Upper teeth. Lingual flank much higher than the buccal one, displaying rough or wrinkled enamel. Parastyle prominent on P4 and M1. Small hypocone, lower than the protocone and connected to it by a short endoloph, making an angle with the postprotocrista and underlined by a shallow sinus. Preparacrista weak or absent; strong postparacrista connected to the mesostyle, and depressed by a buccal notch. Ectocingulum variably present and more or less complete, from D4, P4 to M1, absent on M2-M3. Thick paracone prolonged in the thick buccal protoloph. Protocrista ending free in the mesoflexus or connected to the protoloph, and/or to the extremity of the preprotocrista, which also can be ending free or joining the small anterostyle. Paraconule and metaconule nearly equal in size and strong on molars (M1-2); mesostyle and short mesoloph present on molars; mesoloph absent on D4 and P4. A few extra-ridges present, thicker than the net of wrinkles on the floor of the synclines and synclinids.

Lower teeth. p4 with protoconid present and more distal than the metaconid, as developed as the hypoconid, and slightly higher; protoconid bearing buccally a mesiodistal cingulid plunging to the ectocingulid. Molars with high metalophulid I (at least buccal part present, starting from the apex of the protoconid, lingual descending from the apex of the metaconid, when present). Mesostylid area long and flat. Sloping mesialmost arm of the metaconid, aligned with the anterolophid, which ends close to the buccomesial flank of the protoconid, closing the trigonid basin. Oblique postprotocristid present, more or less long, and less oblique postwardly than in Euromys, Sparnacomys,_Pantrogna and Hartenbergeromys the postprotocristid ending with postmesoconid swellings or ridges. Short ectolophid: with a very low - absent on unworn teeth - mesial part, and a thick and higher distal part. Strong mesoconid, followed by a short prehypocristid; high and long posterolophid ending before the entoconid, overlooking the concave talonid basin. Sketch of a low entolophid, short and directed postwardly (lingual entolophid) or longer and directed linguobuccally to the distal ectolophid or to the prehypocristid. Floor of the talonid basin relatively flat. Numerous low wrinkles surrounding the latter: some being higher as two short lingual entolophids, one of them connected to the hypoconulid.

Differential diagnosis (new). Small Euromyidae with cusps and cuspids slightly lower than those of Euromys thaleri, enamel less ornamented than $E$. woodi.

Differs from Pseudoparamys in the paracone and metacone higher above the loph surfaces, and the talonid basin less concave; from Pantrogna, Hartenbergeromys and Sparnacomys in its $\mathrm{p} 4$ with a protoconid well individualized, and a postprotocristid shorter and less oblique postwardly.

\section{Meldimys louisi (Michaux, 1964)}

Figures 16-19

Holotype. MNHN-AV-5737, M2 dex. (2.42 mm x 2.19 mm; 
fig. e, in Michaux, 1964; Pl. 3, fig. n, in Escarguel, 1999).

Type locality. Avenay (Marne, Bassin de Paris; mid-early Eocene, MP8-9).

Diagnosis. That of the genus.

Material. We have observed the materials stored in the UMCollections and some casts of the teeth figured in Michaux (164, pl. 6, figs.1-3 for Avenay and fig. 4 for Mutigny) as well as some stored at the MNHN (App., S 1).

Measurements. The size distribution of Meldimys louisi from Avenay (Fig. 16) is not much different from that from Mutigny (Table 3), except for the M3, m2-m3 which are significantly longer and M2-M3, m1-m2 which are significantly wider in Avenay than in Mutigny; in both populations, the p4 are narrower than the $\mathrm{m} 1$ and as long as the smallest $\mathrm{m} 1$. From Avenay, the $\mathrm{m} 1$ are narrower and slightly shorter than $\mathrm{m} 2$; $\mathrm{m} 3$ are clearly longer than $\mathrm{m} 1$ and $\mathrm{m} 2$. The observation of the materials from Mutigny led us to question their attribution to the same species as that from Avenay; we will discuss that below. In both localities, D4 and P4 are distinctly shorter than molars, and M1 slightly larger than M2 in Avenay, slightly smaller in Mutigny. The M3 from Avenay are slightly narrower, but quite longer than the M1-M2. If the size of M1-M2 from Mutigny is not much different from the size of these teeth from Avenay, the M3 from Mutigny are narrower than M1-M2. The morphological differences are less strong with the more conservative upper teeth. The description concerns only the type population from Avenay.

\section{Description.}

Upper teeth (Figs. 17-18). The height of the paracone and metacone above the loph surfaces is roughly similar to the height below the base of the crown, whereas it is lower in Pseudoparamys. The lingual flank of teeth is much higher than the buccal one, with an enamel rough or thinly wrinkled.

D4. D4 is triangular. The lingual border displays a conical protocone, the hypocone being much lower and smaller, and more lingually situated than the protocone. If the pre- and post- protocristae are aligned obliquely on UM-AV-727, they make a V shape on AV-605 L. The endoloph has a same elevation as the hypocone on UM-AV-727, but is slightly lower on AV-605 L. The anteroloph is long and low, with weak parastyle and anterostyle. The first connects to the preparacrista, the second to the mesial flank of the protocone. The paracone is only slightly stronger than the metacone. Buccally, it is somewhat flattened and edged by a low and thin para-ectocingulum, ending in front of the mesostyle. The postparacrista runs mesiodistally then turns at its end to join the mesostyle, placed more buccally. It is long (less on AV-605 L), and depressed buccally when it curves. The mesostyle is more central on AV-605L, more distal on UMAV-727. It joins the meta-ectocingulum, which turns around the metacone to join the long and low posteroloph. The mesoloph is absent. The buccal part of the protoloph is transverse, buccally thick then thinning to the base of the paraconule. The latter protrudes in the anteroflexus. The lingual part of the protoloph is oblique and links the paraconule to the apex of the protocone (UM-AV-727) or to the short preprotocrista on AV-605 L. The metacone has short pre- and post- metacristae. The metaloph is transverse, turning distally at its end on UM-AV-727 only. On this tooth, it is doubled mesially by a low transverse ridge (metaloph I?), which connects to the metaconule mesially. It is absent on AV-605 L, on which the metaconule is alone. The metaconule is faintly stronger than the paraconule. It connects to the endoloph via a thin and very low ridge (UM-AV727) or to the short postprotocrista (AV-605 L). The hypocone is not much inflated, and strongly connected to the long posteroloph. It is separated from the protocone by a cleft (on AV-605 L) or connected to it via the endoloph, the latter making an angle with the postprotocrista. There are faint and rare extra-ridges descending from the protoloph and metaloph in the mesoflexus.

$\boldsymbol{P 4}$. It is more oval than D4, because the buccal border is enlarged due to a buccally prominent mesostyle area, the lingual border is bulged by the strong conical protocone, and the medial part of the tooth by the strong metaconule. The low anteroloph begins at the buccomesial corner of the paracone (the para-ectocingulum is absent); it ends at the linguomesial flank of the preprotocrista, from which it is distinct (UMAV-733) or fused (AV-164 L). Pre- and post- paracristae are

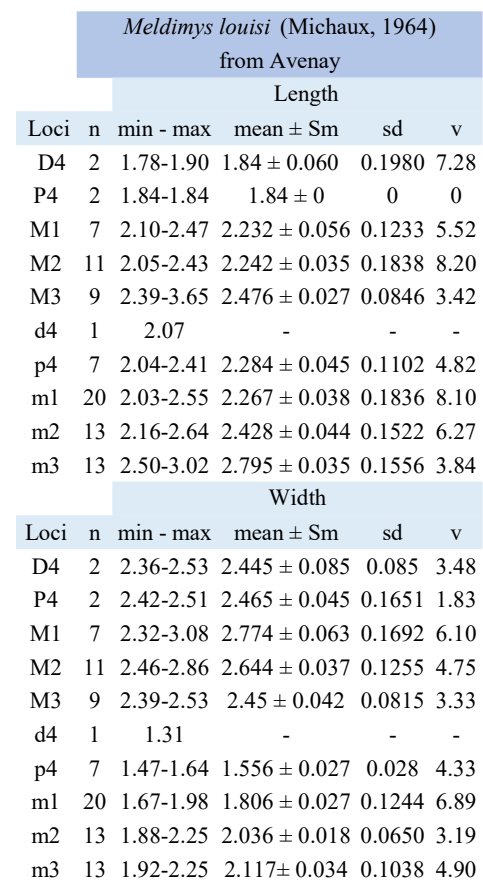

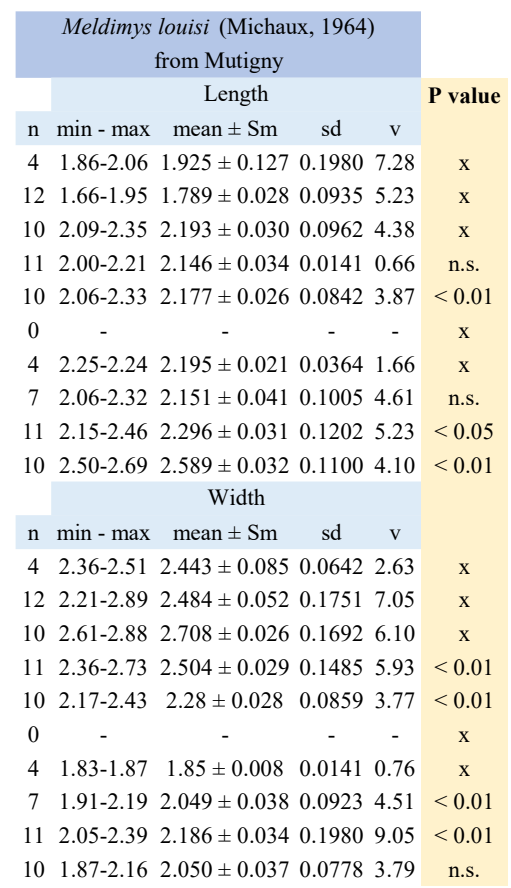

Table 3. Size variations of the different loci of teeth of Meldimys louisi (Michaux, 1964) from Avenay (MP 8-9; Bassin de Paris) and Mutigny (MP 8-9; Bassin de Paris). Comparisons of the size (Length $\mathrm{x}$ Width) of the different loci of teeth between these two species through ANOVAs, in association with a test $F$ of significance $(\mathrm{P}<0.01)$. 
well developed, directed to the mesostyle on UM-AV-733, or directly fused to an extra-conule situated between the paracone and the metacone (AV-164 L). The protoloph bears one to three extra-ridges running mesially in the anteroflexus or distally in the mesoflexus. It is broken at the place of the paraconule, which reduces in two small ridges more or less bulging. The connection with the protocone occurs through the protocrista and/or through the preprotocrista. On UM-AV-733, the main paraconule appears as a preparaconule at the buccal extremity of the preprotocrista, which also fuses with the anteroloph, but not with the protoloph.

The mesostyle is bulging on UM-AV-733, and fuses to the meta-ectocingulum. It is isolated and stretched mesiodistally on AV-164 L. The mesoloph is absent. The metacone has preand post- metacristae (like on D4). The buccal metaloph is thin and discontinuous, with two diverging elements: one mesial directed to the buccomesial flank of the strong metaconule (metalophule I), the other distal directed (AV-164 L) or attached (UM-AV-733) to the posteroloph (metalophule II). The lingual metaloph converges to the protocone, joining the metaconule to the postprotocrista close to the apex of the protocone, the distal part of the postprotocrista being free on UM-AV-733.

M1-M2. M1 is trapezoidal, with a protruding parastyle area, the hypocone at nearly the same lingual level as the protocone, and the anterostyle more buccal. The M2 are more symmetrical, without protruding parastyle, and with the hypocone more buccal than the protocone, at the same buccal level as the anterostyle.

M1. The parastyle is swollen and stretched buccolingually, prolonged in the low transverse anteroloph, which ends at the mesial corner of the preprotocrista. This junction is underlined by an antesinus, or not. Buccally, the parastyle can attach to the more or less strong preparacrista only (AV-4958 and -690) or to the para-ectocingulum, which is more (AV-7 L and AV-32 L) or less (UM-AV-876) developed. The paracone is slightly higher than the metacone; its buccal flank is somewhat depressed. The postparacrista is heading obliquely to the mesostyle area from which it is separated by a narrow cleft. The buccal protoloph is relatively thick and continuous, oblique, and directed to the

A

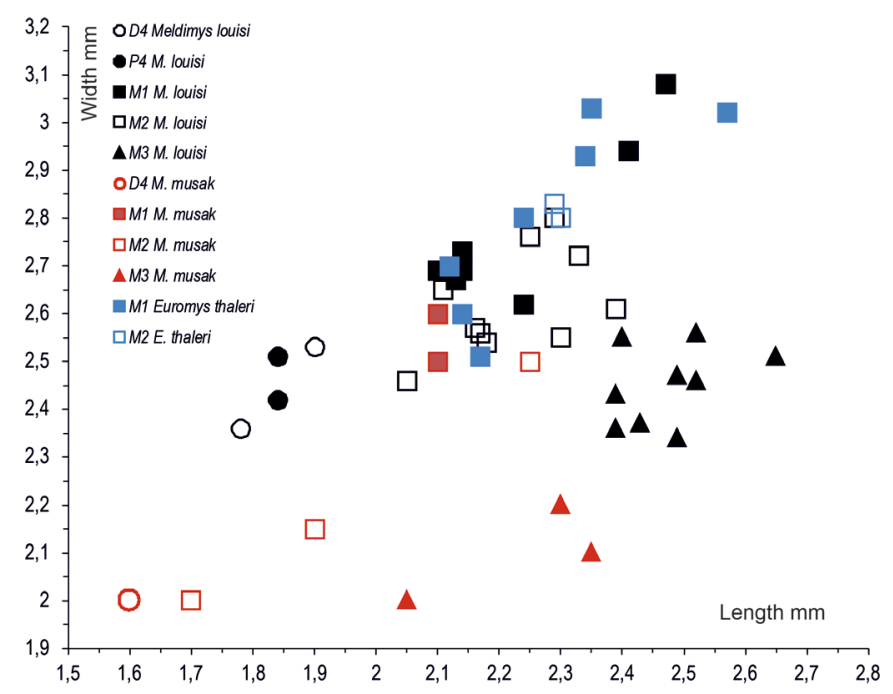

protocone. It joins the distal side of the paraconule, which is nearly as developed as the metaconule. In one case (AV-7 L), the paraconule appears more mesial than on the others, close to the anteroloph. There is always a short protocrista descending from the middle of the protocone. The lingual connection of the protoloph follows two ways: a loph joining the mesial extremity of the preprotocrista, and one in between the latter and the protocrista. Rare low extra-ridges (descending from the buccal protoloph mesially and distally) are present.

The mesostyle is stretched mesiodistally, followed lingually by a more or less long low mesoloph, filling the floor of the mesoflexus. The metacone is slightly more lingual than the paracone; therefore, the buccalmetaloph is shorterthan the buccal protoloph. The developed premetacrista turns mesiobuccally to the mesostyle; its buccal flank is somewhat depressed. The metacone can be bordered by a meta-ectocingulum. A thick low distal metalophule II, directed distally to the posteroloph can occur, and a more mesial one (metalophule I), which connects to the metaconule. On AV-32 L, the connection between the short buccal metaloph and the metaconule is not visible; there is a connection of the metaconule with the long mesoloph. The lingual metaloph joins the postprotocrista, at the level of its connection with the endoloph. The endoloph makes an angle with the postprotocrista. It is underlined by a short or narrow sinus. The hypocone is relatively well developed and distinct from the posteroloph, but still distinctly inferior and smaller than the protocone; it is at the same lingual level or slightly more buccal than the protocone. The posteroloph is low, as is the anteroloph; it can end at the level of the buccal metaloph (UM-AV-4958), or be longer, at the buccomesial corner of the metacone and join the meta-ectocingulum.

M2. They are structurally similar than M1, but with some variations. Buccally, there is neither para- nor metaectocingulum, but only short meso-ectocingulum elements may be present on each side of the mesostyle. The parastyle is present but not as swollen as on one M2 (UM-AV-6770); on the others, the anteroloph tapers buccally to the buccodistal corner of the paracone, lingually joining the descending preprotocrista. At this junction, the anteroloph swells in the anterostyle. The postparacrista is strong. The protoloph is

B

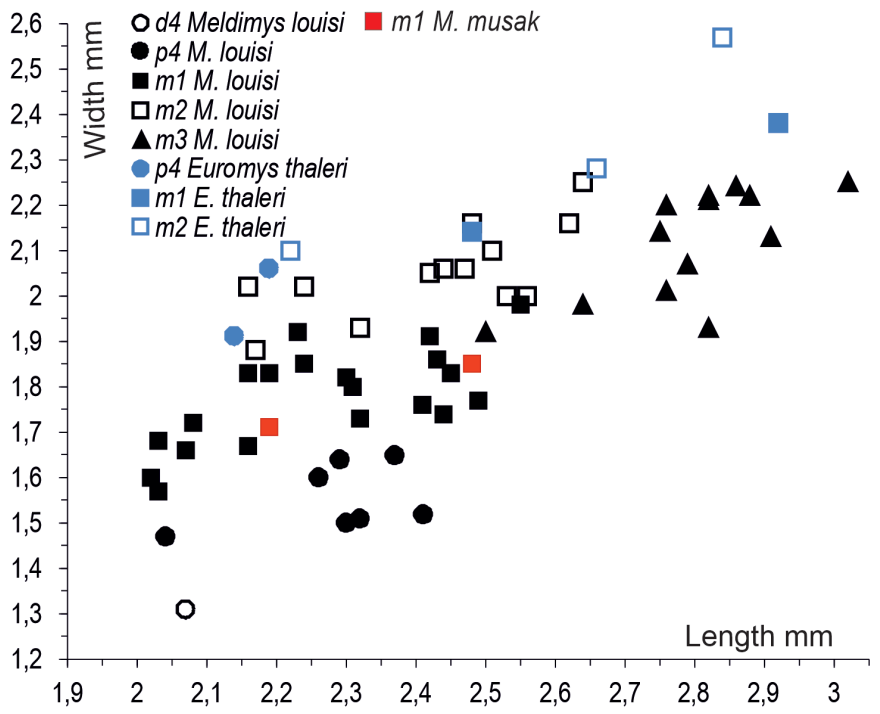

Figure 16. Bivariate graphs (Length $x$ Width) of upper teeth (A) and lower teeth (B) of Euromys thaleri Escarguel, 1999, Meldimys louisi (Michaux, 1964) from Avenay (Ypresian, MP8-9, Bassin de Paris) and Meldimys musak (Rana et al., 2008) from Vastan (Gujarat, India). Graduations in millimetres. 
continuous and sinuous, reaching the protocrista, or once the beginning of the preprotocrista. The paraconule is as developed as the metaconule or less. The pre- and post- protocristae make a V more open than on M1. The preprotocrista ends free in the anteroflexus, its extremity being thickened or bearing a short ridge linguobuccally directed. One or two extra-ridges descends from the buccal protoloph to the anteroflexus. A weak shallow and narrow antesinus is present.

The mesostyle is less elongated mesiodistally than on M1, and the mesoloph is present and often thick, but low. The premetacrista is shorter than on $\mathrm{M} 1$; it is the most developed on UM-AV-6770, on which its distal end is prolonged buccolingually in a short ridge, parallel to the mesoloph. The short buccal metaloph has two branches; one runs postwards to the posteroloph ("metalophule II"), the other forwards to the metaconule ("metalophule I"). The latter bears one mesial and one distal short thick low extra-ridge. It is weakly connected by a low thin lingual metaloph to the junction posprotocristaendoloph, and in one case (UM-AV-5867) also with the endoloph. The hypocone is weakly swollen, low but higher than the anterostyle. The sinus is present, shallow and narrow.

M3. The V structure formed by the pre- and post- protocristae is still more open than on M2, but not aligned mesiodistally. The anteroloph and anterostyle connections are as on M1M2. The paracone is more widened buccally by its long thick postparacrista than on M2. The latter descends to the lower mesostyle, which is somewhat stretched mesiodistally. In one tooth (AV-4715), the protoloph connects the relatively small paraconule to the preprotocrista, and in this case, the protocrista ends free along the buccal flank of the protocone; on the other M3, it joins the protocrista, and the preprotocrista ends free in the anteroflexus; its extremity bulges in a kind of preparaconule on UM-AV-152 and AV-804 L.

The stretched mesostyle is in the continuity with the premetacrista and the arched metacone. The latter is well prominent above the mesostyle area, even if slightly lower than the paracone. One to two metaloph ridges connect to the metacone with the strong metaconule, the latter adjacent or connected by a short ridge to the end of the postprotocrista or to the endoloph. The hypocone is present but small or reduced to an extra-ridge (UM-AV-152), the endoloph underlined by a sinus. From the protoloph, thick extra-ridges, and some smaller wrinkles, develop forwardly in the anteroflexus and distally in the mesoflexus. There are also present in the mesoloph area and in the posteroflexus.

\section{Lower teeth. (Fig. 19)}

d4. Not observed.

p4. The metaconid is the mesialmost, highest and strongest cuspid. The postmetacristid descends moderately to the well-developed and stretched mesiodistally mesostylid. The mesial premetacristid is more (UM-AV-5881) or less (UMAV-192) distinct. It is separated from the metalophulid I by a shallow anteroflexus, open buccomesially. A thick mesiodistal extra-ridge, bordered by thin wrinkles, follows the distal flank of the metaconid to the floor of the talonid basin. The protoconid is present and more distal than the metaconid. It is as developed as the hypoconid, and slightly higher. It bears buccally a mesiodistal cingulid descending to the ectocingulid, which edges the base of the sinusid. The postprotocristid is nearly mesiodistal, aligned with the short mesial ectolophid. The mesoconid is strong, with a short ectomesolophid and a mesolophid spur. The distal ectolophid is very short and

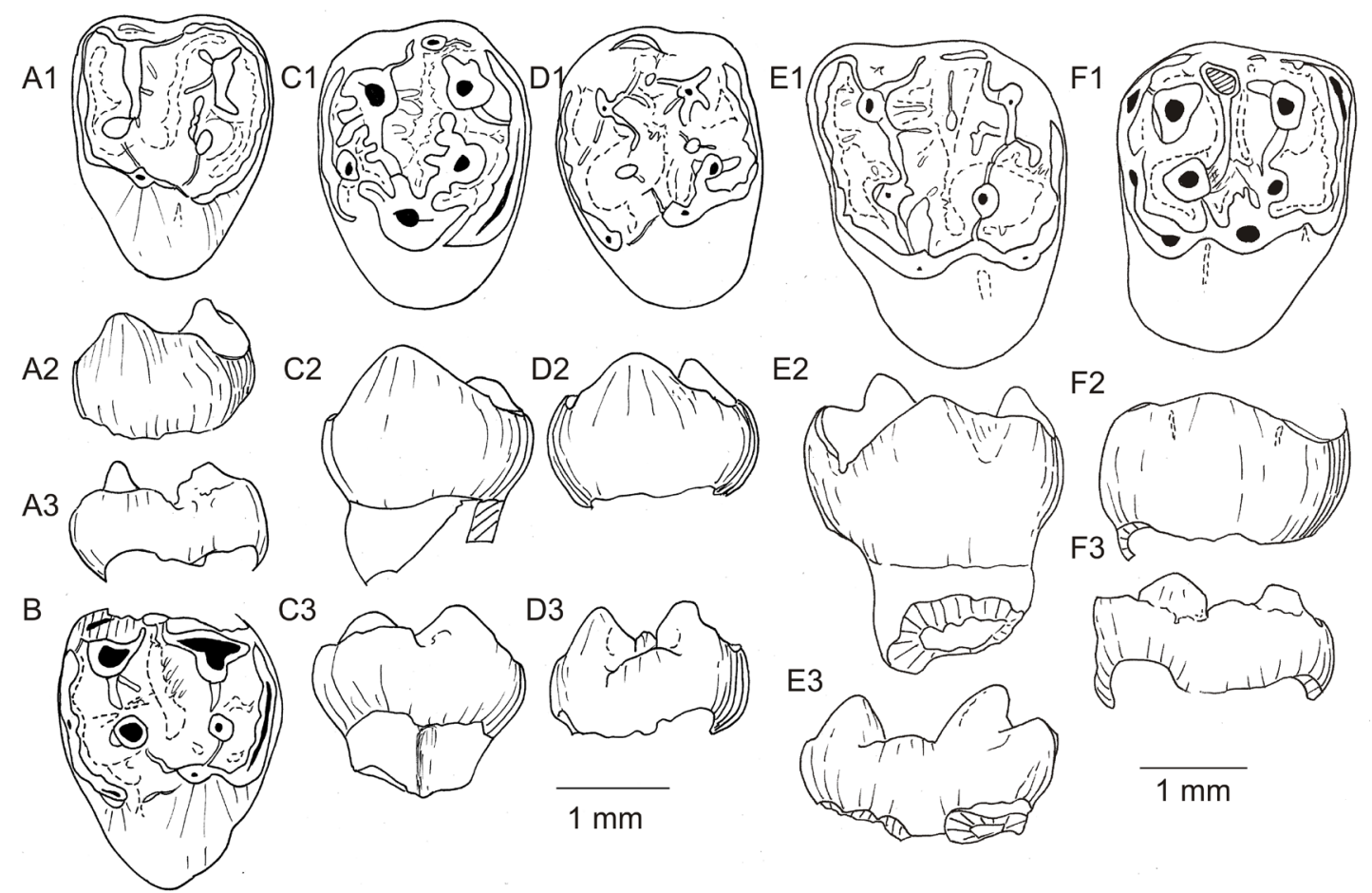

Figure 17. Upper teeth (D4, P4 and M1) of Meldimys louisi (Michaux, 1964) from Avenay (Ypresian, MP8-9, Bassin de Paris). A. UM-AV 727, Left D4; A1, occlusal view, A2, lingual aspect, A3, buccal aspect. B. AV 605 L, right D4, occlusal view. C. UM-AV 733, left P4; C1, occlusal view, C2, lingual aspect, C3, buccal aspect. D. UM-AV 164 L, right P4; D1, occlusal view, D2, lingual aspect, D3, buccal aspect. E. UM-AV-4958, left M1; E1, occlusal view, E2, lingual aspect, E3, buccal aspect. F. AV 32 L, right M1; F1, occlusal view, F2, lingual aspect, F3, buccal aspect. Scale bar, $1 \mathrm{~mm}$. 
low (distinct on the less worn p4), and connected to the prehypocristid.

The hypoconid faces the entoconid. Its short posthypocristid lowers before the junction with the buccolingually stretched hypoconulid. The posterolophid is very short and separated from the conical entoconid. The entolophid is discontinuous, made lingually with short ridges and an entoconulid seen on the weakly worn UM-AV-5881, and buccally with a short ridge joining the prehypocristid or the hypoconid. Thin wrinkles are present around the small talonid basin. Mesial and distal roots are close.

$\boldsymbol{m} 1-\boldsymbol{m} 2$. The metaconid is still higher than the other cuspids; therefore, the postmetacristid descends relatively abruptly to the mesial border of the stretched mesostylid at the buccal opening of the mesoflexid. The main lingual cuspids are nearly facing the buccal ones. As usual for $\mathrm{m} 1$, this molar differs from $\mathrm{m} 2$ mainly in its narrower (buccolingually) trigonid.

The anterolophid is slightly bulged buccally, and merges with the weak sloping premetacristid. Buccally, it joins the mesial flank of the protoconid. The anteroflexid is more or less filled by elements of the metalophulid (and one extra-ridge on UM-AV-673). On most of the lower molars, the buccal metalophulid attaches transversely to the apex of the protoconid (metalophulid I). Rarely there are two buccal metalophulids I. When present, one short buccal metalophulid I stems from the apex, and the second attaches slightly more distally than the first. In contrast, there are two lingual metalophulids I, distal to the premetacristid; following the latter, a thick and short one never joins the transverse buccal metalophulid I, but can be long (UM-AV-673, and -4974). When the metalophulid I is complete, it results from the distalmost lingual metalophulid I to the buccal one, and appears curved mainly on m1 (UMAV-129, -5798, -5827, and -5852). A relatively long and oblique postprotocristid, ending often in a more or less long transverse extra-ridge (premesoconid ridge), descends to the mesial ectolophid. The latter is still very short and low, therefore appears like a break mesial to the bulged mesoconid. The mesoconid bears lingually short ridges as mesolophids. The distal ectolophid is often swollen (postmesoconid swelling) before its junction with the prehypocristid. The ectomesolophid is weak or absent. The sinusid is relatively deep (between $1 / 3$ and $1 / 2$ of the height of the buccal side of the crown). A more or less strong ectocingulid edges the sinusid buccally. The hypoconid and protoconid are bulged buccally. The posthypocristid is oblique and relatively short. It is separated from the transversely stretched hypoconulid by a thin cleft (seen on weakly worn teeth). The short following posterolophid ends on the entoconid flank, distinct from the bulged entoconid. The entolophid is more or less developed: less when it is reduced to short lingual ridges, transversely or postwardly directed. It is complete on the holotype but very low, or its path is marked by extra-ridges and conules on UMAV-5058.

The talonid basin is less deep, the lingual mesostylid wall much lower than in Pseudoparamys teilhardi. Numerous extraridges descend from the lophids.

m3. The posterior lobe is narrower than the anterior. The lingual main cuspids are slightly more mesial than the buccal ones. The extra-ridges are more numerous, and thicker for the main one around the mesoconid and entolophid; the mesostylid is more elongated mesiodistally. Apart from these features, the morphological characters are very similar to those of m1-m2.

\section{Remarks.}

Material formerly identified as Meldimys louisi from Mutigny: Most of the lower teeth from Mutigny we observed display some striking differences with those from Avenay. The cuspids are sharper, and the hypoconulid more salient on $\mathrm{m} 1$ $\mathrm{m} 2$; the trigonid of $\mathrm{m} 1$ is markedly narrower $(\mathrm{Mu} 5135$ and 5632) and somewhat higher; it is narrower than the talonid on $\mathrm{m} 2$, but less than on $\mathrm{m} 1$. A flat mesostylid is generally absent
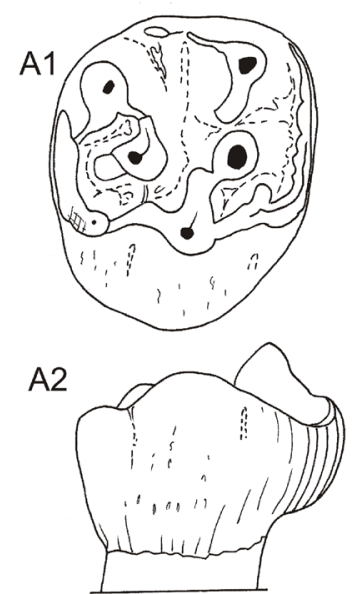

A3

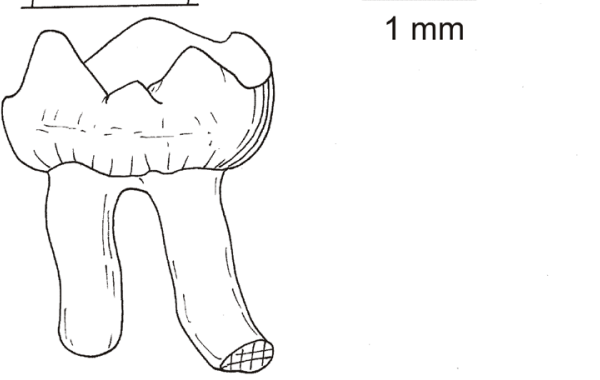

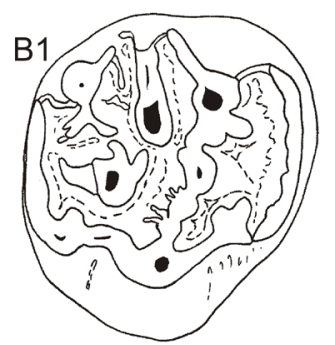

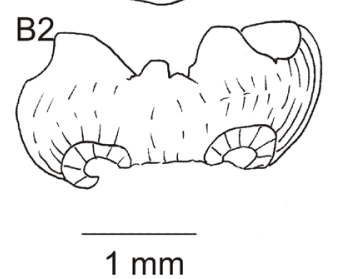

C1

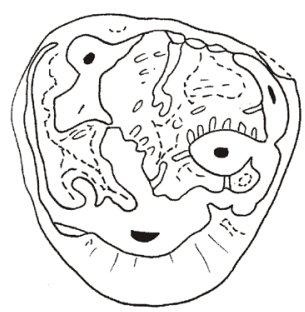

C2

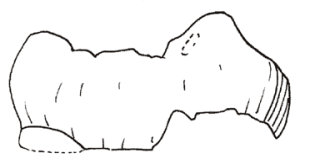

C3
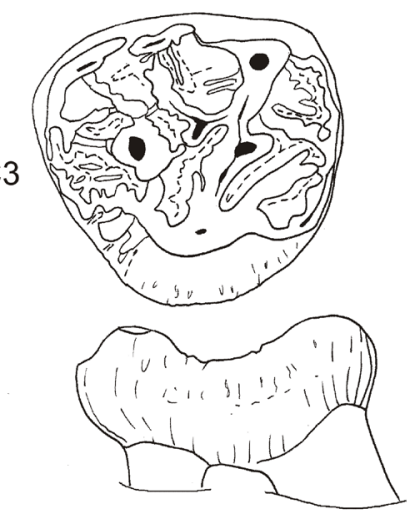

Figure 18. Upper teeth (M2 and M3) of Meldimys louisi (Michaux, 1964) from Avenay (Ypresian, MP8-9, Bassin de Paris). A. UM-AV 9005, right M2; A1, occlusal view, A2, lingual aspect, A3, buccal aspect. B. UM-AV 6770, right M2; B1, occlusal view, B2, buccal aspect. C. AV 804 L, left M3; C1, occlusal view, C2, buccal aspect. D. UM-AV 152, right M3; D1, occlusal view, D2, buccal aspect. Scale bar, $1 \mathrm{~mm}$. 
at the mesoflexid lingual opening. The enamel surface forms a grid of fine wrinkles and granules, especially in flexids; the longest converge in the talonid basin. There are no thicker extra-ridges around the entolophid or the mesolophid. If the upper M1 and M2 of M. louisi are roughly similar in size from both localities, the size of P4 is more variable, and the M3 from Mutigny are clearly smaller than the M3 from Avenay (Table 3). It would be necessary to revise the different assemblages previously referred to $M$. louisi, and not only from Mutigny, but also from Condé-en-Brie, where the tooth specimens referred to this species are the most abundant rodent material from this locality. It is not possible to consider all of this material in the present paper, as the field of study is already very broad.

Teeth formerly identified as Pseudoparamys teilhardi from Avenay and Mutigny: The $\mathrm{m} 2$ from Avenay UM AV-5781 and AV-5050 (in Michaux, 1968: Pl.4, fig. 11), previously referred to $P$. teilhardi are here referred to Meldimys but they could represent another species than $M$. louisi. Indeed, they show characters found in Meldimys: floor of the talonid basin not strongly concave, rather flat, with long buccolingual premesoconid ridge on the postprotocristid, thick mesolophid in the continuity of the strong mesoconid + ectomesolophid, thick extra-ridges in the basin, entolophid low and discontinuous but present, entoconid separated from the posterolophid. Their wear patterns are also different. Another molar, UM-AV-5055, is not a $m 2$, but a m3. Like the m3 UM-AV-5053 and UM-AV-5878, it displays the same features as those characterizing $\mathrm{m} 2$ : weakly basined teeth, long postprotocristid + premesoconid ridge, thick extra-ridges, entolophid discontinuous but present and trigonid wider than talonid.

One m3 from Mutigny ( $\mathrm{Mu}$ 6048) is stored with Pseudoparamys teilhardi but it is smaller than the other $\mathrm{m} 3$; the talonid basin is comparatively less long than on the others, the arched distal lophid less continuous, the extra-ridges stronger, the postprotocristid more developed, and the talonid less wide than the trigonid. By this suite of characters, it could correspond to Meldimys louisi, but it is smaller.

\section{Genus indet.}

" Meldimys " musak Rana et al., 2008

Holotype. GU/RSR/VAS 609, right M2 (not M1).

Type locality. Cambay Shale, Vastan lignite mine (Gujarat, western India, early Eocene).

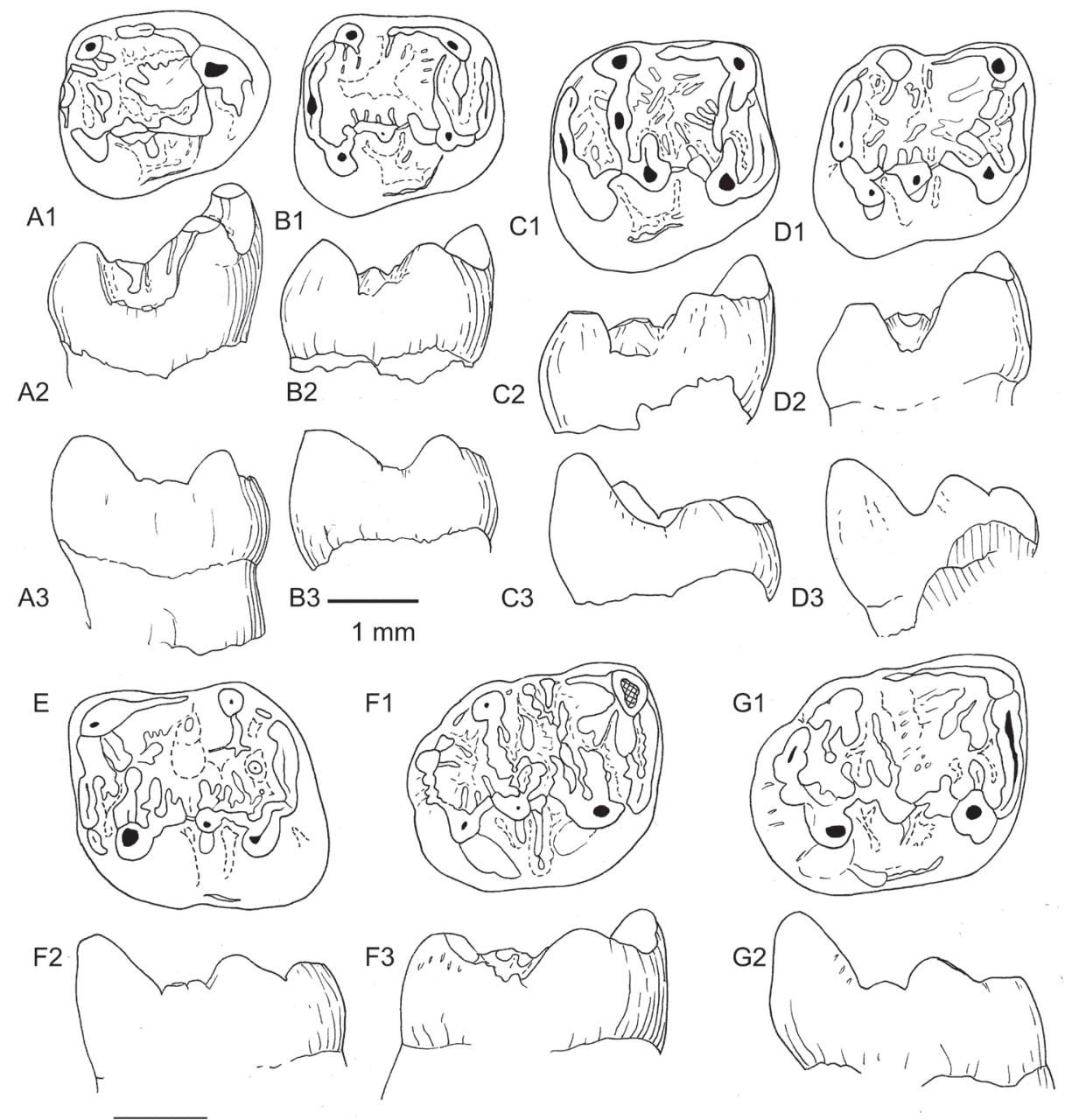

Figure 19. Lower teeth (p4, m1, m2, m3) of Meldimys louisi (Michaux, 1964) from Avenay (Ypresian, MP8-9, Bassin de Paris). A. UM-AV 5881, right p4; A1, occlusal view, A2, buccal aspect, A3, lingual aspect. B. UM-AV 129, right m1; B1, occlusal view, B2, buccal aspect. B3, lingual aspect. C. AV-MNHN-5737, Holotype, right m1; C1, occlusal view, C2, buccal aspect, C3, lingual aspect. D. AV-MNHN-4974, right m1; D1, occlusal view, D2, buccal aspect. D3, lingual aspect. E. UM-AV 5058, left m2. F. UM-AV A-63, right m3; F1, occlusal view, F2, lingual aspect. F3, buccal aspect. G. UM-AV 4572, right m3; G1, occlusal view, G2, lingual aspect. Scale bar, $1 \mathrm{~mm}$. 
Original diagnosis (Rana et al., 2008: 4). Teeth similar in size and occlusal morphology to Meldimys louisi. Differs from $M$. louisi in having P4 with strong metaloph. Upper molars with a small median conule between protoloph and metaloph, and less buccally projecting mesostyle. M1 with less prominent parastyle positioned almost in line with the paracone rather than buccally extended. M2 with a less rounded occlusal outline, and a protocone usually more mesial compared to the more central protocone of $M$. louisi. Distal width of M3 less short than in M. louisi. M3 with sub-complete metaloph and reduced lingual sinus (between hypocone and protocone). m1-2 with antero-posteriorly reduced trigonid and weaker anterolophid, and "waist" (= slight constriction between trigonid and talonid), and no paralophid (= metalophulid I) and metalophulid II. Talonid cuspids considerably lower than trigonid cuspids.

Remark. Based on our phylogenetic results, this species from Vastan is resolved as the closest outgroup (node E, Fig. 4) of the Theridomorpha clade (node TB, Fig. 4).

Emended diagnosis (new). On upper teeth: lingual wall poorly developed, wide angle between pre- and post- protocristae, nearly aligned with the stretched hypocone, ectocingulum on D4 only. On lower teeth, short and high trigonid, incomplete metalophulid, weak and short mesiodistal ridge diving along the distal flank of the protoconid to the break of the mesial ectolophid, cup-shaped talonid, stretched buccolingually hypoconulid, still distinct.

Material. The authors figured all the material (Rana et al., 2008); therefore, it was possible to re-evaluate the locus attributions of upper molars. One tooth referred to as M1 (GU/RSR/VAS 128, fig. 3C) is rather for us a M2, two teeth considered as M2 (GU/ RSR/VAS 450 and 454, figs. 3E-F) are rather interpreted as M1 (see description below for justifications). Moreover, the worn tooth identified as P4 (GU/RSR/VAS 606) is more accurately an eroded and damaged M2. The authors wrote that this tooth is two-rooted, but it should be pointed out that one of these two roots results from the fusion of the distalmost buccal root with the lingual root. This case can occur variably on three-rooted upper molars, as we have observed at least on a M3 referred to Ailuravus inexpectatus from Prémontré (late early Eocene; SLP29PR-1501). On all species observed from French early to middle Eocene localities, when fusion of roots occurs on P4, it happens between the two closely appressed buccal roots prior to a fusion with the stronger lingual root. The tooth GU/RSR/ VAS 449 is too much eroded and worn, to be sure that this tooth is a M1. Therefore, the description of these three loci is not accurate, and the features stated to characterize M1 are clearly features of $\mathrm{M} 2$, and vice versa.

\section{Description and comparisons.}

Upper teeth. It is possible to differenciate M1 from M2, on the bases of comparisons with Meldimys louisi, and with a number of European early Eocene rodents. M1 are wider and narrower than M2; their hypocone is more developed with respect to the protocone; this can be seen on the holotype M2 and the less worn M1 (GU/RSR/VAS 450), when comparing with the figures in Rana et al. (2008; figs. 2F and 5G). On M2, the hypocone and anterostyle are nearly at the same lingual level, more buccal than the protocone and aligned on a mesiodistally axis; the anteroloph is shorter than on M1.

D4. Despite the fact that this tooth is eroded, its pattern can be depicted. It is triangular, with a stronly reduced hypocone, lingual to the larger conical protocone. The anteroloph is arched and develops relatively far from the paracone + protoloph.
Thereby, the anteroflexus is large in its buccal part. This is not the case on the D4 of Meldimys louisi (Rana et al., 2008: fig. 6A). On the latter, the parastyle is closer to the paracone and the anteroflexus narrower. The arched parastyle continues buccally to the para-ectocingulum, which joins the mesostyle area then the meta-ectocingulum, as it is also the case for M. louisi or Euromys woodi, but also for Pseudoparamys teilhardi, Plesiarctomys savagei or Ailuravus inexpectatus and $A$. michauxi. The overall shape (occlusal crown outline) matches that of $E$. woodi (narrower than $M$. louisi), but the hypocone is smaller, and the protoloph and metaloph are more parallel, as the protoloph connects to the mesial extremity of the preprotocrista. A weak swelling of the lingual part of this protoloph probably marks the paraconule. The strong postparacrista connects to the mesostyle. The details of features between the paracone and the metacone, and in the mesoflexus are not visible. The metacone, more lingual than the paracone, is connected by its postmetacrista to the meta-ectocingulum/ posteroloph junction. Postmetacrista, metacone and metaloph run obliquely forwards, parallel to the protoloph, to join the protocone.

M1. The less worn M1 (GU/RSR/VAS 450) shows that there are extra-ridges in the flexi, along the lophs, paracone, metacone, paraconule and metaconule. For the mesoflexus, it is the case of the short swollen ridge close to the paraconule (= median conule of Rana et al., 2008). The parastyle is swollen, stretched and slightly arched. It attaches to the preparacrista. There is no para-ectocingulum. A small anterostyle ends the anteroloph lingually; it is enhanced by a shallow and narrow antesinus. The paracone bears a strong and buccally notched postparacrista, joining the mesial end of the mesostyle, from which a short mesoloph develops lingually. This mesostyle is strong and more buccal than the paracone-metacone axis. The mesoflexus is only slightly longer (mesiodistally) than the anteroflexus. The protoloph angles at the paraconule, the latter protruding mesially. Its weak, short lingual part connects to the thick protocrista, descending linguobuccally in the mesoflexus (on the other M1, the lingual protoloph joins the extremity of the preprotocrista). The pre- and post- protocristae slope along the flanks of the conical protocone, making a widely open V. A short ridge starts from the mesial end of the preprotocrista to the anteroflexus in which it meets two or three short extra-ridges starting from the anteroloph. It ends close to the protruding small paraconule.

The buccally notched premetacrista, slightly shorter than the postparacrista, joins the distal end of the mesostyle. The metacone is faintly lingual to the paracone. The postmetacrista descends to reach the buccodistal corner of the low posteroloph. The buccal metaloph, relatively thick, merges with the strong metaconule. The latter is separated by a cleft from the lingual metaloph, which connects the postprotocrista. On more worn teeth, the metaconule is in continuity with the lingual metaloph. A shallow notch marks the short endoloph at the junction of the postprotocrista with the hypocone; it forms the distal margin of a narrow and shallow sinus. The hypocone is quite smaller to decide if the protocone is as developed (or less) as the hypocone of Meldimys louisi, Euromys thaleri (or even $E$. woodi) or Plesiarctomys savagei. It is slightly stretched mesiodistally, and a weak constriction marks its contact with the posteroloph. The latter disappears on worn teeth.

M2. The less worn M2 (GU/RSR/VAS 609) is the holotype. The other specimen on which the morphology is visible, GU/ RSR/VAS 128, is smaller, but the amplitude of variation of the size does not exceed that observed for the M2 of Meldimys 
louisi from Avenay. The M2 GU/RSR/VAS 606 (previously supposed to be a P4) shows its protoloph and metaloph converging towards the protocone, a relatively long and narrow anteroflexus (even if incomplete), a lingually displaced metacone. Its posteroloph is missing and the hypocone area damaged. On the type and the other teeth on which the structure is observable, the main features are similar as those described for M1, but they differ in their arrangement and relative size. The anteroloph and anteroflexus are shorter buccolingually, the mesostyle weaker, the premetacrista less notched, the metacone more buccal, and the hypocone is more reduced and low. The protoloph joins the mesial end of the preprotocrista and the protocrista appears free on the type. The $\mathrm{V}$ made with the protocone apex by the preprotocrista and the postprotocrista is less open. The endoloph is lower but well defined on the type; the extra-ridges are less visible, but some in the anteroflexus and along the metaloph-metaconule are visible.

M3. Three M3 are well preserved, and thin wrinkles are discernible along the lophs of GU/RSR/VAS 455, as well as a few extra-ridges within the flexi. On this locus, the paracone is large, conical and slightly lower than the protocone, both being lower than on the M1-M2. The small hypocone is slightly buccally positioned; it appears symmetrical to the weak anterostyle with respect to the protocone. The antesinus and sinus are weakly marked. A continuous pericingulum runs from the anteroloph to the long mesiodistally stretched mesostyle, through the lingual and distal walls (low anterostyle attached to the mesial preprotocrista-protoloph junction, preprotocrista, protocone and postprotocrista, endoloph-hypocone, reduced posteroloph and crestiform metacone). This pericingulum overlies the basined mesoflexus, which is empty on GU/RSR/ VAS 455 , or partly filled by a succession of low conules from the protocrista to the base of the mesostyle on GU/RSR/VAS 452. It is nearly filled when these conules merge and make a continuous thick low extra-ridge connected to the protocrista, paraconule and mesostyle (GU/RSR/VAS 451). The protoloph connects to the extremity of the preprotocrista, and the metaloph to the extremity of the postprotocrista (or the endoloph on GU/ RSR/VAS 451). This nearly continuous metaloph, swollen at a stretched metaconule, isolates a short posteroflexus appearing as a distal islet. On M. louisi or E. woodi, the metaloph is less regular, the extra-ridges much more numerous, the posteroflexus less individualized. On Plesiarctomys savagei, the protocrista is not individualized.

\section{Lower molars.}

m1-m2 only present. Although the fact that the three teeth (two $\mathrm{m} 1$ and one $\mathrm{m} 2$ ) are much worn, some characters can be noticed, other than the primitive features such as the metaconid and the entoconid, which are the highest and lowest cuspids, respectively. The postmetacristid descends moderately to the narrow $\mathrm{V}$ opening of the mesoflexid, which overlies the floor of the talonid. The metaconid and entoconid are slightly more mesial than the protoconid and hypoconid. These teeth show a short trigonid higher than the talonid, which is also a primitive feature. The talonid basin is cup-shaped. One can distinguish a short low anterolophid ending at the base of the metaconid on the GU/RSR/VAS $604 \mathrm{~m} 1$; on the less worn (but damaged) GU/RSR/VAS $605 \mathrm{ml}$, this anterolophid joins a mesial lingual metalophulid (= premetacristid). The buccal metalophulid starts from the apex of the protoconid and does not join the metaconid, leaving the trigonid basin open distally. We do not know if a short posterior arm doubles this buccal metalophulid. From it, a short mesiodistal ridge descends along the distal flank of the protoconid to the break of the mesial ectolophid. This disposition reminds that observed in Plesiarctomys savagei, even if this mesiodistal ridge is better developed for this species of Plesiarctomys, and much more on younger species of Plesiarctomys; elsewhere, the attachment of the lingual metalophulid on $P$. savagei is made with a well-developed buccolingual posterior arm of the protoconid (metalophulid II). It is quite different of that of Meldimys louisi, Euromys thaleri or E. woodi, on which there is a longer trigonid due to betterdeveloped metalophulid I elements (mesial and intermediate lingual metalophulids, together with the transverse buccal metalophulid I from the protoconid apex) and sometimes, complete metalophulid I. Moreover, in Meldimys, there is a long high and oblique mesiobucco-distolingually directed postprotocristid, in front of the short interrupted mesial ectolophid. This lengthens this trigonid posteriorly, and makes the transition with the talonid. The oblique postprotocristid is also present in Euromys, even if it is shorter: it is clearly different of the mesiodistal ridge seen in Ailuravinae.

The mesoconid is bulged, followed by a short distal ectolophid - thin at the occlusal surface, as seen on the less worn $\mathrm{ml}$; it joins the thicker and curved prehypocristid. The posthypocristid, oblique, joins the weakly swollen and buccolingually stretched hypoconulid. As seen on the less worn $\mathrm{m} 1$, the posterior cingulum constricts at this junction. The posterolophid appears indistinct and does not reach the apex of the entoconid. It is not clear if a faint "entolophid" is present on the GU/RSR/VAS $604 \mathrm{ml}$ (Rana et al., 2008: fig. $5 \mathrm{~A}$ ). The $\mathrm{m} 2$ shows a faint cuspid at the distal extremity of the postmetacristid that could be either a metastylid or a mesostylid.

Discussion. The upper molars share some features with several European early Eocene ischyromyoid genera. This species (musak) could belong to this group, like the ailuravines. It does not show the critical feature that is present in Meldimys, Euromys or Pseudoparamys: i.e., the relatively high, thick, long and oblique mesiobuccal to distolingual postprotocristid. At least for this reason, its attribution to Meldimys is questionable. It is even more distinct from Ailuravus, characterized by high and acute cuspids, a metalophulid II, the hypoconulid separated by grooves from the posthypocristid and from the entoconid, and by an arched entolophid directed or joined to the hypoconulid (this paper, and Rana et al., 2008: 7). The only species with which it shares some features is Plesiarctomys savagei. These are, on lower teeth, the short trigonid and cup-shaped talonid, and the stretched buccolingually hypoconulid, the possibly mesiodistal postprotocristid ridge; on the upper teeth, the wide angle between the pre- and the post- protocristae, nearly aligned with the stretched hypocone, the shape of the ectocingulum on D4. If it is Plesiarctomys, it represents a more primitive species than $\mathrm{Pl}$. savagei, for which the lingual wall of upper teeth is less developed, and on lower teeth the metalophulid is incomplete and the hypoconulid still defined. This taxonomic option remains however doubtful, due to the scarce material and poor conservation for some loci. Nonetheless, based on the aforementioned characters, it is clearly not attributable to the genus Meldimys. This is the reason why we place the species musak in an indeterminate genus, given that it does not correspond to any genera known thus far. Moreover, the earliest rodents recorded in Europe (e.g., from Dormaal) are not still described in detail; some similarities of them could be found with this species. 
Genus Euromys Escarguel, 1999

Type species. Euromys thaleri (Michaux, 1964).

Referred species. Euromys woodi (Michaux, 1964).

Original diagnosis (Escarguel, 1999; translation from French). "Small to middle sized ailuravine; enamel surface smooth to gridded; dental morphology less robust than in Ailuravus; base of the incisor behind M3. Lower cheek teeth with reduced trigonid, open posteriorly; mesoconid relatively posterior; tendency for the hypoconulid to be duplicate; posterior cingulid less strong and hypoconulid less isolated than in Ailuravus. Typical ailuravine upper cheek teeth, with hypocone, lingual sinus, nearly equal conules, and styles less developed than in Ailuravus; massive mesostyle; weak ridge descending from the protocone to the trigon present."

Remarks. For the type species, the molars and only one lower p4 are present. The features of the deciduous teeth, premolars and $\mathrm{M} 3 / \mathrm{m} 3$ come from the other species we refer to this genus: Euromys woodi, both making a clade associated with Meldimys louisi from our phylogenetic results (Fig. 4). This clade occupies the basalmost position within the Theridomorpha clade.

Emended diagnosis. Middle to large sized basal Theridomorpha. Wrinkled enamel surfaces, especially within the flexi, along the lophs and lophids, on the buccal flank of lower teeth and the lingual flank of upper teeth. Cusps and cuspids conical and stocky at their base, not much salient above the crown walls, but more than in Pseudoparamys, and slightly less than in Meldimys. Large bases of main cusps straightening out the bottom of flexi, notably the $\mathrm{V}$ shaped in profile mesoflexus of upper teeth, but mesoloph always well-developed on molars. Lower teeth basined, but flat floor of the talonid less expanded than in Pseudoparamys. On upper teeth, lingual "wall" higher than the buccal one, with narrow and shallow sinus, and weak antesinus underlining the anterostyle. On lower teeth, small difference in height beween lingual and buccal sides.

D4 much smaller than molars and narrower than P4. P4 much shorter than M1, their parastyle and ectocingulum variably developed on P4, more on D4, rarely on molars. Preand post- protocristae making a widely open $\mathrm{V}$ on molars, and obliquely aligned on D4. Strong mesostyle, buccal to the paracone-metacone axis. Anteroloph and posteroloph welldeveloped. Hypocone large but smaller and lower than the protocone on molars, same level as or slightly lingual than the protocone on M1, more lingual on D4, more buccal and smaller on M2; same level and much smaller on P4. Presence of a short but high endoloph. Strong protocrista rarely joining the mesoloph. Lingual protoloph joining the preprotocrista, and lingual metaloph connecting to the posprotocrista or the endoloph. Single paraconule set along the protoloph, generally one to, less frequently, two metaconules.

Lower p4 more elongated than that of Pseudoparamys teilhardi, like that of Meldimys louisi. Differ from the $\mathrm{p} 4$ of the latters in their more lingual and lower metaconid, and their protoconid and hypoconid stockier. On lower molars, one to two lingual branches of the metalophulid I, one buccal, transverse, attached to the protoconid apex; postprotocristid oblique and thick, making an angle with the weak and short mesial ectolophid; swollen mesoconid with, variably, one (or more) ectomesolophid ridge(s). Low anterolophid limited at the buccal half of the tooth, joining the base of the preprotocristid and the base of the premetacristid. Ectocingulid variably present: very low discontinuous elements of entolophid; hypoconulid weakly salient, more or less stretched buccolingually. Lower $\mathrm{m} 3$ being the longer tooth, with distally salient hypoconulid and reduced posterolophid.

Euromys thaleri (Michaux, 1964)

Figures 20-21

Reithroparamys thaleri Michaux, 1964, p. 153, fig. f.

Genre indéterminé A ; Michaux, 1968, p. 173, pl. 10, figs 1-6.

Holotype. Mu 5956, left m1.

Type locality. Mutigny (Marne, Bassin de Paris; mid-early Eocene, MP8-9).

Original diagnosis of Reithroparamys thaleri. (Michaux, 1964: 153; translation from French). "Species larger than Meldimys louisi; protoconid area less characteristic; talonid basin without ridges; enamel surface irregular."

Original diagnosis of Euromys. (Escarguel, 1999; translation from French). "Small to middle sized rodent; enamel surface smooth to finely ornament; cusps acute and high; lophs and lophids very little developed. Lower teeth with narrow trigonid, slightly protruding, usually closed by a complete metalophulid. Strong metaconid. Anterolophid weakly connected to the protoconid. Strong mesoconid and weak ectolophid. Connection protoconid-mesoconid absent. High posterior cingulum, with weak interruption between hypoconulid and entoconid. Tendency to split hypoconulid. Upper molars with paracone and protocone dominant. Conules isolated and nearly equal. Hypocone well developed; lingual sinus marked. Strong parastyle, linked to the paracone. Posterior cingulum reaching the clear mesostyle, which is sometimes stretched transversely as a sketch of mesoloph".

Emended differential diagnosis (new). Euromys species smaller (M1: $2.304 \mathrm{~mm} \times 2.856 \mathrm{~mm}$ ) than the species E. woodi. Differs from the latter in: the less numerous wrinkles and granules, the ectocingulum limited to the mesostyle area on M1, when present; the endoloph short but well-defined, the more irregular protoloph; the longer mesoloph and the ectocingulum better developed on M1, the conules more bulged.

Material and measurements. (App., S 1) (Fig. 16; Table 4) There are a few specimens referred to this species (Michaux, 1968: 173-174; Escarguel, 1999: 145). Among them, five molars only from Mutigny (two M1-2, one m1, and two m2), and ten (seven M1-2, one $\mathrm{p} 4$, one $\mathrm{m} 1$, and one $\mathrm{m} 2$ ) from Avenay have been used to describe the type species. The anterior teeth (deciduous lower and upper, and upper premolars) and posterior ones (M3, m3) are not present in the collection. The molars and the $\mathrm{p} 4$ are larger than those of Ailuravus inexpectatus and smaller than those in Euromys woodi from the same locality (Avenay). Among the upper molars from Avenay, the M1 UMAV-4749 is very close to that of Pseudoparamys ageiensis (see below), differing from the other teeth in its shorter mesoloph, less ornamented enamel, more symmetrical paracone and ectocingulum reduced to the mesostyle area. Otherwise, we supect that teeth referred to Meldimys louisi from Mutigny and Avenay could be referred to Euromys thaleri. We have observed and revised some specimens (see below), but all the material should be revised.

Description. The enamel is wrinkled, but less than in $E$. woodi. The cusps and cuspids are conical and stocky, not much standing up the crown walls, but more than in Pseudoparamys, and slightly less than for Meldimys, and markedless than on Ailuravus. 
Upper teeth. (Fig. 20).

Mutigny M1-M2. We have not observed the two M1-2 previously referred to this species (Escarguel, 1999: 300).

Avenay M1-M2. Among the six molars, four are M1, with a parastyle more protruding and a hypocone slightly more lingual than the protocone, whereas the two other teeth (UM AV-6821 and UM AV-7208) are possibly M2, their cusps being at the same level and the parastyle does not bypass the mesiobuccal corner of the paracone.

The large bases of main cusps straightened the floor of flexi, notably the mesoflexus, which is $\mathrm{V}$ shaped in profile. The anteroloph is low and continuous. The anterostyle is underlined by a marked antesinus, but quite less than in Ailuravus. The swollen parastyle turns lingually to a more or less continuous para-ectocingulum. The mesostyle is more buccal than the paracone-metacone axis. It is stretched mesiodistally, distally prolonged (UM AV-4950), often connecting to the metaectocingulum (UM AV-4729, -4760, -5809, and -6821). The mesoloph is present, low and more or less continuous. It reaches the middle of the mesoflexus sometimes attached to the distal flank of the paraconule (UM AV-4729 and -4760). The paracone is slightly higher than the metacone. Postparacrista and premetacrista are present, and depressed buccally by shallow notches. The strong postparacrista enlarges the buccal aspect of the paracone. The paraconule is smaller than the metaconule, the lingual protoloph joining the protocrista (UM AV-4729, $-4950,-5809$, and -7208) or the preprotocrista (in this case the protocrista ends free in the mesoflexus; UM AV-4760 and -6821). The pre- and post- protocristae make an "open $\mathrm{V}$ " with the protocone. The metacone is slightly more lingual than the paracone. The lingual metaloph is more or less strong, attached to the distal extremity of the postprotocrista (once to the well-defined endoloph, on UM AV-4950). The sinus is shallow ( $1 / 3$ to $1 / 2$ height of the crown) and narrow.

\section{Lower teeth. (Fig. 21).}

Mutigny. m1-m2. The holotype (Mu 5956; Fig. 21D) is an $\mathrm{m} 1$ with a short anterolophid, which corresponds to a buccolingually stretched anteroconid. It is in continuity with a short mesial arm of the metaconid (premetacristid). The cuspids are stockier and less acute than the cuspids of Ailuravus, like those of E. woodi. A net of smooth and low ridges are distinct in the talonid basin.
A1

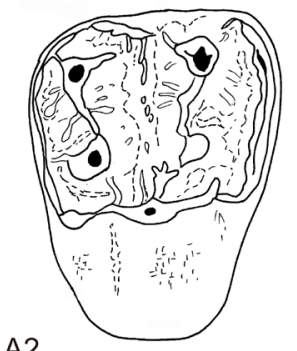

A2

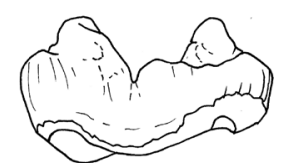

A3

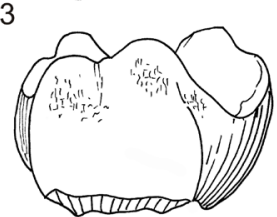

E1

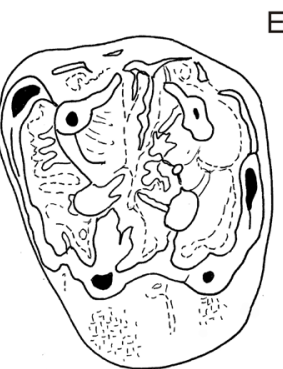

B1

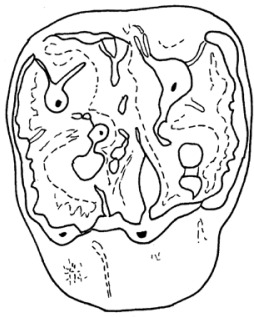

B2

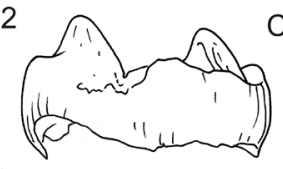

B3 3

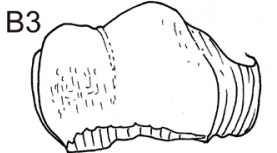

C1

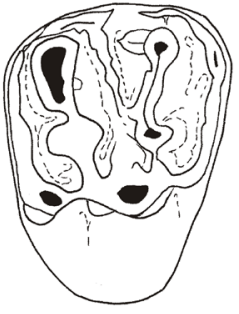

C2

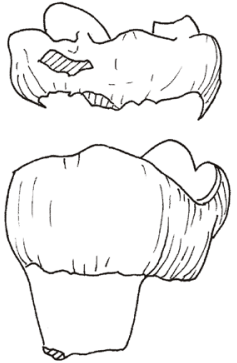

D1

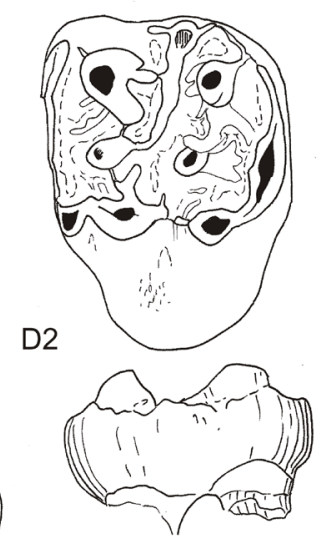

E2
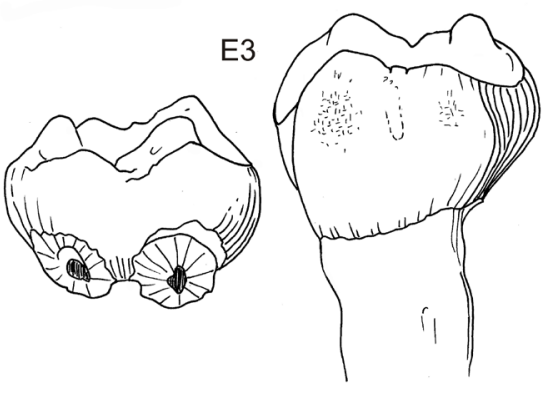

F1

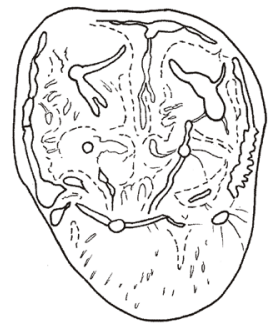

F2
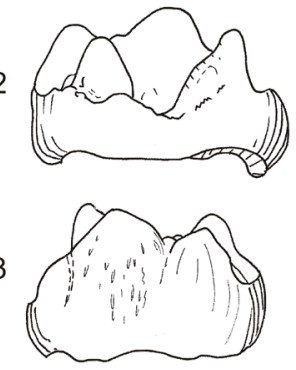

Figure 20. Upper teeth of Euromys thaleri (Michaux, 1964) from Avenay (Ypresian, MP8-9, Bassin de Paris). A. UM-AV 6085, left M1; A1, occlusal view, A2, buccal aspect, A3, lingual aspect. B. UM-AV 6821, right M2; B1, occlusal view, B2, buccal aspect. B3, lingual aspect. C. UM-AV 4760, right M1; C1, occlusal view, C2, buccal aspect, C3 lingual aspect. D. UM-AV 4729, left M1; D1, occlusal view, D2, buccal aspect. E. UM-AV 4950, left M1-2; E1, occlusal view, E2, buccal aspect, E3 lingual aspect. F. UM-AV 7208, left M1-2; F1, occlusal view, F2, buccal aspect, F3 lingual aspect. Scale bar, $1 \mathrm{~mm}$. 
The metaconid is the most salient, but it is not a prominently elevated cuspid, so that the postmetacristid slopes moderately to the $\mathrm{V}$ opening of the mesoflexus. On the $\mathrm{m} 2$ (from Mutigny), the mesostylid area is flat. The buccal metalophulid I is short and transverse from the apex of the protoconid. It weakly fuses with an irregular mesial lingual metalophulid. Another lingual element of the metalophulid I is also present, distal to the previous one. On the $\mathrm{m} 2$ ( $\mathrm{Mu} 5612$ ), the anterolophid is longer, together with a trigonid area wider than on $\mathrm{ml}$. The lingual metalophulid area displays three to four metalophulid ridges, behind the mesialmost premetacristid, one turning mesially to join the anterolophid, one intermediate ending free and facing a branch of the buccal metalophulid I, the last, longer, reaching the other branch of the buccal metalophulid I; both branches are attached to the apex of the protoconid. Several extra-ridges develop along the distal flank of the trigonid. The postprotocristid, originating from the apex of the protoconid, is high and descends obliquely (mesiobuccal to distolingual) to the short mesial ectolophid. Its extremity shows a premesoconid swelling (on the $\mathrm{m} 1$ holotype) or a short transverse ridge (on $\mathrm{m} 2$ ). The mesoconid is bulging and relatively high, with a sloping irregular ectomesolophid, and a few low mesolophid ridges. The very short distal ectolophid joins the prehypocristid. The hypoconid is slightly smaller than the entoconid. The buccomesial-distolingual oblique posthypocristid merges with the linguobuccally stretched hypoconulid; the latter is only slightly salient. It slightly separates from the short posterolophid on $\mathrm{m} 1$, more on $\mathrm{m} 2$, on which it connects to a short lingual entolophid. On $\mathrm{m} 1$, this short entolophid ends free. On $\mathrm{m} 1$, the extra-ridges descending along the slopes bordering the basin are thinner and less numerous than on $\mathrm{m} 2$. On the latter, some are thicker, and traces a discontinuous entolophid to the distal end of the mesoconid. The basin is cup-shaped. The flanks of the crown are sinuously wrinkled, more in the sinusid area and buccal flanks of the protoconid and hypoconid than along the lingual flanks of the metaconid and entoconid. The Mu 5632 $\mathrm{m} ? 1$ and $\mathrm{Mu} 5135 \mathrm{~m} 2$ previously referred to Meldimys louisi are better attributable to Euromys thaleri. MU 5632 could be possibly a p4.

Avenay. p4, m1-2. Two teeth, previously referred to as Meldimys louisi, belong to Euromys thaleri. AV-9001 is a p4, rather than a $\mathrm{m} 1$, and $\mathrm{AV}-5061$ is a $\mathrm{m} 1$, rather than a $\mathrm{m} 2$.

p4. This tooth is slightly smaller than $\mathrm{m} 1$, the metaconid is strongly taller than the other cuspids, and therefore the postmetacristid descends relatively abruptly to the $\mathrm{V}$ opening of the mesoflexid. The protoconid (well-developed for a p4) is closer to the metaconid than on $\mathrm{m} 1$. The short anterolophid is relatively high (compared to Ailuravus), bulged at mid-length in a small anteroconid. Two short buccal metalophulids and two short lingual ones start from the apex of the protoconid and from that of the metaconid, respectively. They do not meet
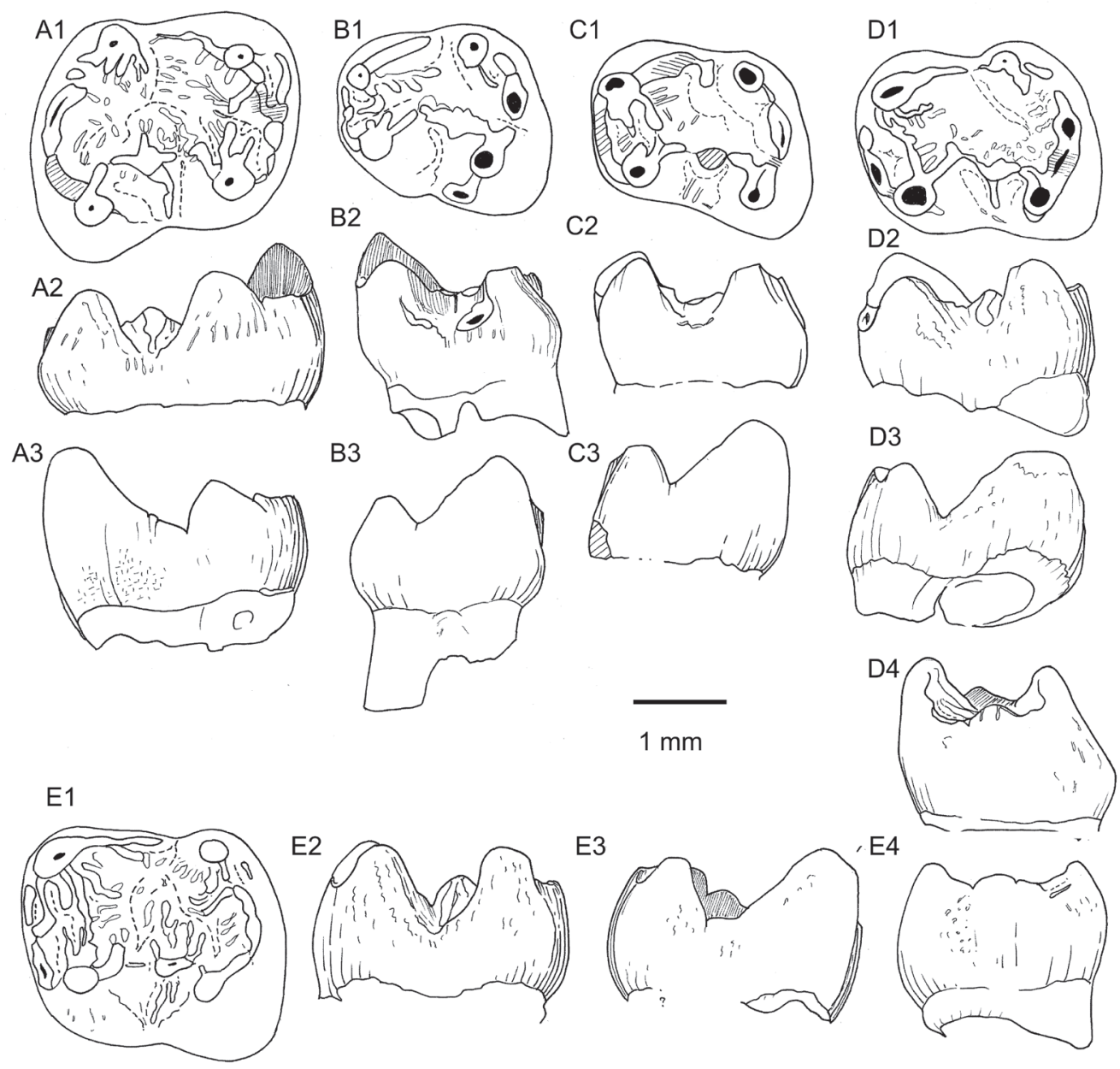

E4

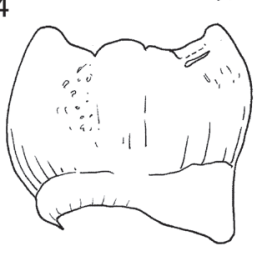

Figure 21. Lower teeth of Euromys thaleri (Michaux, 1964) from Avenay and Mutigny (Ypresian, MP8-9, Bassin de Paris). A. UM-AV 5745, right m2; A1, occlusal view, A2, buccal aspect, A3, lingual aspect. B. UM-AV 9001, left p4; B1, occlusal view, B2, buccal aspect. B3, lingual aspect. C. MU 5632, cast, left? p4; C1, occlusal view, C2, buccal aspect, C3 lingual aspect. D. MU 5956, cast, left m2, Holotype; D1, occlusal view, D2, buccal aspect, D3, lingual aspect, D4, mesial aspect.; E. MU 5612, left m2; E1, occlusal view, E2, buccal aspect, E3, lingual aspect, E4, mesial aspect. Scale bar, $1 \mathrm{~mm}$. 
together, leaving a mesiodistal groove of the trigonid, open distally. The postprotocristid is oblique and thick, joining the low short mesial ectolophid, and the mesoconid is strong with a short ectomesolophid. There is a buccal ridge (cingulid) descending along the buccodistal border of the protoconid, to the large ectostylid, then running up the mesiobuccal flank of the hypoconid. The posthypocristid is separated from the salient hypoconulid by an oblique groove.

$\boldsymbol{m} 1-\boldsymbol{m} 2$. On the $\mathrm{m} 1 \mathrm{AV}-9001$ and AV-5061, a thin mesh is present lingually and mesially. The AV-5745 $\mathrm{m} 2$ is slighlty larger than the holotype from Mutigny, the basin floor and the outskirts of the crown being more wrinkled. The other features are like that of $\mathrm{p} 4$ and molars from Mutigny.

Remarks. On lower molars, like in the large Ailuravus, and even if the cuspids are less salient, a deep groove is distinct from the mesostylid opening to the contact posthypocristidhypoconulid. This feature reflects more a similar grinding fonction than a close relationship between these taxa. Indeed, the origin and path of the postprotocristid in particular being very different, the main cuspids less protruding and more vertical.

Euromys woodi (Michaux, 1964) comb. nov.

Figures 22 to 29.

Paramys woodi Michaux, 1964; fig. 1c.

Paramys woodi Michaux: Louis, 1966: p. 11.

Paramys woodi Michaux: Michaux, 1968, p. 143-147 ; Pl. 2, figs. 1-6, PI. 3, figs. 1-4.

Paramys woodi Michaux: Louis, 1970: p. 55.

Paramys woodi Michaux: pro parte, Louis et al. 1983: p. 11.

« Paramys woodi » Michaux, Escarguel, 1999: p. 232.

Holotype. AV-1, right $\mathrm{m} 1$.

Type locality. Avenay (Marne, Bassin de Paris; mid-early Eocene, MP8-9).

Original diagnosis. (Michaux, 1964, p. 153; translation from French). "Lower molars with irregularities on the enamel surface; ridges in the talonid basin; cuspids of the talonid wellindividualized; $\mathrm{m} 3$ larger than $\mathrm{m} 1-2$; upper $\mathrm{P} 4$ narrow with small hypocone; not well-developed parastyle on premolars and molars."

Emended diagnosis (Michaux, 1968, p. 144; translation from French). "Irregularities on the enamel surface of upper and lower teeth. Lower m1-2, with ridges in the trigonid basin, and well-distinct cuspids on the talonid; $\mathrm{m} 3$ larger than $\mathrm{m} 1-2$; P4 with a small hypocone; well-developed hypocone on M1-2; parastyle not important on upper molars and premolars.

Emended diagnosis in Escarguel (1999; translation from French). "Large sized Ischyromyidae, teeth with irregular enamel surface, finely ornamented; brachydont teeth. P4 relatively compressed antero-posteriorly, with hypocone very reduced or absent, and anterior cingulum reduced; paracone more lingual than the metacone; tendency to duplicate the metaconule. M1-3 with weak ridge descending from the protocone to the trigon (= postprotocrista), between the two conules. M1-2 with strong hypocone, showing a narrow and deep lingual sinus and massive conules, well-connected to the protocone; anterior and posterior cinguli well-developed; mesostyle present and often prolonged in a draft of mesoloph.
M3 close to M1 and M2: anterior cingulum well-developed; protoconule present, reduced metaconule; pericingulum weakly or not developed; metacone relatively reduced; trigonid bicuspidate; slender ectolophid and posterocingulum; hypoconulid stretched transversely. Lower m1-3 with a metalophulid I, frequently, more or less complete; ectolophid absent and a massive mesoconid sometimes present, weakly connected to the hypoconulid; hypoconulid visible, stretched transversely. Trigonid basin on $\mathrm{m} 3$ generally closed; strong and high metaconid-entoconid connection, overhanging the talonid basin, lingual groove shallow to absent."

Emended diagnosis (new). Large species of Euromys, (M1: L mean x W mean: $3.269 \mathrm{~mm} \times 3.853 \mathrm{~mm}$ ); teeth smaller than those of Ailuravus michauxi. Enamel surfaces with numerous wrinkles and granules.

Upper teeth. Pre- and post- protocristae nearly aligned on D4. On P4, anteroloph low and variably long, mesoloph absent, hypocone small but present, and buccal roots merged below the cervix of the crown. On P4 and molars, strong morphological variations, concerning the parastyle, the more or less buccal position of the hypocone, and the anteroloph length on teeth on which the parastyle is strong. On M1-M2, the hypocone is more buccal than the protocone, and much reduced to absent on M3. The sloping pre- and post- protocristae make a wide $\mathrm{V}$ angle with the protocone apex. The endoloph is slightly lower than the hypocone apex, and hardly visible. The protoloph generally connects to the preprotocrista and rarely to the protocrista. The metaconule is present and variable in shape (rounded and/or merged in ridges or wrinkles) equal or larger than the paraconule.

Lower teeth. The metaconid is higher than the other cuspids. The small mesostylid is variably distinct on $\mathrm{d} 4$ and molars, its area overlooking the cup shaped basin floor. Protoconid present on $\mathrm{p} 4$. On molars, the metalophulid I is generally complete, and there are frequently additional short lingual metalophulid spurs between the main one and the mesial premetacristid; the postprotocristid is strong, oblique mesiobuccally to distolingually; the hypoconulid is low and stretched buccolingually. The postprotocristid often prolonges with premesoconid ridges or swellings.

Materials from Avenay. (App. S. 1)

Measurements. (Fig. 22; Table 4) D4 are as long as P4 but less wide; they are smaller than the molars. Only one P4 (AVMNHN-23 L) is out of the distribution of the others, and is of same size as M2. M1 are wider and somewhat longer than M2. M3 are smaller than M1-M2. d4 are smaller than p4; p4 are narrower and for the main part, shorter than $\mathrm{m} 1 ; \mathrm{m} 1$ are smaller than $\mathrm{m} 2$, and $\mathrm{m} 3$ clearly longer than $\mathrm{m} 1-\mathrm{m} 2$. They are larger than teeth of the other species from Avenay. The AVMNHN-10 L m3 is longer than the others, and presents some peculiar features (see below, Fig. 29b).

\section{Description.}

Upper teeth. (Figs. 23-25).

D4 (Fig. 23A-D). The D4 are trapezoidal and flat compared with the molars and P4. The parastyle is slightly swollen and arched, turning at the buccomesial corner of the paracone to join the preparacrista, or, once (AV-MNHN-629 L), a thin paraectocingulum. The anteroloph is long, low and slender, ending lingually in a small anterostyle; its junction to the protocone mesial flank is sometimes enhanced by a weak antesinus. The postparacrista is stronger and longer than the preparacrista. It turns to join the mesostyle, and is depressed buccally by a 
notch. The mesostyle is buccal to the paracone and metacone, aligned with the ectocingulum. In one case (UM-AV-93), it is mesiodistal and joins a small conule, which is at the same mesiodistal level than the paracone and metacone. The buccal protoloph is transverse, thinning and turning a little mesially at its extremity to join the paraconule, which is more or less protruding in the anteroflexus; the paraconule is single or double (UM-AV-A76, -6768, and AV-MNHN- 629 L). The short buccal protoloph connects to the preprotocrista mesially.

The mesostyle is rounded or stretched mesiodistally; in this case, it joins the meta-ectocingulum (UM-AV-93, -4963, and AV-MNHN-629 L). The metacone is lower than the paracone; the premetacrista is short, joining the mesostyle or separated by a narrow cleft, and the postmetacrista is very short and mesiobuccally to distolingually directed. The metaloph is oblique, directed to the distal end of the postprotocrista, through a strong metaconule. The latter is double on AV-MNHN-629 L and -5752 . The pre- and post- protocristae are nearly aligned (as seen on the unworn UM-AV-6768). The protocone bears a weakly marked protocrista, descending in the mesoflexus. The hypocone is more lingual than the protocone, smaller and lower. Their junction on the lingual wall is marked by a narrow sinus, developed on the upper $1 / 3$ of the crown. The low posteroloph is long up to the meta-ectocingulum when present, or only to the mesiobuccal corner of the metacone.

P4 (Fig. 23F-J). On P4, the small hypocone is at the same lingual level as the protocone. These $\mathrm{P} 4$ are more variable than the D4. Their overall shape varies with different developments of the mesostyle and parastyle. On all, the mesoloph is absent. The two buccal roots are coalescent at least in their upper part.

$\mathrm{AV}-748$ is the narrower P4, with a small buccal mesostyle, weakly distinguishable from the postpara- and premeta- cristae. Its anteroloph and posteroloph are parallel, its parastyle weakly swollen. On this tooth, an anterolophule links the paraconule to the anteroloph; more lingually, the preprotocrista ends free in the anteroflexus; a weak antesinus underlines the anterostyle; the mesoflexus is narrow; the posteroloph attaches to the postmetacrista. UM-AV-A21 and UM-AV-503 are trapezoidal with a more salient parastyle, but with a slender anteroloph, on which the anterostyle is indistinct. The unworn UM-AV-5736, with a moderate parastyle and a small mesostyle, shows the mesiodistal alignment of the pre- and post- protocristae, a long endoloph, and a distinct postprotocrista. Two worn P4 (UM-AV-4713 and -299) have a strong parastyle limited at the mesiobuccal aspect of the paracone, and their mesostyle is moderate in size. AV-MNHN-23 L (Fig. 23I), which is eroded and worn, is wider than the others, with a mesiodistally wide anteroflexus, a long mesostyle, and the anterostyle and anteroflexus individualized. On UM-AV-5747, the mesostyle is more buccal and stretched mesiodistally (Fig. 23G).

AV-MNHN-23 L is quite larger than the other P4: its parastyle is hypertrophied, enlarging the buccomesial corner of the tooth around the paracone; it joins a buccally protruding and stretched strong mesostyle, both connecting through the para-ectocingulum.

Finally, one incomplete P4 (AV-MNHN-161) found in the material from the MNHN referred to woodi, shows similar wrinkles on the walls as that of woodi, but is much larger. It is damaged (mainly its paracone - parastyle area). The anterostyle is present; the protocone and hypocone, placed on the same lingual level, are strongly worn. The mesostyle is high, with a cuspule attached distally, and the meta-ectocingulum present. In the anteroflexus, the paraconule is protruding slightly buccal to the anterostyle. The metaconule is worn, and appears fused to the wide worn area of the hypocone + protocone.

M1-M2. M1 and M2 have their hypocone more buccal than the protocone, but this character is more marked on M2. Unlike on D4 or some P4, the development of the ectocingulum is lesser and present only on a few M1. Among these molars, like on P4, there is a relatively strong morphological variation, concerning the parastyle but also the more or less buccal position of the hypocone and the posteroloph length on teeth on which the parastyle is strong. Therefore, it is sometimes difficult to recognize some M1 from M2. The wrinkles are numerous and well defined.

M1 (Fig. 24). The M1 are trapezoidal asymmetrical, more (AV-MNHN $4 \mathrm{Cn}$ and $319 \mathrm{~L}$; UM-AV-518, -5738, -4939, and -5918 ) or less (UM-AV-196, -4940, -4948, and -5813) long, and

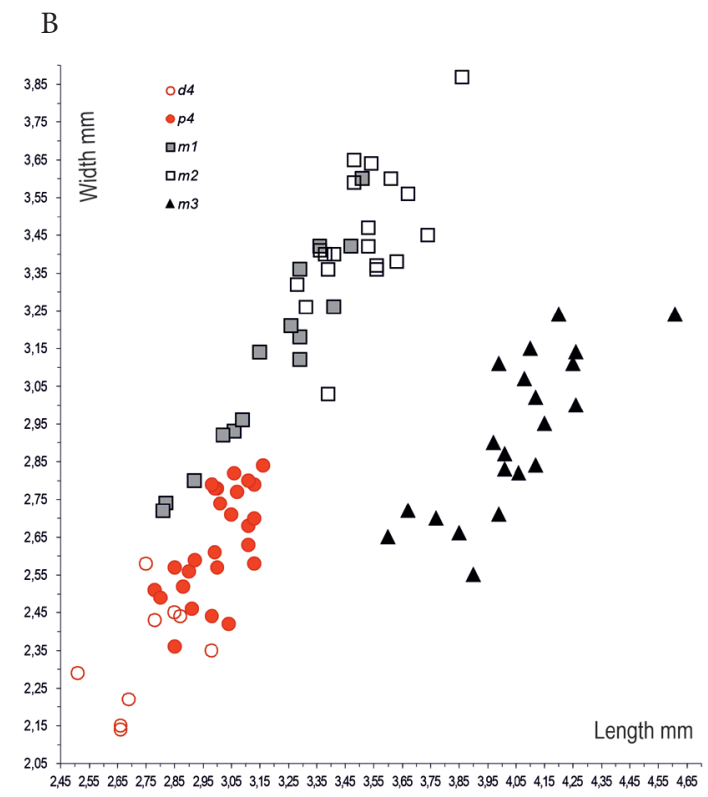

Figure 22. Bivariate graphs (Length x Width) of upper teeth (A) and lower teeth (B) of Euromys woodi (Michaux, 1964) from Avenay (Ypresian, MP8-9, Bassin de Paris). Graduations as millimetres. 
their hypocone is at the same lingual level as or slightly more buccal than the protocone. On these M1, the strong stretched parastyle is moderately arched and projected mesially, ending at the buccomesial corner of the paracone. The specimen UMAV-6695 bears a markedly strong parastyle, reinforced by a conule at the buccal end of the anteroflexus, but its hypocone is more buccal than on the other and its posteroloph is short (Fig. 24E). It is difficult to decide if it is a M1 or a M2.

On the M1, the anteroloph is long, its lingual extremity being bulged in a small anterostyle; a weak antesinus underlines its junction with the mesial flank of the protocone. There is no well-defined preparacrista, and the strong postparacrista separates from the mesostyle by a narrow cleft. The buccal protoloph as the buccal metaloph are high, and their mesial and distal flanks steep. The buccal protoloph connects to the base of the paraconule; the lingual protoloph joins the protocrista, and the extremity of the preprotocrista ends free in the anteroflexus; more frequently, it connects to the preprotocrista and in these cases, the protocrista ends free to mid-length of the mesoflexus.

The mesostyle is small, framed by one or two extra-conules or short ridges, swollen or a little stretched mesiodistally. The mesoloph is present as one to two more or less continuous long low ridges. The metacone is only slightly smaller than the paracone, and the metaconule slightly stronger than the paraconule. The buccal part of the metaloph consists of two short ridges: the mesial (metalophule I) often joins the metaconule; the distal one (metalophule II) is heading obliquely to the posteroloph. The lingual metaloph sometimes connects to the metaconule with the postprotocrista. The sloping pre- and post- protocristae makes a wide $\mathrm{V}$ angle with the protocone. The endoloph is indistinct and the protocone and hypocone are adjacent, only separated at their upper part. The hypocone is lower and smaller than the protocone. The posteroloph is generally long, from the hypocone to the buccal corner of the metacone. On two teeth (UM-AV-518 and -5738), it turns buccally and joins the meta-ectocingulum, until the mesostyle.

M2 (Fig. 25A-B). M2 are more symmetrical than M1, with their protocone more lingual than the hypocone and anterostyle, both being nearly at the same mesiobuccal level. The hypocone is smaller than on M1. The metacone is lingual and smaller than the paracone. The connections of the protocrista and of the preand post- protocristae are similar as on M1. The posteroloph is
A1

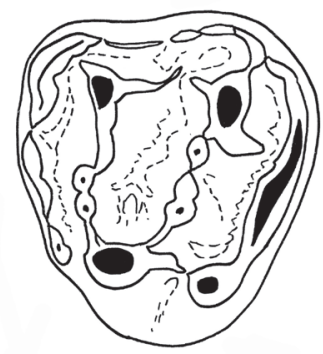

A2

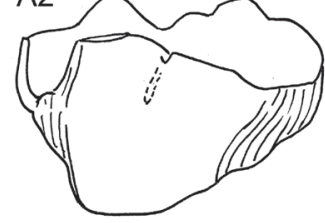

A3

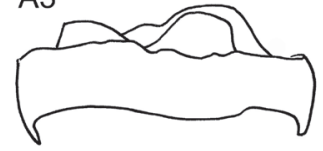

$\mathrm{B}$

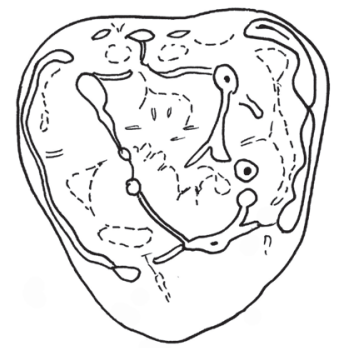

$\mathrm{D}$

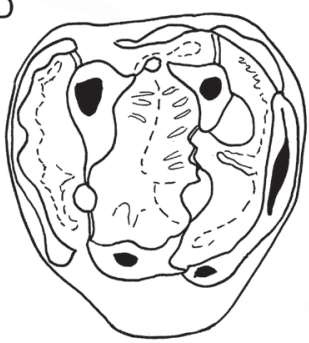

$\mathrm{E}$
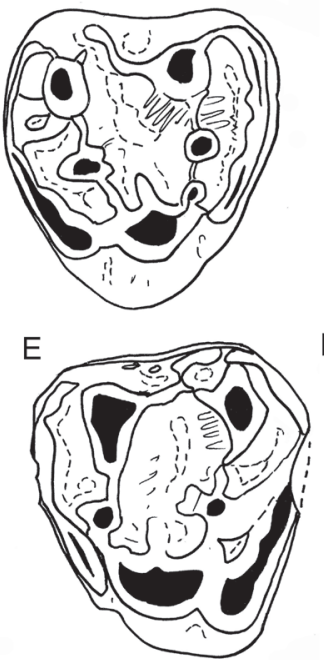

F2
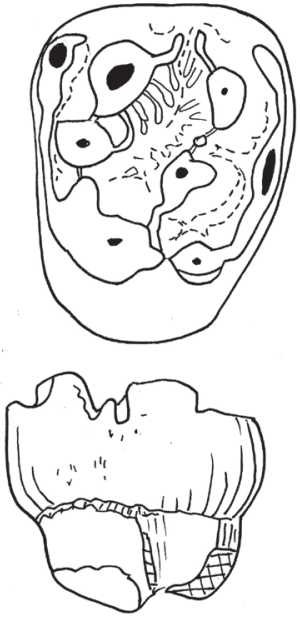

F3

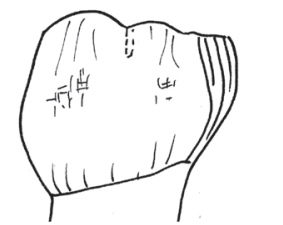

$\mathrm{H}$
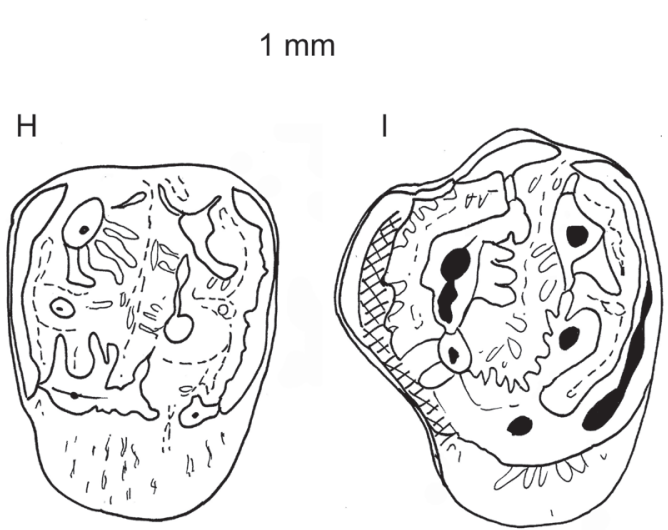

$\mathrm{J}$
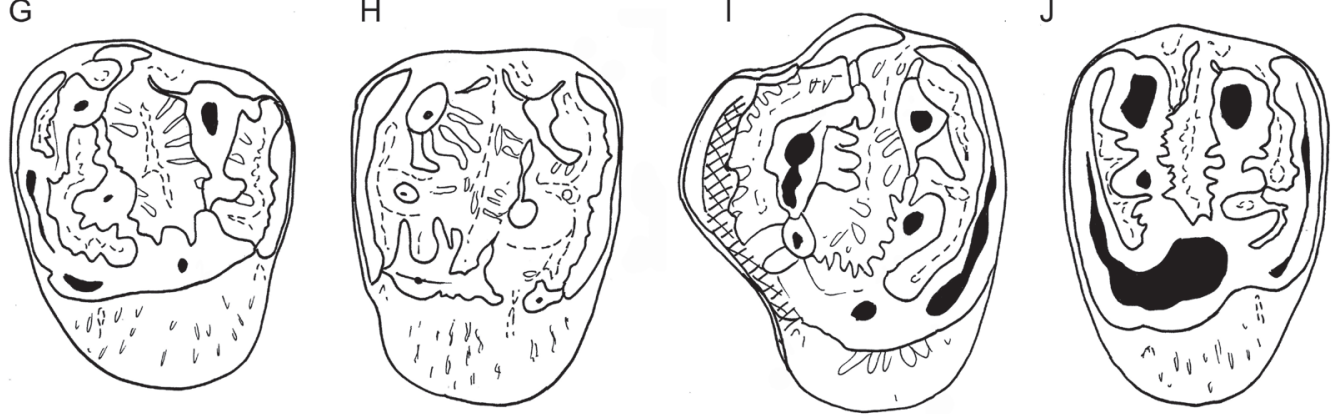

Figure 23. Upper D4 and P4 of Euromys woodi (Michaux, 1964) from Avenay (Ypresian, MP8-9, Bassin de Paris). A. AV-MNHN-629 L, left D4; A1, occlusal view, A2, lingual aspect, A3, buccal aspect. B. UM-AV 6768, right D4: occlusal view. C. UM-AV A76, right D4: occlusal view. D. UM-AV 93, left D4: occlusal view. E. UM-AV 4963, left D4: occlusal view. F. UM-AV A21, left P4; F1, occlusal view, F2, buccal aspect, F3, lingual aspect. G. UM-AV 5747, right P4. H. UM-AV 5736, left P4. I. AV-MNHN-23 L, left P4. J. UM-AV 748, right P4. Scale bar, 1 mm. 
short, generally ending buccally at the level of the beginning of the metaloph; lingually, it connects to the hypocone, except on UM-AV-4627, on which the hypocone prolonges buccally in a kind of "hypoloph", distinct from the thick posteroloph reaching the base of the hypocone. One M2 is larger than the largest M1 (AV-MNHN 41 L); it is strongly wrinkled, with a mesiodistally lengthened mesostyle, the protoloph attaches lingually to the protocrista, and the mesial extremity of the preprotocrista ends freely in the anteroloph.

M3 (Fig. 25C-D). They are triangular, with their hypocone much reduced (e.g., UM-AV-151 and -4938) to absent (e.g., UM-AV-4936). When the teeth are weakly to moderately worn, the protoloph appears sharp, as on M1-M2. The mesostyle, single or divided (in two or three elements) always prolonges with thin mesoloph ridges. It is lower than the metacone. On the unworn UM-AV-4938, which is less triangular than the other M3, the metacone is divided: a conule has shift more lingually whereas a buccal "meta-ectocingulum" as high as the conule joins the mesostyle and the posteroloph buccal end. A distomesial metaloph joins the metaconule. Paraconule and metaconule are present: sometimes similar in size, sometimes the metaconule is larger. Pre- and post- protocristae make a wide $\mathrm{V}$ and the protocrista is like on M1-M2; the junctions of the lingual protoloph with the metaloph are as on other molars.

\section{Lower teeth. (Figs. 26-29)}

$\boldsymbol{d} 4$ (Fig. 26A-E). We have observed only four d4, among the material referred to this locus, but three other specimens, previously considered as p4 (Escarguel, 1999: 315), are here referred to d4: their metaconid is comparatively less strong and less high, and the anteroflexid more developed than on $\mathrm{p} 4$. The protoconid is well developed on all specimens, and nearly as developed as the hypoconid.

The morphological variation mainly concerns the "trigonid". It is narrow buccolingually on AV-MNHN-857 L, UMAV-4928 and UM-AV-4587, and more on AV-MNHN-263 L. The anterolophid is low and short as the metaconid and protoconid are close; it is slightly bulged on UM-AV-4928 and -4587 , in a kind of low mesial anteroconid. This anterolophid joins the mesial arms of the protoconid and of the metaconid, both nearly distomesially oriented. Therefore, the anteroflexid is also elongated. The buccal metalophulid I
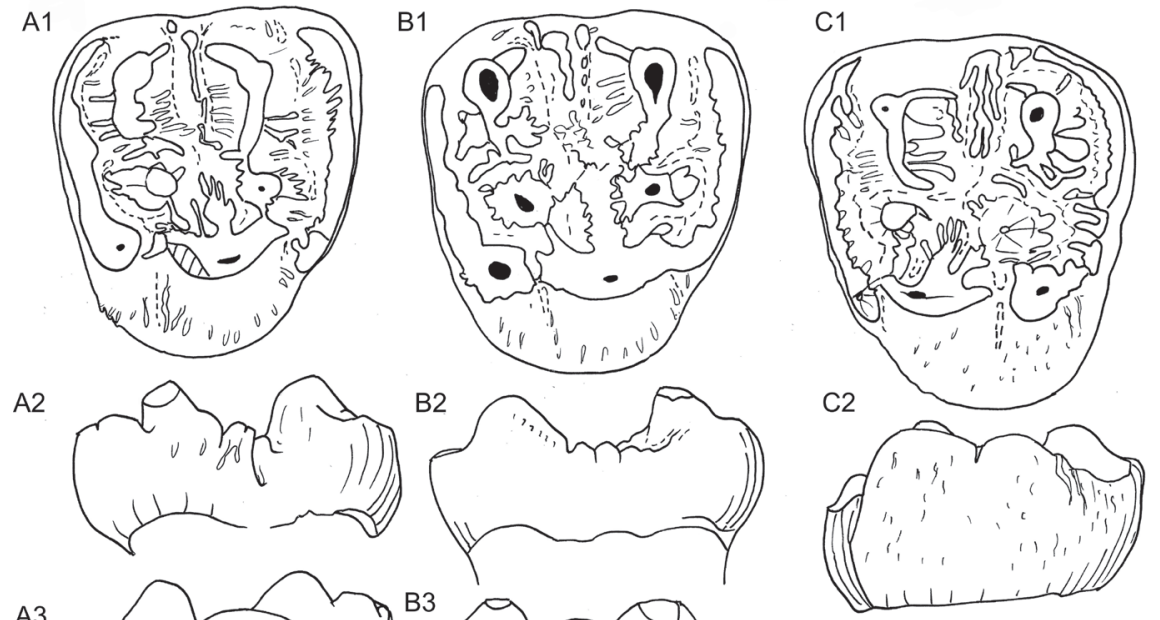

A3
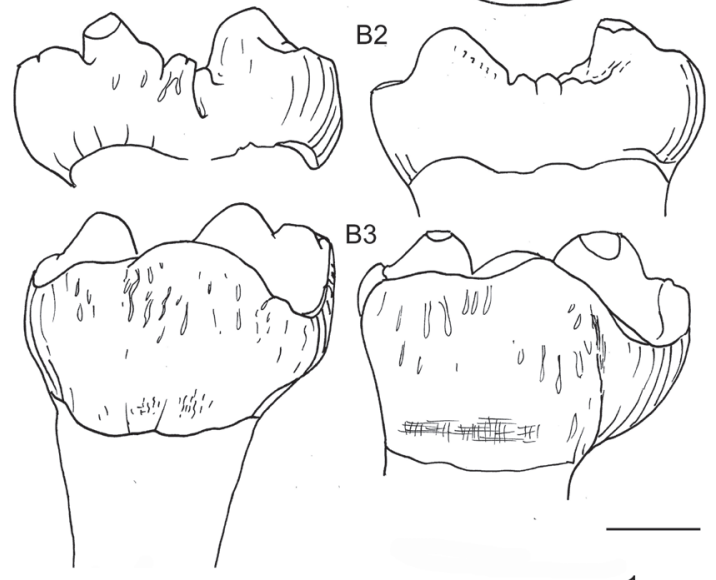

$\mathrm{C} 2$
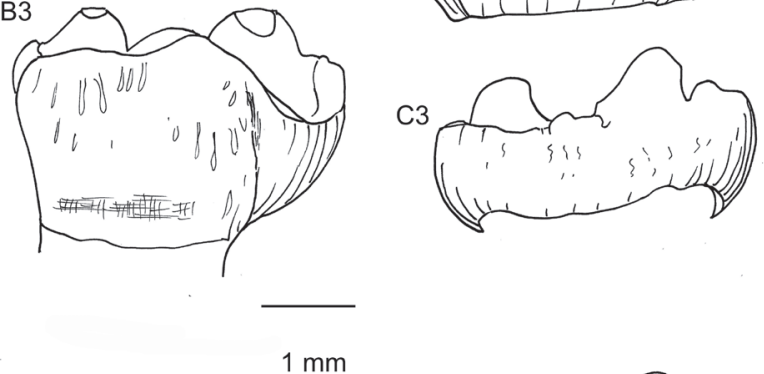

$\mathrm{D}$

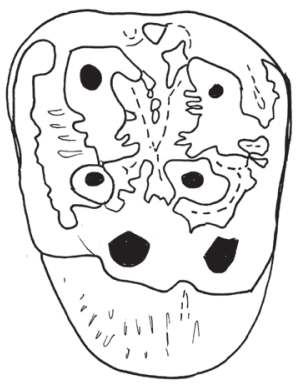

E1

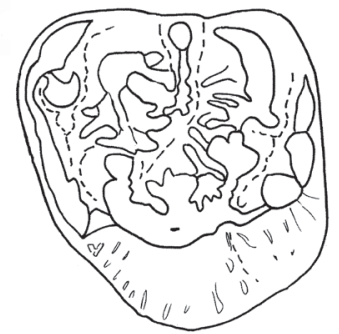

E2

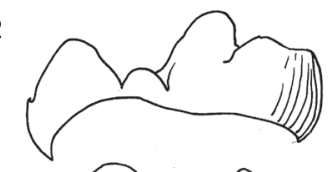

E3

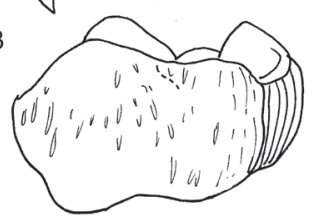

Figure 24. Upper M1 (A to D) and M2 (E) of Euromys woodi (Michaux, 1964) from Avenay (Ypresian, MP8-9, Bassin de Paris). A. AV-MNHN-4 Cn, right M1; A1, occlusal view, A2, buccal aspect, A3, lingual aspect. B. AV-MNHN-319 L, right M1; B1, occlusal view, B2, buccal aspect, B3, lingual aspect. C. UM-AV 5738, left M1; C1, occlusal view, C2, lingual aspect, C3, buccal aspect. D. UM-AV 5813, left M1: occlusal view. E. UM-AV 6695, left M2; E1, occlusal view, E2, buccal aspect, E3, lingual aspect. Scale bar, $1 \mathrm{~mm}$. 
is attached to the protoconid slightly distally to its apex; its joins the lingual metalophulid, closing the anteroflexid distally. The postmetacristid is gently sloping to its low mesostylid extremity, closing there the mesoflexid. The mesoflexid basin is cup- shaped, with the floor area reduced due to the centripetal slope of its surrouding ridges, all bearing numerous thin extraridges, and wrinkles are present on AV-MNHN-263 L or UMAV-682, less on AV-MNHN-857 L or UM-AV-4587.

The posprotocristid is oblique and thick, making and angle with the mesial ectolophid, which is weak and short; the mesoconid is bulged. An ectocingulid can limit the sinusid opening, connected to a weak mesiobuccal hypoconid spur (e.g., AV-MNHN-263 L). The short distal ectolophid joins the prehypocristid. The posthypocristid is short and oblique distally, thinning at its junction with the weakly swollen and stretched buccolingually hypoconulid, buccally indistinct from the posterolophid. There is a narrow break between the latter and the short postentocristid. The entoconid is small and low, facing the hypoconid. The entolophid is absent or reduced to a short lingual extra-ridge.

The small AV-UM-836 differs from the others in its more visible extra-ridges (ectomesolophid and mesolophid), and in displaying a more curved hypoconulid. As for the AV-MNHN-6 L tooth, which was previously determined as a $\mathrm{p} 4$, the base of the crown is broken, but the cuspids are not worn and acute; the metalophulid II connects to the posterior part of the protoconid, but a more mesial incomplete metalophulid I is present as is the postprotocristid. The anterolophid is longer and transverse, like on $\mathrm{ml}$. However, this tooth is much lower than the $\mathrm{ml}$. Both are provisionnaly considered as $\mathrm{d} 4$.

p4 (Fig. 26G-J). These p4 are more elongate than that of
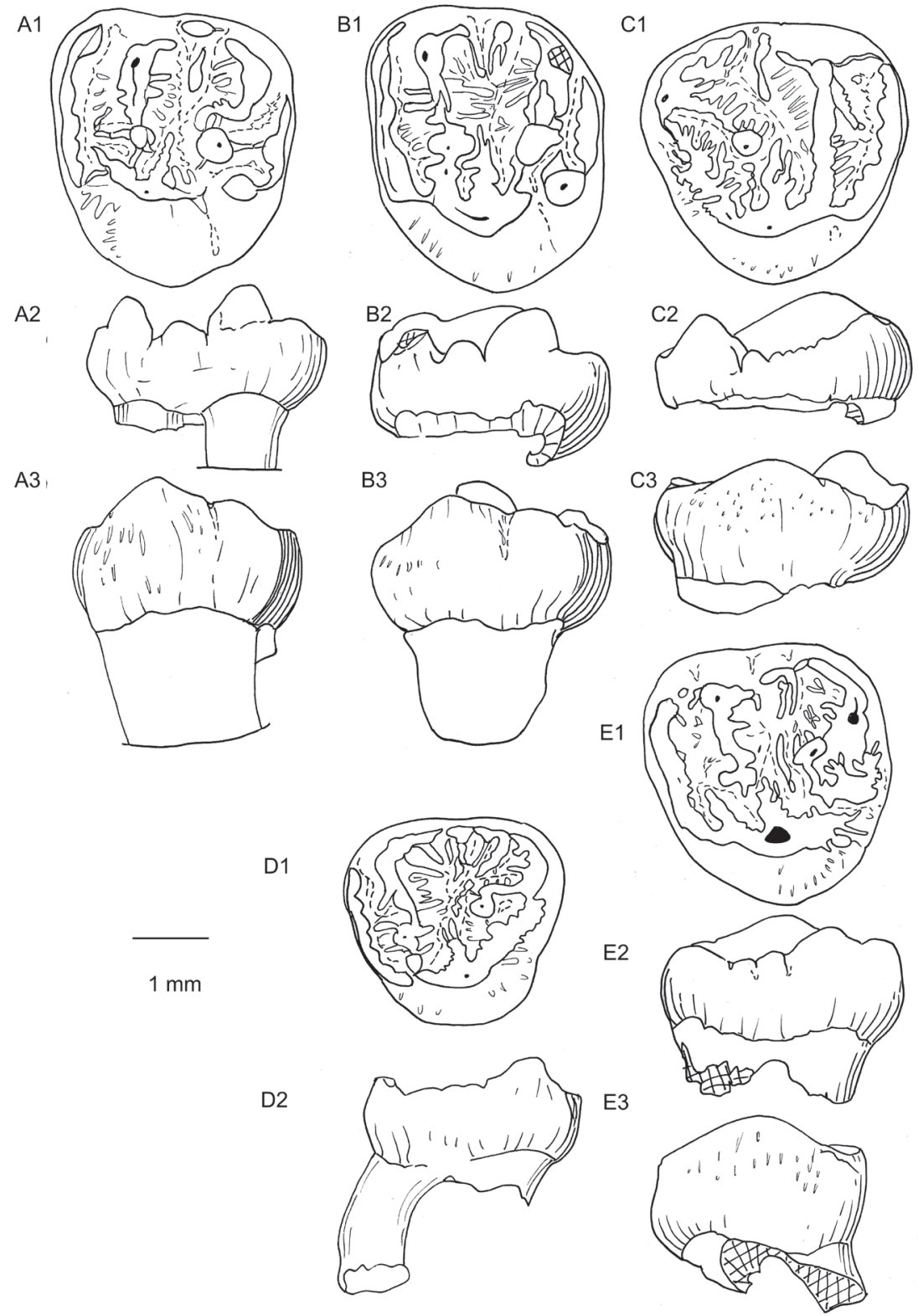

Figure 25. Upper M2 (A, B) and M3 (C to E) of Euromys woodi (Michaux, 1964) from Avenay (Ypresian, MP8-9, Bassin de Paris). A. UM-AV 4996, left M2; A1, occlusal view, A2, buccal aspect, A3, lingual aspect. B. UM-AV 747, left M2; B1, occlusal view, B2, buccal aspect, B3, lingual aspect. C. UM-AV 4947, right M3; C1, occlusal view, C2, buccal aspect, C3, lingual aspect. D. UM-AV 4936, left M3; D1, occlusal view, D2, buccal aspect. E. AV-MNHN-148 L, left M3; E1, occlusal view, E2, buccal aspect, E3, lingual aspect. Scale bar, $1 \mathrm{~mm}$. 


\begin{tabular}{|c|c|c|c|c|c|}
\hline \multirow[b]{3}{*}{ Loci } & \multicolumn{5}{|c|}{$\begin{array}{l}\text { Euromys woodi (Michaux, 1964) } \\
\text { from Avenay (Bassin de Paris) }\end{array}$} \\
\hline & & \multicolumn{4}{|c|}{ Length } \\
\hline & $\mathrm{n}$ & $\begin{array}{l}\min - \\
\max \end{array}$ & mean $\pm \mathrm{Sm}$ & sd & $\mathrm{v}$ \\
\hline D4 & 9 & $2.59-2.95$ & $2.721 \pm 0.041$ & 0.1980 & 7.28 \\
\hline P4 & 13 & $2.43-3.09$ & $2.655 \pm 0.049$ & 0.1272 & 4.79 \\
\hline M1 & 14 & $2.82-3.49$ & $3.269 \pm 0.052$ & 0.1485 & 4.54 \\
\hline M2 & 15 & $3.09-3.67$ & $3.242 \pm 0.041$ & 0.1612 & 4.97 \\
\hline M3 & 19 & $2.93-3.34$ & $3.155 \pm 0.037$ & 0.1614 & 5.11 \\
\hline $\mathrm{d} 4$ & 9 & $2.51-2.98$ & $3.750 \pm 0.046$ & 0.2051 & 7.46 \\
\hline $\mathrm{p} 4$ & 26 & $2.80-3.16$ & $2.998 \pm 0.021$ & 0.1556 & 5.19 \\
\hline $\mathrm{m} 1$ & 15 & $2.81-3.51$ & $3.183 \pm 0.057$ & 0.1838 & 5.76 \\
\hline $\mathrm{m} 2$ & 19 & $3.28-3.86$ & $3.511 \pm 0.034$ & 0.0849 & 2.42 \\
\hline \multirow[t]{2}{*}{$\mathrm{m} 3$} & 21 & $3.60-4.61$ & $4.046 \pm 0.048$ & 0.1556 & 3.84 \\
\hline & & \multicolumn{4}{|c|}{ Width } \\
\hline Loci & $\mathrm{n}$ & $\begin{array}{l}\min - \\
\max \end{array}$ & mean $\pm \mathrm{Sm}$ & sd & v \\
\hline D4 & 9 & $2.54-3.11$ & $2.879 \pm 0.062$ & 0.2970 & 10.32 \\
\hline $\mathrm{P} 4$ & 13 & $3.06-3.56$ & $3.343 \pm 0.045$ & 0.1651 & 4.94 \\
\hline M1 & 14 & $3.52-4.09$ & $3.853 \pm 0.042$ & 0.1560 & 4.15 \\
\hline M2 & 15 & $3.56-4.13$ & $3.745 \pm 0.055$ & 0.1485 & 3.96 \\
\hline M3 & 19 & $2.96-3.65$ & $3.294 \pm 0.042$ & 0.1877 & 5.70 \\
\hline $\mathrm{d} 4$ & 9 & $2.14-2.58$ & $2.339 \pm 0.050$ & 0.0919 & 7.46 \\
\hline p4 & 26 & $2.36-2.84$ & $2.635 \pm 0.027$ & 0.2899 & 11.00 \\
\hline $\mathrm{m} 1$ & 15 & $2.72-3.42$ & $3.119 \pm 0.069$ & 0.0778 & 2.49 \\
\hline $\mathrm{m} 2$ & 19 & $3.26-3.87$ & $3.449 \pm 0.040$ & 0.1697 & 5.08 \\
\hline $\mathrm{m} 3$ & 21 & $2.66-3.24$ & $2.918 \pm 0.045$ & 0.3323 & 11.39 \\
\hline
\end{tabular}

Pseudoparamys teilhardi, but are similar in size to those of Meldimys louisi. They differ from the latter in their less mesial and lower metaconid relative to the other main cuspids, and their protoconid and hypoconid stockier. The anterolophid, buccolingually directed, is very short and lower than the metalophulid I. It can be weak and cingular, attached to the middle of the mesial flank of the metaconid (AV-MNHN-64 $\mathrm{L}$ and $-295 \mathrm{~L}$ ) and to that of the protoconid. It can connect to the mesial arm of the metaconid (premetacristid) and to the preprotocristid (AV-MNHN-184 L and -117 L). The anteroflexid is reduced and shallow, its floor clearly overlying the talonid basin. The postmetacristid is gently sloping, prolonged by a low mesostylid closing the mesoflexid opening. The mesostylid overlies the floor of the cup-like shaped talonid basin. One to three mesiodistal extra-ridges descend from the metaconid to the basin. The protoconid is slightly distal to the metaconid. The buccal metalophulid I can be absent or very short, attached to the apex of the protoconid, and separated by a cleft from a short lingual metalophulid I, or attached to it (AV-MNHN-64 $\mathrm{L})$. The thick oblique postprotocristid descends to the low mesial ectolophid (visible on weakly worn AV-MNHN-184 L).

The mesoconid is swollen and relatively small, in front of the short distal ectolophid. It bears a postmesoconid thickening on AV-MNHN-184 L, before joining the prehypocristid. The posthypocristid is short, in continuity with the transverse (buccolingual) hypoconulid-posterolophid. The latter shows aligned conulids at its upper part (three on AV-MNHN-64 $\mathrm{L},-153 \mathrm{~L},-828 \mathrm{~L}$, and UM-AV-5772; or one or two on AVMNHN-22 L, -184 L, -262 1, -306 L, and UM-AV-139, -4930, $-5815)$, more or less stretched, which disappears with wear, like does the shallow break between the posterolophid and the short postentocristid. The hypoconulid part of this posterior lophid is higher than the posthypocristid and posterolophid (e.g., AVMNHN-9 L, -117 L, and UM-AV-4952). The posterior lophid is the highest lophid of p4; overhanging abruptly the talonid basin like for Pseudotheridomys teilhardi, but it does not strongly curve.

m1-m2. m1 (Fig. 27) differ from m2 (Fig. 28) in their closer
Table 4. Size variations of the different loci of teeth of Euromys woodi (Michaux, 1964) and Euromys thaleri (Michaux, 1964) from Avenay (MP 8-9; Bassin de Paris).

metaconid and protoconid, but less than on $\mathrm{p} 4$. Their other features are like those depicted on $\mathrm{p} 4$. The metaconid is still higher than the other cuspids. The low anterolophid is limited at the buccal half of the tooth, sometimes bulged as a small buccolingually stretched anteroconid. It joins the base of the preprotocristid and the base of the premetacristid, of which it often separates by a cleft. It could be prolonged buccally as a sloping cingulid continuous or discontinuous (e.g., m1 UMAV-4951; m2 UM-AV-4977), like on some $\mathrm{p} 4$. The anterolophid is quite lower than the metalophulid on $\mathrm{m} 1$, and less on $\mathrm{m} 2$. The trigonid basin is shallow and well overlooking the talonid floor on $\mathrm{m} 1$, less on $\mathrm{m} 2$. The buccal metalophulid I is short and thick but longer than on $\mathrm{p} 4$. It can be single or double: one is directed - and often connected (on m2) to the main lingual metalophulid $\mathrm{I}$, the other to an intermediate lingual metalophulid ( $\mathrm{m} 1 \mathrm{AV}$ MNHN-30 L). The intermediate lingual metalophulid between the premetacristid and the main metalophulid I is generally short, thick and high. The mesostylid, blocking the opening of the mesoflexid, is generally very small to strong (UMAV-4977), sometimes prolonged buccally by a short lingual mesolophid ridge.

The relatively long and oblique postprotocristid descends to the short low and mesial ectolophid. The mesoconid is weakly to moderately bulged, buccally and lingually, bearing wrinkles longer than the others do. They design a single or double ectomesolophid, short buccal mesolophids, and very low discontinuous elements of the entolophid. The distal ectolophid is low and short, swollen as a postmesoconid in two cases (UM-AV-4977 and AV-MNHN-30 L). An ectocingulid can be present at the buccodistal corner of the sinusid. The hypoconid is nearly as developed as the protoconid, but somewhat slightly lower. The posterior lophid is arranged as on $\mathrm{p} 4$.

$\boldsymbol{m} 3$ (Fig. 29). On unworn $m 3$, the wrinkles of the outskirts of the crown and in the basin floor appear more developed than on the other molars. $\mathrm{m} 3$ differ from $\mathrm{m} 1-\mathrm{m} 2$ in their apparent lower crowns, their trigonid floor at nearly the same level as the floor of the talonid, the entoconid-hypoconid width shorter than the metaconid-protoconid width, the entoconid more mesial 
(but not reaching the transverse level of the mesoconid). The posterior lophid is reduced to the oblique posthypocristid and a bulged hypoconulid. The latter may be even less distinct, with small conules hardly distinguishable from the wrinkles (e.g., AV-MNHN-8 L; Fig. 29C). The hypoconulid is often conical and slightly higher than the posthypocristid and preentocristid (e.g., UM-AV-183). In these cases, it can be displaced distally, the postentocristid and posthypocristid making a $\mathrm{V}$ at their junction (e.g., UM-AV-5910, -5740, and -7654). Other features participate to the lengthening of the $\mathrm{m} 3$ : the mesoconid is strong (UM-AV-183), reinforced by pre- and post- mesoconid swellings (e.g., UM-AV-5669 and -5689); the mesostylid is stretched mesiodistally, as is the case of the preentocristid.
The larger m3 (AV-MNHN-10 L; Fig. 29B) is still more elongated than the other $\mathrm{m} 3$ with its postprotocristid hardly visible, and its metaconid-protoconid width equal to the entoconid-hypoconid width.

\section{Family Plesiarctomyidae nov.}

Type genus. Plesiarctomys Bravard, 1850.

Referred genera. Pseudoparamys Michaux, 1964; Patriarchamys Harrison, 2006.

Remarks. This family, differentiated at the node G (Fig. 4), includes in our analysis two genera corresponding to the

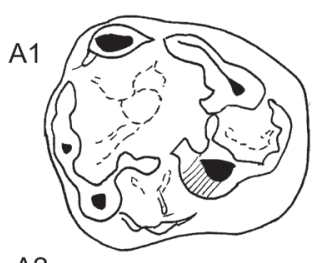

A2
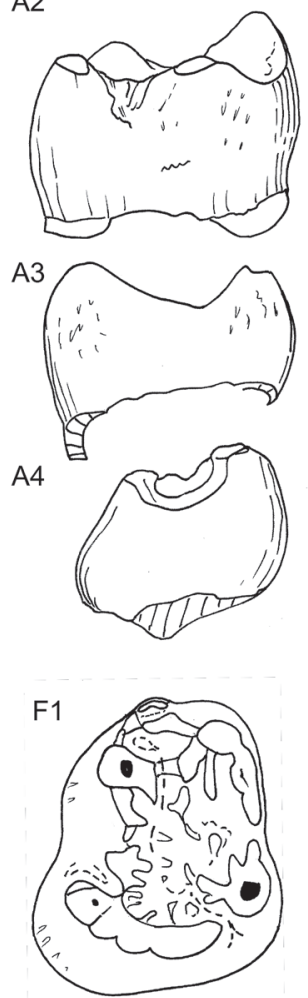

G

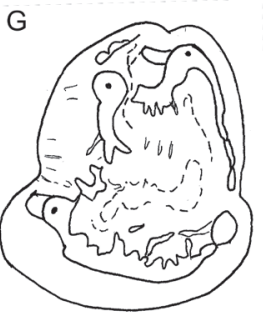

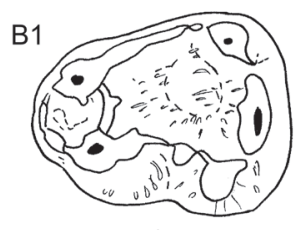

B2

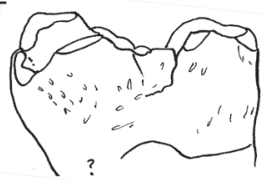

B3

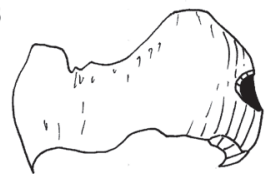

B4

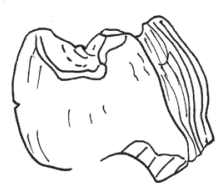

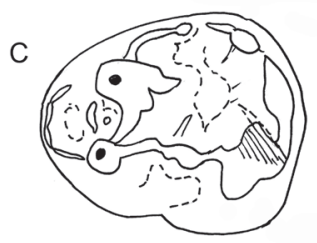

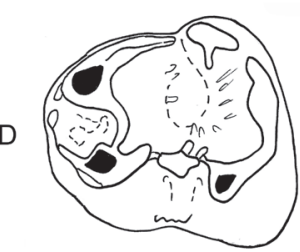

E

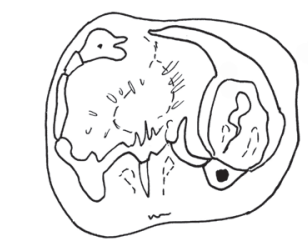

$1 \mathrm{~mm}$

F2
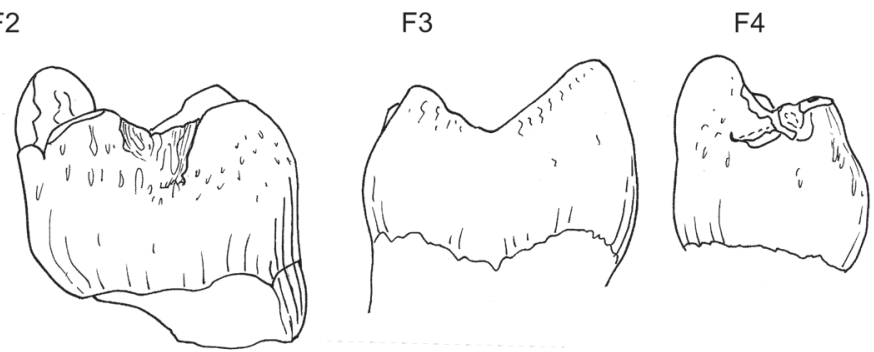

$\mathrm{H}$
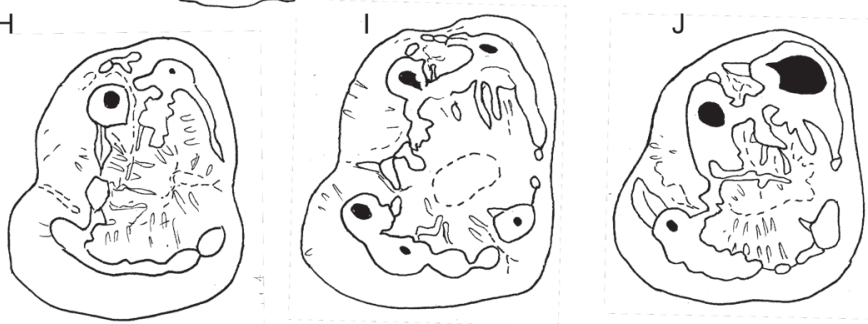

Figure 26. Lower d4 (A-C, E) and p4 (F-J) of Euromys woodi (Michaux, 1964) from Avenay (Ypresian, MP8-9, Bassin de Paris). A. AV-MNHN-857 L, right d4; A1, occlusal view, A2, buccal aspect, A3, lingual aspect, A4, mesial aspect. B. AV-MNHN-263 L, left d4; B1, occlusal view, B2, buccal aspect, B3, lingual aspect, B4, mesial aspect. C. AV-MNHN-4928 L, left d4: occlusal view. D. UM-AV 4587, left d4: occlusal view. E. AV-MNHN-6 L, right d4: occlusal view. F. AVMNHN-295 L, left p4; F1, occlusal view, F2, buccal aspect, F3 lingual aspect, F4, mesial aspect. G. AV-MNHN-153 L, left p4, occlusal view. H. AV-MNHN-184 L, left p4, occlusal view. I. AV-MNHN-64 L, left p4, occlusal view. J. AV-MNHN-828 L, left p4, occlusal view. Scale bar, 1 mm. 

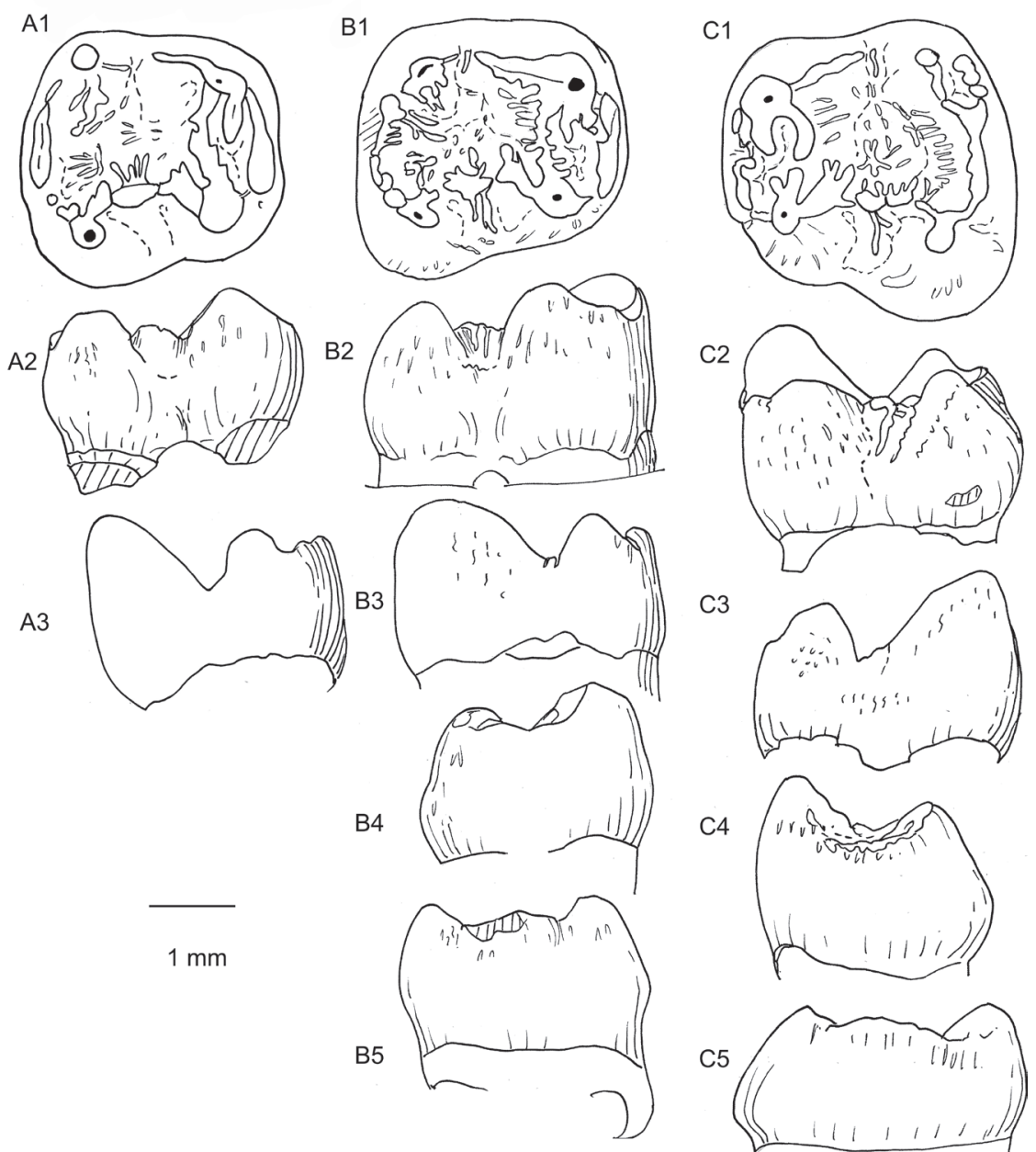

C3
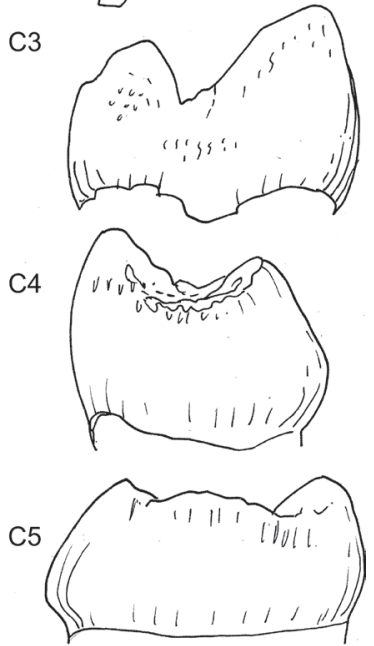

Figure 27. Lower $\mathrm{m} 1$ of Euromys woodi (Michaux, 1964) from Avenay (Ypresian, MP8-9, Bassin de Paris). A. AV-MNHN-01, right m1, Holotype; A1, occlusal view, A2, buccal aspect, A3, lingual aspect. B. AV-MNHN-20 L, right m1; B1, occlusal view, B2, buccal aspect. B3, lingual aspect. B4, mesial aspect. B5, distal aspect. C. AV-MNHN-30 L, left m1; C1, occlusal view, C2, buccal aspect. C3, lingual aspect. C4, mesial aspect. C5, distal aspect. Scale bar, $1 \mathrm{~mm}$. 


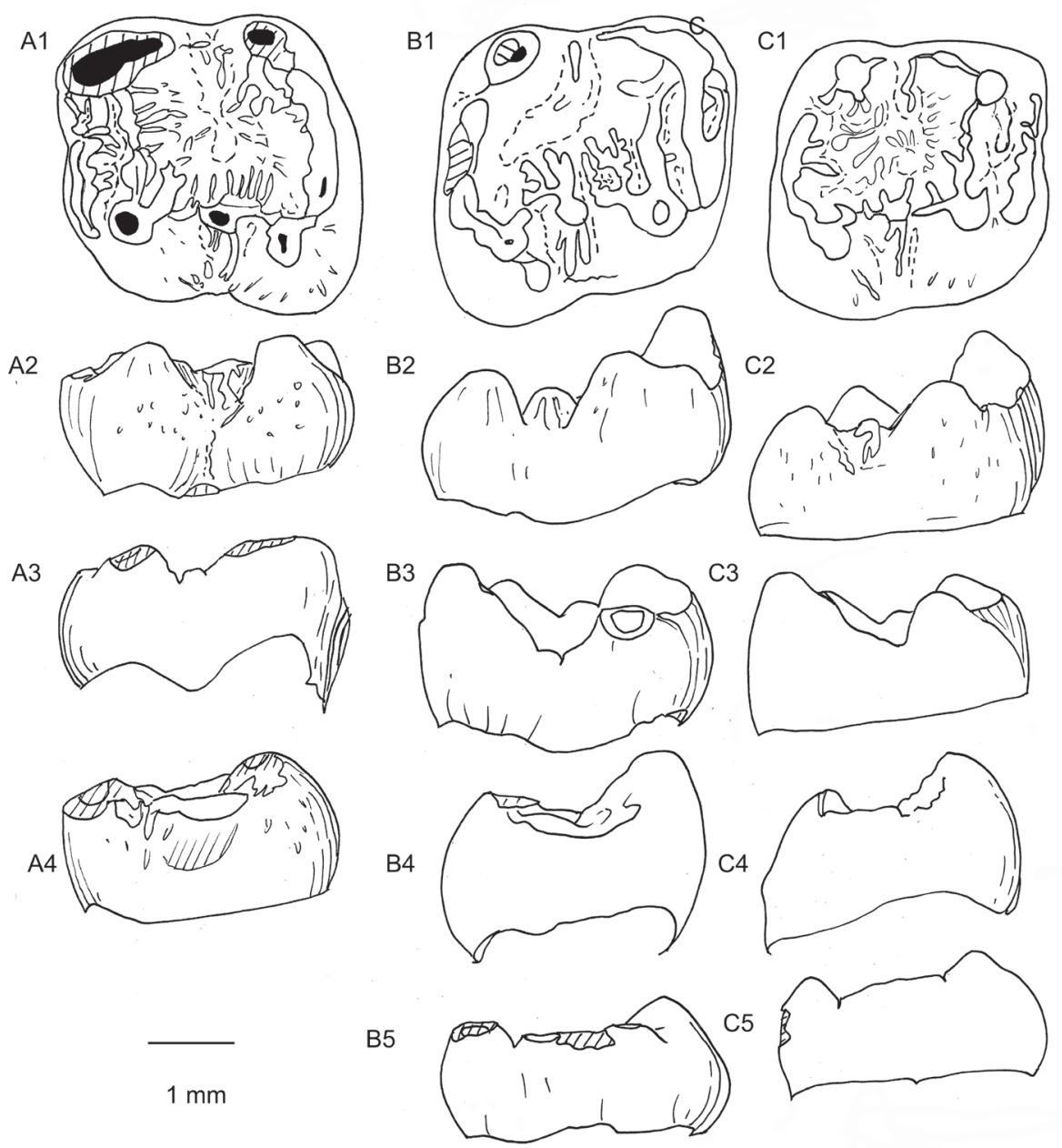

Figure 28. Lower $\mathrm{m} 2$ of Euromys woodi (Michaux, 1964) from Avenay (Ypresian, MP8-9, Bassin de Paris). A. AV-MNHN-55 L, left m2; A1, occlusal view, A2, buccal aspect, A3, lingual aspect, A4, mesial aspect. B. AV-MNHN-364 L, right m2; B1, occlusal view, B2, buccal aspect. B3, lingual aspect. B4, mesial aspect. B5, distal aspect. C. AV-MNHN-305 L, right m2; C1, occlusal view, C2, buccal aspect. C3, lingual aspect. C4, mesial aspect. C5, distal aspect. Scale bar, 1mm. 
A1

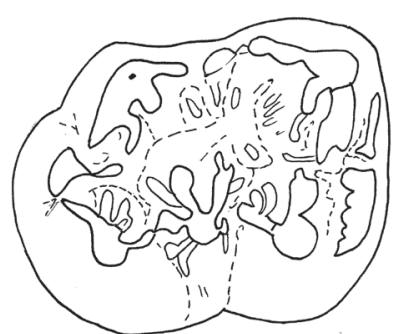

A2

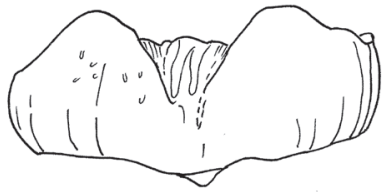

$\mathrm{B} 2$
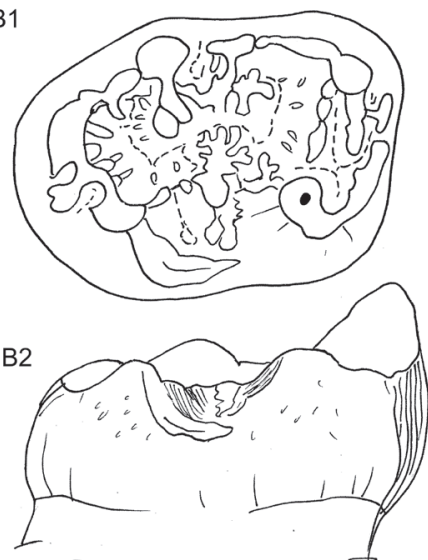

A3

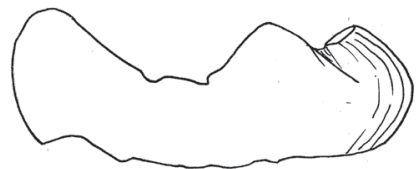

B3

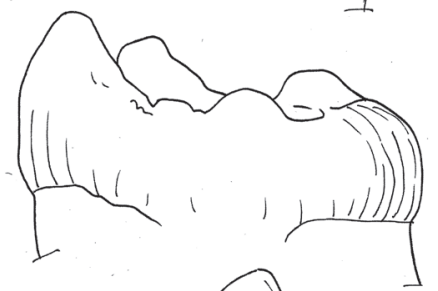

B4

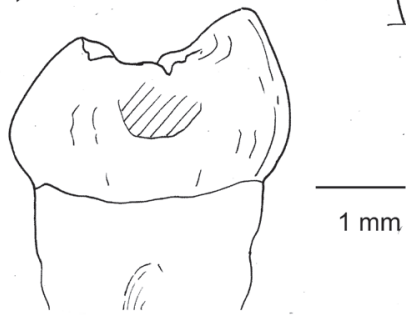

C1

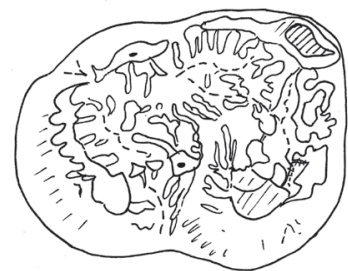

C2

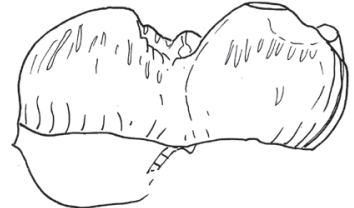

C3

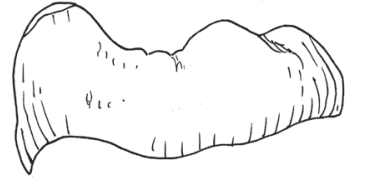

$\mathrm{C} 4$

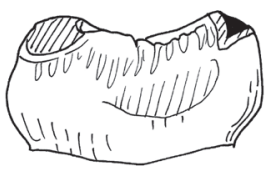

Figure 29. Lower $\mathrm{m} 3$ of Euromys woodi (Michaux, 1964) from Avenay (Ypresian, MP8-9, Bassin de Paris). A. UM-AV 183 BN, right m3; A1, occlusal view, A2, buccal aspect, A3, lingual aspect, A4, mesial aspect. B. AV-MNHN-10 L, right m3; B1, occlusal view, B2, buccal aspect. B3, lingual aspect. B4, mesial aspect. C. AV-MNHN-8 L, right m3; C1, occlusal view, C2, buccal aspect. C3, lingual aspect. C4, mesial aspect. Scale bar, $1 \mathrm{~mm}$.

Pseudoparamys clade (node H, Fig. 4) and the Plesiarctomys clade (node I, Fig. 4). We have not included Patriarchamys Harrison, 2006 in the analyses. We detail here only the late early Eocene species "Paramys" savagei (Michaux, 1964), subsequently identified as Plesiarctomys (Hartenberger, 1975). We transfer the species Plesiarctomys lapicidinarum (Escarguel, 1999: 168) to the genus Pseudoparamys. As a result of our analyses, these genera are no longer included in the Ischyromyidae Manitshinae (Wood, 1970), due to their infraorbitary and dental features, that put them within the basal Theridomorpha.

Diagnosis. Medium-sized to large rodents. Moderate (Plesiarctomys) to large (Pseudoparamys) infraorbitary foramen. In Plesiarctomys: high crowned teeth with stocky main cusps faintly protruding, and teeth tending to develop a pericingulum and pericingulid; for the oldest species cup-like shaped talonid basin with a wide flat floor, and then reduced for the youngest, due to the increasing bulging of the base of the main cuspids. In Pseudoparamys: upper teeth with pre- and post- protocristae aligned mesiodistally, the hypocone smaller than in Plesiarctomys, the endoloph shorter, the ectocingulum less developed, the extra-ridges and wrinkles thinner. On lower teeth, metalophulid I (at least buccal) present and metalophulid II variably developed, trigonid basin cup shaped, with flat floor surrounded by steep edges.

Genus Plesiarctomys Bravard, 1850

Type species. Plesiarctomys gervaisii Bravard, 1850.

Type locality. La Débruge (Vaucluse, near Apt; late Eocene, MP18).

Referred species. Plesiarctomys huerzeleri Wood, 1970; P. spectabilis (Major, 1873); P. hartenbergeri Wood, 1970; P. savagei (Michaux, 1964); P. curranti Hooker, 1986. 
Original diagnosis (from Wood, 1970: 241-242). "Medium to large sized manitshine; cresting of cheek teeth developing progessively within the genus, and more prominent than in any other manitshine except Manitsha; cuspids of lower teeth swelling in talonid basin and reducing size of lingual gorge. P4 small; P3 progressively lost; frequently junction of mesostyle and posterior cingulum lateral to metacone, especially in $\mathrm{P} 4$ and $\mathrm{Ml}$; pulp cavity of incisors tending to be constricted from the sides."

Emended diagnosis (with new dental features). Rodent of medium to large size. Infraorbital foramen weakly to moderately enlarged, more than in Paramys, Ischyromys, Manitsha or Ailuravus.

On upper tooth row, P3 (D3?) present and reduced, to absent. D4 and P4 quite smaller than M1; M2 narrower than M1. On lower tooth row, $\mathrm{d} 4$ and $\mathrm{p} 4$ quite smaller than $\mathrm{m} 1$. Trigonid of $\mathrm{m} 1$ only slightly narrower than the talonid; $\mathrm{m} 2$ slightly larger than $\mathrm{m} 1$, and $\mathrm{m} 3$ a little longer than $\mathrm{m} 2$. Buccal upper cusps and lingual lower cuspids stocky, with wide bases and rising slightly above the edges of the crown. Mesiodistal ridge developed along the apices of main lingual cusp(-id)s of upper and lower teeth. Tendency to develop a pericingulum and pericingulid. Wrinkles always present along the lophs/lophids, and at least on the lingual flank of upper teeth and the buccal flanks of lower teeth.

Upper teeth with protocone - postprotocrista and hypocone aligned and stretched, making a nearly straight mesiodistal crest, only weakly undulating on some teeth at the sinus level; their lingual slope rise vertically at their base, then strongly inclines linguobuccally; sinus generally shallow and very narrow, at the $1 / 3$ to $1 / 2$ upper part of their lingual flank. Anteroloph straight, and lower than the posteroloph and developed from a weak lingual anterostyle to a moderately swollen and linguobuccally stretched parastyle. Parastyle attaches to the preparacrista, and rarely on less specialized species, to a part of the ectocingulum (para-ectocingulum). Protoloph straight buccolingually, bearing a relatively weak paraconule and connecting to the extremity, either of the preprotocrista or of the postprotocrista, or even of the protocone. Postparacrista shallowly depressed by a buccal notch, directed to a more buccal mesostyle; this more or less stretched in mesial and distal small crestids, variably extended to a more (on some M1) or less (on most of M2) developed para-ectocingulum and meta-ectocingulum; short to longer mesoloph present. Premetacrista linked to the mesoloph or to the mesostyle. Metacone more (on M2) or as (on M1) lingual as the paracone, with buccal metaloph parallel to the protoloph, then interrupted frequently at the relatively strong metaconule. Lingual metaloph low and thin, connecting the postprotocrista, the endoloph or rarely the hypocone. Posteroloph always attaches to the hypocone lingually, and to the postmetacrista buccally. D4 with small stretched hypocone, more lingual than the protocone. P4 differs from M1-2 in its much shorter hypocone, the reduction or absence of mesostyle, ectocingulum and mesoloph. M3 basined, with paracone and protocone weakly salient, lengthened mesostyle area, low metacone, short posteroloph, hypocone absent.

Lower teeth has metaconid more salient than the other cuspids, but not much high; metalophulid I the higher lophid; metalophulid II variably present; bottom of the trigonid basin higher than the talonid basin, but lesser and lesser difference from $\mathrm{m} 1$ to $\mathrm{m} 3$. On less specialized species, talonid basin cuplike shaped with enamel covered by thin ridges convergent to its bottom. On more specialized and higher crowned species, talonid reduced by the enlargement of the main cuspids at their base and partly filled with thicker ridges (among them, the more or less continuous entolophid, connected to the mesolophid/ mesoconid) reducing the hollowed basin to a buccolingual gutter. Mesoflexid lingual opening overlying the floor of the talonid basin. Postprotocristid mesiodistally oriented, aligned with the mesial ectolophid, from very low to high. Ectolophid short to very short, with small to reduced mesoconid.

\section{Plesiarctomys savagei (Michaux, 1964)}

Plate 1, Figures 30-34

"Paramys" savagei Michaux, 1964: 153, fig. 1d (Michaux, 1968).

"Paramys" savagei Michaux: Michaux, 1968: 147-148, Pl. 3, figs. 5-6.

Plesiarctomys sp. 2: Wood, 1970: 272, fig. 15.

Plesiarctomys savagei (Michaux, 1964): Hartenberger, 1975: 779.

Plesiarctomys savagei (Michaux, 1964): Escarguel, 1999: 170177.

Holotype. GR-12, right m1-2 (Michaux, 1964: 153, fig. d; and Michaux, 1968: P1. 3, fig. 5).

Type locality. Grauves (= Cuis, Bassin de Paris, late early Eocene, MP10).

Original diagnosis. (Michaux, 1964: 153). "Species close to Paramys woodi, but larger".

Emended diagnosis (Escarguel, 1999: 170-171; translation from French). "Small sized Plesiarctomys. Enamel rough to thinly wrinkled. Cheek teeth relatively more globulous and hypsodont than those of Pl. lapicidinarum. Much reduced P3, but possibly present. p4 trigonid relatively reduced. Lower molars with ectolophid and posterior cingulid well-developed. Mesoconid and hypoconulid generally fused in these ridges. Frequent start of hypolophid. Tendency of lingual mesoflexid opening to disappear. $\mathrm{m} 3$ weakly different from $\mathrm{m} 1-2$. Trigon of M1-2 tending to be U shaped; massive lingual margin; lingual sinus weak to absent; metaconule never connected to the protocone; pericingulum strongly developed, frequently fused to a strong mesostyle".

Remarks. Wood (1970) revised the systematics of middle and late Eocene species of Plesiarctomys. Later, following Hartenberger (1975), Escarguel (1999) included in the genus the species previously described by Michaux as Paramys savagei, on the bases of scarce material from Cuis (Bassin de Paris, late early Eocene, MP10) first on the base of one m1-2 only (Michaux, 1964), then he add one M3 (Michaux, 1968). The type material being scarce, Escarguel added new features from more numerous materials from several late early Eocene localities (Escarguel, 1999: 171; e.g. Saint-Agnan and Prémontré, MP10). As there are specimens better preserved in Prémontré (maxillary and dentary fragments), we use here this material for analysing the variability of this species and emend its diagnosis.

Emended diagnosis (new). Small sized Plesiarctomys (M1: L mean x W mean: $3.018 \mathrm{~mm}$ x $3.769 \mathrm{~mm})$. Plesiarctomys with i.o.f. moderately enlarged (Plate 1A). On upper tooth row, P3 (D3?) present. D4 narrower than $\mathrm{P} 4$, with fused buccal roots, and P4 quite shorter than M1, M2 narrower than M1. On upper teeth, pericingulum incomplete. Hypocone lower and smaller than the protocone. 
On lower tooth row, $\mathrm{d} 4$ narrower than $\mathrm{p} 4$; trigonid of $\mathrm{m} 1$ slightly narrower than the talonid; $\mathrm{m} 2$ slightly larger than $\mathrm{m} 1$, and $\mathrm{m} 3$ slightly longer than $\mathrm{m} 2$. Metaconid markedly higher than the other cuspids on lower teeth. Metalophulid I, incomplete, distinct from the complete metalophulid II. Discontinuous low elements of an entolophid more or less developed and continuous on $\mathrm{d} 4, \mathrm{p} 4$ and $\mathrm{m} 1-\mathrm{m} 2$, and complete on $\mathrm{m} 3$.

Material and measurements (Fig. 30; Table 5). Twenty-one lower teeth and 47 upper teeth are present in the collection (App., S 2); among them only a few have changed from the previous identifications (Escarguel, 1999).

Description. The left hemi-maxillary fragment SLPZ 185 bears M1, the two alveoli of P4 and the alveolus of P3 (or D3) (P1. 1 A2). The infraorbitary foramen is moderately enlarged (P1. $1 \mathrm{~A} 1)$. The main cusps and cuspids weakly stand up from the plane of the grinding surface, and the height of enamel below, all around the crown, is well higher. Even if it is incomplete, a pericingulum tends to develop on upper molars. Until moderate wear of teeth, the enamel is thinly to strongly wrinkled in the flexi, along the lophs-lophids and on enamel slopes of the outskirts of the crown.

Upper teeth. (Figs. 31-32)

D4 (Fig. 31A-B). D4 are quite narrower than P4 and molars, and lower crowned. The anteroloph is long and low, ending lingually at the base of the mesial flank of the protocone, and higher buccally, at the curved parastyle, which merges with the preparacrista. The anteroflexus is longer at its buccal half and shorter lingually. The paracone is stronger than the metacone, which is lingual to it. The protoloph joins the extremity of the preprotocrista; the paraconule is weak. The postparacrista connects to the mesoloph on SLP29PR-1350, and ends free on SLP29PR-2081. The mesostyle, more buccal than the paracone and metacone, is stronger on the first, connected to the metaectocingulum; on the second, it is tiny at the junction between the long para-ectocingulum and meta-ectocingulum. The protocone is obliquely stretched (mesiobuccal to distolingual), and prolonged linguodistally by a short weak hypocone; a weak posterostyle is hardly distinct on SLP29PR-1350, before

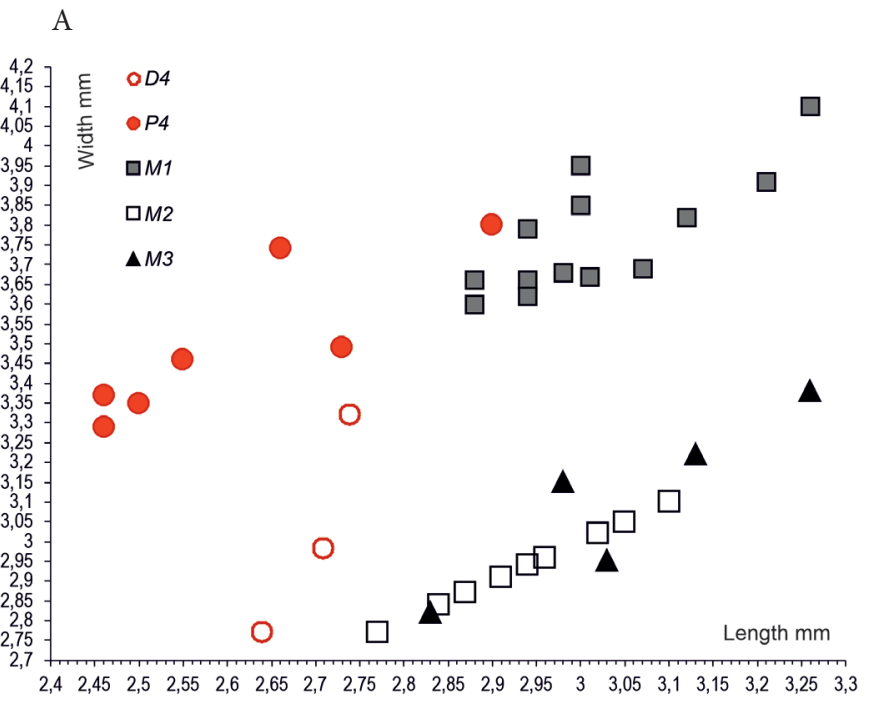

turning to the posteroloph. The latter is continuous to the meta-ectocingulum, their junction being at the contact with the postmetacrista. The metaloph is discontinuous, with two metaconule swellings. Its lingual part links to the hypocone. A mesoloph is not present.

P3 or D3. The alveolus of this tooth is smaller than that of the fused buccal roots of P4 on SLPZ-185 Plate 1, Fig. A2).

$P 4$ (Fig. 31C-E). Eleven P4 have been found in the collection; their size is relatively variable. Three are much smaller (SLP29PR-1105 and two buds), but their features are not very different from the others. The larger (SLP29PR-506) is much worn; it could be a damaged M1. The buccal length is more often the same as the lingual length; two specimens only are slightly wider buccally (SLP29PR-226 and -304). They are shorter than M1. On teeth on which they are preserved, the buccal roots fuse more or less below the cervix. The anteroloph is low and often long, the parastyle indistinct from its buccal extremity; the latter being generally weakly linked to the weak preparacrista $(8 / 10)$. Paracone and metacone are often at the same buccal level; the metacone is rarely lingual to the former. The postparacrista is strong, directed more or less buccally to a minute mesostyle, when present. The latter is isolated and stretched, and sometimes prolonges with the meta-ectocingulum. There is a thin and weak mesoloph ridge only in one case (SLP29PR-226). There are rarely weak and discontinuous elements of a para-ectocingulum. The protoloph is transverse, and connected to the extremity of the preprotocrista; the paraconule is indistinct or slightly swollen and marked by a few extra-ridges. Protocone and hypocone are closely appressed and stretched mesiodistally, the first the longest and slightly higher. The posthypocrista continues via the posteroloph (higher than the anteroloph), which ends at the postmetacrista distal corner, or up to the meta-ectocingulum $(4 / 10)$. The metacone has a premetacrista, symmetrical of the postparacrista on half of the specimens. The metaloph is discontinuous and bears a swollen or crested (one or two ridges) metaconule. The lingual metaloph joins the distal end of the postprotocrista/endoloph.

M1-M2. The M1 are less asymmetrical than that of Ailuravus, the parastyle being less variable and less protruding. The parastyle of M1 is more distinct than on M2.

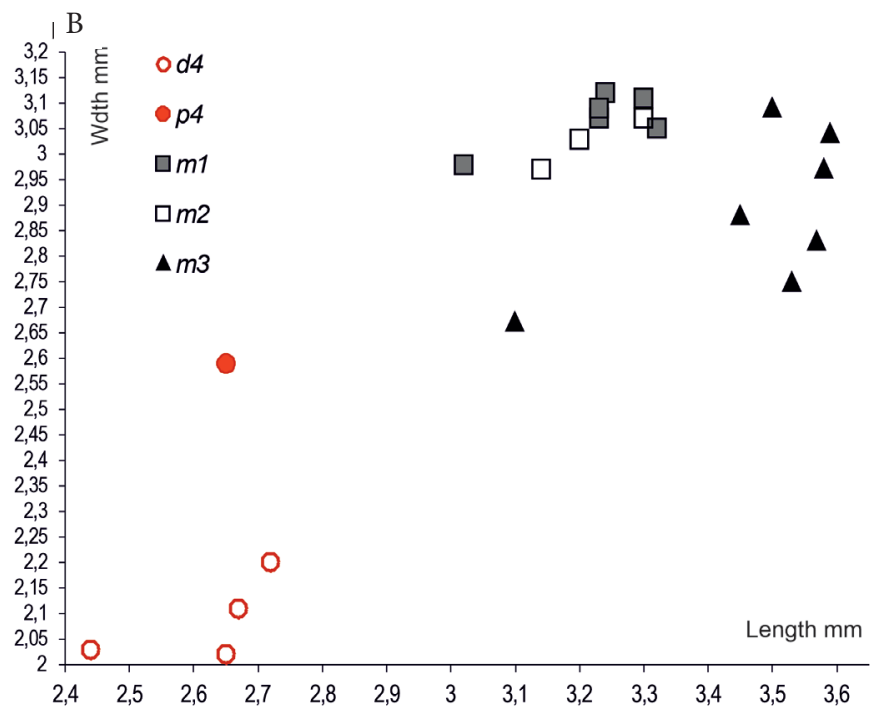

Figure 30. Bivariate graphs (Length x Width) of upper teeth (A) and lower teeth (B) of Plesiarctomys savagei (Michaux, 1964) from Prémontré (late Ypresian, MP10, Bassin de Paris). Graduations as millimetres. 


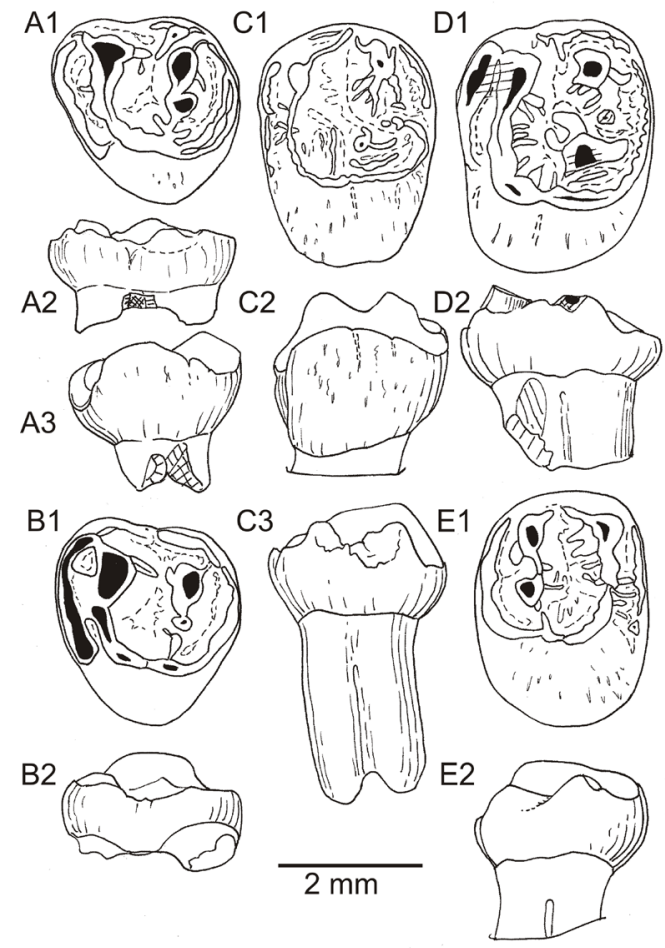

Figure 31. Upper D4 and P4 of Plesiarctomys savagei (Michaux, 1964) from Prémontré (late Ypresian, MP10, Bassin de Paris). A. SLP29PR-1350, left D4; A1, occlusal view, A2, buccal aspect, A3, lingual aspect. B. SLP29PR-2081, left D4; B1, occlusal view, B2, buccal aspect. C. SLPZ-88, left P4; C1, occlusal view, C2, lingual aspect. C3, buccal aspect. D. SLP29PR-226, left P4; D1, occlusal view, D2 buccal aspect. E. SLP29PR-1394, right P4; E1, occlusal view, E2, buccal aspect. Scale bar, $2 \mathrm{~mm}$.
M1 (Fig. 32A-B). The weakly swollen parastyle curves to attach to the thin preparacrista $(9 / 15)$ and the para-ectocingulum $(6 / 15)$. The latter rarely reaches the mesiodistally stretched mesostyle (3/6). This mesostyle is only slightly more buccal than the paracone. The postparacrista is moderately notched buccally, before its junction with the mesostyle; sometimes it joins more lingually the short mesoloph. The faintly elevated mesostyle is extended mesially and distally in more or less long sloping ridges, the distal one being connected to the metaectocingulum on all the teeth. This meta-ectocingulum can be more or less strong. The premetacrista joins either the mesoloph or the mesostyle. The mesoloph is reduced to wrinkles or well distinct, rarely reaching the level of the metaconule.

The anteroloph shows a low weak anterostyle lingually; an antesinus marks its junction with the mesial flank of the protocone. The protoloph generally attaches to the mesial extremity of the preprotocrista (12/15). More rarely, it connects to the protocone more distally, and the extremity of the preprotocrista ends free in the anteroflexus. The paraconule is weakly or not bulged but always bear at least one distomesial short ridge, which can, rarely reach the anteroloph.

The buccal part of the metaloph lowers before joining the moderately bulged metaconule; the latter attaches lowly to the endoloph or to the distal end of the postprotocrista through the thin lingual metaloph. The endoloph is distinct on SLPZ234. The wall made with the protocone + postprotocrista + endoloph + hypocone is stretched mesiodistally, the hypocone being lower and smaller than the protocone. A narrow sinus is weakly marked on the lingual flank, as a cleft in its upper $1 / 3$. The posthypocrista continues without interruption to the posteroloph. The latter merges with postmetacrista at the buccodistal corner of the metacone.

M2 (Fig. 32C-D). The para-ectocingulum is present, but weak and incomplete on 3/11. The meta-ectocingulum is not developed, or much reduced and short. The metacone is more
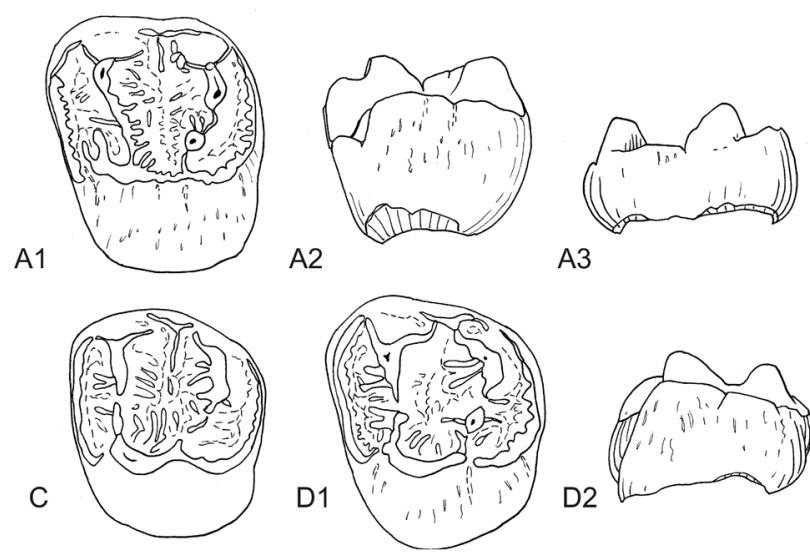

A3
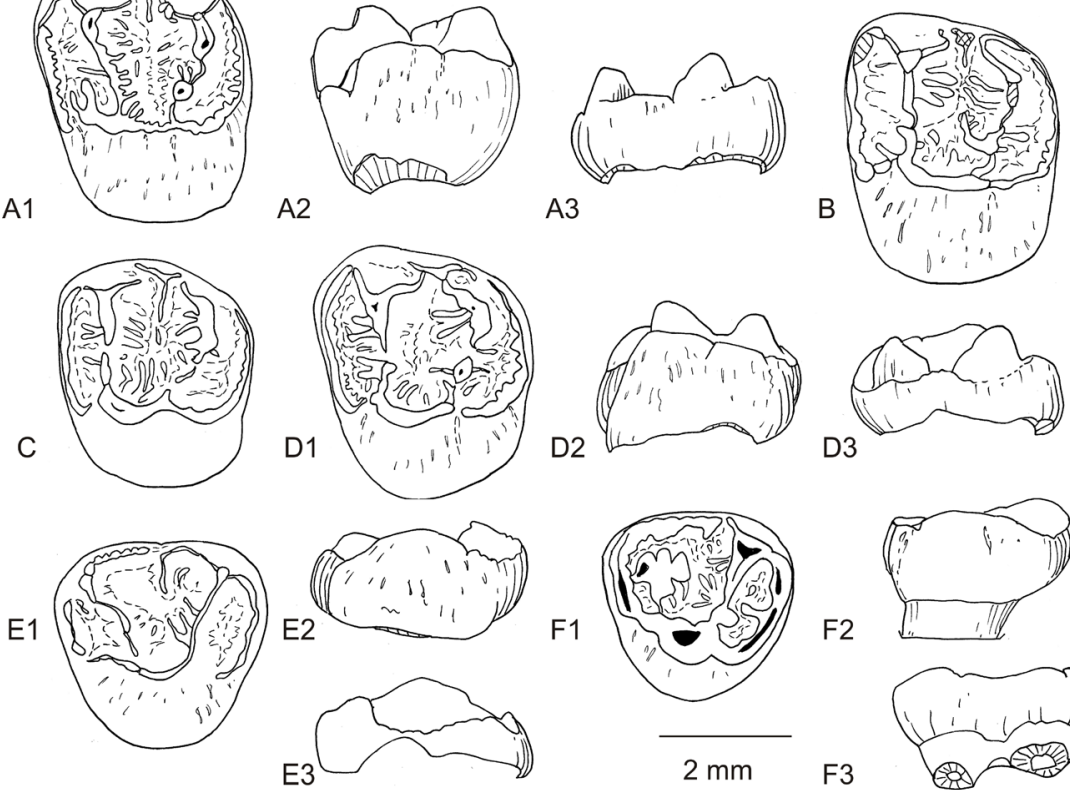

F2

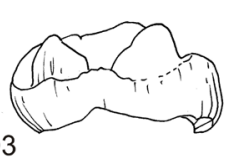

F3

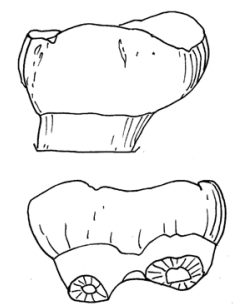

Figure 32. Upper molars of Plesiarctomys savagei (Michaux, 1964) from Prémontré (late Ypresian, MP10, Bassin de Paris). A. SLP29PR-170, left M1; A1, occlusal view, A2, lingual aspect, A3, buccal aspect. B. SLP29PR-1411, left M1: occlusal view. C. SLP29PR-310, left M2: occlusal view. D. SLP29PR-1308, left M2; D1, occlusal view, D2, lingual aspect, D3, buccal aspect. E. SLP29PR-458, right M3; E1, occlusal view, E2, lingual aspect, E3, buccal aspect. F. SLP29PR-852, right M3; F1, occlusal view, F2, lingual aspect, F3, buccal aspect. Scale bar, $2 \mathrm{~mm}$. 
lingual than the paracone, more than on M1; therefore, the posteroloph is shorter, but it reaches the bucco-distal corner of the metacone. The hypocone is shorter and lower than the protocone, which is less elongated than on M1.

M3 (Fig. 32E-F). The M3 are flatter than M1-M2, as long and much narrower. The anteroflexus is well developed as on M1-M2, and underlined lingually by a clear antesinus; the anteroloph links to the preprotocrista. The protocone makes a wide $\mathrm{V}$ with its pre- and post- protocristae, and the protoloph joins the mesial extremity of the preprotocrista. The paraconule is weak to absent, and a preparaconule is once present. The mesostyle is elongated mesiodistally, overlying the basined mesoflexus; it participates with the low crestiform metacone and the short posteroloph in the distal pericingulum. The metaloph is present joining the metacone apex to the distal postprotocrista through the more or less distinct metaconule. The hypocone is indistinct, its position only indicated by a weak sinus.

\section{Lower teeth.}

$d 4$ (Fig. 33A-B). d4 can be recognized by their roots diverging from the base of the crown. The protoconid is present and relatively low, slightly distal from the metaconid on a buccolingual axis. The anterolophid is low and short at the mesial extremity of the preprotocristid, making the front part of the tooth relatively narrow. The metalophulid II is complete, i.e., its buccal part (postprotocristid) and lingual part (oriented obliquely postwards from the metaconid), which close distally the shallow trigonid basin. The long postmetacristid descends gently to a narrow opening of the mesoflexid; however, this opening overlies the floor of the talonid basin. It ends as a tiny mesostylid, except on one. There is a mesiodistal arm of the protoconid starting from the metalophulid II, and in continuity with the mesial ectolophid. The lengthened mesoconid is connected by a very short distal ectolophid to the prehypocristid. A few short ridges are a little stronger than the wrinkles, one at the mesolophid level, from the mesoconid (SLP29PR-1802, SLP43PR-279, and PLPRE-748) or from the prehypocristid (PLPRE-116), and the other from the entoconid as a short low entolophid. The posterior cingulid is continuous from the posthypocristid, oblique, via the buccolingually stretched hypoconulid (the posterolophid is indistinct), and to the postentocristid-entoconid. The pre-entocristid stops at the narrow mesoflexid opening.

p4 (Fig. 33C). Only one worn specimen documents p4. It is relatively short. Its two roots are very close and merged only in their upper and proximal part. Even if worn the metaconid appears clearly higher than the other cuspids, the long postmetacristid descending gently to the shallow and narrow mesoflexid opening. The trigonid basin appears more reduced than on $\mathrm{d} 4$, and the anterolophid is not developed. Mesiodistal wrinkles descend to the floor of the talonid basin; thicker wrinkles fill the basin at the mesolophid and entolophid levels.

m1-m2. m1 (Fig. 34A) differ from $\mathrm{m} 2$ (Fig. 34B-C), mainly in their trigonid faintly narrower than their talonid. The anterolophid is long (shorter on $\mathrm{m} 1$ compared to $\mathrm{m} 2$ ) and nearly straight from the base of a mesial arm of the metaconid (premetacristid) to fuse with a short mesial arm of the protoconid. It appears higher than the posterior lophid. The metaconid is clearly higher than the other cuspids: its postmetacristid descends moderately to a more (e.g., SLPZ7 and SLP29PR-1287) or less (e.g., SLP29PR-329, -760) differentiated mesostylid area. Elements of a metalophulid
I can be present: only a lingual ridge (4/9), with also a low buccal ridge (2/9). The lingual metalophulid I once fuses with the buccal metalophulid II. In the other cases, the buccal and lingual elements of the metalophulid II connects together, or weakly separates. Thin wrinkles descend from it towards the floor of the cup-shaped talonid basin. Like on d4, a mesiodistal postprotocristid descends from the protoconid distal flank to the horizontal, short and low mesial ectolophid, just in front of the mesoconid. It is distinct from the buccal metalophulid II. The mesoconid is slightly swollen or stretched mesiodistally. The distal ectolophid, slightly higher than the mesial one, attaches to the prehypocristid. One or several short mesolophid ridges descend from the ectolophid (mesoconid area to the talonid basin). As on d4 and p4, discontinuous low elements of an entolophid can be more or less developed and continuous. The buccal slope of the shallow sinusid bears wrinkles; one of these wrinkles being stronger along the distal slope of the hypoconid, and one another can make a slender ectomesolophid.

$\boldsymbol{m} 3$ (Fig. 34C-D). $\mathrm{m} 3$ differ from $\mathrm{m} 2$ in their lower trigonid and shorter posterior cingulid. On all, the entolophid is present, directed or attached to the mesolophid. The mesiodistal postprotocristid is less high than on the m1-m2, composed of discontinuous small ridges/granules developed at the base of the distal flank of the protoconid (seen on unworn SLP29PR-975, -1087, -1186, and SLPZ-820).

\section{Genus Pseudoparamys Michaux, 1964}

Type species. Pseudoparamys teilhardi (Wood, 1962).

Referred species. ?Pseudoparamys lapicidinarum (Escarguel,

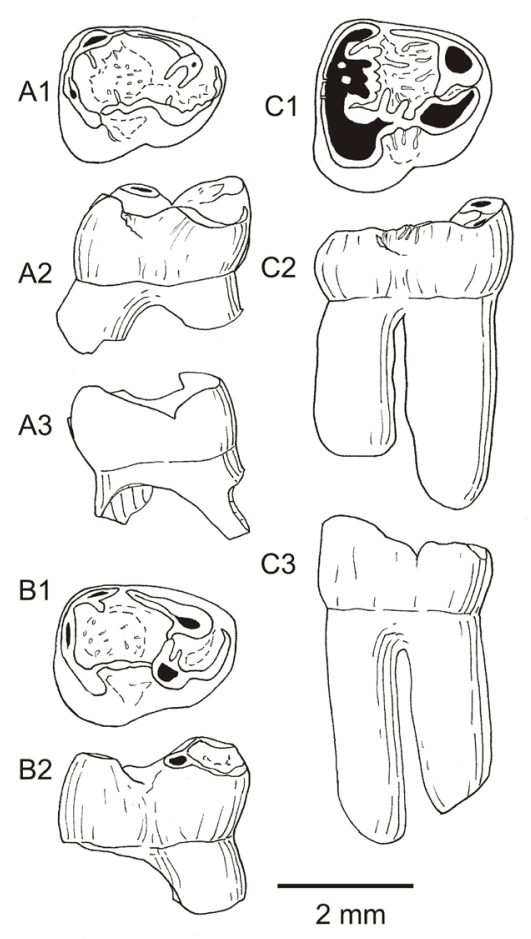

Figure 33. Lower d4 and p4 of Plesiarctomys savagei (Michaux, 1964) from Prémontré (late Ypresian, MP10, Bassin de Paris). A. SLP29PR-1802, right d4; A1, occlusal view, A2, buccal aspect, A3, lingual aspect. B. MSPRE-116, right d4; B1, occlusal view, B2, buccal aspect. C. SLP29PR-1298, right p4; C1, occlusal view, C2, buccal aspect. C3, lingual aspect. Scale bar, 2 mm. 


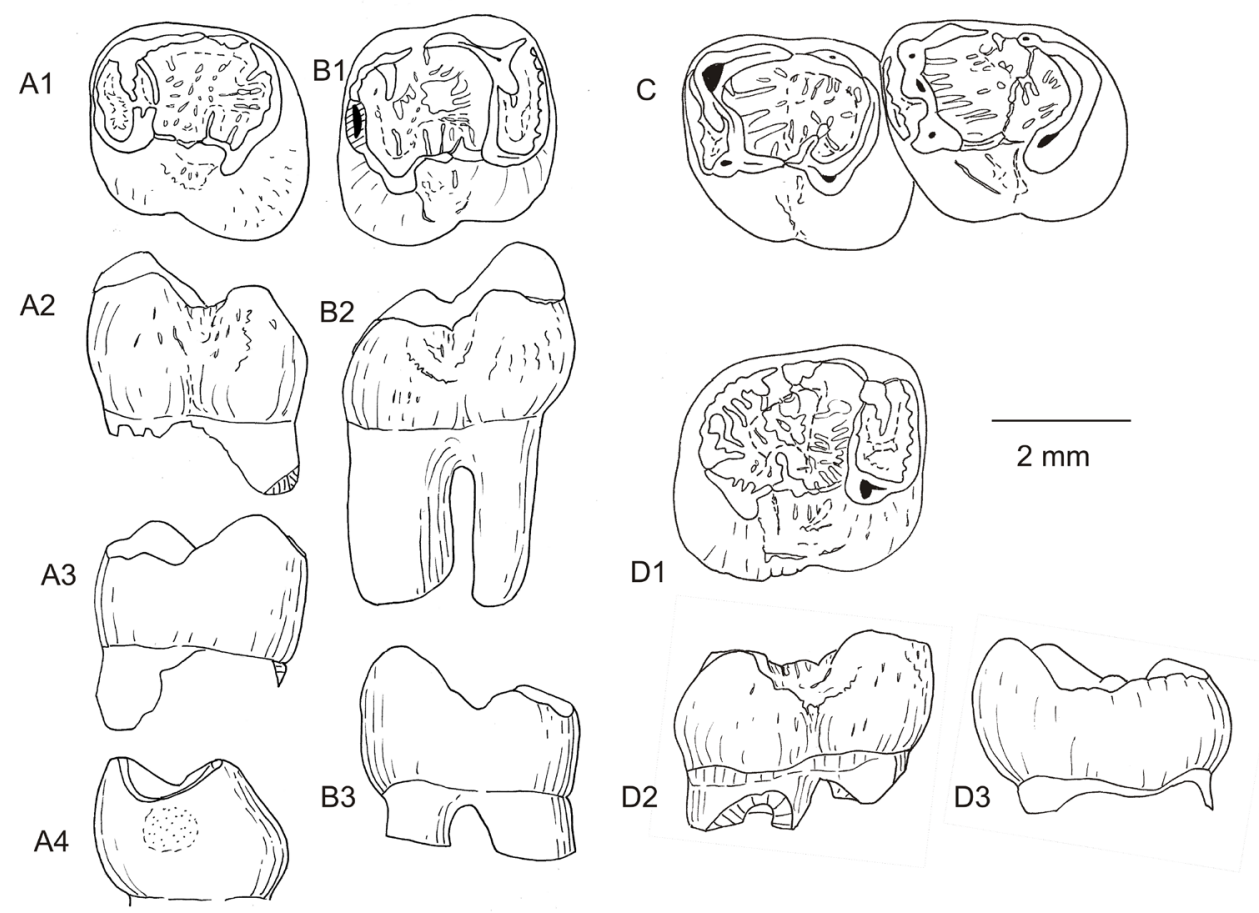

Figure 34. Lower molars of Plesiarctomys savagei (Michaux, 1964) from Prémontré (late Ypresian, MP10, Bassin de Paris). A. SLP29PR-760, left m1; A1, occlusal view, A2, buccal aspect, A3, lingual aspect, A4, mesial aspect. B. SLP29PR-329, right m1; B1, occlusal view, B2, buccal aspect, B3, lingual aspect. C. SLPZ-7, left m2-m3 on a fragment of mandible: occlusal view. D. SLP29PR-1087, right m3; D1, occlusal view, D2, buccal aspect, D3, lingual aspect. Scale bar, $2 \mathrm{~mm}$.

Table 5. Size variations of the different loci of teeth of Plesiarctomys savagei (Michaux, 1964) from Prémontré (MP 10; Bassin de Paris).

\begin{tabular}{cccccc}
\multicolumn{5}{c}{$\begin{array}{c}\text { Plesiarctomys savagei (Michaux, } \\
\text { from Prémontré }\end{array}$} \\
Loci & $\mathrm{n}$ & $\min -\mathrm{max}$ & Length $\mathrm{m} \pm \mathrm{Sm}$ & $\mathrm{sd}$ & $\mathrm{v}$ \\
$\mathrm{D} 4$ & 3 & $2.64-2.74$ & $2.697 \pm 0.029$ & 0.0513 & 1.90 \\
$\mathrm{P} 4$ & 8 & $2.16-2.90$ & $2.553 \pm 0.077$ & 0.2197 & 8.61 \\
$\mathrm{M} 1$ & 13 & $2.88-3.26$ & $3.018 \pm 0.032$ & 0.1180 & 3.91 \\
$\mathrm{M} 2$ & 9 & $2.84-3.04$ & $2.94 \pm 0.035$ & 0.1056 & 3.59 \\
$\mathrm{M} 3$ & 5 & $2.83-3.26$ & $3.046 \pm 0.072$ & 0.1613 & 5.30 \\
$\mathrm{~d} 4$ & 4 & $2.44-2.72$ & $2.62 \pm 0.061$ & 0.1236 & 4.72 \\
$\mathrm{p} 4$ & 1 & 2.65 & - & - & - \\
$\mathrm{m} 1$ & 6 & $3.02-3.32$ & $3.223 \pm 0.043$ & 0.1067 & 3.31 \\
$\mathrm{~m} 2$ & 3 & $3.14-3.30$ & $3.213 \pm 0.046$ & 0.0808 & 2.51 \\
$\mathrm{~m} 3$ & 7 & $3.10-3.59$ & $3.474 \pm 0.065$ & 0.1723 & 4.96 \\
$\mathrm{~L}$ Loci & $\mathrm{n}$ & $\min -\mathrm{max}$ & Width $\mathrm{m} \pm \mathrm{Sm}$ & $\mathrm{sd}$ & $\mathrm{v}$ \\
$\mathrm{D} 4$ & 3 & $2.77-3.32$ & $3.023 \pm 0.160$ & 0.2775 & 9.18 \\
$\mathrm{P} 4$ & 8 & $3.07-3.80$ & $3.446 \pm 0.083$ & 0.2374 & 6.89 \\
$\mathrm{M} 1$ & 13 & $3.60-4.10$ & $3.769 \pm 0.041$ & 0.1501 & 3.98 \\
$\mathrm{M} 2$ & 9 & $3.30-3.87$ & $3.532 \pm 0.035$ & 0.1657 & 4.69 \\
$\mathrm{M} 3$ & 5 & $2.82-3.38$ & $3.104 \pm 0.099$ & 0.2214 & 3.10 \\
$\mathrm{~d} 4$ & 4 & $2.02-2.20$ & $2.09 \pm 0.041$ & 0.0837 & 4.00 \\
$\mathrm{p} 4$ & 1 & 2.59 & - & - & - \\
$\mathrm{m} 1$ & 6 & $2.98-3.12$ & $3.07 \pm 0.020$ & 0.0510 & 1.66 \\
$\mathrm{~m} 2$ & 3 & $2.97-3.07$ & $3.023 \pm 0.029$ & 0.0503 & 1.66 \\
$\mathrm{~m} 3$ & 7 & $2.75-3.09$ & $2.89 \pm 0.057$ & 0.1531 & 5.30
\end{tabular}

1999). ?Pseudoparamys ageiensis 'Michaux, 1968)

Original diagnosis (Michaux, 1964: 154; translation from French): "P3 absent, P4 small, upper molars nearly bilophodont, protoloph and metaloph nearly parallel; lower molars with posterior cingulid fully continuous with the entoconid."

Emended diagnosis (Michaux, 1968: 149; translation from
French): "Paramyidae of relatively small size: P3 absent, P4 compressed mesiodistally, upper molars nearly bilophodont, protoloph and metaloph nearly parallel. Lower teeth with developed anterior cingulid, talonid and trigonid basins not widely communicating, mesoconid lengthened transversely, posterior cingulid continuous with the entoconid."

Emended diagnosis (Escarguel, 1999; translation from French). "Small to medium sized Pseudoparamyinae. P3 much reduced to absent; lower and upper $\mathrm{p} 4 / \mathrm{P} 4$ compressed anteroposteriorly. Upper molars with protoloph and metaloph developed and nearly parallel; with strong metaconule and mesostyle. Lower molars with trigonid relatively compressed mesiodistally; developed anterior cingulum and trend to a posterior closing of the talonid basin; mesoconid stretched transversely; strong posterior cingulid; trend to a fusion of the hypoconulid within the posterolophid."

Remarks. Aside the type species Pseudoparamys teilhardi from Mutigny, several species have been ascribed more or less formally to Pseudoparamys: P. cezannei Hartenberger, 1987, from Palette; P. ageiensis (Michaux, 1968) from Avenay; genus Pseudoparamys from Dormaal (cited in Hartenberger, 1987); Pseudoparamys sp. C and cf. Pseudoparamys from Dormaal (Smith, 1999). This genus appears as a "catch-all" including not only the type species teilhardi, with peculiar specialized features on both upper and lower teeth, but also many early Eocene forms sharing only a continuous, higharcuate posterolophid from the hypoconid to the entoconid, with the hypoconulid poorly individualized. This character is also present in some other lower crowned species, e.g., some species of Paramys, or the species cardosoi from Silveirinha here referred to Ailuravus.

For these reasons, we consider only the type species of the genus; another is questionably referred to this genus 
(?Pseudoparamys lapicidinarum). The species ageiensis must be more extensively revised to support the taxonomic homogeneity of the teeth referred to the material from Avenay; but it shows marked differences with $P$. teilhardi and possibly would be referred to another genus.

Emended diagnosis (new). Plesiarctomyidae with strongly enlarged infra-orbitary foramen, at least for $P$. teilhardi. Enamel on the surroundings of the crown rough to smooth. On upper teeth: parastyle, mesostyle and ectocingulum elements (para-, meso- and/or meta- ectocinguli) more or less developed. On upper molars, hypocone smaller than the protocone and only slightly stronger than the anterostyle; pre- and post- protocristae aligned mesiodistally. Protocrista absent or reduced to a spur. Antesinus and sinus weakly marked or absent; protoloph and metaloph parallel. On lower p4, protoconid variably developed to absent; on lower molars deep cup-like shaped talonid, with flat floor. Lower molars with three high and narrow more or less continuous lophids (premetacristid + anterolophid, metalophulid I, and "posterocingulid"); entolophid absent. Entoconid lower than the metaconid, separated from the mesostylid extremity of the postmetacristid (V opening of the mesoflexid). From the apex of the protoconid, high and short oblique postprotocristid, sloping towards the talonid basin, until the broken and very short mesial ectolophid; strong mesoconid and short distal ectolophid linked to the prehypocristid; "Posterocingulid" continuous from the hypoconid to the crestiform entoconid, and hypoconulid indistinct; Entolophid absent; "Posterocingulid" (composite lophid, including the posthypocristid, the hypoconulid and the posterolophid) wider than the trigonid on $\mathrm{m} 3$.

\section{Differential diagnosis.}

Differs from Meldimys:

- In having upper teeth without strong protocrista, molars with smaller protocone and less salient paracone and metacone, postparacrista and premetacrista less directed buccally (at least nearly mesiodistal);

- In having lower molars with more concave basin, with flat floor, slender and higher lophids (anterolophid, metalophulid I, and "posterocingulid") and shorter postprotocristid, higher and stronger mesoconid, higher and stronger postmetacristid, the entolophid always absent, the weakness of the hypoconulid, not salient.

Differs from Plesiarctomys savagei:

- In having upper teeth with relatively smaller hypocone, more reduced endoloph, ectocingulum less developed, extra-ridges and wrinkles thinner.

- In having lower teeth with metalophulid I (at least buccal part) present, and metalophulid II absent; oblique postprotocristid directed/connected to the mesial ectolophid present; stronger mesoconid.

\section{Pseudoparamys teilhardi (Wood, 1962)}

App., S 1; Figures 35-40

Pseudoparamys lemoinei Teilhard de Chardin, 1922, pl.4, fig. 9.

Paramys teilhardi Wood 1962, fig. 21K-N.

Pseudoparamys teilhardi (Wood); in Michaux, 1964.

Pseudoparamys teilhardi (Wood); in Michaux, 1968 (Fig. 2a-c; pl. 4, figs. 1-11; pl. 5, figs. 1-2).

Pseudoparamys teilhardi (Wood) in Escarguel, 1999 (Pl. 12, 13 and 14 pro parte).
Holotype. Lower left m1-2; fig. 21K, Wood, 1962; pl. 4, fig. 9, Teilhard de Chardin, 1922.

Type locality. An "early Eocene unknown locality, close to Reims and Epernay" (France; Michaux, 1968). Therefore, as the material of the Lemoine collection was scarce (Teilhard de Chardin, 1922; Wood, 1962: 63, fig. 21), Michaux (1964) described the genus Pseudoparamys first briefly on the base of the original assemblage. Then, he precised the description with more details from the assemblage from Mutigny and Avenay (Michaux, 1968: 150-154), in which the dental features correspond to those of the six original teeth.

Original diagnosis. (Wood, 1962: 63). "Size small, lower tooth row with an alveolar length of $9 \mathrm{~mm}$. Anterior cingulid of lower molars forming prominent boundary of trigonid basin; broad interconnection in unworn teeth between trigonid and talonid basins; mesoconid elongated transversely; posterior cingulid continuous with entoconid."

Emended diagnosis. (Escarguel, 1999: 159; translation from French). "Medium sized Pseudoparamyinae; globular cheekteeth with well-developed ridges; enamel surface more and more irregular from front to rear; P3 reduced to absent; P4 and p4 strongly compressed mesiodistally. Upper molars with strong lingual margin, including protocone and hypocone. Protoloph and metaloph nearly parallel; well-developed metaconule and mesostyle. Trigonid of p4 strongly reduced. Enamel fold sloping from the metaconid to the talonid basin always present. Lower teeth with short trigonid; trigonid basin closed with generally complete anterolophid and metalophulid II (?); metalophulid I present and generally well-developed; strong mesoconid, relatively well-isolated, tending to be stretched transversely. Posterocingulid massive, in which the hypoconulid is rarely distinct, except on $\mathrm{m} 3$."

Emended diagnosis (new). Medium sized rodent (M1: L mean X W mean, from Mutigny, $2.119 \mathrm{~mm}$ x $2.625 \mathrm{~mm}$; from Avenay: $1.998 \mathrm{~mm}$ x $2.380 \mathrm{~mm}$ ) (Table 6). Pseudoparamys with strongly enlarged infra-orbitary foramen. Rough enamel on the surroundings of the crown; thinly wrinkled along the loph(-id)s and on the flexus surfaces, converging in the talonid basin.

Upper teeth. Lingual flank of the crown relatively high. (D3)P3 reduced. D4 smaller than molars. P4 narrow mesiodistally, with one buccal root and one lingual. D4 and molars with parastyle, mesostyle and ectocingulum elements (para-, meso- and/or meta- ectocinguli) more or less developed; postparacrista and premetacrista present.

Lower teeth. $\mathrm{d} 4$ and $\mathrm{p} 4$ smaller than molars, protoconid present on p4 and d4. Stubby (short and relatively wide) p4 with protoconid present, lower than the metaconid. Short trigonid on lower molars. Deep cup- shaped talonid with flat floor of the basin. Lingual metalophulid always present, composed of three elements from the metaconid apex; the premetacristid sloping to the transverse anterolophid, one distal (classical metalophulid I) joining the buccal metalophulid and generally one intermediate, more or less short; buccal metalophulid I transverse buccolingually, attached to the apex of the protoconid, always present. Stong mesoconid, short mesolophid often present and ectomesolophid; "Posterocingulid" wider than the trigonid on $\mathrm{m} 3$.

Material. We have observed the material stored in the UMcollections and some casts of the teeth figured in Michaux (1968: 164, pl. 4, figs.1-8 for Mutigny and figs. 9-11, pl. 5, fig. 1 for Avenay) and some stored in the collections of the MNHN (see App. S 1). 
Measurements. (S1, Table 6) Taking into account the previous measurements (Escarguel, 1999: 311), the distribution (Length $\mathrm{x}$ width) of the teeth from Avenay is less homogeneous than for Mutigny. It is due to the inclusion of specimens previously (Michaux, 1968) referred to another species, P. ageiensis, and to some misidentifications (i.e., a few teeth are rather Meldimys than Pseudoparamys). The Table S1 (sup data) provides new distribution of these specimens from Avenay between $P$. teilhardi, $P$. ageiensis and Meldimys.

The size distribution of $P$. teilhardi from Avenay is not much different from that of Mutigny, the M1 from Mutigny only are significantly larger than the M1 from Avenay (Table 6) (Fig. 35A-B). The unique D4 from Mutigny is quite shorter and narrower than the molars, whereas the size of the unique D4 from Avenay is not much different than the size of molars. If the P4 are clearly shorter than the molars, their width is not much less. In both localities, M1, M2 and M3 have close lengths. Two M1 from Mutigny are wider than all the other teeth. In both localities, $\mathrm{p} 4$ are wider than $\mathrm{d} 4, \mathrm{~m} 1$, and $\mathrm{m} 2$ are wider than $\mathrm{m} 1 ; \mathrm{m} 3$ are generally markedly longer than $\mathrm{m} 1$ and $\mathrm{m} 2$.

\section{Description.}

Maxillary features. See Michaux (1968: 150-151) for Mutigny: The infraorbitary foramen is enlarged: "... The root of the zygomatic arch is rather thick antero-posteriorly. On it lower surface, the insertion traces of the masseter are clearly visible. If it is not possible to determine the exact shape of the infraorbitary foramen, it is possible to say that it was quite wide transversely: the lower edge, which is the only one visible, has a large radius of curvature. The infraorbital foramen of a paramyine, on the other hand, has its major axis directed obliquely, the lower edge having a small radius of curvature." (Translated from Michaux, 1968: 150).

Upper teeth. (Figs 36-37, for Mutigny, and Fig. 40A-H, for Avenay)

D4. Among the four D4 from Mutigny measured by Escarguel (1999: 302), we have observed only one unworn D4 (Fig. 36A). The crown alone is present: the roots are absent. The anteroloph, lower than the protocone and its arms, begins lingually by a tiny anterostyle; it is slender and straight then curves to the weakly swollen parastyle, joining buccally a para-ectocingulum, weakly separated from the mesiodistally stretched mesostyle, prolonged mesially and distally in a mesoectocingulum; the latter ends on the middle of the buccal side of the metacone. The paracone is stronger than the metacone, both being conical. The postparacrista is strong, ending at the opening of the mesoflexus. The buccal protoloph is thin and joins the paraconule, which is only faintly protruding, and slightly weaker than the metaconule; both conules are conical. The lingual protoloph connects to the mesial extremity of the preprotocrista. The protocone and its arms (pre- and postprotocristae) are aligned mesiodistally.

The premetacrista is weak, and there is a weak and short postmetacrista. The buccal metaloph is parallel to the protoloph and joins the conical metaconule. The lingual

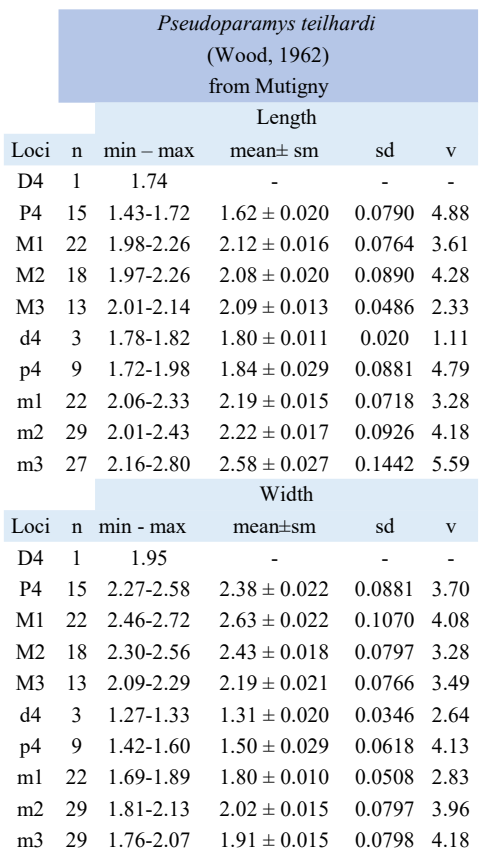

\begin{tabular}{|c|c|c|c|c|c|}
\hline \multirow{2}{*}{\multicolumn{5}{|c|}{$\begin{array}{l}\text { Pseudoparamys teilhardi } \\
\text { (Wood, 1962) } \\
\text { from Avenay }\end{array}$}} & \multirow{3}{*}{$P$ value } \\
\hline & & & & & \\
\hline $\mathrm{n}$ & $\min -\max$ & mean $\pm \mathrm{sm}$ & sd & $\mathrm{v}$ & \\
\hline 1 & 1.99 & - & - & - & $\mathrm{x}$ \\
\hline 7 & $1.54-1.90$ & $1.71 \pm 0.060$ & 0.1591 & 9.30 & n.s. \\
\hline 9 & $1.77-2.24$ & $2.00 \pm 0.058$ & 0.1764 & 8.83 & $<0.01$ \\
\hline 11 & $1.85-2.25$ & $2.12 \pm 0.033$ & 0.1119 & 5.29 & n.s. \\
\hline 4 & $1.91-2.15$ & $2.09 \pm 0.058$ & 0.1179 & 5.65 & n.s. \\
\hline 2 & $1.61-1.69$ & $1.65 \pm 0.04$ & 0.5656 & 34.28 & n.s. \\
\hline 7 & $1.65-1.94$ & $1.83 \pm 0.039$ & 0.1056 & 5.76 & n.s. \\
\hline 11 & $1.83-2.26$ & $2.23 \pm 0.037$ & 0.0864 & 3.87 & n.s. \\
\hline 12 & $2.12-2.35$ & $2.23 \pm 0.025$ & 0.0864 & 3.87 & n.s. \\
\hline 15 & $2.09-2.76$ & $2.46 \pm 0.054$ & 0.2120 & 8.63 & $<0.05$ \\
\hline $\mathrm{n}$ & $\min -\max$ & $\begin{array}{l}\text { Width } \\
\text { mean } \pm \text { sm }\end{array}$ & sd & $\mathrm{v}$ & \\
\hline 1 & 1.99 & - & - & - & \\
\hline 7 & $1.54-1.90$ & $2.33 \pm 0.044$ & 0.1166 & 5.00 & n.s. \\
\hline 9 & $1.77-2.24$ & $2.38 \pm 0.075$ & 0.2271 & 9.54 & $<0.01$ \\
\hline 11 & $1.85-2.25$ & $2.40 \pm 0.045$ & 0.1509 & 6.29 & n.s. \\
\hline 4 & $1.91-2.15$ & $2.26 \pm 0.042$ & 0.8505 & 37.72 & n.s. \\
\hline 2 & $1.30-1.30$ & $1.30 \pm 0$ & 0.0000 & 0.00 & n.s. \\
\hline 7 & $1.35-1.62$ & $1.49 \pm 0.049$ & 0.1302 & 8.71 & n.s. \\
\hline 11 & $1.59-1.91$ & $1.74 \pm 0.031$ & 0.1034 & 5.94 & n.s. \\
\hline 12 & $1.84-2.25$ & $2.01 \pm 0.031$ & 0.1095 & 5.45 & n.s. \\
\hline 15 & $1.72-2.14$ & $1.89 \pm 0.030$ & 0.1175 & 6.23 & n.s. \\
\hline
\end{tabular}

Table 6. Size variations of the different loci of teeth of Pseudoparamys teilhardi (Wood, 1962) from Avenay (MP 8-9; Bassin de Paris) and Mutigny (MP 8-9; Bassin de Paris). Comparisons of the size (Length $\mathrm{x}$ Width) of the different loci of teeth of this species from the two localities through ANOVAs, in association with a test $\mathrm{F}$ of significance $(\mathrm{P}<$ $0.01)$. Size variations of Pseudoparamys ageiensis (Michaux, 1964) from Avenay.

\begin{tabular}{cccccc|cccccc}
\multicolumn{10}{c}{ Pseudoparamys ageiensis (Michaux, 1964) from Avenay (Bassin de Paris) } \\
Loci & $\mathrm{n}$ & $\min -\mathrm{max}$ & $\begin{array}{c}\text { Length } \\
\text { mean } \pm \mathrm{sm}\end{array}$ & $\mathrm{sd}$ & $\mathrm{v}$ & $\mathrm{n}$ & $\min -\max$ & $\begin{array}{c}\text { Width } \\
\text { mean } \pm \mathrm{sm}\end{array}$ & $\mathrm{sd}$ & $\mathrm{v}$ \\
$\mathrm{D} 4$ & 0 & - & - & - & - & 0 & - & - & - & $\mathrm{x}$ \\
$\mathrm{P} 4$ & 1 & 1.44 & - & - & - & 1 & 1.92 & - & - & $\mathrm{x}$ \\
$\mathrm{M} 1$ & 2 & $1.93-2.04$ & $1.985 \pm 0.55$ & 0.0778 & 3.92 & 2 & $2.23-2.34$ & $2.285 \pm 0.055$ & 0.0778 & 3.40 \\
$\mathrm{M} 2$ & 2 & $1.71-1.95$ & $1.83 \pm 0.20$ & 0.1697 & 9.27 & 2 & $2.14-2.30$ & $2.22 \pm 0.080$ & 0.1131 & 5.09 \\
$\mathrm{M} 3$ & 3 & $2.21-2.30$ & $2.267 \pm 0.028$ & 0.0493 & 2.17 & 3 & $2.13-2.34$ & $2.253 \pm 0.063$ & 0.1097 & 4.87 \\
$\mathrm{~d} 4$ & 0 & - & - & - & - & 0 & - & - & - & $\mathrm{x}$ \\
$\mathrm{p} 4$ & 0 & - & - & - & - & 0 & - & - & - & $\mathrm{x}$ \\
$\mathrm{m} 1$ & 2 & $1.87-2.06$ & $1.965 \pm 0.095$ & 0.1344 & 6.84 & 2 & $1.55-1.70$ & $1.625 \pm 0.075$ & 0.1061 & 6.53 \\
$\mathrm{~m} 2$ & 1 & 1.92 & - & - & - & 1 & 1.70 & - & - & $\mathrm{x}$ \\
$\mathrm{m} 3$ & 4 & $2.18-2.44$ & $2.340 \pm 0.056$ & 0.1120 & 4.79 & 4 & $1.64-1.82$ & $1.720 \pm 0.041$ & 0.0812 & 4.72
\end{tabular}



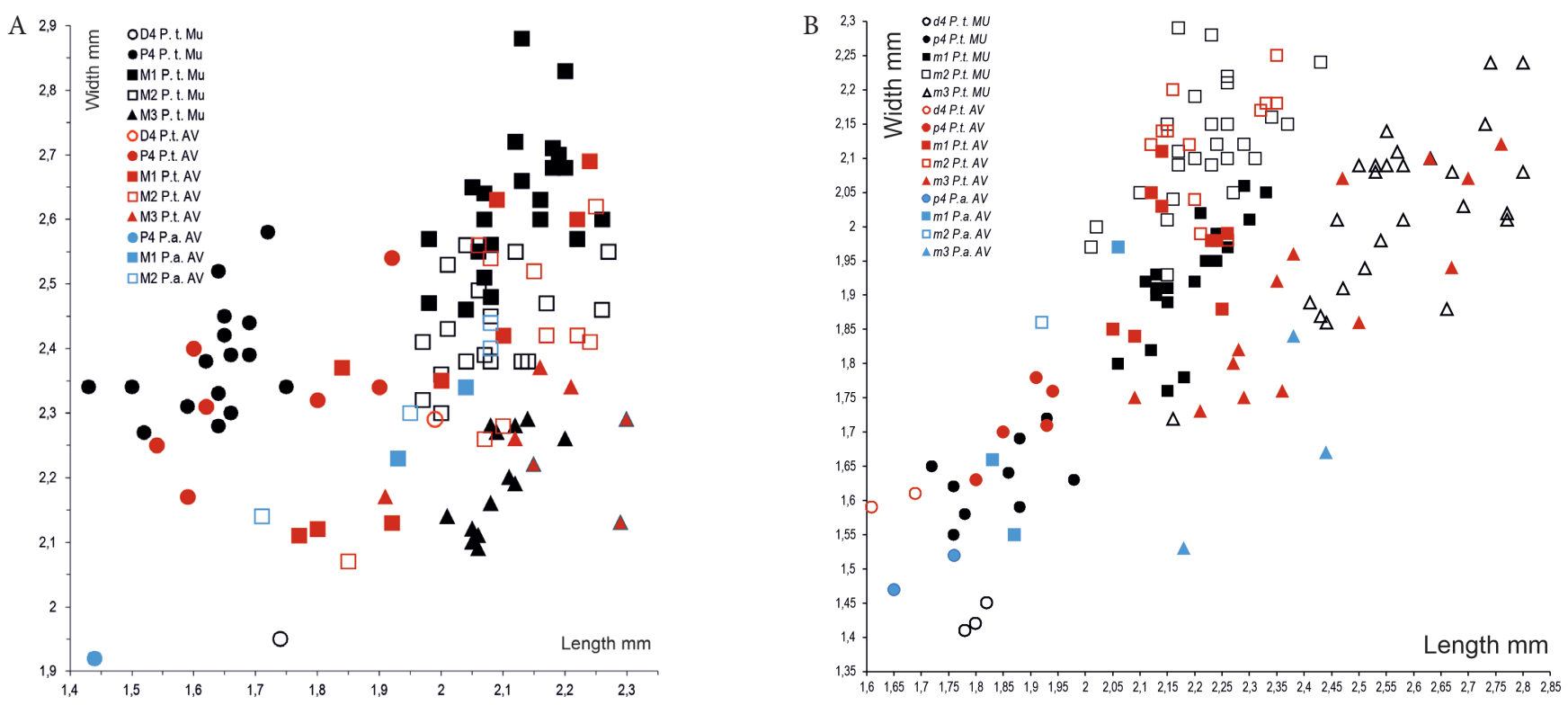

Figure 35. Bivariate graphs (Length $x$ Width) of upper teeth (A) and lower teeth (B) of Pseudoparamys teilhardi (Wood, 1962) from Mutigny (black plots) and Avenay (red plots), and Pseudoparamys ageiensis from Avenay (blue plots) (middle Ypresian, MP8-9, Bassin de Paris). Graduations as millimeters.

metaloph connects to the distal end of the postprotocrista. The small hypocone is slightly distal to that; it is higher than the anterostyle and posteroloph, and lower than the protocone. The posteroloph is thin and long, up to the mesiobuccal side of the metacone. The mesoflexus is wide, and bordered with very weak undulations, hardly distinct at the base of the buccal protoloph and metaloph.

The weakly worn UM-AV-107 tooth from Avenay (Fig. 40A) was previously identified as a M1. It is quite smaller than the other M1; its cusps are slender, with well-defined protoloph and metaloph. We tentatively identify this tooth as a D4, even if the base of the crown and the roots are missing. It differs from $\mathrm{Mu} 6591$ in the absence of any ectocingulum, the occurrence of a short mesoloph and the much swollen parastyle.

P4. Among the P4 from Mutigny (Fig. 36B-G), there is a noticeable variation in shape even if most are narrow and wide, and among them $\mathrm{Mu} 6130$ is the largest and Mu 5622 the smallest. Their buccal border is often bulged at the level of the mesostyle area, and the tooth appears more regularly oval than the others do. Mu 5951 is the less narrow, and its shape is more trapezoidal than the others are. Even if the material is less numerous from Avenay, there is also a variation in size and shape (small AV-4955 to large UM-AV-5788 (Fig. 40B-C).

The anteroloph is slender and low, leaving space for an anteroflexus, even if it is shallow, and narrow in its buccal half. It ends lingually in a weak anterostyle. Buccally, it stops mesially to the paracone on the majority of P4 from Mutigny or Avenay; it turns slightly buccally on $\mathrm{Mu} \mathrm{6130;} \mathrm{it} \mathrm{rarely}$ connects to the paracone $(\mathrm{Mu} 5394$ and $\mathrm{Mu}$ 5622); on $\mathrm{Mu}$ 5951, it joins a short low para-ectocingulum, not observed in teeth from Avenay. The paracone is stronger than the metacone, and prolonged in a thick protoloph. It refines at its lingual half, on which the paraconule is weakly swollen, sometimes bearing one $(\mathrm{Mu}$ 6061, 6067, 6402, UM-AV-5788, -6792, and -4955) or two (Mu 5594) mesiodistal extra-ridges. The lingual protoloph connects generally to the mesial extremity of the preprotocrista, sometimes slightly more distally, and in this case, the short extremity of this arm is free (Mu 6067, 6130, 6466, 6652, 6684, UM-AV-6792, -4955, and -4740). The protocone and its arms form an angle tighter than on the D4 or on the molars. The paracone bears a strong postparacrista often underlined buccally by a shallow notch. It can connect to the mesostyle placed more buccally; the latter can be slightly

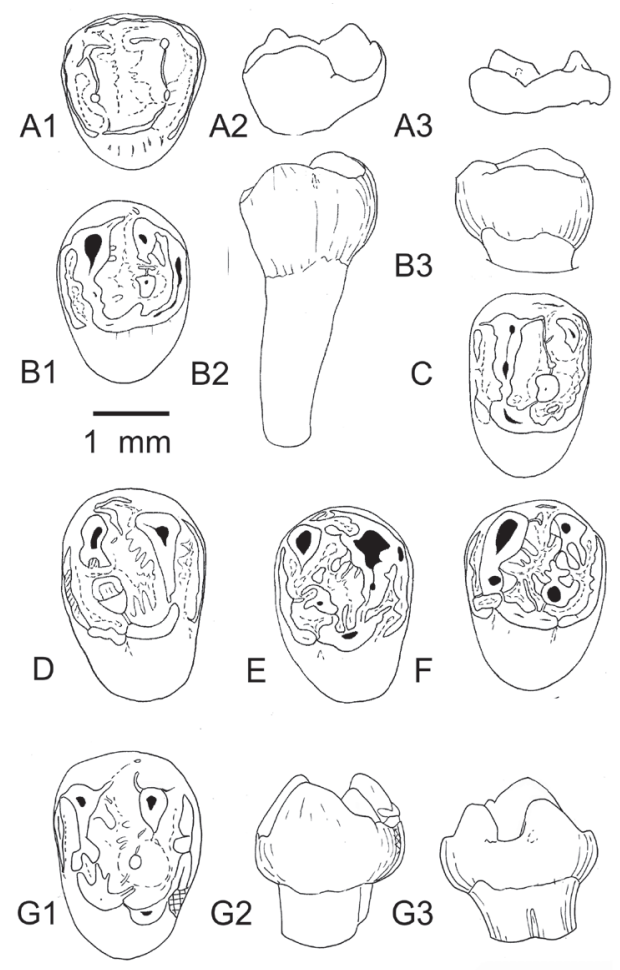

Figure 36. Upper D4 and P4 of Pseudoparamys teilhardi (Wood, 1962) (AE) and P4 of a species indet. (G), from Mutigny (Ypresian, MP8-9, Bassin de Paris). A. UM- MU 6591 right D4; A1, occlusal view, A2, lingual aspect, A3, buccal aspect. B. UM- MU 5622 left P4; B1, occlusal view, B2, lingual aspect, B3, buccal aspect. C. UM- MU 6684, left P4: occlusal view. D. UM- MU 6130, right P4: occlusal view. E. UM- MU 6466, left P4: occlusal view. F. UM-MU5951, left P4: occlusal view. G. UM-MU 6438, left P4; G1, occlusal view, G2, lingual aspect, G3 buccal aspect. Scale bar, $1 \mathrm{~mm}$. 
stretched mesiodistally, but it is generally short, reduced or absent for the narrowest P4, but can be lined buccally by a

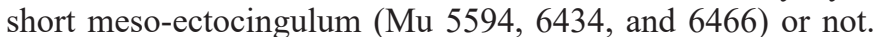
The mesoloph is generally absent, reduced to a granule $(\mathrm{Mu}$ 6466 and AV-5788) or connected to an extra-ridge going to the metaconule $(\mathrm{Mu} 6684)$. The metacone can bear a very short premetacrista. The buccal thick metaloph is short, sometimes bearing one mesial and/or one distal sloping extra-ridge (MU 6253 5951, UM-AV-6792, and -5788), then refining rapidly to join the metaconule; but it often separates from it (Mu 5594, $5622,6061,6130,6426$, and 6466). The metaconule is once single and more often double in Mutigny, more often single in Avenay. The buccal metaloph joins the postprotocrista. On $\mathrm{Mu}$ 6684, its joins more mesially the protocone, and there is a sort of isolated conule in the posteroflexus, between the metaconule and the hypocone; on AV-4955, it is a short ridge parallel to the lingual metaloph. The hypocone is small, but somewhat swollen, close to and lower than the protocone, and at the same lingual level. The endoloph is not well defined, and sometimes a swelling of the postprotocrista is seen (Mu 6466), or a sketch of a sinus is present (Mu 5951, 6402, and UMAV-4740), marked by a cleft (Mu 6426 and UM-AV-4955). The posteroloph, lower than the hypocone, is relatively thin and long, up to the mesial side of the metacone, turning to a weak short meta-ectocingulum on $\mathrm{Mu} 5607$.

Sloping weak extra-ridges are present on the flanks of the lophs towards the flexi on a few teeth (Mu 6061, 6067, and 6466); the less narrow P4 of Mutigny (Mu 5951) has the most numerous extra-ridges; it is also the case for UM-AV-5788. On teeth not too much worn, the enamel lingual flank of the crown bears thin wrinkles. There is only one buccal root and one lingual.

M1-M2 (Figs 37A-E; 40E-G). It is quite possible to distinguish M1 from M2. Indeed, the parastyle is generally less swollen, the posteroloph and posteroflexus are shorter on M2, never reaching the buccal corner of the metacone. The hypocone is smaller than on M1, about the same size as that of the anterostyle. This gives to M2 a more symmetrical appearance than M1: the anterostyle and the hypocone are at the same mesiodistal level, more buccal than the protocone. The contour of M1 is more trapezoidal, that of M2 more oval. Some M2 from Avenay are nearly quadrate (UM-AV-106, 4669, and 6820), whereas a few are shorter (UM-AV-6772), like those from Mutigny.

On M1 the parastyle is stretched buccolingually and slightly
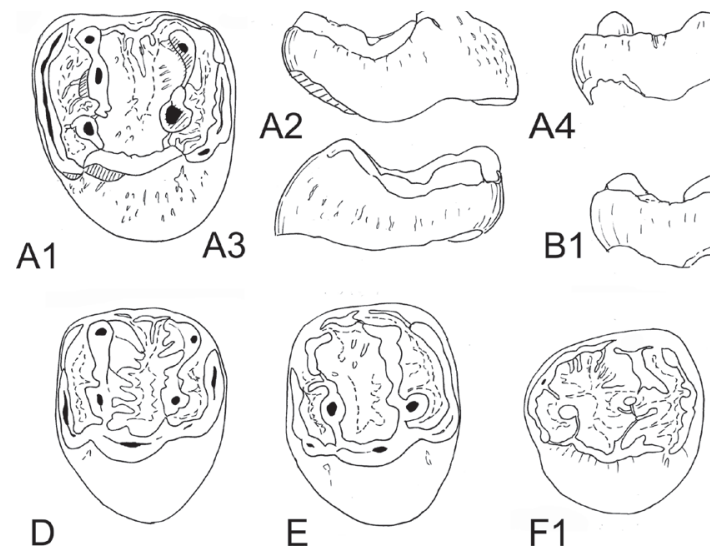

F1
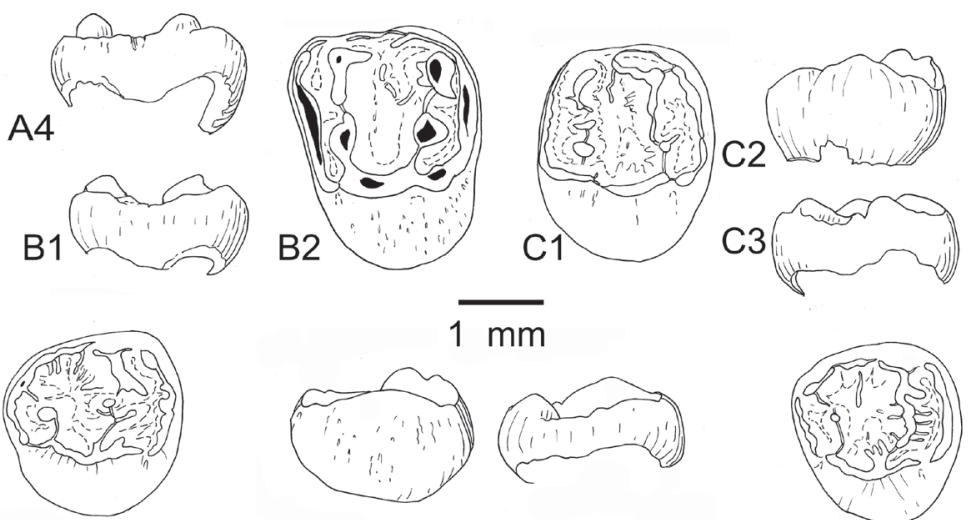

F2
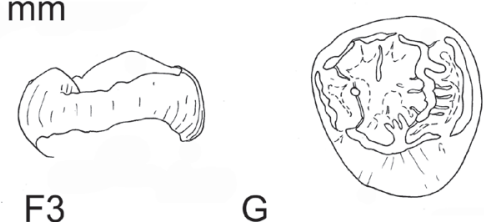

G swollen; it generally ends at the buccomesial corner of the paracone, or rarely continues to the para-ectocingulum $(\mathrm{Mu}$ 6301; AV-MNHN-5889 figured in Michaux, 1968, pl. a, fig. 10). This buccal extension is longer and more frequent on M2 from but not on the few teeth observed from Avenay. The straight anteroloph is low; at its lingual extremity, it turns distally at the The anteroflexus is well defined. The paracone is prolonged in the thick buccal protoloph, for two M1 and one M2, the buccal protoloph is bulged and therefore, the paracone seems double, buccolingually. The postparacrista is high, and descends to the mesostyle area, from which it is generally $\mathrm{Mu} 6314$ and 6384). The mesostyle is scarcely bulged (M1: Mu 6595; M2: UM-AV-106, UM-AV-4669, and UM-AV-6820), often stretched mesiodistally, connected to the low paraand meta- ectocinguli when present (mainly for Mutigny). A few slender extra-ridges sometimes develop as one or two short Avenay M1-M2, where this mesoloph is longer when present. The paraconule, slightly protruding in the anteroflexus, is well developed, nearly as large as the metaconule. It connects to the are nearly aligned mesiodistally, making only a wide angle with its buccal slope.

The metacone is generally smaller than the paracone, at least at its base; the premetacrista is generally short, rarely escending to the mesoflexus buccal opening. It is surrounded by the ectocingulum connected to the mesostylar ectocingulum and to the posteroloph on M1 only from Mutigny (e.g., Mu $6063,6064,6234,6301$ ), once on a M1 (or M2?; UM-AV-no n ${ }^{\circ}$ see $\mathrm{S} 1$ ). The metacone is double buccolingually on $\mathrm{Mu} 6063$. The short thick metaloph can bear two ridges, one directed obliquely to the posteroloph, the other, weak and connected buccal is the weaker) on two M1 and four M2 from Mutigny, there is only one on the few molars from Avenay. They join lingual metaloph in Mutigny. The connection is weaker on some molars from Avenay: the UM-AV-6820 M2, where there is a very low connection with the hypocone or the UM-AV-5832 $\mathrm{M} 1$, where both connections are present, to the endoloph and

Figure 37. Upper molars of Pseudoparamys teilhardi (Wood, 1962), from Mutigny (Ypresian, MP8-9, Bassin de Paris). A. UM- MU 6234 left M1; A1, occlusal view, A2, distal aspect, A3, buccal aspect, A4, buccal aspect. B. UM- MU 6301 left M1; B1, buccal aspect; B2, occlusal view. C. UM- MU 6384, right M2; C1, occlusal view, C2, lingual aspect; C3, buccal aspect. D. UM- MU 6311, left M2: occlusal view. E. UM- MU 6314, right M2: occlusal view. F. UM-MU 6245, right M3; F1, occlusal view, F2, lingual aspect, F3 buccal aspect. G. UM-MU 6244, right M3: occlusal view. Scale bar, 1 mm. 
to the hypocone. As seen on a weakly worn M1 (Mu 6234), the endoloph is reduced and short at the end of the postprotocrista, mesial to the hypocone. It can be hardly distinguished from the postprotocrista on the more worn molars. The small hypocone is only faintly higher than the anterostyle on M1 and M2, and much lower than the protocone. The posteroloph appears attached to the hypocone; it reaches at least the buccomesial corner of M1, and the buccal metaloph level on M2.

Only a weak notch marks the sinus below the endoloph area. There is also a very weak notch below the attachment of the anterostyle to the preprotocrista. A ridge borders this notch on the UM-AV-6820 M2. On the same specimen, the enamel bears a strong wrinkle below the endoloph. The enamel surface of the flexi and the slopes of the lophs are somewhat wrinkled, but the wrinkles and extra-ridges are hardly distinct due to wear. The enamel outskirts of the crown display wrinkles.

M3 (Figs. 37F-G and 40H). Among the M3 from Mutigny stored in the UM collections, two teeth were excluded $(\mathrm{Mu}$ 5150 and $\mathrm{Mu}$ 5607), as they probably belong to Meldimys louisi, with pre- and post- paracristae making a tighter V, and welldeveloped protocrista. Compared to Meldimys, the distal cusps from the mesostyle area to the hypocone of Pseudoparamys teilhardi makes a more complete and low pericingulum, around a more basined central area. The AV-5890 M3 from Avenay, referred to $P$. teilhardi (Escarguel, 1999: pl. 14, fig. h) is rather attributable to $P$. ageiensis, as well as AV-5723 and AV-5851. The AV-640BN M3 has prominent paracone and metacone, a larger anteroflexus and displays a strongly ornamented enamel surface of the meso- and postero- flexi. It cannot belong to Pseudoparamys; it could better fit with Euromys woodi.

Like on M2, the anteroloph is long, reaching the buccomesial corner of the paracone. On one $(\mathrm{Mu} 6439)$, the parastyle is strong, as high as the paracone. The small anterostyle is generally stronger than the hypocone. The protoloph is continuous, or interrupted buccally to the paraconule; the latter is generally present, sometimes well protruding $(\mathrm{Mu} 5603$, 6066, AV-5701, and -197), often worn. The lingual protoloph joins the preprotocrista more distally than on M1-M2 on the main part of the M3 (2/12 for Mutigny; 3/5 for Avenay); in these cases, the short extremity of the preprotocrista ends free in the anteroflexus. The anterostyle and hypocone are still more buccal than on $\mathrm{M} 2$, and therefore the $\mathrm{V}$ of the two protocristae appears less open.

The postparacrista is short, and often lined buccally by the meso-ectocingulum, extending mesially the mesostyle for all the teeth from Mutigny, and one from Avenay. The mesostyle is stretched mesiodistally, generally prolonged lingually with a mesoloph ridge descending in the cup-shaped basin. It takes part of the pericingulum, with the premetacrista, then the metacone, then the posteroloph. The ridge-like metacone is much lower than the paracone, and not much higher than the pericingulum. It is possible to distinguish a weak hypocone between the lingual end of the posteroloph and the distal end of the postprotocrista, on a few weakly worn teeth. The metaconule is always present, generally connected to the postprotocrista, rarely to the metacone, more often on M3 from Avenay (e.g., UM-AV-5855); therefore, the mesoflexus can communicate with the reduced posteroflexus. Extra-ridges descend from the pericingulum and from the lophs in the basin, and in the anteroflexus. On weakly worn teeth, the enamel of the lingual margin bears wrinkles and the extra-ridges descend from the lophs to the flexi (e.g., UM-AV-197).

\section{Lower teeth.}

d4. The tooth UM-AV-5838 from Avenay (previously identified as a d4; Escarguel, 1999: 311) is interpreted here as a p4; we cannot observe the two others (AV-MNHN-136, and -791). The following description concerns the $\mathrm{d} 4$ from Mutigny (Fig. 38A). The metaconid is dominant (less than on $\mathrm{p} 4$ ), the protoconid lower, but well developed. The metaconid and protoconid join through a continuous short anterolophid and a curved metalophulid II. A very short buccal metalophulid, from the protoconid apex, faces a short lingual metalophulid I. There is a relatively wide anteroflexid. The long postmetacristid connects to a pre-entocristid. The thick postprotocristid alignes with the protoconid and the ectolophid, the latter being indistinct from the mesiodistally stretched mesoconid. The continuous curved lophid from the hypoconid to the entoconid, includes their arms and the weakly thickened hypoconulid, making a kind of high "posterocingulid". There is a strong ectocingulid at the buccal border of the sinusid.

p4. (Figs. 38B-C and 40I) Nine teeth from Mutigny are identified as $\mathrm{p} 4$. Among the seven teeth from Avenay considered as $\mathrm{p} 4$ of P. teilhardi (Escarguel, 1999: 311) one is a damaged m1 (UMAV-4949), one (UM-AV-114 BN) is referred to P. ageinsis, and we add UM-AV-5838.

The specimens from Mutigny and that from Avenay are relatively short and wide. The mesiolingual metaconid is stocky; its base occupies about $2 / 3$ of the tooth length. The protoconid is well distinct but much lower than the metaconid. The anteroflexid is reduced, with very short anterolophid and metalophulid. The postmetacristid ends at the mesoflexid lingual opening, the latter being closed by a mesostylid on one $(\mathrm{Mu} 6627)$. One thick to two close extra-ridges descend from the metaconid to the floor of the cup-like shaped basin. A lower and discontinuous ridge descending to the buccal bases of the sinusid and hypoconid rarely underlines buccally the protoconid and the short thick postprotocristid flanks (2/9 from Mutigny, Fig. 38C, 0/6 from Avenay). The ectolophid is indistinct from the mesoconid, which is only a little bulged; there is a continuous connection between the hypoconid and the entoconid, including the posthypocristid, the weakly swollen hypoconulid, the posterolophid, postentocristid, entoconid and the preentocristid; a few short extra-ridges - vanishing with

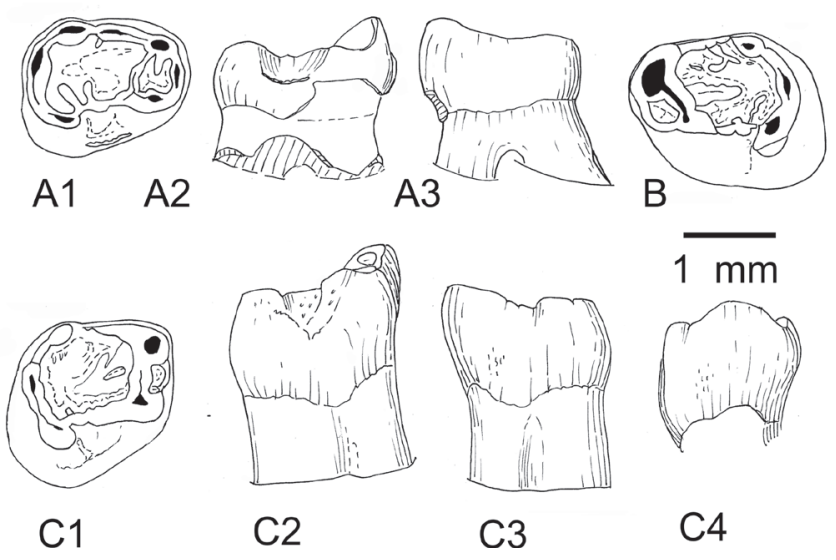

Figure 38. Lower p4 of Pseudoparamys teilhardi (Wood, 1962) from Mutigny (Ypresian, MP8-9, Bassin de Paris). A. UM- MU 6044 right d4; A1, occlusal view, A2, buccal aspect, A3, lingual aspect. B. UM- MU 6427 left p4: occlusal view. C. UM-MU 5625, right p4; C1, occlusal view, C2, buccal aspect. C3, lingual aspect, C4, distal aspect. Scale bar, $1 \mathrm{~mm}$. 
wear - descend from the lophids, converging to the floor of the basin. The enamel of the periphery of the crown is rough, sometimes wrinkled, when not too much worn. The two roots fuse below the cervix; when the roots are preserved along their whole height, it appears that they separate on their lower part and diverge a little.

$\boldsymbol{m} 1$ (Figs. 39A-C and 40J) and $\boldsymbol{m} \mathbf{2}$ (Figs. 39D-E and 40K). The description concerns first the type material from Mutigny. The $\mathrm{m} 1$ differs from $\mathrm{m} 2$ in its trigonid narrower and higher than the talonid, whereas it is as wide and not much higher on $\mathrm{m} 2$. On both, the anterolophid is high and regularly thick, in the continuity of the plunging linguobuccal premetacristid. It attaches to the protoconid to close the anteroflexid buccally. The metaconid is the highest cuspid, and the postmetacristid descends to the mesoflexid opening, which separates it from the entoconid. The metalophulid I is generally continuous and complete on $\mathrm{m} 2$, sometimes interrupted between its high transverse buccal part, connected to the apex of the protoconid and the lingual metalophulid descending from the metaconid summit on $\mathrm{m} 1$ (metalophulid I). This lingual metalophulid is frequently doubled mesially by a more or less short and thick ridge parallel to the linguobuccal premetacristid (Fig. 39BD). Sometimes, distally, there is another branch of the lingual metalophulid I. The floor of the trigonid basin overlooks the talonid basin. The latter is cup-like shaped and deep, with borders clearly higher than its flat floor. There is a thick but short sloping postprotocristid (shorter and less oblique than for Meldimys).

It is the same for the lower molars from Avenay (e.g., m1: UM-AV-5705 and -5793: Fig. 40J); m2: UM-AV-4573: Fig. $40 \mathrm{~K})$. The mesial ectolophid is generally absent or very low. The mesoconid is often strong and bulged, underlined buccally by a not well-defined ectomesolophid; it can bear a thin short mesolophid, sometimes doubled by a short postmesoconid ridge. The distal ectolophid is present and hardly distinct from the short prehypocristid. There is frequently a spur along the mesiobuccal border of the hypoconid, and a well-marked low ectocingulid edging the buccal base of the sinusid. The posthypocristid continues to the posterolophid, without a swollen hypoconulid, and joins a high postentocristid. The entoconid is not strongly bulged, and can be crestiform, at the linguomesial end of this long arched posterior lophid. There are no main ridges inside the cup-like shaped deep basin, not any distinct entolophid, only very low extra-ridges converging to the floor, and granules; rarely there are one or two thin short extra-ridges close to the base of the entoconid or of the posterolophid.

$\boldsymbol{m} 3$ (Figs. 39F-G; 40L-M). The features are the same as those described for $\mathrm{m} 1$ and $\mathrm{m} 2$, but they have a trigonid narrower than the wide curved posterior side of the teeth (on 27/28 wellpreserved teeth from Mutigny). The metalophulid I always interrupts between its buccal and lingual halves; therefore, the anteroflexid is open distally. The entoconid faces the thick mesoconid, therefore more mesial than the hypoconid. The curved and thick lophid running from the entoconid to the hypoconid has its inner slope steep, while the outer slope (mainly the posterior one) curves dorsoventrally. The less numerous $\mathrm{m} 3$ from Avenay show the same features.

\section{Remarks about a species indet.}

One P4 from Mutigny (UM-MU 6438; Fig. 36G) is stored with the P4 of $P$. teilhardi but previously listed as Meldimys louisi (Escarguel, 1999: 300). It differs from the P4 of Meldimys louisi, in its complete and transverse buccal protoloph, its reduced anteroloph and mesostyle, and in having higher cusps. It differs also from $P$. teilhardi by the following features. The tooth is brachydont, its occlusal crown outline is close to a narrow P4 but larger, and its cusps stand up prominently above the occlusal plane, whereas it is not the case for $P$. teilhardi. There are also differences between the shape and development of their hypocone, which is here more lingual than the protocone, the anteroloph, which is low and attached to the mesial flank, and the mesostylar area that is widely open without any mesostyle. The two lingual roots are contiguous, but we distinguish them thanks to a well-marked vertical groove. It likely belongs to another genus and species, indeterminated for the moment.

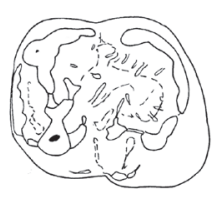

A1

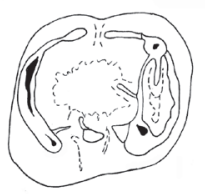

C

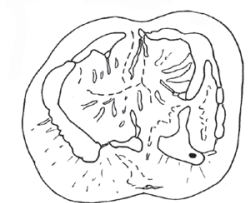

F1

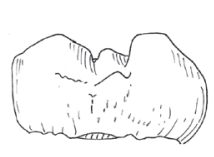

A2

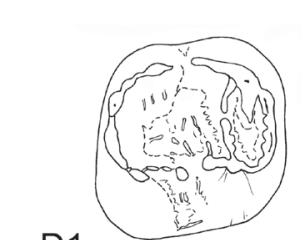

D1

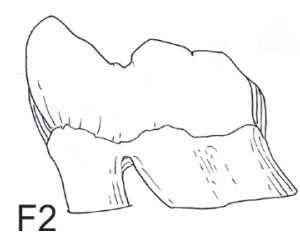

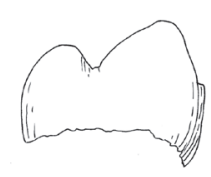

A3

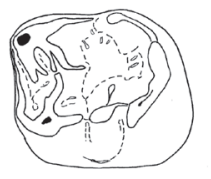

B1

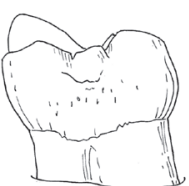

B2

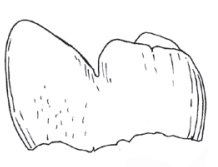

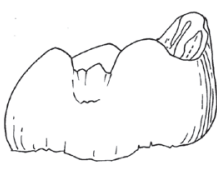

D2
D3

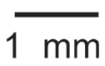

B3

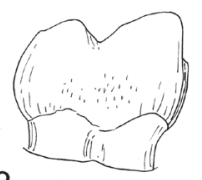

E

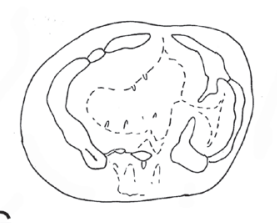

G

Figure 39. Lower molars of Pseudoparamys teilhardi (Wood, 1962), from Mutigny (Ypresian, MP8-9, Bassin de Paris). A. UM- MU 5621, left m1; A1, occlusal view, A2, buccal aspect, A3, lingual aspect. B. UM- 5892 left m1; B1, occlusal view, B2, buccal aspect, B3, lingual aspect. C. UM- MU 6249 right m1: occlusal view. D. UM- MU 6228, right m2; D1, occlusal view, D2, buccal aspect, D3, lingual aspect. E. UM- MU 5977 right m2: occlusal view. F. UM-MU 5615, right m3; F1, occlusal view, F2, lingual aspect. G. UM- MU 5146, right m3: occlusal view. Scale bar, 1 mm. 

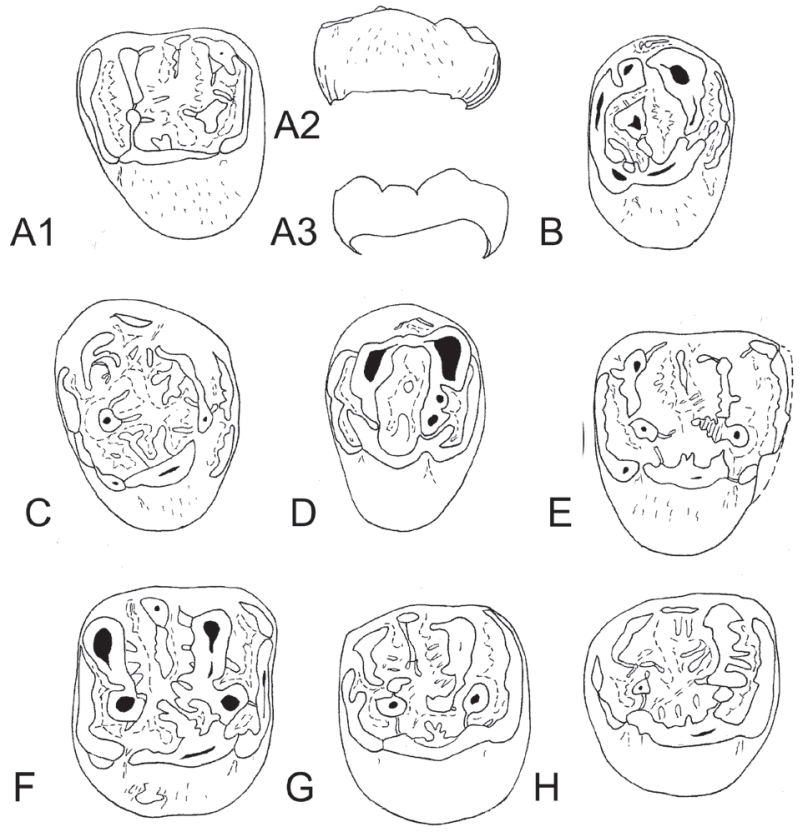

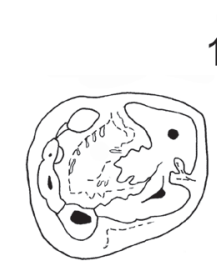

11

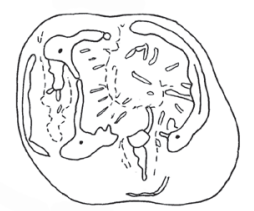

$\mathrm{K}$
$1 \mathrm{~mm}$
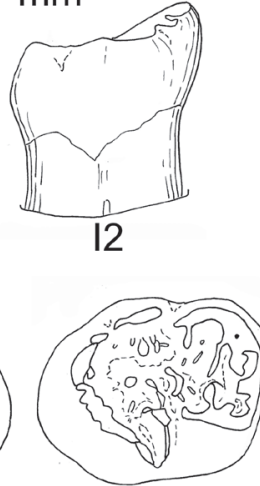

L

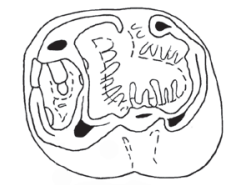

$\mathrm{J}$

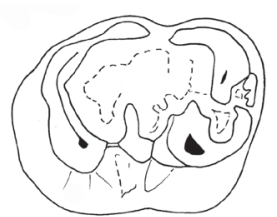

M
Figure 40. Upper (A-H) and lower (I-M) teeth of Pseudoparamys teilhardi (Wood, 1962), from Avenay (Ypresian, MP8-9, Bassin de Paris). A. UM-AV 107, left D4; A1, occlusal view, A2, lingual aspect, A3, buccal aspect. B. UM-AV-4955, right P4: occlusal view. C. UM-AV 5788, left P4: occlusal view. D. UM-AV 5740, right P4: occlusal view. E. UM-AV 4575, right M1: occlusal view. F. AV-6820, right M2: occlusal view. G. UM-AV 106, right M2: occlusal view. H. UM-AV 197, right M3: occlusal view. I. UM-AV 6480, right p4: I1, occlusal view, I2, buccal aspect. J. UM-AV 5793, left m1: occlusal view. K. UM-AV 4573, left m2: occlusal view. L. UM-AV 184, right $\mathrm{m} 3$ : occlusal view. M. UM-AV 5686, right m3: occlusal view. Scale bar, $1 \mathrm{~mm}$.

\section{?Pseudoparamys lapicidinarum (Escarguel, 1999)}

Figure 41

Plesiarctomys lapicidinarum, nov. sp. Escarguel, 1999: 168, pl. 14 pro parte.

Holotype. CB-511, right $\mathrm{m} 2$, unworn, roots lacking.

Type locality. Condé-en-Brie (Aisne, Bassin de Paris; midearly Eocene, MP8-9).

Original diagnosis (Escarguel, 1999; translation from French). "Small sized Plesiarctomys, with a dental morphology still primitive, close to Pseudoparamys teilhardi, from which it differs significantly in its more massive and high crowned cheek teeth. Enamel surface displaying few irregularities. Lower $\mathrm{p} 4$ well developed. Lower molars with trigonid relatively developed, less reduced than on $P$. teilhardi and complete lophids; massive mesoconid, stretched buccolingually; deep lingual opening; strong posterior cingulid. Upper molars (M12) with a V shaped trigon; hypocone, lingual sinus, conules and mesostyle well developed, the latter being connected to the two labial cusps; reduced posterior cingulum.

Emended diagnosis. Lower and upper molar features similar to those of Pseudoparamys teilhardi, only a little larger. Lower p4 not reduced mesiodistally, contra P. teilhardi, with strong anterolophid and well-developed protoconid; entoconid more reduced and crestiform.

Material. This species is only known from Condé-en-Brie (Aisne; mid-early Eocene, MP8-9). The material is very scarce: one M1 and one M2; one p4, three m2, two m3 (CB-492 is not a $\mathrm{m} 1$ but interpreted here as an $\mathrm{m} 3$, its distal root being inclined distally, and CB-525, quite larger than the m3 of $P$. teilhardi, and smaller than E. woodi, is neither Plesiarctomys nor Pseudoparamys); one M1 and one M2. Given this record, the morphological variability of this species remains unknown.

Description and comparisons. The upper and lower molars are very close to that of the largest of $P$. teilhardi from Avenay or Mutigny, their features entering the variation of this species (see above).

Upper molars. (Fig. 41A-B) The worn M1 is very similar for instance to $\mathrm{Mu}$ 6315: with similar organization, similar shape and size of the hypocone/protocone, of the paraconule and metaconule, of the mesostyle and ectocingulum, the reduced to absent mesoloph. It is the same for the M2 of lapicidinarum figured by Escarguel (1999: P1. 14, fig. s), which is close to the PLPRE-1099 M2 of P. teilhardi from Mutigny (Escarguel, 1999: P1. 12, fig. i), with its long and widely open V post- and pre- protocristae + protocone, reduced hypocone, symmetrical with the anterostyle.

Lower teeth. (Fig. 41C-E), m2-m3. The CB-511 m2, the type of lapicinidarum (MP8-9), has a low trigonid, only slightly higher than the talonid. If it was a species of the genus Plesiarctomys, the difference in height between the trigonid and the talonid would be more important, as it does for the species Plesiarctomys savagei from Prémontré (MP10). The postprotocristid descending from the apex of the protoconid is not mesiodistal but oblique, even if weak and short, less visible on $\mathrm{m} 3$. The entoconid is more reduced and more integrated in the continuous posterior cingulid than in $\mathrm{Pl}$. savagei. The mesoconid is more bulged as for $P$. teilhardi. The entolophid is absent.

\section{Remarks on two other teeth.}

p4. The shape of the unique p4 (UM-CB-b1-12, Fig. 41C, and PL.14, fig. 1 in Escarguel, 1999) is clearly distinct from that of the $\mathrm{p} 4$ of Pseudoparamys or Plesiarctomys: the $\mathrm{p} 4$ of $P$. teilhardi are much shorter with a reduced protoconid; that of $P l$. savagei has a protoconid more distal than the metaconid, and bears a strong anterolophid. Here, $\mathrm{p} 4$ is longer with respect to $\mathrm{m} 2$, and the protoconid is well developed. The metaconid is moderately salient, the postmetacristid moderately sloping, ending at the V shaped opening of the mesoflexid. Protoconid and metaconid are nearly facing buccolingually, and are separated by a deep and narrow mesiodistal gutter. The anterolophid is limited to a very low and short cingulid, at the 
mesial base of the gutter. The lingual metalophulid I is reduced to a short onset, plunging towards the gutter, and it connects to the strong mesiodistal ridge descending along the distal flank of the metaconid. It is the same for the very short buccal metalophulid I, but the mesiodistal ridge is weaker. A low and weak junction can occur at the base of the gutter, between the metalophulid I onsets. A high, oblique postprotocristid starts from the protoconid apex; it ends before the mesial flank of the small mesiodistally stretched mesoconid: therefore, the mesial ectolophid is broken. The distal ectolophid is very short and joins the prehypocristid. The mesolophid is a short thin ridge. The posterior cingulid is continuous from the posthypocristid to the entoconid, like in Pseudoparamys and Plesiarctomys. There is no trace of entolophid, but thin wrinkles descend from the posterior cingulid to the floor of the talonid basin; there are also wrinkles along the postmetacristid and postprotocristid, buccally and lingually.

m3. The large m3 CB-525 (Escarguel, 1999: Pl. 14 fig. q) is also clearly distinct, and much larger than that of the $\mathrm{m} 3$ of Pseudoparamys teilhardi or Plesiarctomys savagei. It is longer than it is wide, with a talonid narrower than the trigonid. As the metaconid area is very worn (and damaged), its features are difficult to depict. However, the oblique postprotocristid is present, the entoconid is swollen and stretched mesiodistally, and placed mesial to the entoconid level, but not facing the strong mesoconid. The latter bears a long ectomesolophid. The entolophid is absent. There are worn wrinkles towards the basin along the curved posterior cingulid, on which the hypoconulid is not salient.

Discussion. This species was defined on a few teeth, from Condé-en-Brie (Escarguel, 1999). Its affiliation to the genus Plesiarctomys was hypothetized based on evolutionary trends supporting an anagenetic filiation between Pseudoparamys teilhardi (MP8-9) and Plesiarctomys savagei (MP10): "increase in height of the crown, strengthening of the conules on upper teeth, development of the mesoconid on lower teeth" (Escarguel, 1999: 170). However, only nine teeth document this species. And not all the loci are present; the above trends are poorly argued. With such a scarce material, it is not possible to find any difference in height between Pseudoparamys teilhardi and Plesiarctomys lapicidinarum; it is the same for the strength of conules, which however appear less strong for Plesiarctomys savagei than for Pseudoparamys teilhardi. The mesoconid is small in Plesiarctomys, as well in Pl. savagei as in younger species as Pl. hartenbergeri or huerzeleri.

The assemblage of the nine teeth of Condé-en-Brie is possibly heterogeneous: the $\mathrm{m} 3 \mathrm{CB}-525$ is neither Plesiarctomys nor Pseudoparamys, as the $\mathrm{m} 3$ of these genera are easily characterized, with their posterior lobe relatively wide, their posterocingulum continuous from hypoconid to entoconid and their cup-like shaped talonid basin. The trigonid on $\mathrm{m} 2$ (holotype) and on $\mathrm{m} 3$ (not $\mathrm{m} 1$, as previously identified), is not more reduced than on $P$. teilhardi. The mesoconid is not more "massive" than on P. teilhardi, it is not stretched buccolingually, but bears a mesolophid and an ectomesolophid as it can occur on some specimens of the latter (ectomesolophid generally absent for $P$ l. savagei). If the $\mathrm{p} 4$ is associated with the $\mathrm{m} 1$, the $\mathrm{m} 3$ and the two upper teeth, the species could be valid, as this $\mathrm{p} 4$ is quite different from the characteristic $\mathrm{p} 4$ of $P$. teilhardi. However, this species is very poorly documented. We keep it provisionnaly close to Pseudoparamys mainly on the basis of the lower $\mathrm{m} 2$ and $\mathrm{m} 3$.
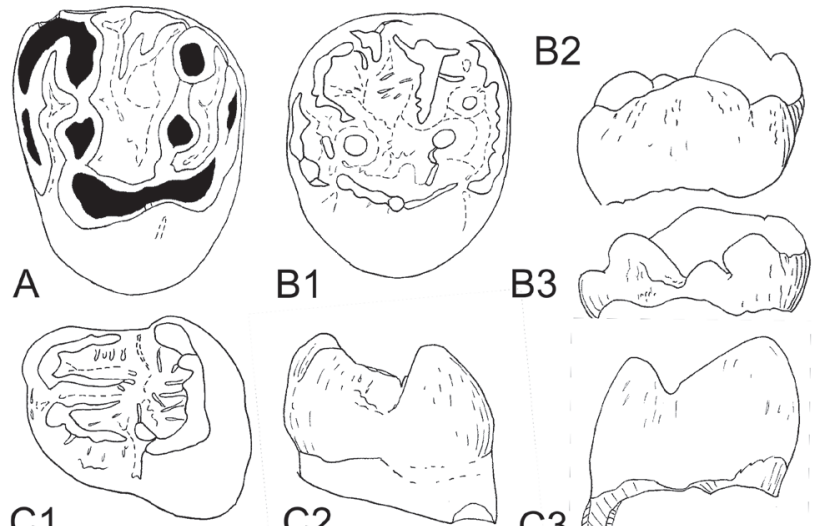

C1
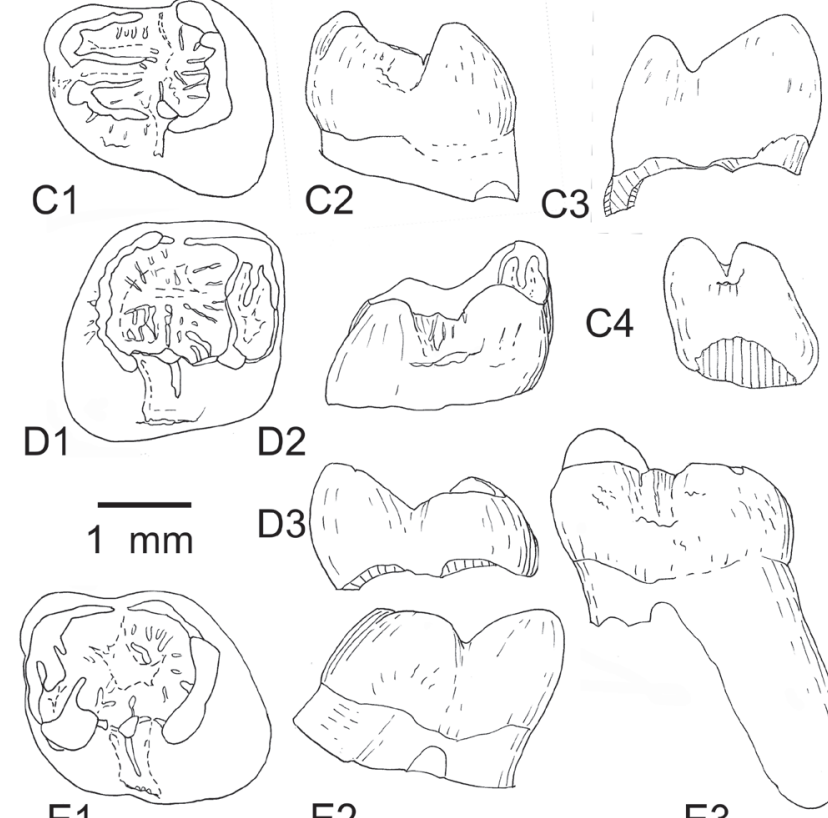

E1
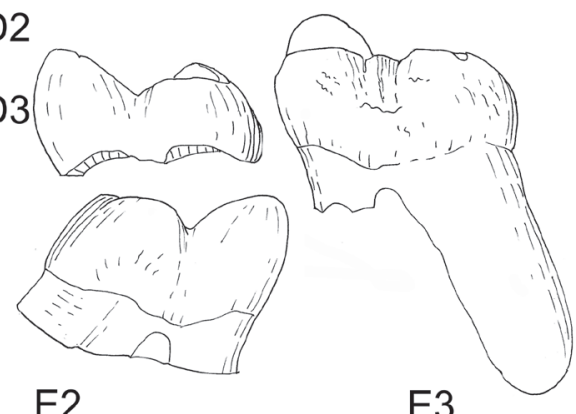

E2

E3

Figure 41. Upper (A-B) and lower (C-E) teeth of 'Pseudoparamys' lapicidinarum (Escarguel, 1999), from Condé-en-Brie (Ypresian, MP89, Bassin de Paris). A. UM- CB 551, left M1: occlusal view. B. UM- CB "without $\mathrm{n}^{\circ}$,, right M2: B1, occlusal view, B2, lingual aspect, B3, buccal aspect. C. UM-CB b1-12, left p4; C1, occlusal view, C2, buccal aspect, C3, lingual aspect, C4, mesial aspect. D. UM-CB 511, Holotype, right m2; D1, occlusal view, D2, buccal aspect, D3, lingual aspect. E. UM-CB 492, left m3; E1, occlusal view, E2, lingual aspect, E3, buccal aspect. Scale bar, $1 \mathrm{~mm}$.

Pseudoparamys ageiensis (Michaux, 1964)

Figure 42

Paramys ageiensis Michaux, 1964: fig. 1a.

Paramys ageiensis Michaux, 1968: pl.1, figs. 1-7.

Pseudoparamys teilhardi (Wood, 1962), in Escarguel (1999), pro parte, (see App.S 1).

Paramys cf. ageiensis Michaux; Hooker, 1996: p. 209, table 2.

Paramys cf. ageiensis Michaux; Hooker, 1998: p. 449.

Paramys ageiensis Michaux; Hooker et al., 2005: p. 84.

Pseudoparamys ageiensis (Michaux); Hooker, 2010, p. 30.

Holotype. Lower right m1 (Michaux, 1964: fig. a; Michaux, 1968: pl. 1, fig. 5).

Type locality. Avenay (Marne, Bassin de Paris; mid-early Eocene, MP8-9).

Original diagnosis (Michaux, 1964: 153; translation from French). "Small sized Paramys, enamel smooth; high metaconid; $\mathrm{m} 3$ with continuous bead-shaped posterolophid; on upper M1-2, hypocone and protocone not clearly separated".

Remarks. Escarguel synonymized this species with P. teilhardi 
(1999: 159), but Hooker (2010: 30) resurrected ageiensis based on the size distribution of teeth in Avenay and some morphological features. We agree with the opinion that this species is valid, but the morphological differences it shows with the type species of Pseudoparamys makes its inclusion in this genus questionable. In addition, the "population" of $P$. teilhardi from Avenay, as understood (and measured) by Escarguel (1999) is heterogeneous, including not only Pseudoparamys teilhardi, the valid species ageiensis, but also a few teeth of Meldimys and Euromys.

Emended diagnosis. Species slightly smaller than $P$. teilhardi (M1: L mean x W mean: $1.985 \mathrm{~mm}$ x $2.285 \mathrm{~mm}$ ) with smooth enamel on the periphery of the crown and rare wrinkles along the loph(-id)s and on the flexi surfaces.

Differs from $P$. teilhardi also: - In its hypocone clearly stronger than the anterostyle, the latter being more buccal than the hypocone, mainly on M1, and the sinus slightly more marked on M1-M2, the pre- and post- protocristae less aligned with the protocone; P4 with the hypocone slightly more lingual than the protocone. - In the constant break between the posterocingulid and the entoconid; the lingual metalophulid I weak or absent on lower molars; the metaconid stronger and protoconid weaker on $\mathrm{p} 4$; the talonid basin less deep.

Material and measurements (Fig. 35A-B; Table 6). Among the material figured by Michaux (1968) from Avenay, we remove the AV-MNHN-4972 p4 from ageiensis, and transfer it to $P$. teilhardi. Only one small p4 (UM-AV-114 BN) and one small P4 (UM-AV-672) differ morphologically from the p4/P4 of $P$. teilhardi, and are referred to ageiensis. Only some small lower (two $\mathrm{m} 1$, one $\mathrm{m} 2$, and four $\mathrm{m} 3$ ) and upper (two M1, two $\mathrm{M} 2$, and three M3) molars are included in ageiensis (two of these M3 with doubt). It has not been possible to observe the whole material from Avenay from the MNHN collections: it is possible that some small upper and lower molars from Avenay are also ageiensis. Despite this, we will describe the available material, including the holotype.

\section{Description.}

Upper teeth.

$\boldsymbol{P} 4$ (Fig. 42A). The P4 is smaller, its shape more triangular than that of $P$. teilhardi. The parastyle is more developed, even if weak, and is located relatively farther from the paracone mesial flank than in $P$. teilhardi. The postparacrista is very short. The thick short paracone (+ protoloph) fuses with a small paraconule. The later connects to the anteroloph by a thin anterolophule, and more lowly and distally, to the preprotocrista; a very short free extremity of the preprotocrista lays between these two connections. The protocone is slightly more bulged; the endoloph runs obliquely from the postprotocrista distal flank to the small hypocone, which is lingual to the former. The posteroloph is long, to the buccodistal corner of the metacone. The mesostyle is stretched mesiodistally towards the middle of the buccal flank of the metacone; there is no trace of mesoloph. There are only faint short plunging extra-ridges along the distal flanks of the protoloph and metaloph.

M1 (Fig. 42B) and M2 (Fig. 42C-D). Like for P. teilhardi, it is possible to distinguish M1 from M2. On M2, the parastyle is present but less swollen, the posteroloph and posteroflexus are shorter, never reaching the buccal corner of the metacone, and the metacone is less buccal. The hypocone is more reduced, but still stronger than the anterostyle. The contour of M1 is more trapezoidal, that of M2 more rectangular.
On M1, the parastyle is strong, curved along the buccomesial side of the paracone; therefore the anteroloph appears long, ending lingually at a well-developed anterostyle, underlined by a weak antesinus. This anterostyle is slightly buccal than the protocone and hypocone. The buccal protoloph is thicker than

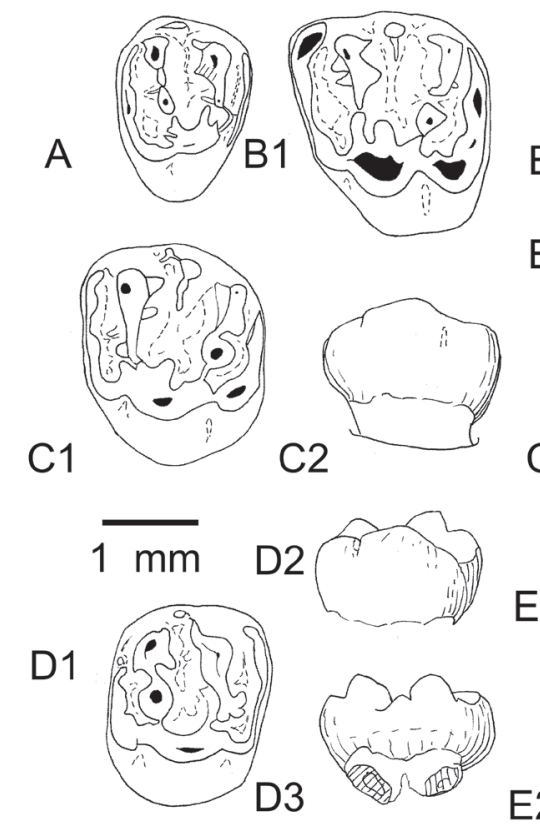

B2

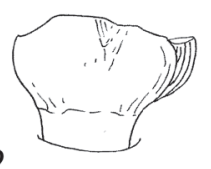

B3

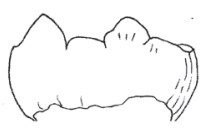

E2

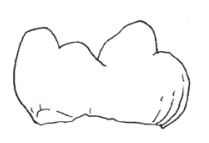

C3

E1

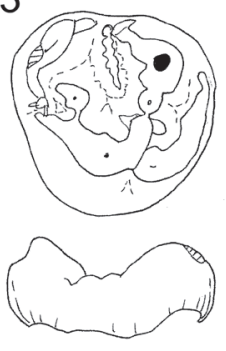

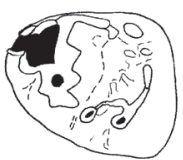

F1
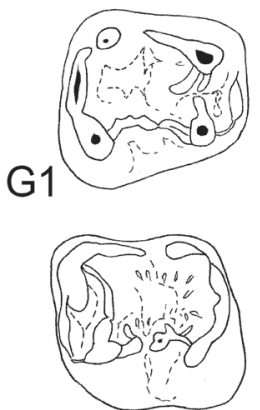

H1

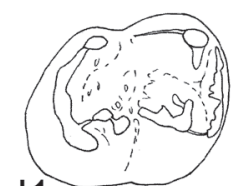

11

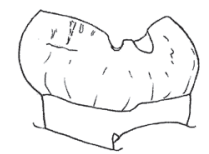

F2

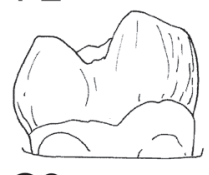

G2

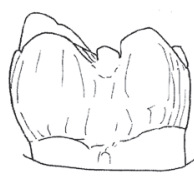

$\mathrm{H} 2$

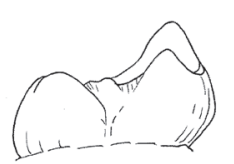

12

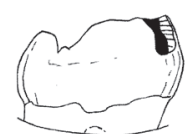

F3
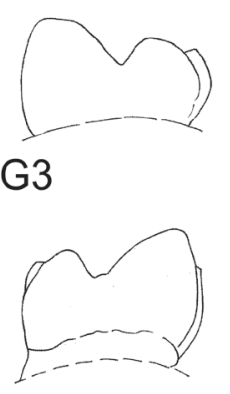

H3

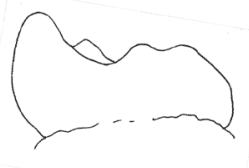

13
Figure 42. Upper (A-E) and lower (F-I) teeth of 'Pseudoparamys' ageiensis (Michaux, 1964) from Avenay (Ypresian, MP8-9, Bassin de Paris). A. UMAV 672, right P4: occlusal view. B. UM-AV 5730, left M1: B1, occlusal view, B2, lingual aspect, B3, buccal aspect. C. UM-AV 5864, left M2: C1, occlusal view, C2, lingual aspect, C3, buccal aspect. D. UM-AV 650, right M2. D1, occlusal view, D2, lingual aspect, D3, buccal aspect. E. UM-AV 5890, right M3: E1, occlusal view, E2, buccal aspect. F. AV 114 BN, left p4: F1, occlusal view, F2, buccal aspect, F3, lingual aspect. G. UM-AV 5863, right m1: G1, occlusal view, G2 buccal aspect, G3, lingual aspect. H. AV MNHN 4870, left m2, Holotype: H1, occlusal view, H2, buccal aspect, H3, lingual aspect. I. UM-AV $191 \mathrm{BN}$, right m3: I1, occlusal view, I2, buccal aspect, I3, lingual aspect. Scale bar $1 \mathrm{~mm}$. 
the metaloph. The paracone and metacone are more saillant than in $P$. teilhardi, therefore the high postparacrista descends abruptly to the mesostyle area, from which it separates by a cleft, and not attached, and as it is the case in P. teilhardi. The mesostyle is strongly bulged on the two M1 and on one M2, M2 on which a short meso-ectocingulum is present. The mesoloph is weak and short or absent. The paraconule, slightly protruding in the anteroflexus, is smaller than the unique bulged metaconule. The protoloph connects to the thick preprotocrista distally to its extremity. The pre- and post- protocristae make a $\mathrm{V}$ with the protocone apex: they are not aligned mesiodistally on both M1 and M2; they are at the same lingual level only on UM-AV-4954. A short thick protocrista is present on the two $\mathrm{M} 1$ and on the AV-MNHN-5864 M2.

The premetacrista is long on M1, short on M2. The buccal part of the metaloph is transverse and weakly connected to the metaconule. Then the thinner lingual metaloph runs obliquely to the postprotocrista extremity: the protoloph and metaloph are converging to the pre- and post-protocristae. A well-defined and narrow sinus (hypoflexus) underlines the very short, thick and mesiodistal, endoloph. The hypocone is less reduced than in P. teilhardi. The enamel surface of the flexi and the slopes of the lophs are not markedly wrinkled, only one or two short faint ridges are present along the protoloph. The enamel outskirts of the crown are smooth.

M3 (Fig. 42E). Within the smallest M3 from Avenay previously referred to Pseudoparamys, AV-MNHN-4932 has been figured as ageiensis (Michaux, 1968: pl 1, fig. 2). It is worn, damaged distally, but a small hypocone seems present; the pre- and postprotocristae makes a wide $\mathrm{V}$ with the protocone; the mesostyle is stretched and doubled with short mesolophs; the mesoflexus shows low extra-ridges and the protocrista is short. Four other teeth differ from the M3 of $P$. teilhardi in their lower size (like AV-MNHN-4932), salient metacone, lower mesostylar area and in having less cup-shaped basin: UM-AV-5890 (referred to P. teilhardi in Escarguel, 1999: pl. 14, fig. h), UM-AV-5723, UM-AV-5851, and UM-AV-640BN. Their attribution to ageiensis is however dubious. If AV-MNHN-4932 and UMAV-5890 have their flexi weakly to moderately ornamented, with reduced and short wrinkles and the periphery of the crown smooth, it is not the case for the others. UM-AV-640BN differs from UM-AV-5890 and AV-MNHN-4932 in displaying a larger anteroflexus and a thinly ornamented enamel surface of the meso- and postero- flexi, ressembling in these aspects to molars of $E$. woodi. The two last teeth (UM-AV-5723 and -5851) share characters with Meldimys: the lophs are thick, with strong mesolophs and numerous extra-ridges, a well-distinct hypocone and sinus, rough enamel outskirts, their metacone is less salient than for the others.

\section{Lower teeth.}

p4. The only p4 (UM-AV-114 BN: Fig. 42F) has a prominent and dominant metaconid. The latter occupies the mesial margin of the tooth, whereas the protoconid is more distal and strongly reduced. The postmetacristid is high, sloping moderately, and becoming steep only when it reaches the level of the mesoflexid opening, closed by a weak mesostylid. Buccally, the postprotocristid is first high then descends (even more abruptly than the postmetacristid) to the mesial ectolophid level. This ectolophid is "interrupted" (i.e., very low in front of the mesoconid). The mesoconid is distinct but not strong, merged with the short and thin distal ectolophid, which connects to the prehypocristid. The upper part of the buccal slope of the crown shows short and shallow grooves mainly at the metaconid-protoconid junction, and the sinusid is well defined in its postmesoconid part. The hypoconulid is not salient, stretched buccolingually and subsumed within the posterocingulid, between the posthypocristid and the posterolophid. The entoconid is swollen and separated from the posterolophid. The entolophid is absent. A few short, faint extra-ridges descend from the posterocingulid to the basin.

$\boldsymbol{m} \mathbf{1}$ (Fig. 42G) and $\boldsymbol{m} \mathbf{2}$ (Fig. 42H). Two $\mathrm{m} 1$ are identified as ageiensis, the holotype AV-MNHN-4990 and UM-AV-5863. We have observed casts of these two specimens. The protoconid and hypoconid are equally developed and bulged. The metaconid is the highest cuspid, and the entoconid the smallest. The inner cuspids are facing the outer cuspids. The trigonid basin (anteroflexid) is higher than the talonid basin (meso + posteroflexid). The type specimen being damaged, the mesial part of $\mathrm{ml}$ is observed on UM-AV-5863. On this tooth, the anterolophid is short and swollen, limited at the buccal half of the tooth. The mesialmost lingual metalophulid (premetacristid) and the lingual metalophulid I are present, sloping from the high metaconid but not much marked. A thin groove separates the latter from the short and thick buccal metalophulid I, connected to the apex of the protoconid. On the type, the two parts of the metalophulid I are connected. The postmetacristid descends abruptly from the high metaconid and the mesoflexid opening is V shaped.

The postprotocristid is long and oblique; its connection with the short mesial ectolophid is indistinct on the type, but there is a short interruption at this level on the less worn UM-AV-5863. The mesoconid is swollen and the mesolophid restricted to a short spur on the latter. The distal ectolophid is short and mesiodistal, fused with the oblique prehypocristid. The posterocingulid (posthypocristid + stretched buccolingually and fused hypoconulid + posterolophid) reaches the base of the entoconid. The latter is bulged, not stretched. There are only a few faint extra-ridges along the metalophulid area and within the basin.

$\boldsymbol{m} 3$ (Fig. 42I). Among the observed small $\mathrm{m} 3$, three were identified as ageiensis, AV-MNHN-4973 (Michaux, 1968: pl. 1, fig. 6), AV-MNHN-191 BN and ULM-AV-4991. We are not sure that the latter is really ageiensis because its entoconid (facing the mesoconid) is stretched and connected to the posterolophid, and its lingual metalophulid I is present and connected to the buccal one: it could be better a small P. teilhardi; however, this tooth is much worn. The two other differ from $P$. teilhardi in their talonid slightly less wide than the trigonid, the entoconid more distal than the mesoconid, the basin less cup-like shaped, the postprotocristid longer, the metalophulid incomplete and shorter (mainly its lingual half is present).

Another small m3 (AV-MNHN-189 BN) is more elongated than the others are. It shows numerous thick extra-ridges and elements of the entolophid. It ressembles m3 of Meldimys louisi, but it is smaller, having a size similar to that of the UMAV-5723 m3 and UM-5851 m3.

\section{Superfamily and Family incertae sedis 1}

\section{Genus and sp. indet.}

Figure 43

Remarks. Three teeth from Avenay, one p4 (AV-MNHN194BN) and two m2-m3 (UMAV-5060 and -5718) were identified as Pantrogna russelli (Escarguel, 1999: 314). Slightly larger than this species, they are however smaller than 
Meldimys louisi or Pseudoparamys from the same locality (App. S1). They display features very distinct from that of $P$. russelli, notably the high trigonid compared to the talonid, or the presence of a strong protoconid on $\mathrm{p} 4$.

\section{Description.}

p4. This tooth is weakly worn. Numerous slender and high extra-ridges dive from the metalophulid I area, from the ectolophid, from the hypoconid, from the posterior cingulid, and from the entoconid to the groove of the talonid basin. Metaconid and protoconid are close, isolated only by a short notch (small anteroflexid), bordered mesially by a low and short anterolophid. The metaconid is strongly salient. The postmetacristid descends first steeply then much less before joining the mesoflexid opening. The protoconid, nearly at the same buccolingual level as the metaconid, is well developed, contra in Pantrogna russelli. Short spurs connect to the two cuspids such as a very short metalophulid I; from this junction, a relatively high extra-ridge descends along the trigonid distal flank to the bottom of the talonid basin. The postprotocristid, first mesiodistal, makes an angle at its end, where an oblique ridge slopes parallel to the main extra-ridge. The postprotocristid does not reach the lower mesiodistal ectolophid. The mesial ectolophid is longer than the distal, and the mesoconid is weak, bearing a short ectomesolophid. Two mesolophid extra-ridges run from part to part of the mesoconid to the basin. There are a short prehypocristid and a short posthypocristid, the latter weakly distinct from the faintly protruding hypoconulid. The posterolophid joins the entoconid, and there is a pre-entocristid. Therefore, as for Pseudoparamys or Plesiarctomys, the posterior cingulid is continuous from the prehypocristid to the pre-entocristid, but the extra-ridges are higher. The protoconid is stronger than on Pseudoparamys.

$\boldsymbol{m} 2-\boldsymbol{m} 3$. The AV-5060 tooth is either an $\mathrm{m} 2$ or an $\mathrm{m} 3$. The trigonid and posterior cingulid are similar in breadth. It is difficult to decide if this tooth could be a $\mathrm{m} 2$ with a vertical distal root or a $\mathrm{m} 3$ with and oblique distal root, because this root is incompletely preserved. On this weakly worn tooth, the trigonid basin is higher than the talonid basin, with a high metaconid, facing the protoconid. The anterolophid swells slightly at mid-length; from its lingual extremity, on the metaconid flank, a short ridge lines it buccally; it does not reach the summit of the protoconid, but a thin preprotocristid closes the anteroflexid buccally. The metalophulid I is complete and closes the high trigonid distally. There is only a short, thin and mesiodistal postprotocristid. The mesial part of the ectolophid is nearly indistinct, at least very low. The small mesoconid is stretched buccolingually, i.e., it is in line with a short mesolophid and ectomesolophid. The distal ectolophid is less low than the mesial one; it is short and offset lingually from the postprotocristid; it connects to the short sloping prehypocristid. The posthypocristid is thicker, and oblique from the hypoconid. The posterior cingulid is high; like on $\mathrm{p} 4$, it is continuous from the prehypocristid to the entoconid, and the hypoconulid is weakly salient. The entoconid faces the mesoconid. The entolophid is very low, hardly visible, and not attached to the apex of the entoconid. There are faint wrinkles and granules in the talonid basin and along the metalophulid distal slope.

We interpret the AV-5718 tooth as an m3, because its distal root is clearly inclined posteriorly; the latter merges with the mesial root as long as the height of the crown. As far as this tooth is worn, its features seem similar to those of AV-5060.

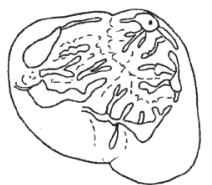

A1

B1

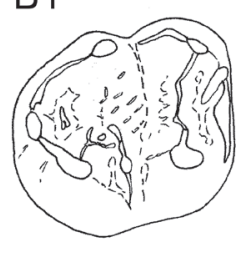

A2
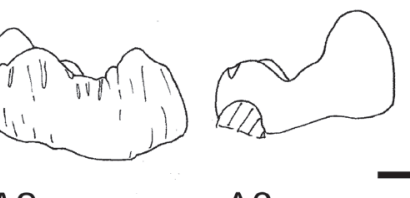

A3

$1 \mathrm{~mm}$

B2

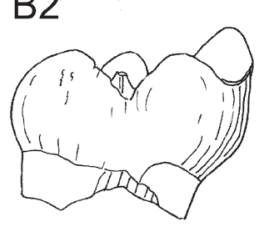

B3

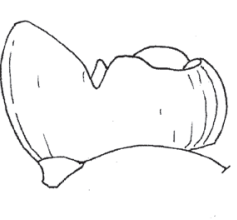

Figure 43. Genus and species indet., from Avenay (Ypresian, MP8-9, Bassin de Paris). A. UM-AV-134 BN, left p4: A1 occlusal view, A2, buccal aspect, A3, lingual aspect. B. UM-AV $5060 \mathrm{BN}$, right m3: B1, occlusal view, B2, buccal aspect, B3, lingual aspect. Scale bar $1 \mathrm{~mm}$.

\section{Super-family and Family incertae sedis 2}

Remarks. Among the basal Theridomorpha, Sparnacomys chandoni and Pantrogna russelli are successive taxa positioned consecutively (node J, Fig. 4) after the Plesiarctomyidae clade (node G, Fig. 4) and the Euromyidae clade (node F, Fig. 4). The following clade (node K, Fig. 4) is that gathering the hystricomorphous "Pantrogna" marandati and Hartenbergeromys hautefeuillei. The two latter species are small-sized species, showing basal theridomorph features, teeth characterized by an unilateral hypsodonty being weakly developed nonetheless; on upper molars, complete protoloph and metaloph connecting to the protocone apex; the hypocone is still smaller than the protocone, the endoloph nearly as high as the protocone and hypocone, and the sinus absent or shallow. On lower molars, the postprotocristid has its distal part well higher than the mesial ectolophid. The protoconid is strongly reduced or absent on $\mathrm{p} 4$.

Sparnacomys (Hartenberger, 1971) (new rank, Escarguel, 1999)

Remarks. The type species of Sparnacomys was described by Michaux (1968) from Avenay, as Microparamys nanus (Teilhard de Chardin, 1922), a microparamyine paramyid. Then Hartenberger (1971) defined it as a new species chandoni and new subgenus Microparamys (Sparnacomys). He included in this subgenus two other species, the species parvus originally referred to Masillamys by Tobien (1954), and ?Microparamys monspeliensis Thaler, 1966. Masillamys parvus is maintained in the genus Masillamys (Vianey-Liaud et al., 2019), and the unique tooth on which the species monspeliensis has been described is rather a p4 of a glirid (study in progress). Escarguel (1999) completed the description of S. chandoni and considered Sparnacomys as a genus of the ischyromyid Reithroparamyinae.

Our observation and revision of all the dental materials attributed to Sparnacomys chandoni, from the type locality of Avenay, allows us to give a more precise and discriminant definition of the genus and species. Moreover, among the numerous teeth available, a few indicate that two other species 
(of Sparnacomys?) are present. Three lower teeth, also different, remain as genus and species indet. Finally, some lower teeth are strongly distinct and represent a new genus (Reinomys rhomboides gen. et sp. nov.). Otherwise, we question here the inclusion of the species georgei from Abbey Wood (Hooker, 2010) in the genus Sparnacomys.

Type species. Sparnacomys chandoni Hartenberger, 1971.

Original diagnosis (Hartenberger, 1971: 105; translation from French). "Microparamys with small hypocone. Tendency to develop lophs (-ids) on lower and upper teeth".

Emended diagnosis (Escarguel, 1999; translation from French). "Small sized Microparamyini, with cusps rather sharp and lophs rather thin and developed; anterior and posterior cinguli rectilinear and well-developed. Upper cheek teeth with reduced hypocone, protoconule absent, anteroloph double lingually. Lower cheek teeth with anterolophid weakly attached to the protoconid; mesoconid and ectolophid in internal position".

Emended diagnosis new. Basal Theridomorpha, with protoconid strongly reduced to absent on p4. D4/d4 and P4/ p4 smaller than $\mathrm{M} 1 / \mathrm{m} 1 . \mathrm{m} 3$ as wide as $\mathrm{m} 2$, and slightly longer. Differs from Pantrogna and Hartenbergeromys:

- In its lower sized teeth (Table 7).

- On upper teeth, in D4 with a hypocone smaller and more lingual than the protocone, often more reduced on P4. Molars with stronger parastyle and longer anteroloph; their sharper conical protocone, narrowly $\mathrm{V}$ shaped mesoflexus due to the close connection of the protoloph and metaloph on the protocone apex; the preparaconule frequent at the mesial extremity of the sloping preprotocrista and the paraconule variably present on the protoloph; the smaller hypocone often not more developed than the anterostyle.

- On lower teeth, in their more concave cup-shaped talonid basin, their entolophid always short, incomplete, the granules and low faint extra-ridges weaker, and their higher metaconid.

\section{Sparnacomys chandoni Hartenberger, 1971}

Figures 44-49

Microparamys nanus (Teilhard de Chardin, 1922); in Michaux, 1968: p. 163-166, Pl. 8, figs. 1-11.

M. (Sparnacomys) chandoni Hartenberger, 1971: p. 105-107, fig. 3, Pl. 5, fig. 5.

Microparamys sp. 1, Hartenberger, 1971: p. 109-111, fig. 4b, P1. 5, fig. 1.

Sparnacomys chandoni Hartenberger; in Escarguel, 1999: p. 183, P1. 17, figs.g-o; P1. 18, figs. a-g.

Holotype. AV-6246, left Ml-2 (1.08 mm x $1.24 \mathrm{~mm})$.

Type locality. Avenay (Marne, Bassin de Paris; mid-early Eocene, MP8-9).

Original diagnosis. (Hartenberger, 1971: 106; translation from French). "Small sized Microparamys; hypocone weak; protoloph and metaloph continuous; 'ectolophid' on lower molars".

Emended diagnosis. (Escarguel 1999; translation from French). "Small sized Microparamyini; P4 with hypocone reduced or absent; oblique ridge cutting in half the anterior cingulum. M1-2 with well-developed proto- and metaloph. M1-3 with anteroloph split lingually (= mesial end of the preprotocrista free); anterior and posterior cinguli rectilinear; hypocone lingual and weakly developed; protoloph continuous. M3 with metaloph low and generally complete. Trigonid of p4 reduced to a sharp cuspid, raising high above the talonid basin; p4-m3 with mesoconid and ectolophid well-developed in internal position; m1-3 with well-developed and rectilinear anterolophid, not joining the protoconid; trigonid basin generally posteriorly open."

Emended diagnosis, new. That of the genus.

Material and measurements. (App. S 1; Table 7, Fig. 44) We have observed about 300 teeth of Sparnacomys (and drawn the main part). Among them, the previously assigned loci of some teeth change, as well as the taxonomic attribution of others (see following descriptions). The size of the teeth of different loci are significantly smaller than those of Pantrogna russelli.

\section{Description.}

Upper teeth. (Figs 45-46).

D4. Among the teeth referred to Sparnacomys chandoni (Escarguel, 1999), three (AV-492 L, AV-658 L, and UM-AV-643 $\mathrm{BN})$ are larger than the others, and their morphology is close to that of Pantrogna russelli, with their protocone stretched obliquely together with its anterior and posterior arms: they are transferred to this species. Two are absent of the collection (AV-MNHN 14680 and AV-573 L).

The four remaining specimens share an asymmetrical occlusal crown outline due to the presence of a small hypocone, which is strongly more lingual than the larger protocone (whereas it is only slightly lingual or at the same level in Pantrogna russelli); the protocone is narrow mesiodistally, with the attachments of the protoloph and metaloph forming a V. The pre- and post- paracristae, distinct from the protoloph and metaloph, are plunging down and low. The parastyle is weakly bulged on three specimens (AV-646 L, AV-656 L, and AV -577 L), and more on AV-467 L, and turns slightly buccally; it continues lingually in a more (AV-646 L and AV-467 L) or less (AV-656 L and -577 L) long anteroloph. There is neither anterostyle nor paraconule on AV-467 L, whereas there is a small protruding paraconule on AV-646 L. On AV-656 L and $-577 \mathrm{~L}$, the paraconule is more mesial from the protoloph: it joins the mesial border of the teeth, breaking the anteroloph in two parts. This mesial paraconule is probably the equivalent of the preparaconule developed on the molars (see below). The paracone wears an arcuate postparacrista notched buccally, which makes the mesostyle in relief. The small hypocone is without arm. It separates from the short, low endoloph and from the posteroloph as seen on AV-467 L and AV-577 L. The posteroloph is long to the posterobuccal corner of the tooth (AV-646 L), slightly shorter on AV-656 L and -577 L, and the shortest on AV-467 L.

P4. Twenty-five P4 are referred to Sparnacomys chandoni and among them, one was previously misidentified as an M2 (AV$657 \mathrm{~L}$ ). There is a relatively wide variation in size (Fig. 45E$\mathrm{H})$ and contour, from nearly triangular to ovoid. When ovoid, the contour can be nearly circular (AV-470 L, -478 L, -579 L, $-590 \mathrm{~L}$, and $-726 \mathrm{~L}$ ) or more oval, mesiodistally shorter than wide (AV-396 L, -402 L, -768 L, and -720 L). When triangular (the others), the inner side can be more (AV-394 L, -558 L, AV-MNHN-7209, and -7244, ) or less (AV-369 L, -371 L, $-403 \mathrm{~L}$, and $-660 \mathrm{~L}$ ) narrow, more or less asymmetrical. The $\mathrm{UM}-\mathrm{AV}-636 \mathrm{BN}$ specimen is the shortest $\mathrm{P} 4$ recorded. When preserved, the two buccal roots can be rarely distinct; more often merged in their upper part, and on two specimens, there is 
only one buccal root (wide on AV-768 L because of the fusion of the two small roots and narrower on the small and nearly circular AV-579 L). As the specimen AV-470 L is very damaged and worn, we cannot correctly depict its morphology.

The anteroloph is slender, without a parastyle. It is strongly reduced on AV-569 L and nearly absent on UM-AV-96 BN; on both, the mesial border of the tooth is shortened, and the paracone more lingual in position than the metacone. The anteroloph often attaches the mesial edge of the paracone + protoloph, and it is low, leaving only a cleft, as a "virtual" anteroflexus. On a few teeth $(\mathrm{AV}-369 \mathrm{~L},-371 \mathrm{~L},-478 \mathrm{~L},-490 \mathrm{~L}$, $-657 \mathrm{~L}$, and UM-AV-726 BN), the anteroflexus is slightly wider. The anteroloph can split in two parts when the preparaconule or paraconule areas join the mesial border (AV-525 L, -590 L, -726 $\mathrm{L}$, and UM-AV-636 BN). The paraconule is rarely absent, but always much smaller than the metaconule. Sometimes, at the mesial extremity of the preprotocrista, there is a preparaconule swelling, which is indistinct of the paraconule on AV-569 L and AV-720 L, but distinct on UM- AV-7244. The protoloph generally joins the extremity of the preprotocrista, sometimes via the preparaconule. When the junction is direct with the apex of the protocone (AV-525 L), the preprotocrista is distinct. It can be one to two low sloping extra-ridges from the buccal protoloph towards the mesoflexus.

Except on the two teeth AV-569 L and AV-720 L, the paracone and metacone follows the same mesiodistal long axis. A postparacrista is generally present slightly lingual to the buccal border of the paracone; it often reaches the mesostyle, or more rarely, it ends before. A short notch borders this postparacrista buccally. The mesostyle is absent on UM-AV-96 BN, AV-402 $\mathrm{L},-569 \mathrm{~L}$ and $-720 \mathrm{~L}$, and reduced on AV-470 L. It is generally present and stretched as a mesiodistal thin short ridge, between the postparacrista and the premetacrista. On AV-660 L, it is more buccal and isolated. On AV-768 L, a para-ectocingulum surrounds the paracone buccally from the parastylar area to the mesostyle. The mesostyle rarely prolonges lingually as a short and thin mesoloph (AV-369 L, -579 L, -657 L, and -676 L). The premetacrista is always present. The buccal metaloph
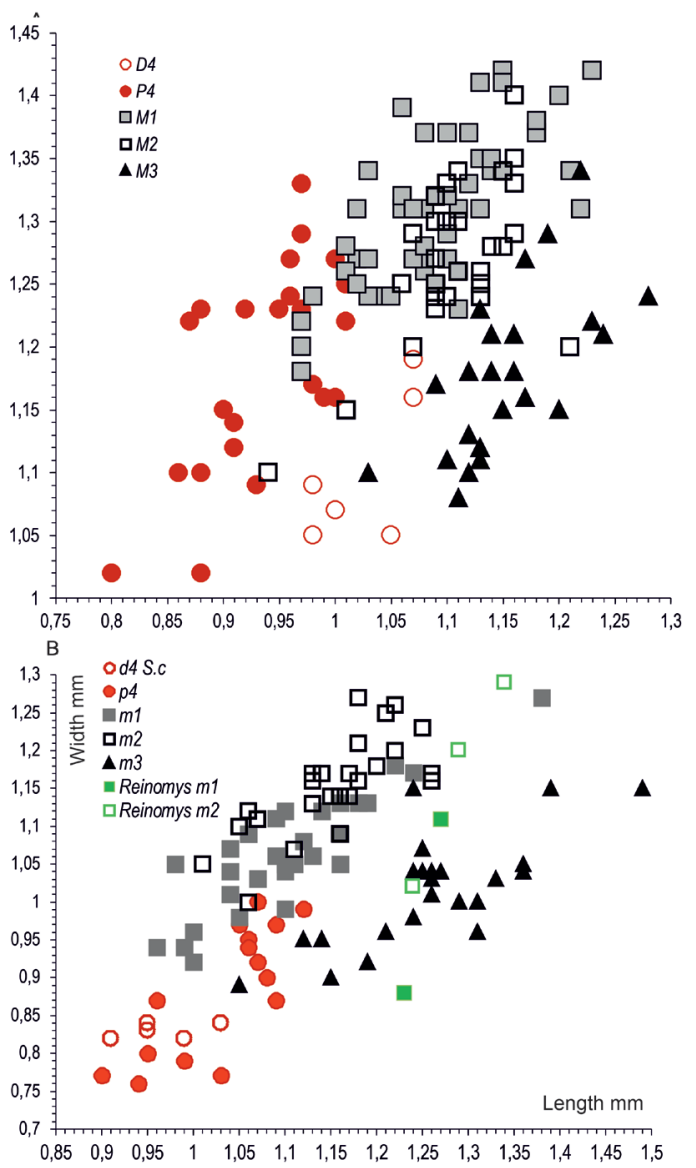

Figure 44. Bivariate graphs (Length $\mathrm{x}$ Width) of upper teeth (A) and lower teeth (B) of Sparnacomys chandoni Hartenberger, 1971 from Avenay (Ypresian, MP8-9, Bassin de Paris). Graduations as millimetres.

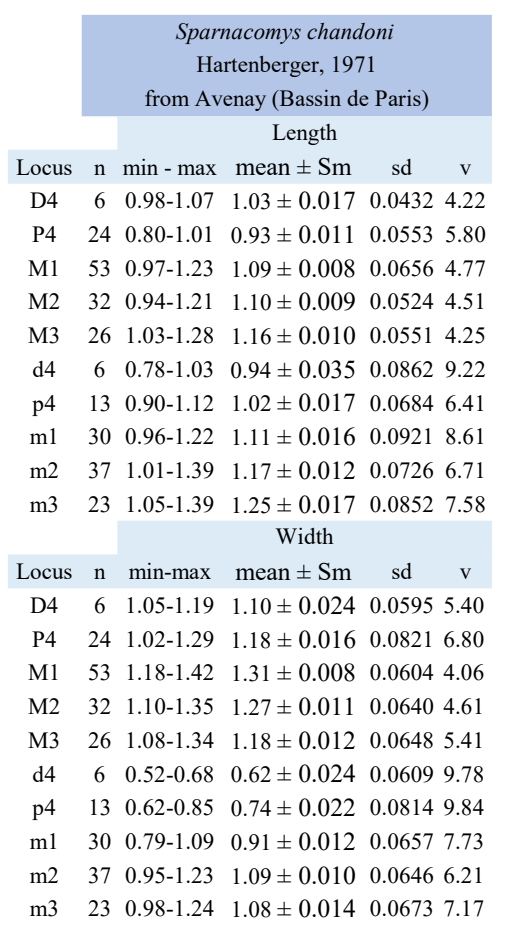

Table 7. Size variations of the different loci of teeth of Sparnacomys chandoni (Hartenberger, 1971) and Pantrogna russelli (Michaux, 1964) from Avenay (MP8-9; Bassin de Paris). Comparisons of the size (Length $\mathrm{x}$ Width) of the different loci of teeth between these two species through ANOVAs, in association with a test $\mathrm{F}$ of significance $(\mathrm{P}<0.01)$. 
is short, thick and transverse; before reaching the metaconule area, it can divides in two short elements, the mesial one as the metalophule I and the distal one being considered as the metalophule II. Rarely, the distal one can be directed to the posteroloph (UM-AV-7244 and -726 BN). For the main part of $\mathrm{P} 4$, it is the metalophule I, curved slightly mesially, which reaches or not the metaconule. On two specimens, metalophule I and II are present (AV-369 L and $-657 \mathrm{~L})$. There is often a single metaconule $(12 / 25)$, two are distinct on six specimens, the other teeth being too much worn to decide. The metaloph always connects to the center of the protocone; it never turns more distally. This connection is more or less strong. The hypocone is short, narrow and a little swollen, lower than the protocone. The endoloph is as high as the hypocone, and well defined on some weakly worn teeth (AV-525 L). The posteroloph is nearly as high as the hypocone; it is generally longer and higher than the anteroloph.

M1-M2. Fifty-seven teeth are M1 and 34 M2 (App. S1). Five M1 and three M2 are particularly large, and differ somewhat from the other teeth in a suite of morphological details (we describe them separately below). We will do the same for three M1 and one M2, which are the smallest (UM- AV-247 BN is close to those small teeth but its length is underestimated, its mesial border being damaged). We relate the small size of two other teeth to their preservation: a pristine M2 probably unerupted and digested (AV-493 L), and another particularly heavily digested and damaged M1-2 (AV-388 L).

M1 differ from M2 in their more developed parastyle and

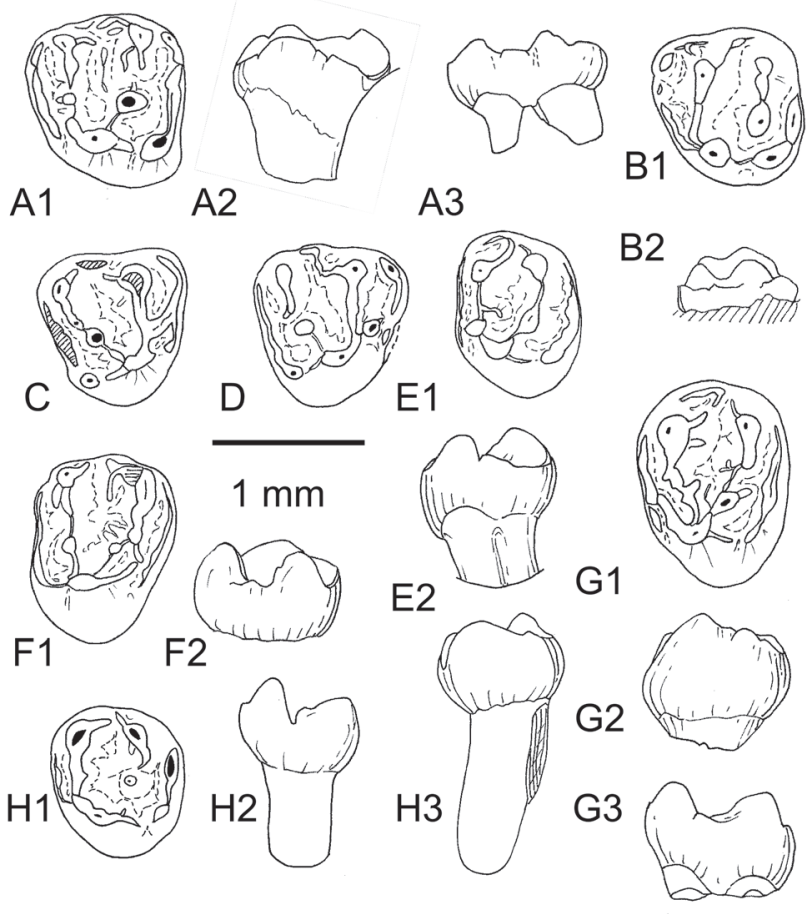

Figure 45. Upper D4 and P4 of Sparnacomys chandoni Hartenberger, 1971 from Avenay (Ypresian, MP8-9, Bassin de Paris). A. AV-646 L, left D4; A1, occlusal view, A2, lingual aspect, A3, buccal aspect. B. AV-467 L, left D4; B1, occlusal view, B2, buccal aspect. C. AV-577 L, right D4: occlusal view. D. AV 656 L, right D4: occlusal view. E. AV-768 L, left P4: E1, occlusal view, E2, buccal aspect. F. AV-369 L, right P4: F1, occlusal view, F2, buccal aspect. G. AV-525 L, left P4: G1, occlusal view, G2, lingual aspect, G3 buccal aspect. H. AV-579 L, left P4: H1, occlusal view; H2, buccal aspect; $\mathrm{H} 3$, lingual aspect. Scale bar $1 \mathrm{~mm}$. hypocone, the latter being at the same mesiodistal level or slightly more lingual than the protocone. On M2, the hypocone is more buccal than the protocone, on the same mesiodistal axis than the anterostyle. Therefore, M1 have rather a trapezoidal occlusal crown outline, whereas the M2 are more symmetrical.

M1. On the type (AV-MNHN-6246) and on the majority of teeth, the parastyle swells at the buccal extremity of a slender, straight and very low anteroloph. At its lingual extremity, it is hooked, and sometimes slightly bulged, thereby generating an anterostyle. The latter appears well defined from the preprotocrista, as seen on unworn or weakly worn teeth. If teeth are in an advanced stage of wear, the anterostyle is confluent with the mesiolingual flank of the protocone. On two teeth only, there is a low anterolophule closing the anteroflexus lingually (UM-AV-100 BN and-104 BN). The anteroflexus is wider mesiodistally than the posteroflexus.

The protocone is conical and pointed on weakly worn teeth. Its anterior arm, preprotocrista ("anterolophe 2" of Escarguel, 1999) descends obliquely to the anteroflexus, and it is separated from (and higher than) the anteroloph (e.g., the holotype and AV-746 L or AV-521 L). Its extremity ends frequently with a conule, occupying the position of a preparaconule (25/50; e.g., AV-0149, UM-AV-100 BN or AV-225 L). On these teeth, the lingual half of the protoloph is indistinct on the protocrista, which slopes buccally from the apex of the protocone, whereas the lingual metaloph inserts slightly distally, both making a narrow $\mathrm{V}$. The protoloph often bears a weak paraconule, aligned with the loph and hardly bulged (e.g., AV-7179 and AV-746 L), more swollen (e.g., UM- AV-7247 BN, -677 BN, and AV-225 L), slightly (e.g., AV-561 L, -766 L, and -576 L) or more (UM-AV-999 BN) protruding. On a few teeth (AV$686 \mathrm{~L}$ and $\mathrm{AV}-535 \mathrm{~L}$ ), the protocrista weakens and becomes low, and the paraconule of the protoloph connects directly to the preprotocrista. In these cases, the preparaconule and paraconule remain still well defined (AV-535 L) or replaced by a new stronger paraconule (AV-686 L). UM-AV-7211 or UMAV-104 display an intermediate state, on which the protocrista is free and the buccal protoloph is weakly attached to a strong preparaconule, at the extremity of the preprotocrista. A direct junction of the "paraconule" (new paraconule) with this preprotocrista, without any medial connection, is rare (AV-398 $\mathrm{L}$ and $-598 \mathrm{~L}$ ).

The paracone is only slightly stronger than the metacone. The postparacrista is always present, slightly depressed buccally by a shallow notch. It joins the mesostyle, which is small but lengthened mesiodistally by a thin ridge, which is the only element of an ectocingulum. Frequently, the mesostyle prolonges lingually in a slender and more or less long mesoloph $(35 / 50)$. This can reach the center of the mesoflexus (UMAV-104, -187, -677 BN, -999 BN, and AV-569 L). Sometimes, a short ridge lines the mesoloph (AV-576 L and $-766 \mathrm{~L})$. It is nearly absent on the small AV-466 L or on AV-208 L. There can be one or two weak and low extra-ridges on the distal flank of the protoloph, and only one (rarely) on the mesial flank of the metaloph. The premetacrista is thicker than the postprotocrista and shorter; it ends behind the mesostyle, from which it separates by a narrow cleft. This opens buccally the mesoflexus.

Premetacrista, metacone and buccal metaloph make an arcuate loph, which is thick until reaching the metaconule. At this junction, the metaloph reduces to a weak and low thin ridge. There is no trace of a second metaloph. The metaconule is bulged, rounded and stronger than the paraconule; rarely double (UM-AV-7179, 178 BN, and AV-384 L). It weakly 


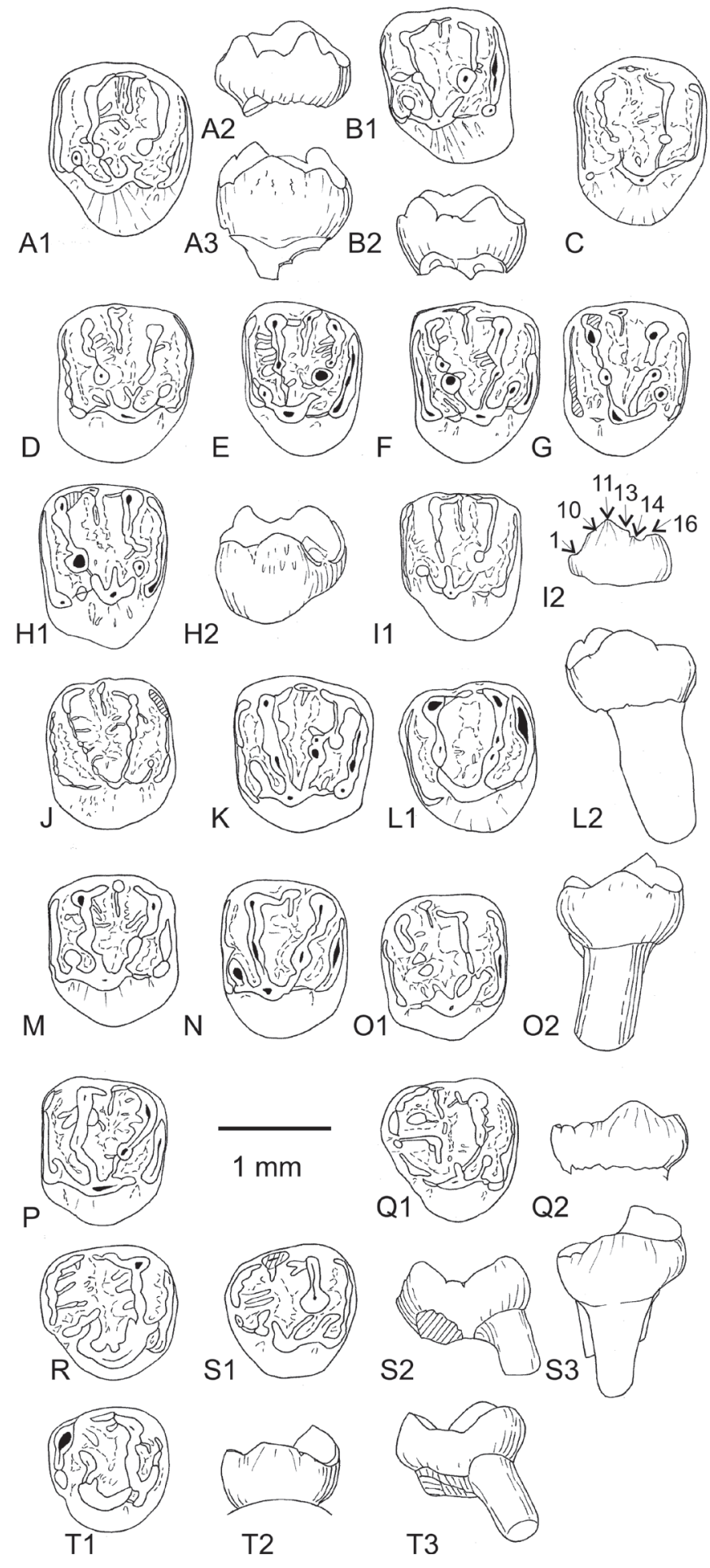

connects lingually to the postparacrista trough the low lingual part of the metaloph; as this connection is very low, the metaconule remains isolated on weakly worn or unworn teeth (e.g., AV-208 L and -560 L). The endoloph is slightly less high than the preprotocrista, and does not join the apex of the hypocone, which appears separated from it by a shallow notch. It is marked by a wide and shallow sinus on the lingual flank of the crown. The small hypocone does not show any arm, but its separation with the posteroloph is shallow: it connects to it as early as moderate wear. The posteroloph is regularly slender on unworn to moderately worn teeth; it ends at the level of the metacone. The posteroflexus is narrow but always well defined and open buccally.
Figure 46. Upper molars of Sparnacomys chandoni Hartenberger, 1971 from Avenay (Ypresian, MP8-9, Bassin de Paris). (A-I: M1; J-P: M2; Q-T: M3). A. AV-560 L, left M1: A1, occlusal view, A2, buccal aspect, A3, lingual aspect. B. AV-559 L, left M1: B1, occlusal view, B2, buccal aspect. C. AV-208 L, right M1: occlusal view. D. UM-AV-639 BN, right M1: occlusal view. E. UM-AV-677 BN, left M1: occlusal view. F. UM-AV-7179, right M1: occlusal view. G. UM-AV-7247, right M1: occlusal view. H. UM-AV-7211, right M1: H1, occlusal view, H2, lingual aspect. I. AV-746 L, unerupted left M1: I1, occlusal view, I2, lingual aspect, the numbers refer to the dental terminology: 1, anteroloph, 10, preprotocrista, 11, protocone apex, 13, postprotocrista, 14, endoloph, 16, hypocone. J. AV-735 L, unworn right M2: occlusal view. K. UM-AV-506 L, left M2: occlusal view. L. UM-AV-644 BN, right M2: L1, occlusal view, L2, lingual aspect. M. AV-377 L, left M2: occlusal view. N. UM-AV-920 BN, left M2: occlusal view. O. UM-AV-730 BN, left M2: O1, occlusal view, O2, lingual aspect. P. AV-565 L, left M2: occlusal view. Q. AV-MNHN-6774, right M3: Q1, occlusal view, Q2, lingual aspect. R. UMAV-246 BN, left M3: occlusal view. S. UM-AV-399 L, left M3: S1, occlusal view, S2, buccal aspect, S3, lingual aspect. T. UM-AV-696 BN, right M3: T1, occlusal view, T2, lingual aspect, T3, buccal aspect. Scale bar, $1 \mathrm{~mm}$.

M2. Same structures and variations are as on M1, notably for the connections of the lingual protoloph and the development of the preparaconule and paraconule. On all specimens, the endoloph is well defined. The hypocone, more buccal than the protocone, is at same lingual level as the anterostyle. As it is generally only slightly stronger than the anterostyle + preprotocrista, the M2 appears more symmetrical than the M1. If some granules are present in the mesoflexus of the M1-M2, the extra-ridges are not frequent. The enamel of the lingual flank of the crown rarely displays a few thin wrinkles.

M3. Twenty-eight teeth were identified as M3 (Escarguel, 1999). We observed 25 (S. 1) and among them, one of the largest is much worn and its distal edge is damaged (AV-456 $\mathrm{L})$, another (AV-105 BN) will be described apart, due to some peculiar features. The occlusal crown outline varies from nearly circular to trapezoidal, and the posterocingulum - from the hypocone to the premetacrista - can be more (AV-468 L, $-647 \mathrm{~L}$, and UM-AV-692 BN) or less asymmetrical.

We begin with the description of the M3 figured in Michaux (1968: fig. 5, Pl.8; AV-MNHN-6774). The anteroloph is long and slender, without a bulged parastyle, and with an anterostyle. The latter connects to the preprotocrista by an anterolophule. Compared to the lower pericingulum, the paracone and protocone are more prominent than in M3 of Pantrogna russelli. The paracone, the highest cusp, shows a sloping postparacrista, which does not reach the mesostyle; it bears a shallow buccal notch. The buccal part of the protoloph is parallel to the anteroloph. It bears two parallel short extraridges going mesially; then it is weakly bulged at the level of the paraconule, before turning distally to connect to the protocrista. The preprotocrista ends free in the anteroflexus, its extremity bulging as a preparaconule. The postprotocrista is indistinct from the endoloph, and joins a hardly visible minute hypocone. They take part to the low postero-buccal pericingulum, in which the metacone is not well defined: one small swelling follows distally the hypocone, and could be the posterostyle; another swelling follows buccally, longer and slightly thicker, but not higher than the hypocone, and could be the metacone, connected buccally to the postmetacrista. Two ridges occupy the basin: the lingual one, the thicker, turns at right angle towards the hypocone and could represent the metaloph; the metaconule is absent; the more buccal is lower and less continuous. A short mesostyle, buccal to the postmetacrista, bears a thin mesoloph. 
These three ridges converge to the center of the mesoflexus; its bottom shows rare low granules.

The other M3 show some variations. As on M1-2, the preprotocrista is free on half of the specimens $(12 / 23)$, its extremity being bulged on nine, seven appear too much worn to decide. On the others, the protoloph connects to the preprotocrista alone. The hypocone can be more distinct, although small and the sinus more marked (e.g., UM-AV-246 BN, -692 BN, AV-468 L, -591 L, and -730 L).

\section{Lower teeth (Figs. 47-49)}

d4. Seven teeth have been previously referred to d4 of $S$. chandoni (Escarguel, 1999). Among them, one (AV-744 L) is smaller than the others, and displays distinct features; it could document another species, and as such it will be described apart. The larger tooth (UM-AV-135 BN), with its metaconid not as high as the others, is referred to P. russelli. The five remaining $\mathrm{d} 4$ have their metaconid slightly higher and slightly more mesial than the protoconid. The little swollen protoconid is stretched mesiodistally. These two cuspids are close buccolingually, so that the anterior part of the tooth is narrow. A more (AV-479 L) or less (AV-643 L) short anterolophid is developed. A small anteroconid is isolated (AV-707 L) or prolonged buccally and lingually in a short anterolophid. The metalophulid is absent (AV-643 L and $-707 \mathrm{~L}$ ) or incomplete (AV-479 L and-681 L) or even complete as a metalophulid I (AV-551 L). When present, it closes distally a small and shallow trigonid basin. One very low mesiodistal ridge descends from the metalophulid area on one specimen only (AV-681 L). As the metaconid is high, the postmetacristid descends steeply to the opening of the mesoflexid (it is less steep on UM-AV-135 BN, considered here as $P$. russelli, where we can distinguish a weak and low mesotylid). Buccally, the postprotocristid, postwardly directed, ends in a weak premesoconid swelling. The ectolophid (mesial and distal to the mesoconid) is very short and broken on weakly worn teeth, mainly at its distal part; the mesoconid swells moderately, with an ectomesolophid on AV-479 L. A short, low mesolophid occurs once (AV-479 L); it is slightly distal on $\mathrm{AV}-551 \mathrm{~L}$ or $-707 \mathrm{~L}$ (postmesoconid ridge). The prehypocristid is short and low, absent on unworn teeth. The sinusid is asymmetrical, widely open and short.

The hypoconulid is slightly swollen and stretched buccolingually at the extremity of the posthypocristid. Following the hypoconulid, lingually, the posterolophid is very short or indistinct; it separates from the isolated entoconid. The entolophid is absent. Therefore, the basin is wide, only filled by a few low granules or extra-ridges. On the larger d4, UM$\mathrm{AV}-135 \mathrm{BN}$, the enamel has weak wrinkles on the buccal flank of the crown.

The roots are shortly fused in their upper part only (near the cervix), and then diverge moderately.

p4. Upon the $25 \mathrm{p} 4$ measured and referred to $S$. chandoni from Avenay by Escarguel (1999), we observed 13 specimens only. Except the large d4 UM-AV-135 BN, these teeth are generally wider for the majority (10/13), and seven also longer (AV-228 $\mathrm{L},-366 \mathrm{~L}$, and $-716 \mathrm{~L}$ ) than the $\mathrm{d} 4$. The mesial and distal roots fuse below the crown, shortly or completely (AV-740 L). The crown is nearly as high lingually as buccally.

The metaconid is mesiolingual to mesial and much higher than the distal cuspids, and relatively higher than in P. russelli. The lingual postmetacristid descends steeply to the wide mesoflexid opening; its end is rarely swollen. Only one low extra-ridge, nearly indistinct, descends from the metaconid to the center of the basin (8/13). More buccally, another and higher low ridge descends posteriorly: it corresponds to a metalophulid ridge prolonged by the protoconid, which is not individualized, indistinct from its postprotocristid ( $\mathrm{cf}$. Fig. $47 \mathrm{E}-\mathrm{F}$ ). The mesial part of the short ectolophid is very low as seen on weakly worn teeth. There is always a small but well-defined mesoconid. It once prolonges lingually in a short mesolophid (AV-585 L), and buccally in a short ectomesolophid (AV-556 L, -585 L, and $-695 \mathrm{~L})$. A short and low anterolophid/premetacristid can be present from the mesiobuccal border of the metaconid (8/13); it is weaker and shorter on AV-MNHN-1249 BN and AV-625 L, and absent on AV-695 L and -740 L. The sinusid is not deep and the crown relatively high below.

The entoconid is relatively small with respect to the other main cuspids. The entolophid is absent, except on AV-556 L, the larger $\mathrm{p} 4$, on which a short lingual part, free and directed linguobuccally, is present; it is also seen on AV-695 L, where it is thin and curved postwardly to join the lingual extremity of the hypoconulid. The latter, weakly bulged and stretched buccolingually follows the extremity of the posthypocristid. There is no lingual extension of the hypoconulid in a distinct posterolophid. The posteroflexid is open lingually at the base of the isolated entoconid. Extra-ridges and granules are tiny or absent.

$\boldsymbol{m} 1-\boldsymbol{m} 2$. Among the lower molars referred by Escarguel (1999)

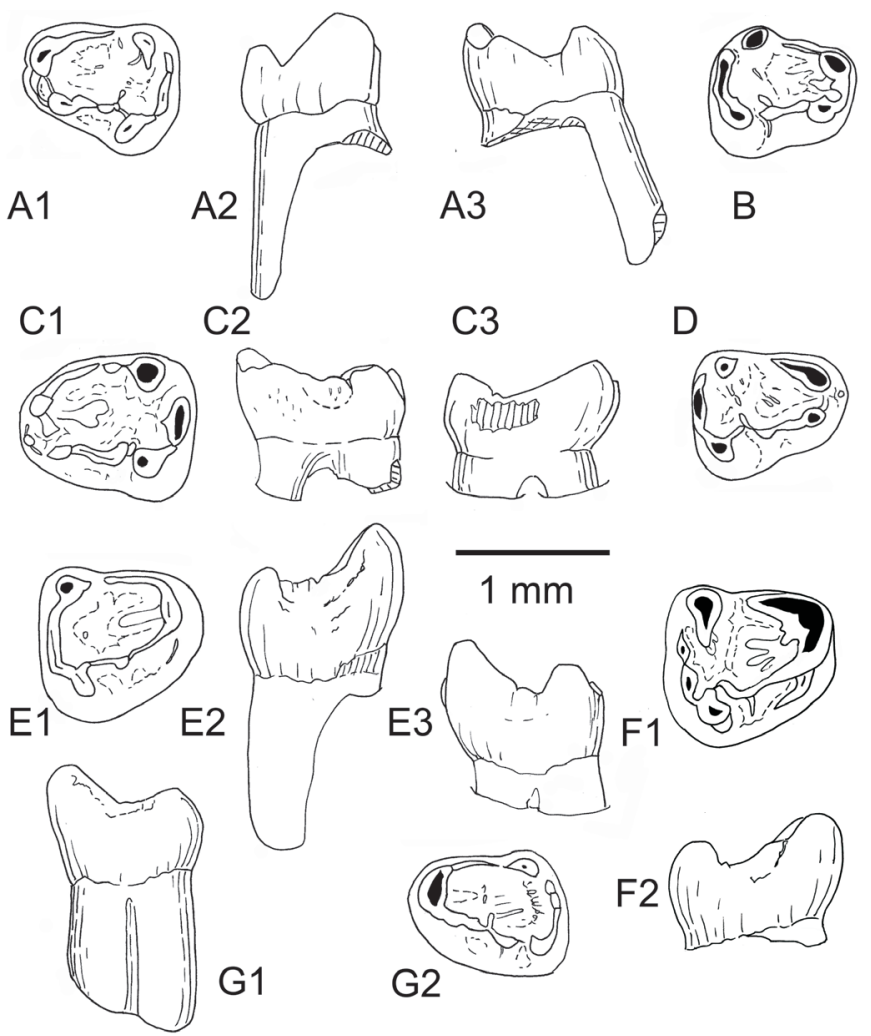

Figure 47. Lower d4 and p4 of Sparnacomys chandoni Hartenberger, 1971 from Avenay (Ypresian, MP8-9, Bassin de Paris) (A-B, D-G). A. AV-551 L, left d4; A1, occlusal view, A2, lingual aspect, A3, buccal aspect. B. AV-479 L, right d4: occlusal view. C. UM-AV-135 BN, possibly Pantrogna russelli, left d4; C1, occlusal view, C2, buccal aspect. C3, lingual aspect. D. AV-707 L, right d4: occlusal view. E. AV-625 L, left p4; E1, occlusal view, E2, buccal aspect, E3, lingual aspect. F. AV-556 L, right p4; F1, occlusal view, F2, buccal aspect. G. AV-740 L, left p4; G1, buccal aspect, G2, occlusal view. Scale bar, $1 \mathrm{~mm}$. 


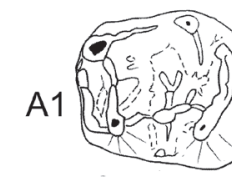

$\mathrm{B} 1$

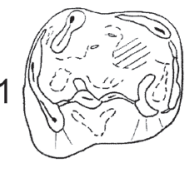

C1
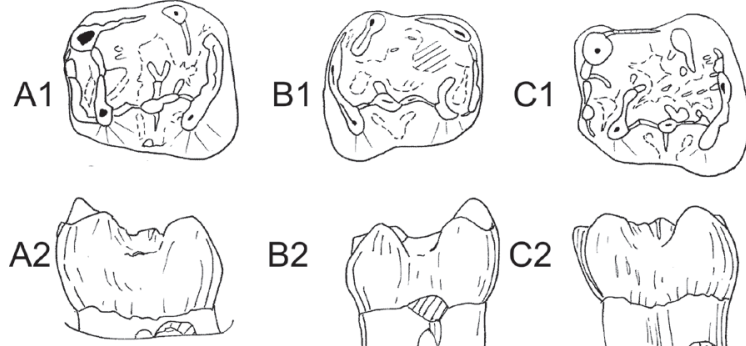

B2
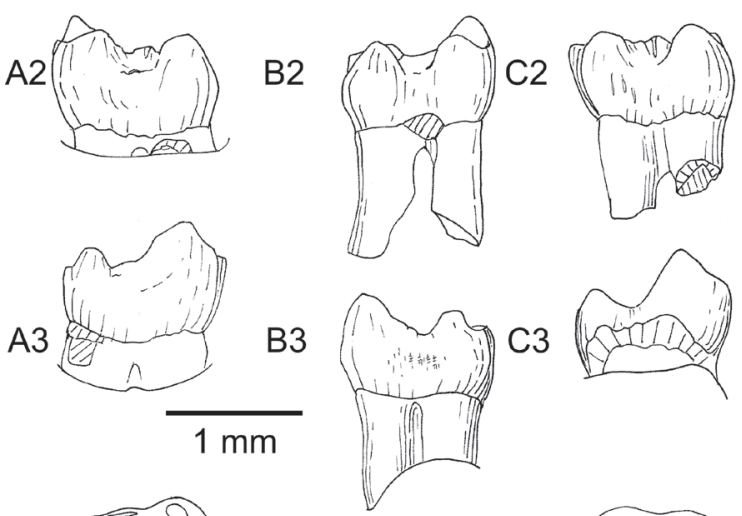

1
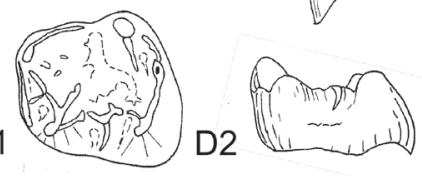

E
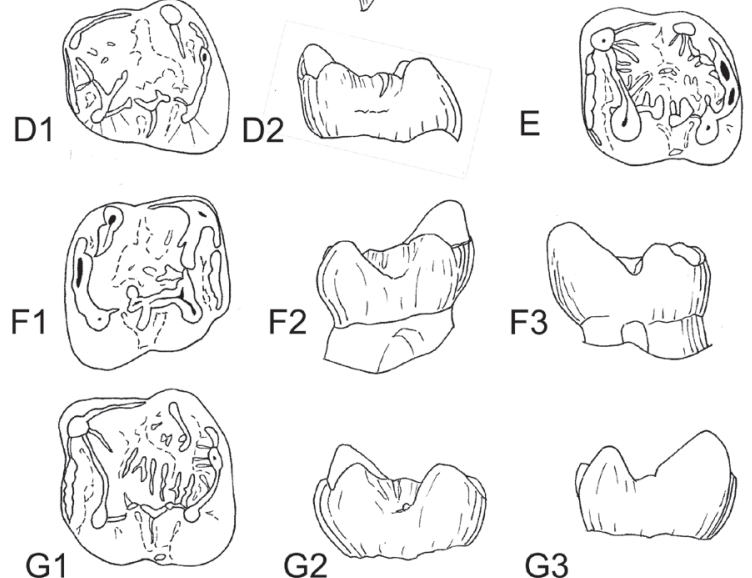

G3
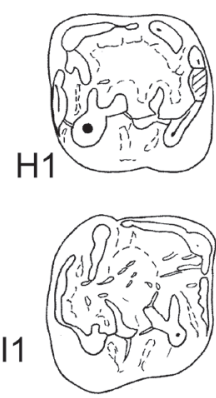

$\mathrm{H} 2$
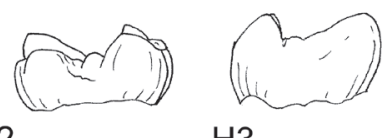

$\mathrm{H} 3$

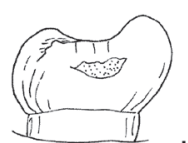

12

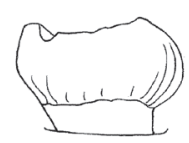

13
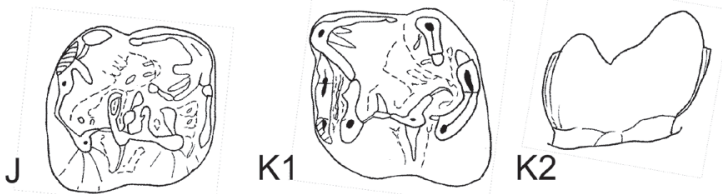

Figure 48. Lower $\mathrm{m} 1$ (A-G) and $\mathrm{m} 2$ (H-K) of Sparnacomys chandoni Hartenberger, 1971 from Avenay (Ypresian, MP8-9, Bassin de Paris). A. UM-AV-735 BN, left m1; A1, occlusal view, A2, buccal aspect, A3, lingual aspect. B. UM-AV-4617, right $\mathrm{m} 1$; B1, occlusal view, B2, buccal aspect, B3, lingual aspect. C. UM-AV-186 BN, left m1; C1, occlusal view, C2, buccal aspect. C3, lingual aspect. D. UM-AV-6827, left m1; D1, occlusal view, D2 buccal aspect. E. UM-AV-683 BN, left $\mathrm{m} 1$ or $\mathrm{m} 2$ : occlusal view. F. UMAV-7656, right $\mathrm{m} 1$; F1, occlusal view, F2, buccal aspect, F3, lingual aspect. G. UM-AV-256 BN, left m2; G1, occlusal view, G2 buccal aspect, G3, lingual aspect. H. AV-252 BN, right $\mathrm{m} 2$; H1, occlusal view, $\mathrm{H} 2$ buccal aspect, H3, lingual aspect. I. AV-734 BN, left m2; I1, occlusal view, I2 mesial aspect, I3, distal aspect. J. AV-209 L, left m2: occlusal view. K. AV-531 L, right m2; K1, occlusal view, K2, lingual aspect. Scale bar, $1 \mathrm{~mm}$.

to $\mathrm{m} 1$ and $\mathrm{m} 2$ of $P$. russelli from Avenay, three $\mathrm{m} 1$ and five $\mathrm{m} 2$ are re-attributed to Sparnacomys chandoni; two $\mathrm{m} 2$ have different patterns and would be referred to two other species/ genera, and they will be described separately (see p.70). Among the material referred by Escarguel (1999) to $\mathrm{m} 1$ of $S$. chandoni, four specimens are $\mathrm{m} 2 ; 35 \mathrm{~m} 1$ and $40 \mathrm{~m} 2$ remain attributed to as $S$. chandoni.

The $\mathrm{m} 1$ differ from $\mathrm{m} 2$ mainly in their trigonid transversely shorter than the talonid, thereby involving a short anterolophid. The $\mathrm{m} 2$ are only slightly longer and clearly wider than $\mathrm{m} 1$ (Fig. 44B; Table 7). Both $\mathrm{m} 1$ and $\mathrm{m} 2$ have a narrow and shallow trigonid basin, higher than the cup-like shaped talonid basin. The crown is as elevated buccally as lingually; buccally it is relatively high below the sinusid, and the main buccal cuspid (protoconid and hypoconid), bulged at mid-height, make the crown overhanging the crown cervix (e.g., AV-734 BN; Fig. 48 I2, I3). The metaconid (primarily) and entoconid are bulged buccally, their lingual flanks being more steep-sided. The two roots generally shortly merge below the crown cervix, and are slightly flattened mesiodistally; the distal one is the strongest. The buccal main cuspids are generally slightly distal to the lingual ones. The lophids are thin at their top, and thicker at their base.

On $\mathrm{m} 1$ and $\mathrm{m} 2$, the metaconid is very high relative to the other cuspids, even on worn teeth. For this reason, its posterior arm descends steeply to the lingual opening, which is V-shaped. The mesostylid is here absent, but on some teeth the distal end of the postmetacristid makes a short mesiodistal flat (12/75: UM-AV-686 BN, -85 BN, -116 BN, -734 BN, -735 BN, -994 BN, AV-209 L, -526 L, -582 L, -653 L, and -751 L). The edge of the tooth at this level forms a low wall overhanging the floor of the cup-like shaped talonid basin.

The anterolophid is aligned with a more or less weak sloping premetacristid, both making a straight ridge narrow at its upper part (on unworn teeth) and thick at its base (as seen on more worn teeth), straighter and longer on $\mathrm{m} 2$ than on $\mathrm{m} 1$. A short and intermediate lingual metalophulid I can double the premetacristid distally (e.g., AV-375 L, -512 L, -526 L, -567 $\mathrm{L}$, and UM-AV-122 BN). If on some m1 (AV-186 L, -504 L, $-582 \mathrm{~L}$, and $-630 \mathrm{~L}$ ), the short anterolophid is swollen buccally, there is no distinct anteroconid on the others and on the $\mathrm{m} 2$. On unworn or weakly worn m1-m2, the anterolophid does not join the protoconid, and the anteroflexid is shallow and remains open buccally. A low buccal anterolophulid sometimes closes it (e.g., UM-AV-130 BN) or often, on more worn teeth. A shallow antesinusid makes a narrow and shallow re-entrant on some teeth $(\mathrm{AV}-138 \mathrm{~L},-200 \mathrm{~L},-526 \mathrm{~L},-637 \mathrm{~L},-751 \mathrm{~L}, \mathrm{UM}-\mathrm{AV}-85$ $\mathrm{BN},-252 \mathrm{BN},-683 \mathrm{BN}$, and $-994 \mathrm{BN})$.

The metalophulid I, attached on the middle of the protoconid, is complete (its low and sloping lingual part connected to its stronger and more horizontal and stronger buccal part) on 31/75 $\mathrm{m} 1-\mathrm{m} 2$; in a few cases $(10 / 75)$, the two parts are shallow and separated by a more or less narrow break. On one m1 (AV-512 L), the buccal metalophulid I attaches slightly more distally to the protoconid. The floor of the trigonid is higher than that of the talonid basin. The entolophid is absent, and the extraridges are faint and thin. The other features are close to those of the other molars. When present, the lingual metalophulid I starts slightly mesial to the apex of the metaconid; it is reduced and replaced by low extra-ridges on some (AV-637 L and UM$\mathrm{AV}-7181$ ), or rarely absent (UM-AV-4617), or even hardly recognizable due to wear. 
There is a short and oblique (mesiobuccal to distolingual) postprotocristid, slightly lower than - or as high as - the mesoconid, bearing lingually a premesoconid swelling or spur, or thin ridge. The ectolophid + mesoconid are mesiodistally oriented on the whole teeth. The mesial and distal parts of the ectolophid, both very short, are clearly lower than the postprotocristid and mesoconid. The mesial ectolophid is lower than the distal one, and a break appears at its level on weakly worn teeth. The mesoconid is generally moderately bulged or slightly mesiodistally stretched. The mesolophid is generally short and low, from the middle of the mesoconid, but more often, it attaches at its distal end. There is generally only one mesolophid, but sometimes doubled. Low postmesoconid spurs are rarely present. The ectomesolophid is rarely present on $\mathrm{m} 1(9)$, more on $\mathrm{m} 2$ (21). The sinusid is not deep, thereby the ectolophid is closer to the buccal margin of the teeth than to their lingual half; we have observed wrinkles along the buccal enamel flank only once (UM-AV-735 BN) on which an ectostylid is seen on the edge of the floor of the sinusid.

The entolophid is never complete. It is generally reduced to its lingual part; very short (e.g., UM-AV-131 BN, -141 BN, -252 $\mathrm{BN},-259 \mathrm{BN}$, and $\mathrm{AV}-630 \mathrm{~L}$ ) or longer but without exceeding mid-width of the tooth. It is generally oblique postwardly, connecting the hypoconulid-posterolophid (e.g., AV-200 L, $-209 \mathrm{~L},-575 \mathrm{~L}, \mathrm{UM}-\mathrm{AV}-683 \mathrm{BN},-6778 \mathrm{BN}$, and $7656 \mathrm{BN})$ or remaining separated from these (e.g., UM-AV-256 BN, -7181 $\mathrm{BN}, \mathrm{AV}-567 \mathrm{~L}$, and $-653 \mathrm{~L})$. In this case, there is often a low ridge making possible a connection with advanced wear, and separating a small islet from the rest of the posteroflexid. Due to the incomplete entolophid, the posteroflexid opens towards the talonid basin. As seen on unworn or weakly worn teeth, the posthypocristid, oblique postwardly, is thinner than the

A1

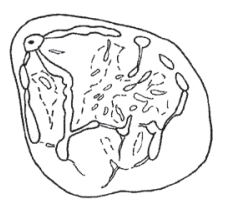

A2

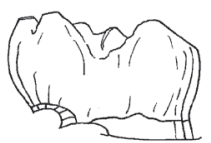

B2

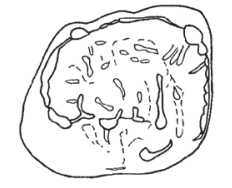

C1

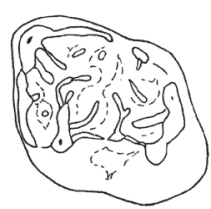

2
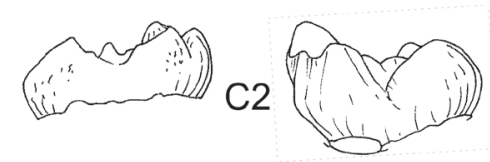

A3

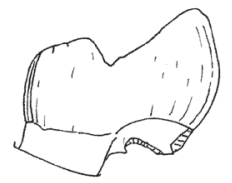

B3

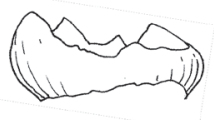

C3

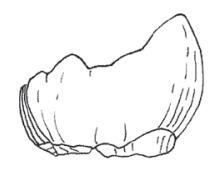

$1 \mathrm{~mm}$

D2

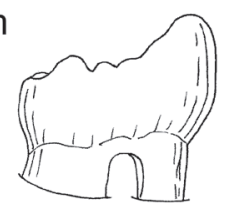

hypoconulid area, as long as this or longer. The hypoconulid is rarely well defined (AV-635 L, UM-AV-126 BN, and -256 $\mathrm{BN})$; it is more often stretched and subsumed within the posterolophid, which is very short lingually to the hypoconulid (e.g., UM-AV-256 BN), and does not reach the entoconid.

The occurrence of low or faint extra-ridges and discrete granules is constant, even if their number varies, from few to numerous, and even hardly visible on worn or eroded teeth. They converge to the center of the cup-like shaped basin.

One small tooth, the unworn UM-AV-6822, previously considered as an $\mathrm{m} 1$ (Escarguel, 1999) is probably an $\mathrm{m} 2$. Compared to the UM-AV-133 BN m2 of close size, they differ in the mesiodistal width of the anteroflexid (narrower for UM-AV-133 BN), the absence of entolophid, and the more developed net of low converging extra-ridges and granules in the basin on UM-AV-6822; the latter shows some wrinkles on the enamel flanks of the sinusid. We refer this tooth only tentatively to $S$. chandoni.

m3. (Fig. 49) We refer $25 \mathrm{~m} 3$ to $S$. chandoni, among them one was previously considered as P. russelli (Escarguel, 1999). We have been able to observe 23 of them. The $\mathrm{m} 3$ are slightly narrower and longer than $\mathrm{m} 2$ (Fig. $44 \mathrm{~B}$; Table 7). They differ from $\mathrm{m} 1-\mathrm{m} 2$ in their reduced posterior lophid. The flat at the end of the postmetacristid is more frequent than on m1-2 (18/23), and a mesostylid is present and well defined on five specimens. Wrinkles and granules are present on all. On unworn teeth, like AV-102 L or $-722 \mathrm{~L}$, it is obvious that the thick postprotocristid is high, higher than the mesial short part of the ectolophid. It is less high on one unworn tooth (AV-552 L), but there is an additional thick high cristid lining buccally the protoconid, and that could play the same functional role. The premesoconid ridge is more frequent and more developed than on $\mathrm{m} 1-\mathrm{m} 2$. The ectomesolophid is distinct on 13/23 m3. The short lingual entolophid is frequent (20/23). Their other features are the same as for $\mathrm{m} 1-\mathrm{m} 2$.

Remarks. Among the specimens previously referred to Sparnacomys chandoni, several shows different features that do not fit with this species. We discuss them below. Additionally, we describe a new genus and species for four teeth stored with S. chandoni.

\section{? Genus and sp. indet. Size close to that of Sparnacomys chandoni}

M3. The AV-105 BN M3 (Fig. 50A) differs from M3 of $S$. chandoni in being widely basined, with a cingular metacone as high as the protocone. The buccal protoloph is short, separated from the paraconule, which joins the anteroloph at its buccal half. The short lingual protoloph reaches the extremity of the preprotocrista. The postparacrista dives to a short mesostyle, followed by the long sloping premetacrista. This makes an arcuate ridge with the metacone, the postmetacrista and the short posteroloph. The latter ends lingually by the low elevation of the hypocone. A notch (hypoflexus) separates the latter from the postprotocrista. There is no distinct metaconule or metaloph.

\section{? Sparnacomys indet. 1 Size smaller than Sparnacomys chandoni:}

M1. AV-398 L, -466 L, -599 L, and -714 L (Fig. 50B-E) are narrow mesiodistally, with an anterostyle weakly developed or absent (AV-714 L), and a weak parastyle except on AV-398 L.
Figure 49. Lower m3 of Sparnacomys chandoni Hartenberger, 1971 from Avenay (Ypresian, MP8-9, Bassin de Paris). A. AV-722 L, left m3; A1, (iew, A2, buccal aspect, A3, lingual aspect. B. AV-552 L, right m3; right $\mathrm{m} 3$; $\mathrm{C} 1$, occlusal view, $\mathrm{C} 2$, buccal aspect. $\mathrm{C} 3$, lingual aspect. D. AV80 L, left m3; D1, occlusal view, D2 lingual aspect. E. AV-102 L, right m3: occlusal view. Scale bar, $1 \mathrm{~mm}$. 
The other features are similar to those of M1 of $S$. chandoni.

M2. AV-4628 (Fig. 50F) is a small specimen, which has a wellmarked sinus and a short posteroloph, and is less symmetrical than M2 of $S$. chandoni. The buccal metaloph curves at its extremity to join the posteroloph, whereas it is separated from the metaconule. Paraconule and preparaconule are present.

d4. AV-744 L (Fig. 50G) is smaller than the d4 of S. chandoni, and displays distinct features. The roots of this $\mathrm{d} 4$ are arched and more divergent than that of $S$. chandoni. The occlusal pattern of this specimen is simpler than that of the $\mathrm{d} 4 \mathrm{~d} S$. chandoni, without any lophid or extra-ridge. The postmetacristid ends very low.

?Sparnacomys sp. indet. 2 of intermediate size between Sparnacomys chandoni and Pantrogna russelli, slightly smaller than $\mathrm{S}$. georgei

The association between the following M1 and M2 is only tentative.

M1. AV-691 BN and -984 BN (Fig. 50I-J) are among the largest specimens of that dental locus. They are longer relative to their width than M1 of S. chandoni. The preprotocrista of AV-984 BN and AV-691BN is nearly on the same mesiodistal line with the endoloph and the hypocone, like in P. russelli. The paraconule, attached by a short lingual protoloph to the preprotocrista extremity, is nearly as strong as the metaconule on AV-984 BN, and less on the other. The postparacrista and premetacrista are similarly arranged as in M1 of $S$. chandoni and $P$. russelli. The mesostyle is stretched mesiodistally and the mesoloph is absent on AV-984 BN but present on the other. The buccal metaloph is short and divided in two short crests, one oblique and low towards the strong metaconule, the other postwards connecting to the posteroloph.

M2. AV-662 L, -644 L, UM-AV-6835, and -729 BN (Fig. $50 \mathrm{~K}-\mathrm{L}$ ) differ from molars of $S$. chandoni in the junction of the protoloph with the preprotocrista, like for Pantrogna, the protocone being more elongated mesiodistally. They are more symmetrical than the M2 of $P$. russelli, due to the presence of a smaller hypocone. On UM-AV-729 BN and UM-AV-6835, there is a short spur distinct from the protoloph, lingual to the parastyle. The latter is moderately to weakly developed. The paraconule and metaconule are weakly developed on UM-AV-729 BN (and on the worn AV-662 L), more on UMAV-6835. The mesostyle is stretched mesiodistally (UMAV-6835 and AV-644 L) and the mesoloph is absent. These teeth recall the M2 of Sparnacomys georgei (Hooker, 2010, text. fig. 12). However, they are smaller.

\section{Genus Reinomys nov.}

Remarks. Four lower molars (App. S1), of size close as $S$. chandoni, display much distinguishable features, allowing characterizing a new taxon. We did not find any upper tooth that could be associated with these teeth. Michaux (1968: pl. 8, fig. 9) described one of the $\mathrm{m} 2$ as Microparamys nanus.

Derivatio nominis. The genus name derives from the French town of Reims, of which the locality of Avenay is close.

Type species. Reinomys rhomboides sp. nov.

Diagnosis of the genus. That of the type-species.

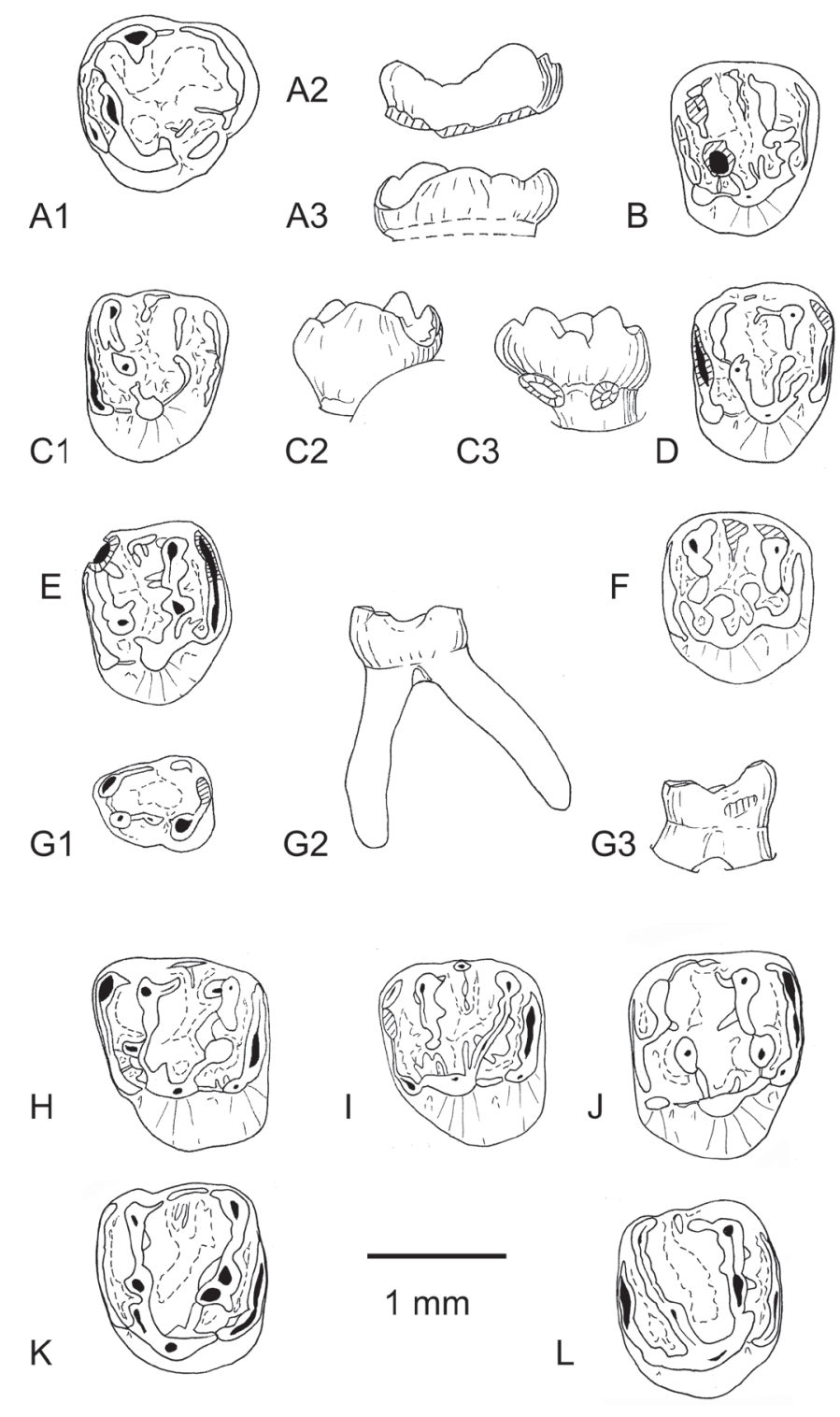

Figure 50. Gen and sp. indet., teeth previously identified as Sparnacomys chandoni from Avenay (Ypresian, MP8-9, Bassin de Paris). A. UM-AV-105 BN, left M3; A1, occlusal view, A2, buccal aspect, A3, lingual aspect. Sparnacomys sp. indet. 1 (B-G), smaller than S. chandoni. B. AV-714 L, right M1; occlusal view. C. AV-398 L, right M1; C1, occlusal view, C2, buccal aspect. C3, lingual aspect. D. AV-466 L, right M1; occlusal view. E. AV691 L, right M1; occlusal view. F. UM-AV-4628, left M2; occlusal view. G. AV-744 L, left d4; G1, occlusal view, G2, buccal aspect, G3, lingual aspect. Sparnacomys sp. indet. 2 (H-L), a little larger than S. chandoni. H. AV-691 L, left M1; occlusal view. I. UM-AV-691 BN, left M1; occlusal view. J. UMAV-984 BN, right M1; occlusal view. K. AV-6835 L, left M2; occlusal view. L. UM-AV-729 BN, right M2; occlusal view. Scale bar, $1 \mathrm{~mm}$.

\section{Reinomys rhomboides gen. et sp. nov.}

Figure 51

Holotype. AV-597 L, right m1 (Fig. 51A)

Derivatio nominis. Refers to the shape of $\mathrm{m} 2$, with the mesiolingually inclined metaconid

Type locality. Avenay (Marne, France; mid-early Eocene, MP8-9).

Diagnosis. Small basal Theridomorpha, size nearly similar to that of Sparnacomys chandoni. Differs from the latter in: 
- the enamel of flexids covered with tiny granules and rare very thin wrinkles; - the high metaconid mesially slanting and displaced mesiolingually with respect to the protoconid; - the generally complete, rarely incomplete, metalophulid I; - the short trigonid, higher than the talonid; - the cup-shaped basin, with flat floor and high surrounding walls, wheras the floor of the basin is concave in Sparnacomys.

Material and measurements. two m1(AV-597 L: $1.27 \mathrm{~mm}$ $\mathrm{x} 1.11 \mathrm{~mm}$; and worn AV $646 \mathrm{BN} ; 1.23 \mathrm{~mm} \times 0.88 \mathrm{~mm}$ ) and three $\mathrm{m} 2$ (AV-MNHN-6783: $1.34 \mathrm{~mm} \times 1.29 \mathrm{~mm}, \mathrm{UM}-\mathrm{AV}-742$ BN: $1.29 \mathrm{~mm} \times 1.20 \mathrm{~mm}$ and UM-AV 687: $1.24 \mathrm{~mm} \times 1.02$ $\mathrm{mm})$.

\section{Description.}

$\boldsymbol{m} 1$. The type AV-597 L is less worn than the other m1 UMAV-646 BN. The trigonid is clearly narrower than the talonid. It shows a high metaconid, inclined mesially and lingually. The postmetacristid dives to a short horizontal mesostylid ridge, at the lingual opening of the mesoflexid. This lingual ridge overlies the cup-shaped basin. A steep linguobuccal premetacristid joins the low anterolophid, ending in front of the mesial flank of the protoconid. Thereby, the anteroflexid is open buccally. There is only one complete metalophulid I (from the protoconid apex to the metaconid apex) on the type, closing distally the anteroflexid, the bottom of which is well higher than the talonid basin. On UM-AV-646 BN, an additional lingual metalophulid lines mesially the lingual metalophulid I, reducing the size of the anteroflexid. The posprotocristid dives up to the mesiodistal ectolophid, on which the mesoconid is weakly bulged, mesolophid and ectomesolophid short ridges being present and low. A short break marks the contact of the ectolophid with the short prehypocristid. The oblique posthypocristid connects to the non-salient hypoconulid and fuses with the posterolophid. A thin narrow slot separates the latter from the swollen and moderately stretched entoconid.

$\boldsymbol{m} 2$. Features of $\mathrm{m} 1$ described above are present on $\mathrm{m} 2$, with a few variations. The trigonid is only slightly less wide than the talonid. If the metalophulid I is complete on UM-AV-742 $\mathrm{BN}$, its buccal part only is present on AV-MNHN-6783, the lingual metalophulid I is limited to a short thin ridge, against the premetacristid. Thereby, the trigonid basin remains open distally. On the same tooth, there is a distomesial spur sloping to the buccal closure of the sinusid, and the swollen entoconid is crested, the latter joining the long and flat mesostylid ridge.

"Sparnacomys" georgei Hooker, 2010

Remarks. The species Sparnacomys georgei, showing a wide i.o.f. (hystricomorphous), has been described from Abbey Wood (early Eocene; Hooker, 2010). It was referred to the genus Sparnacomys, on the basis of "a centrally placed M1-2 protocone, with complete protoloph and metaloph, and equalsized anteroloph and posteroloph on M2, the extension of the preprotocrista buccally bypassing the newly formed crest of the protoloph joining the paraconule more distally" (Hooker, 2010: description, p. 32).

The protocone is central on the lingual wall of M2 only, and not on M1, for typical S. chandoni; complete protoloph and metaloph (with breaks on unworn and weakly worn teeth on $S$. chandoni) are similarly present in P. russelli; it is the same for the short free extremity of the preprotocrista. Therefore, these dental features cannot support the attribution to the only genus Sparnacomys. The wide i.o.f. of georgei being enlarged like at least two species of the younger Hartenbergeromys, $H$. marandati and H. hautefeuillei, the sister clade of Pantrogna
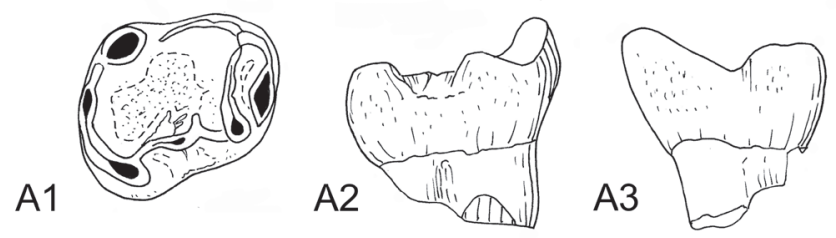

B1

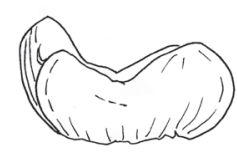

B2
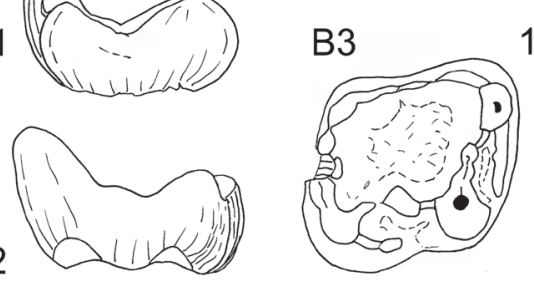

$1 \mathrm{~mm}$

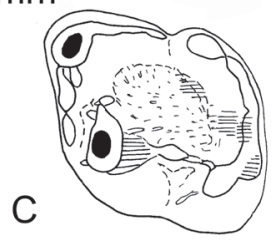

Figure 51. Reinomys rhomboides, nov. gen. nov. sp., from Avenay (Ypresian, MP8-9, Bassin de Paris). A. AV-597 L, right m1, Holotype; A1, occlusal view, A2, buccal aspect, A3, lingual aspect. B. AV-742 BN right m2; B1, buccal aspect, B2, lingual aspect B3, occlusal view. C. AV-MNHN-6783, left $\mathrm{m} 2$; occlusal view. Scale bar, $1 \mathrm{~mm}$.

russelli; it would be more parcimonious to refer georgei to Pantrogna or to Hartenbergeromys. However, the lingual width of the M1 is clearly narrower than the buccal one, as seen for Sparnacomys chandoni, and not for Pantrogna or Hartenbergeromys. The M2 is symmetrical and rectangular, with a long posteroloph, whereas it is more square and the posteroloph shorter in Pantrogna russelli. If the P4 is really wider than the M1-2, it is not generally the case for the P4 of $S$. chandoni. It is not possible to conclude that $S$. georgei represents a more primitive state than $S$. chandoni based on what we know about the variability of upper teeth of $S$. chandoni. It could even be the opposite, if we take into account the larger size of $S$. georgei and its wide P4.

\section{Superfamily and Family incertae sedis 3}

\section{Genus Pantrogna Hartenberger, 1971}

Genus type species. Pantrogna russelli (Michaux, 1964).

Original diagnosis (Hartenberger, 1971: 104; translation from French). "That of $P$. russelli".

Emended diagnosis (Escarguel, 1999; translation from French). "Microparamyini genus, medium to large sized; cheek teeth generally massive and bulbous, with wide and rounded cusps and cuspids, ridges initially weakly marked, but tending to develop. D4 with well-developed anterior (= anteroloph) and "lingual" (protocone and its arms?) cinguli. P4 with anteroloph reduced to absent; Hypocone generally present. M1-2 with lingual cingulum, hypocone, conules and mesostyle always well-developed. M3 triangular, with hypocone and lingual sinus generally present; metaconule developed. p4 bulbous and stocky. m1-2 with anterolophid strongly linked to the protoconid; strong mesoconid, tending to stretch transversely; posterior cingulid massive. $\mathrm{m} 3$ with mesoconid stretched transversely; hypolophid present, more or less complete; hypoconulid generally visible."

Remarks. Michaux (1968) has first described the species russelli from Avenay as a Microparamys. Based on a more abundant fossil material, Escarguel (1999) completed the description of this taxon, which is the type species of the 
genus Pantrogna (Hartenberger, 1971). From the results of our phylogenetic analyses, we propose that the two species from Prémontré referred to as two different genera, Pantrogna marandati and Hartenbergeromys hautefeuillei, form a clade (node K; Fig. 4), which is distinct and subsequently positioned with respect to the type species of the genus Pantrogna (i.e., $P$. russelli). Moreover, we will show below that the morphological distinctions (discrete dental differences) between the two species ( $P$. marandati and $H$. hautefeuillei) are better specific than generic distinctions. Therefore, we decided here to refer the species " $P$." marandati to the genus Hartenbergeromys in order to uphold the monophyly of the genera Pantrogna and Hartenbergeromys.

Emended diagnosis (new). Small sized basal Theridomorpha (Table 7), with large i.o.f. (i.e., hystricomorphous), protoconid strongly reduced or absent on $\mathrm{p} 4$. On lower molars, short and oblique postprotocristid, nearly as high as the mesoconid, bearing a premesoconid swelling/spur.

Differs from Sparnacomys in: - the larger size, even if small; the bulged and weakly salient main cusps and cuspids; the more frequent constant main extra-ridges along the lophs and lophids, sloping in the basins,

- On upper teeth, in the less acute main cusps. The hypocone less reduced and only exceptionally absent on P4. On D4, the hypocone only slightly more lingual than the protocone, or at the same level. On molars the protoloph connecting frequently to the preprotocrista, sometimes to the protocone. The preprotocrista and postprotocrista making a wide open $\mathrm{V}$. The protruding paraconule slightly lower to equal to the metaconule, and the preparaconule absent. The hypocone smaller than the protocone, but larger than on upper molars of Sparnacomys. The anterostyle and the short endoloph relatively weaker. The metacone less defined on M3, inasmuch as it merges in a linguobuccal pericingulum.

- On lower teeth, in the metaconid less higher than the other cuspids, the entolophid and lingual metalophulid I more often complete; the stronger oblique postprotocristid; the hypoconulid less defined, and stretched linguobuccally; the metaconid of $\mathrm{p} 4$ more lingual.

\section{Pantrogna russelli (Michaux, 1964)}

Figures 52-56

Microparamys russelli Michaux, 1964: p. 153-154, fig. Ig.

Microparamys russelli in Louis, 1966: p. Il.

Microparamys russelli in Michaux, 1968: p. 166-169, Pl. 9, figs. 1-16.

Microparamys sp. in Louis, 1970: p. 55.

M. (Pantrogna) russelli in Hartenberger (1971): p. 104-105.

Microparamys sp. 2 in Hartenberger (1971): p. 109-111, fig. 4a, P1. 5, figs. 2, 4.

M. cf. russelli in Louis et al., 1983: p. 11.

Pantrogna russelli in Escarguel (1999): p. 189; pl. 18 proparte and 19.

Holotype. AV-MNHN-4987, right m1-2.

Type locality. Avenay (Marne, Bassin de Paris: mid-early Eocene, MP8-9).

Original diagnosis (Michaux, 1964: 153). Size larger than that of Microparamys nanus Teilhard, 1922, upper molars with strong hypocone distinct from the metaconule; anterolophid distinct from the protoconid and hypolophid sketched on lower molars.

Emended diagnosis (Escarguel 1999; translation from French). "Species of the genus Pantrogna; bunodont cheek teeth; ridges weakly developed. Enamel surface smooth to weakly wrinkled.

D4 with relatively strong "lingual cingulum" (= protocone and its arms); P4 bulbous, without anteroloph; hypocone and mesostyle generally present; M1-2 with massive "lingual cingulum", hypocone, conules and mesostyle well-developed, protoloph and metaloph reduced to absent; M3 triangular with hypocone and sinus present, metacone weakly reduced and metaloph generally absent. $\mathrm{d} 4$ with trigonid basin open distally; p4 bulbous and stocky, ectolophid and mesolophid reduced to absent; m1-2 with anterolophid better linked to the protoconid than in Sparnacomys, mesoconid and posterolophid massive; m3 with complete anterolophid and metalophulid, ectolophid absent, mesoconid stretched buccolingually, hypoconulid individualized".

Remarks. All along its description, Escarguel (1999) compared russelli to Sparnacomys chandoni from the same locality. "In total, P. russellifrom Avenay (Bassin de Paris, MP8-9) is therefore characterized by rather massive cheek-teeth, with low but wide and bulbous cusps, and low and relatively reduced ridges... These teeth are sensibly more bunodont and less lophodont than Sparnacomys chandoni from the same locality" (Escarguel, 1999: 193). The comparison with the younger P. marandati from Prémontré (Bassin de Paris, MP10) is less thorough. Escarguel only noted that the ectolophid is more developed in P. marandati than in P. russelli (p. 197); he also remarked that as in P. russelli, the $\mathrm{P} 4$ in $P$. marandati have a reduced to absent anteroloph; the upper molars are morphologically similar, those of $P$. marandati being nonetheless more massive and bulbous. Moereover, he described a new genus and a new species from Prémontré, Hartenbergeromys hautefeuillei (Escarguel, 1999). Both genera were included among the Microparamyini (Ischyromyoidea). Based on the large i.o.f. of the two species found in Prémontré, both Hartenbergeromys and Pantrogna cannot be considered as protrogromorphous (as originally considered), and as such cannot be included among the protrogomorphous Ischyromyoidea.

We failed to find strong diagnosic and differential features for separating the two genera Hartenbergeromys and Pantrogna in the original descriptions and diagnoses of the two species from Prémontré. However, we have found some dental characters distinguishing the two species, like the shape of $\mathrm{p} 4$, or the more or less fused buccal roots of P4, but it is not enough to support a generic distinction. There are lower jaws of $H$. hautefeuillei, but none of $P$. marandati, which could have yielded more differential characteristics. However, we do not retain Pantrogna as a distinct genus from Hartenbergeromys for the species from Prémontré. Elsewhere, teeth from other localities have been approached to Hartenbergeromys, but according to us, based on non-convincing features: we will see that $H$. hautefeuillei from Hérault localities, such as Mas de Gimel or Naples, strongly differ from the type species (VianeyLiaud et al., in prep.), and should be later described as new genus and species.

Emended diagnosis (new). Species of Pantrogna smaller and faintly lower crowned than Hartenbergeromys. Slender extra-ridges along the lophs and lophids; on upper molars, lingual metaloph connection with the postprotocrista; short ectocingulid on $\mathrm{p} 4$, with weak wrinkles on the buccal flank. 
On lower molars, generally only one lingual metalophulid I, sometimes short, lower than the buccal metalophulid I, and variably merged to it; entolophid generally incomplete, exceptionally complete.

Material and measurements (see App. S. 1; Table 7). Among the ten D4 ascribed here to Pantrogna russelli, three were previously referred to Sparnacomys chandoni by Escarguel (1999). Twenty-eight P4 are here referred to P. russelli from Avenay. Among them, two were previously considered as Sparnacomys (AV-395 L and -505 L) (Escarguel, 1999). The M1-M2 previously referred (Escarguel, 1999) to russelli are slightly re-distributed: finally, $34 \mathrm{M} 1$ and 34 M2 are here tentatively referred to this species from Avenay. Measurements are plotted on a bivariate graph (Fig. 52): M1 are slightly wider and longer than M2. We have observed 28 (25 measured) M3: they are as long as the M2, but narrower. All the teeth are significantly larger than those of Sparnacomys chandoni, from the same locality (Table 7).

Sixteen d4 were referred to P. russelli (Escarguel, 1999). Among them, one is absent of the material we have observed (AV-MNHN-14675) and two are p4 (UM-AV-195 and UM$\mathrm{AV}-254)$. The remaining $\mathrm{d} 4$ are slightly shorter but less wide than the $\mathrm{d} 4$ of $H$. hautefeuillei from Prémontré, and clearly larger than the $\mathrm{d} 4$ of $S$. chandoni. Twenty-two teeth are referred to as $\mathrm{p} 4$ of $P$. russelli from Avenay. They are wider for the majority (14/22), and three only are longer (AV-228 L: Fig. $55 \mathrm{G}$; $\mathrm{AV}-366 \mathrm{~L}$, and $-716 \mathrm{~L}$ ) than the $\mathrm{d} 4$. The size variation is wide, between the three latter and the others.

Among the material referred by Escarguel (1999) to m1 and $\mathrm{m} 2$ of $P$. russelli from Avenay, we observed $37 \mathrm{~m} 1$ and $44 \mathrm{~m} 2$; a few teeth are of intermediate size between these and teeth referred to Sparnacomys chandoni, and their morphology is slightly distinct from russelli. The $\mathrm{m} 1$ differ from the $\mathrm{m} 2$ mainly in their talonid basin, which is slightly higher and transversely shorter than the talonid. The $\mathrm{m} 2$ have same length and are only faintly wider than $\mathrm{m} 1$ (Fig. 52B; Table 7).

Twenty-seven $\mathrm{m} 3$ were referred to $P$. russelli (Escarguel, 1999 , p. 314). We observed 20 of them, and the $m 3$ figured in Michaux (1968, pl.9, fig. 13). We retained only 17 specimens as documenting $P$. russelli. Another (AV-623 L) is smaller than the $\mathrm{m} 3$ of $P$. russelli, but stronger than the $\mathrm{m} 3$ of $S$. chandoni; however, due to its simpler pattern, we consider that specimen

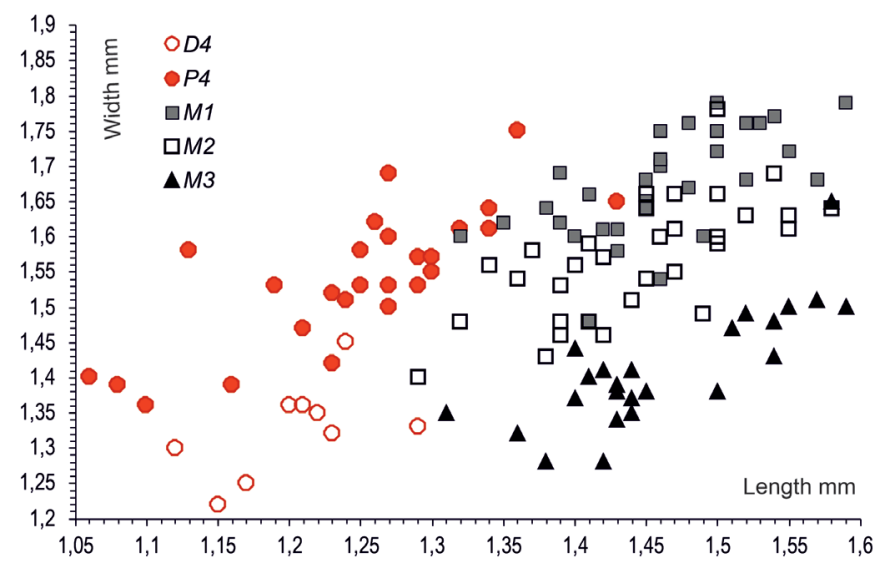

Figure 52. Bivariate graphs (Length $x$ Width) of upper teeth (A) and lower teeth (B) of Pantrogna russelli (Michaux, 1964) from Avenay (Ypresian, MP8-9, Bassin de Paris). Graduations as millimetres. as a large variant of $\mathrm{m} 3$ of $S$. chandoni. The last two (AV5060 and -5718) are quite larger, with a high trigonid and a mesiodistal and reduced postprotocristid: they do not belong to Pantrogna (cf. p. 115-116).

\section{Description.}

Upper teeth. (Figs. 53-54) The cusps are bulged, slightly protruding from the edge of the crown.

D4. Their shape is trapezoidal. The main cusps are slightly bulged. The hypocone is present, smaller than the protocone, and slightly more lingual, except for AV-633 L, on which the two cusps are at the same lingual level. Between these two main lingual cusps, there is a short endoloph, slightly lower than the protocone and hypocone apices, and the sinus is absent or weakly marked. The parastyle is weak, stretched in the anteroloph, beginning at the level of the buccal edge of the paracone, except on AV-251 L on which it turns buccally. The long and low anteroloph reaches the mesial flank of the preprotocrista, separated from it on the less worn teeth (AV-251 L and AV-587 $\mathrm{L})$ or connected to on the others. Once, its lingual end swells as an anterostyle (AV-257 L). The paraconule is more or less (AV$341 \mathrm{~L}$ ) protruding, once attached both to the anteroloph and to the preprotocrista $(\mathrm{AV}-257 \mathrm{~L})$ : there, it occupies the position of a preparaconule, as seen on Sparnacomys. The buccal half of the protoloph is short and transverse, its lingual half, which bears the paraconule, is low and joins the mesial end of the preprotocrista. The metacone is as developed as the paracone. The short buccal half of the metaloph is parallel to that of the protoloph. It connects to the rounded metaconule by a lower ridge. This metaconule is slightly stronger than the paraconule and the lingual metaloph joins the postparacrista.

The mesostyle, slightly protruding buccally, is stretched mesiodistally, and double at least in three specimens (AV-257 $\mathrm{L},-373 \mathrm{~L}$, and $-508 \mathrm{~L}$ ). It joins generally the postparacrista and sometimes the premetacrista. A short buccal mesoloph develops from the mesostyle (6/10). Even if they are hardly distinguishable, due to wear, two short extra-ridges descend from the buccal part of the protoloph, two other from the buccal metaloph, and another from the metaconule to the center of the mesoflexus. On AV-587 L or AV-341 L, one of these ridges can correspond to a weak metalophule I, whereas the thick buccal

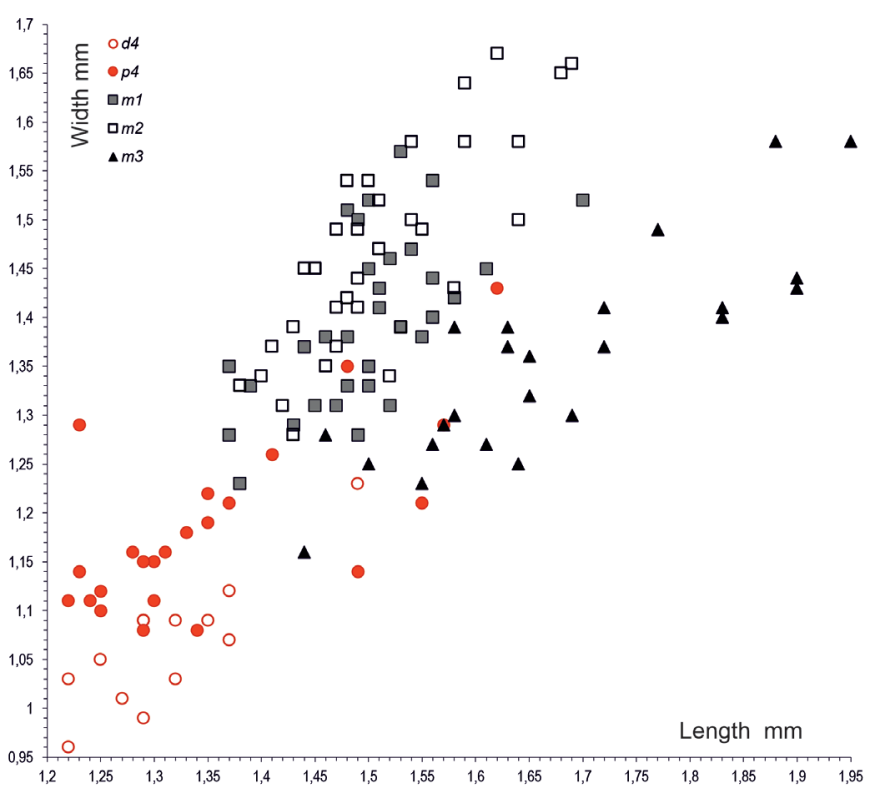


metalophule II connects to the posteroloph (3/6). Same features are present in the species hautefeuillei from Prémontré.

$\boldsymbol{P} 4$. All the P4 display very close buccal roots; these roots sometimes are contiguous, and in one case are fused like in Hartenbergeromys hautefeuillei. The occlusal crown outline of $\mathrm{P} 4$ shows some shape variation. It varies from nearly triangular (UM-AV-89 BN, -94 BN, -198 BN, AV-MNHN-244 BN, AV-

A1
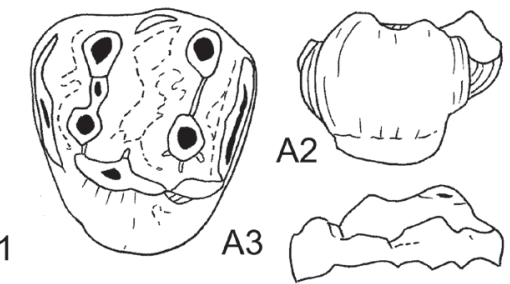

B1
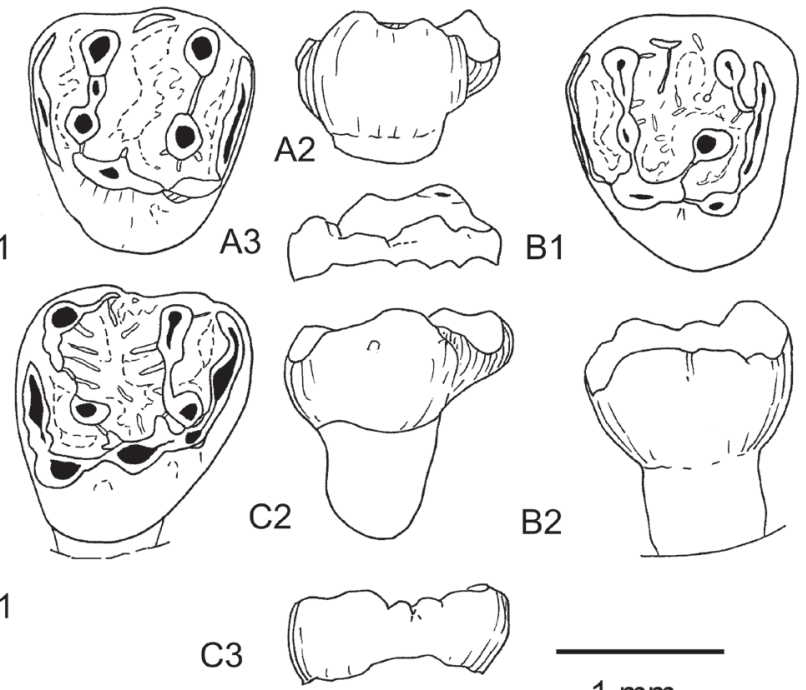

B2

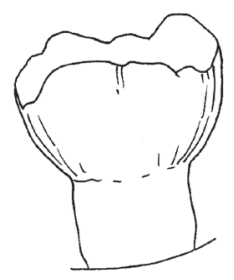

$1 \mathrm{~mm}$

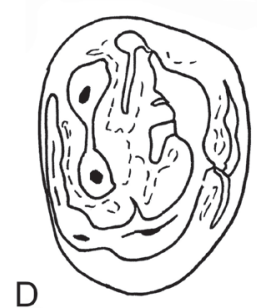

E1

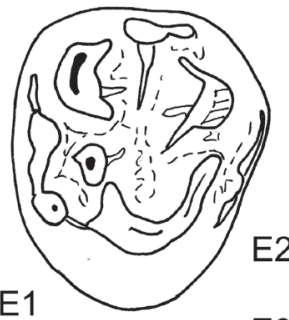

E3
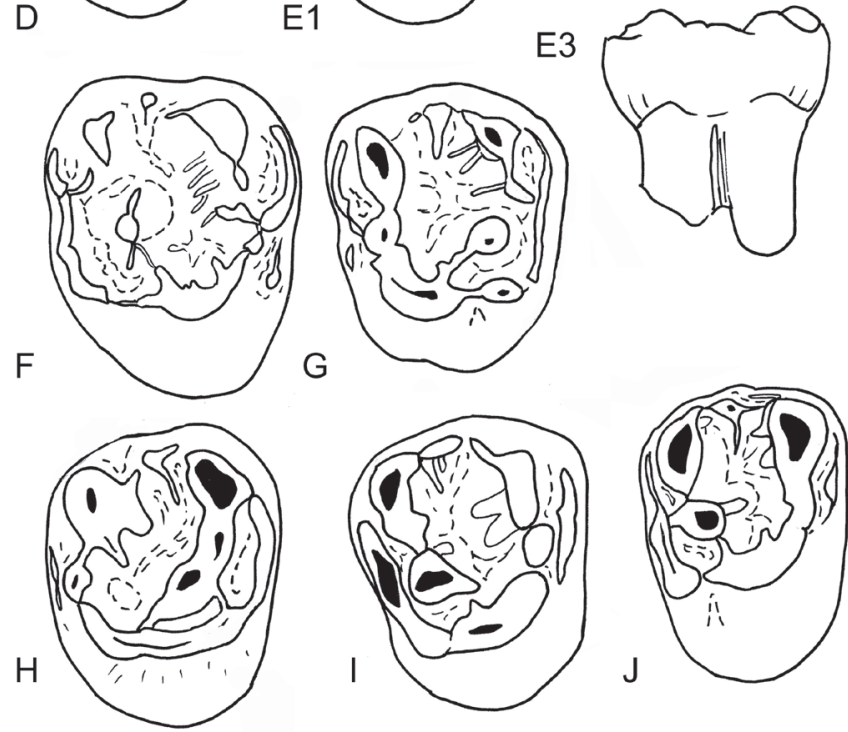

Figure 53. Upper D4 and P4 of Pantrogna russelli (Michaux, 1964) from Avenay (Ypresian, MP8-9, Bassin de Paris). A. AV-251 L, left D4; A1, occlusal view, A2, lingual aspect, A3, buccal aspect. B. AV-341 L, left D4; B1, occlusal view, B2, lingual aspect. C. AV-257 L, right D4; C1, occlusal view, C2, lingual aspect, C3, buccal aspect. D. AV-651 L, right P4: occlusal view. E. AV-364 L, right P4: E1, occlusal view, E2, lingual aspect, E3, buccal aspect. F. AV-312 L, right P4; occlusal view. G. UM-AV-198 BN, left P4; occlusal view. H. AV-356 L, left P4; occlusal view. I. AV-MNHN-4927, right P4: occlusal view. J. AV-359 L, right P4: occlusal view. Scale bar $1 \mathrm{~mm}$.
$258 \mathrm{~L},-312 \mathrm{~L},-339 \mathrm{~L},-351 \mathrm{~L},-354 \mathrm{~L},-356 \mathrm{~L},-364 \mathrm{~L},-505 \mathrm{~L}$, $-527 \mathrm{~L},-728 \mathrm{~L},-4927$, and -7180$)$ to ovoid (AV-188 L, -345 L, -359 L, -395 L, -571 L, -612 L, -651 L, UM-AV-198 BN, and UM-AV-6771). The ovoid shape relates to the paraconemetacone proximity, a more or less buccally protruding mesostyle, and a well-marked hypocone. The protocone is larger and higher than the hypocone. The hypocone varies from small but well defined, to reduced; it is absent on one specimen (AV-258 L). The anteroloph is always present and very low, continuous, or sometimes divided in a buccal part -the longestand a short lingual part (UM-AV-198-BN; AV-312 L, -354 L, $-612 \mathrm{~L}$, and $-728 \mathrm{~L}$ ). The anteroflexus and posteroflexus are narrow mesiodistally. The paracone is often slightly more buccal than the metacone. The buccal protoloph, thick and short, ends at the small to reduced paraconule. The latter can attach to the anteroloph, via a short anterolophule, or they can remain separate. The lingual end of the paraconule can be free, or attached to the buccal extremity of the preprotocrista. The mesostyle is single (16/22), rarely doubled mesially by a slender thickening of the postparacrista. A more or less long buccal mesoloph is frequent $(14 / 21)$. The postparacrista and premetacrista are generally present, lowering at the connection with the mesostyle, the first being the strongest. The buccal metaloph is thick and bucco-lingual. It joins a strong metaconule at its base or, once (UM-AV-198 BN), it turns distally to the posteroloph. The metaconule is rarely isolated (AV-345 L and $-364 \mathrm{~L}$ ). The lingual metaloph runs mesially to connect to the postprotocrista.

The posteroloph is long, from the posthypocrista to the mesiobuccal flank of the metacone. Like for D4, generally two short extra-ridges descend from the lophs and one from the metaconule to the center of the central basin.

M1-2. The M1 versus M2 occlusal crown outlines of Pantrogna russelli ressemble those characterizing $H$. marandati or $H$. hautefeuillei. On M1 and M2 of all these species, the paracone is more buccal than the metacone, and the metacone is, even, more lingual on M2. On M1, the parastyle is not thicker than on $\mathrm{M} 2$, and not more elongated; it is more often curved buccally on M1 than on M2; the hypocone is more reduced and buccal on M2, and the posteroloph is shorter. On some M2, the outline pattern is nearly symmetrical, when the hypocone is small and the anterostyle strong (e.g., AV-347 L and -570 L).

On M1, the parastyle is well defined and often turns, closing the anteroflexus buccally. On M1 and M2, the paracone is slightly swollen and merged in the transverse buccal protoloph. As seen on the buccal aspect of teeth, paracone and metacone are roughly equal in size. The anteroloph (and posteroloph) are less high than the protoloph and metaloph, mainly in their buccal halves. The anteroloph is not, or is weakly, wrinkled posteriorly; it links a small anterostyle ending free against the mesial flank of the preprotocrista. The latter generally ends free, as a more or less short spur. It is sometimes long and linked through a short anterolophule to the anterostyle (M1: AV-348 L and -822 L; M2: AV-449 L) or to the paraconule (M2: AV-219 L, $-352 \mathrm{~L}$, and $-654 \mathrm{~L}$ ). The anteroflexus is less wide mesiodistally than the mesoflexus, and wider than the posteroflexus. On some teeth, the buccal protoloph bears mesially and rarely distally two short weak extra-ridges. It connects to the paraconule, which protrudes mesially like the preparaconule of Sparnacomys chandoni; it never fuses with the anteroloph. At the beginning of the lingual protoloph, following the paraconule, a short extra-ridge, distally oriented, is sometimes present. On M1, the protoloph generally joins the mesial part of the preprotocrista, and, more often on M2, the 


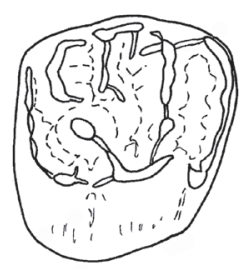

A1

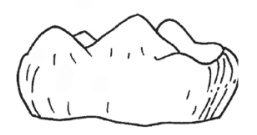

A2
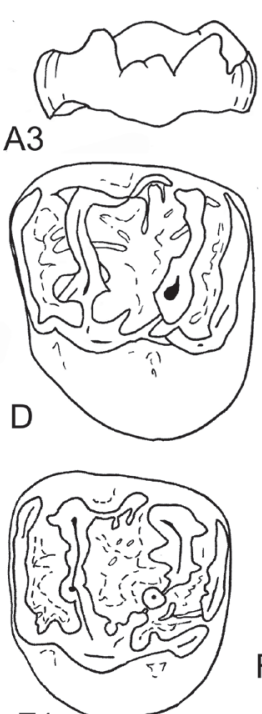

F1

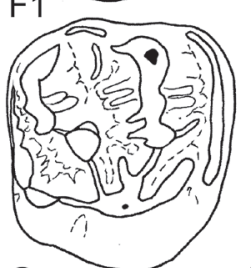

$\mathrm{G}$

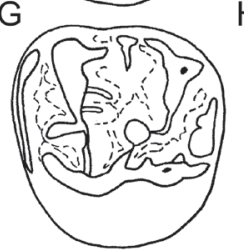

$\mathrm{J}$

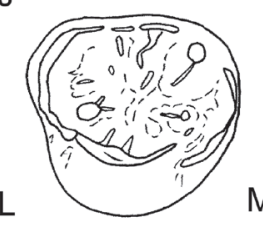

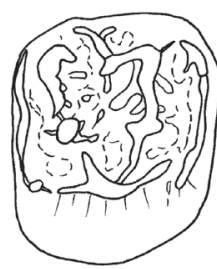

B1

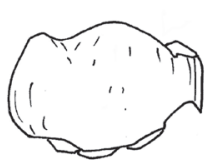

B2

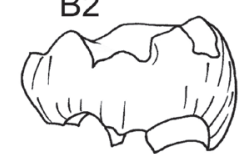

B3
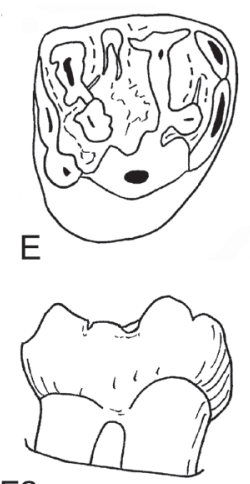

$\mathrm{F} 2$

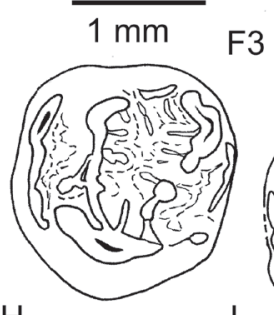

$\mathrm{H}$

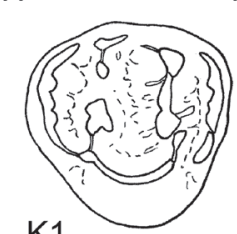

$\mathrm{K} 1$

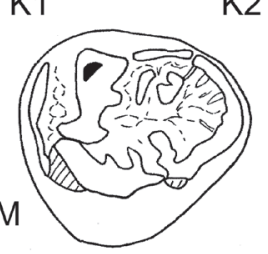

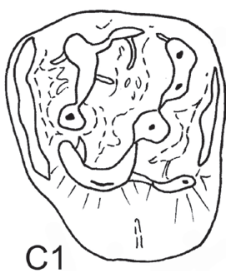
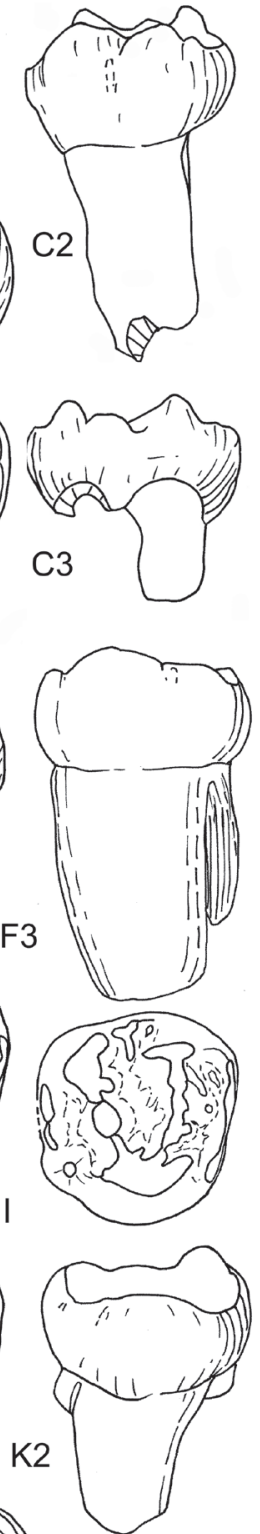

Figure 54. Upper molars of Pantrogna russelli (Michaux, 1964) from Avenay (Ypresian, MP8-9, Bassin de Paris). A. UM-AV-7213, right M1; A1, occlusal view, A2, lingual aspect, A3, buccal aspect. B. AV-199 BN, right M1; B1, occlusal view, B2, lingual aspect, B3, buccal aspect. C. AV-765 L, left M1; $\mathrm{C} 1$, occlusal view, $\mathrm{C} 2$, lingual aspect, $\mathrm{C} 3$, buccal aspect. D. AV-822 L, left M1: occlusal view. E. UM-AV-6834, right M1: occlusal view. F. UM-AV-95 BN, left M2; F1, occlusal view, F2, buccal aspect, F3, lingual aspect. G. AV518 L, right M2; occlusal view. H. AV-654 L, left M2; occlusal view. I. AV570 L, right M2: occlusal view. J. AV-240 L, left M2: occlusal view. K. AV382 L, right M3; K1, occlusal view, K2, lingual aspect. L. AV-237 L, right M3: occlusal view. M. AV-519 L, left M3: occlusal view. Scale bar; 1 mm. connection is closer to the protocone apex.

The mesostyle is faintly buccal in position with respect to the paracone-metacone axis. It is generally slightly stretched mesiodistally, and underlined buccodistally by a short ectoflexus. It generally prolonges in one short buccal mesoloph, rarely two (UM-AV-723 BN, UM-AV-6834, UM-AV-7213, AV$347 \mathrm{~L}$, and AV-546 L). A thin postparacrista descends on the distal flank of the paracone towards the mesostyle from which it separates by a narrow pinched notch. Another narrow notch separates the mesostyle from the strong premetacrista. On M2, there is sometimes a thin extra-ridge parallel to the mesoloph from the mesial end of the premetacrista. The metacone makes an arch with the buccal metaloph, more arcuate on M2 than on M1. Two extra-ridges more (on M2) or less (M1) well defined descend distomesially from the buccal metaloph; in any cases, they are more visible than in $S$. chandoni. The metaconule is bulbous, hardly stronger than the paraconule; it connects to the transverse buccal metaloph only by a thin and low ridge, and rarely completely separates (AV-189 L). The lingual metaloph connects to the postprotocrista, close to its apex, or more posteriorly, but before the endoloph. On its mesial side, the metaconule bears rarely a short extra-ridge.

The protocone is robust, with its long pre- and postprotocristae making a wide obtuse angle, not completely aligned mesiodistally with the endoloph. The latter is lower than these arms and very short. It caps a short internal sinus, weakly marked at the upper part of the crown, or absent in a few cases (AV-765 L and UM-AV-245), and a narrow cleft can be present below the sinus. The hypocone is smaller and lower than the protocone. Its anterior and posterior arms are nearly absent. On moderately or unworn teeth, the hypocone is separated from the posteroloph by a narrow notch.

Wear affects the cusps and plunging lophs to make a mesiodistal gutter at mid-width of the teeth, when the buccal and lingual cusps remain higher. When present, the weak extra-ridges converge to the middle of the basined mesoflexus. The enamel of the vertical lingual flanks of the crown appears smooth, whereas it is generally rough on less worn or unworn teeth. The lingual root is strong and vertical on M1, slightly inclined distally on M2. The small buccal roots are distinct from below the crown.

M3. Their occlusal crown outlines vary from circular to triangular or trapezoidal. The extra-ridges are not numerous, and, when present, they are slender and low. The teeth are cupshaped: the anteroloph, mesostyle area, posteroloph-metacone and the arms of the protocone have the same elevation, surrounding the central basin. From this kind of pericingulum, two cusps are moderately emerging (less than for $S$. chandoni): the paracone is the most protruding cusp, followed in height by the protocone. The hypocone is much reduced or absent; the sinus is faintly marked or absent. The paraconule is small, not linked to the buccal protoloph on two unworn teeth (AV$237 \mathrm{~L}$ and AV-763 L), and connected to it on two others (AV-382 L and AV-626 L). The lingual protoloph fuses with the preprotocrista, but this arm can be short and ending free: the connection of the protoloph occurs more distally on the protocone. Both connections can occur. The generally unique mesostyle is stretched mesiodistally, closing more or less completely the buccal opening of the mesoflexus. There are one or two short, low and weak mesolophs, sometimes reduced to faint extra-ridges. The metacone is slightly higher than the arcuate distal cingulum, which expands more (AV-599 L and UM-AV-703) or less (AV-383 L, $-370 \mathrm{~L}$, and $-626 \mathrm{~L}$ ) the tooth posteriorly. This cingulum does not connect to the extremity 
of the postprotocrista, whereas the metacone can join the metaconule. This metaconule is frequently isolated.

Lower teeth. (Fig. 55) The trigonid basin is only slightly higher than the talonid basin. The latter is cup-shaped on molars; the flat floor area is restricted underneath the lingual wall, when the entolophid and mesolophid ridges are developed.

d4. The metaconid is the highest cuspid but it is quite less protruding than that of $S$. chandoni. All d4 have their metaconid slightly more mesial than the protoconid. These two cuspids are close bucco-lingually, so that the anterior part of the tooth is narrow. A more or less long anterolophid develops generally from the protoconid or from the metaconid. It is sometimes bulged in a small anteroconid (UM-AV-1012, -125, -192, and AV-515 L). Generally, a metalophulid I develops, like on some teeth of $S$. chandoni, and on the few $\mathrm{d} 4 \mathrm{~d} H$. marandati, and it is often complete; it is absent on one specimen $(\mathrm{AV}-515 \mathrm{~L})$. It closes distally a small, short mesiodistally and shallow trigonid basin. One very low mesiodistal ridge descends frequently $(11 / 13)$ from the metalophulid I area. The posmetacristid lowers gradually, but this ridge may show a slope break at the mesostylid level, before the lingual opening of the mesoflexid. The postprotocristid is relatively slender, postwardly directed, bearing a short lingual spur on UM-AV-125 and -192 . The ectolophid (mesial and distal to the mesoconid) is very short and low below the wear surface on weakly worn teeth; the mesoconid bulges moderately, without ectomesolophid. A short low mesolophid can occur (UM-AV-7254, -1012, -599, AV-392 $\mathrm{L},-624 \mathrm{~L}$, and $-718 \mathrm{~L}$ ). There is also a short postmesoconid (spur or ridge) on UM-AV-146, -192, -1012, and AV-624 L. The prehypocristid is short and low, absent on unworn teeth. The sinusid is asymmetrical, widely open and short buccolingually.

The hypoconulid is slightly prominent at the extremity of the posthypocristid, and then merges with the short posterolophid; it is bulged and rarely stretched buccolingually. The posterolophid is sometimes absent or reduced to a thin ridge ending against the entoconid distal flank. There is frequently a short transverse lingual entolophid; there may be granules and weak extra-ridges along the entolophid path. On the larger d4 (UM-AV-146; Fig. 55D) these extra-ridges are directed to a long postmesoconid ridge. The extra-ridges are variably present, generally as tiny granules, or thin wrinkles; they may be absent (UM-AV-125 and AV-515 L).

p4. The mesial and distal roots are shortly fused below the crown and the distal one is somewhat flattened posteriorly. The crown is nearly as high lingually as buccally. The buccal enamel surface is sometimes rough. The metaconid is mesiolingual, less high and voluminous than in S. chandoni. Its base is less wide buccolingually than that of $H$. hautefeuillei, and much less than $H$. marandati. The lingual postmetacristid is strong; it rarely ends in a short lingual mesolophid (UM-AV-140) and often shows a break of slope and lowering at the mesostylid level, on weakly worn teeth. The mesoflexid opening is narrow. The trigonid is relatively wider (compared to the talonid) than on $S$. chandoni or H. hautefeuillei, and like H. marandati. This is in relation with the path of the low premetacristid + anterolophid, which is first linguobuccally oriented, before sloping distally. This lophid is short on AV-233 L, -245 L, and $-557 \mathrm{~L}$; it may be rarely longer, making a weak cingulid parallel to the protocristid ridge, and slightly crenulated. When present, it ends at the level of the beginning of the buccal edge of the sinusid. One or two long extra-ridges descend from the metaconid apex to the center of the basin: they are more distinct than on S. chandoni, slightly less strong than in H. marandati. More buccally, another and thicker low ridge descends posteriorly: it corresponds to a buccal metalophulid I prolonged by the protocristid, indistinct from the postprotocristid and ectolophid. The protoconid is not visible, weak to absent, indistinct from the protocristid ridge. The ectolophid swells slightly at the mesoconid, rarely prolonged lingually by a generally short mesolophid (UMAV-140, -195, -685, -193; AV-228 L, and -366 L). There can be a postmesoconid spur or ridge (UM-AV-5667, -7668, -685, and AV-589 L). The ectomesolophid is rarely present and weak (AV-740 L, -245 L, and -366 L). The sinusid is not deep, and the crown relatively high below. The entoconid is relatively small and isolated. The entolophid is never complete; it may be limited to a short lingual part, free and directed towards the postmesoconid spur/ridge or rarely towards the posterolophid. The weakly bulged hypoconulid is at the extremity of the long
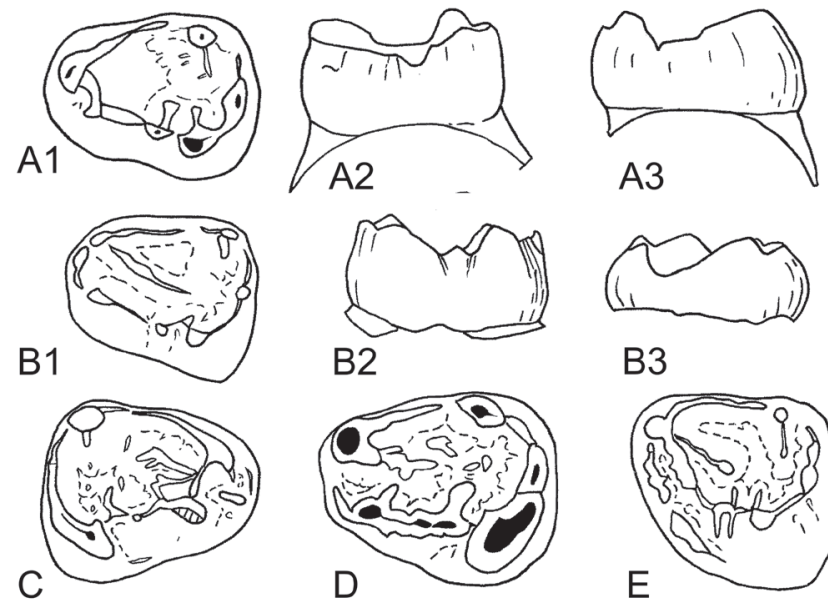

B2

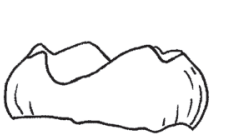

B3
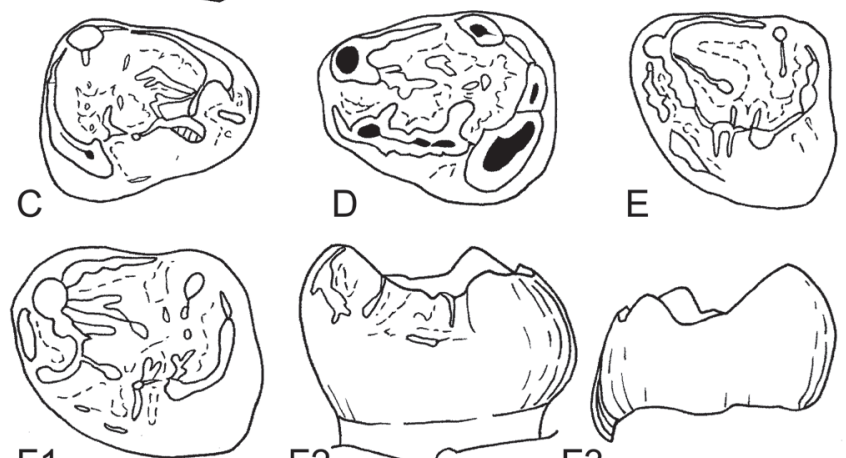

F1
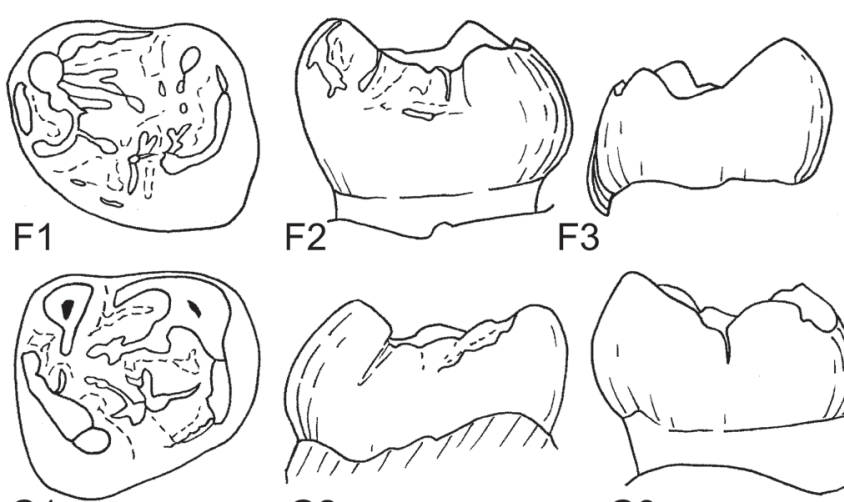

G1

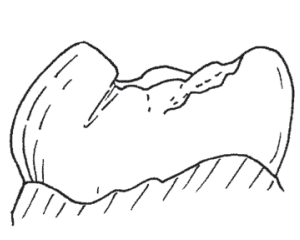

$\mathrm{G} 2$
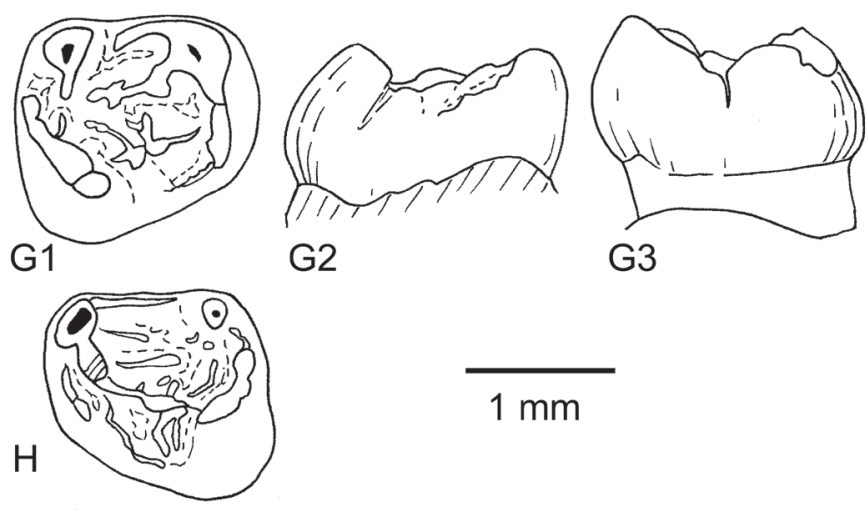

G3

Figure 55. Lower d4 and p4 of Pantrogna russelli (Michaux, 1964) from Avenay (Ypresian, MP8-9, Bassin de Paris). A. AV-718 L, left d4; A1, occlusal view, A2, lingual aspect, A3, buccal aspect. B. AV-515 L, left d4; B1, occlusal view, B2, buccal aspect, B3, lingual aspect. C. UM-AV-192, right d4: occlusal view. D. UM-AV-146, left d4: occlusal view. E. UM-AV-140, left p4: occlusal view. F. AV-366 L, left p4; F1, occlusal view, F2, buccal aspect, F3, lingual aspect. G. AV-228 L, right p4; G1, occlusal view, G2, buccal aspect, G3, lingual aspect. H. UM-AV-685, left p4: occlusal view. Scale bar, $1 \mathrm{~mm}$. 
posthypocristid. Then, the posterolophid is short, ending at the base of the isolated entoconid. Extra-ridges and granules are weak, absent to variably present in the basin, or in the sinusid.

$\boldsymbol{m}$ 1-m2. We first describe the holotype (right $\mathrm{m} 2, \mathrm{AV}-$ MNHN-4987) and the variations within the assemblage are then developed.

The metaconid is the highest cuspid. Its posterior arm (postmetacristid) slopes moderately to the lingual opening of the mesoflexid, which forms a wide V. From the distal end of the postmetacristid, there is a very short low linguobuccal ridge. It is rarely present on the other m1-2. The mesostylid is absent. The anterolophid is in line with the sloping premetacristid, both making a long straight ridge narrow at its upper part (on unworn teeth) and thick at its base. There is no distinct anteroconid. A short anterocingulid is present on the holotype (rarely present on the other teeth), limiting a weak shallow antesinusid. This can be blocked lingually by a weak buccal anterolophulid. The latter connects to the apex of the protoconid on worn teeth only.

The premetacristid is double distally only in one case (AV$490 \mathrm{~L}$ ). The metalophulid I is complete (its low and sloping lingual part connected to its stronger and more horizontal buccal part) on the holotype and on $34 \mathrm{~m} 1$ and $38 \mathrm{~m} 2$; in a few cases (one $\mathrm{m} 1$ and four $\mathrm{m} 2$ ), the two parts are shallowly separated by a more or less narrow break. The buccal main cuspids are generally slightly distal to the lingual ones. There is a short oblique postprotocristid, nearly as high as the mesoconid, bearing a premesoconid swelling/spur. The ectolophid + mesoconid are mesiodistally oriented on the type and the majority of teeth. The mesial and distal parts of the ectolophid are clearly lower than the postprotocristid and mesoconid, both being very short. They can be somewhat offset lingually with respect to the mesiodistal axis. As on $S$. chandoni, the mesial ectolophid is lower than the distal one, and a break appears at at the mesial ectolophid level on weakly worn teeth. The mesoconid is generally moderately bulged or slightly mesiodistally stretched. On the type and generally, it bears distally a postmesoconid swelling or short lingual ridge whereas a short mesolophid distinct from the postmesoconid is rarely present (AV-507L and AV-508L). Nearly all the teeth display one long ectomesolophid, and once, two ectomesolophids (AV$521 \mathrm{~L})$. The sinusid is not deep, and the crown is relatively high below. The sinusid is bounded buccally by one (AV-692 $\mathrm{L}$ and UM-AV-579 BN on which the ectomesolophid is short) or two (AV-484 L) ectostylid(s). Wrinkles or extra-ridges along its enamel flanks, or a mesiobuccal spur of the hypoconid are very rare.

The entolophid is complete on the holotype, encompassing a low transverse lingual entolophid fusing with the oblique postmesoconid ridge and swelling. This kind of connection occurs on $19 \mathrm{~m} 1$ and $\mathrm{m} 2$. On 33 teeth, the junction between the lingual part and the postmesoconid ridge is not fused, and the components of this entolophid are variably low. Rarely, in addition to the postmesoconid ridge, there is a short buccolingual spur from the prehypocristid (AV-455 L). On some teeth (e.g., AV-330 L or AV-337 L), the entolophid is made of discontinuous low extra-ridges. On five teeth, the lingual part of the entolophid is postwardly oriented, towards the hypoconulid, and it reaches the latter on seven teeth. On unworn teeth, like UM-AV-136 or UM-AV-738, we can distinguish the posthypocristid, lower than and as long as the hypoconulid. Lingually to the latter, the posterolophid is short, and always separated from the entoconid, even on worn teeth. The hypoconulid is slightly stretched buccolingually, and only slightly salient on a few unworn teeth.
From the metaconid area to the center of the basin, there can be only one little oblique low extra-ridge, or some others mainly from the lingual metalophulid (AV-361L, $-522 \mathrm{~L}$, and $-601 \mathrm{~L})$. There are a few extra-ridges on the holotype, then

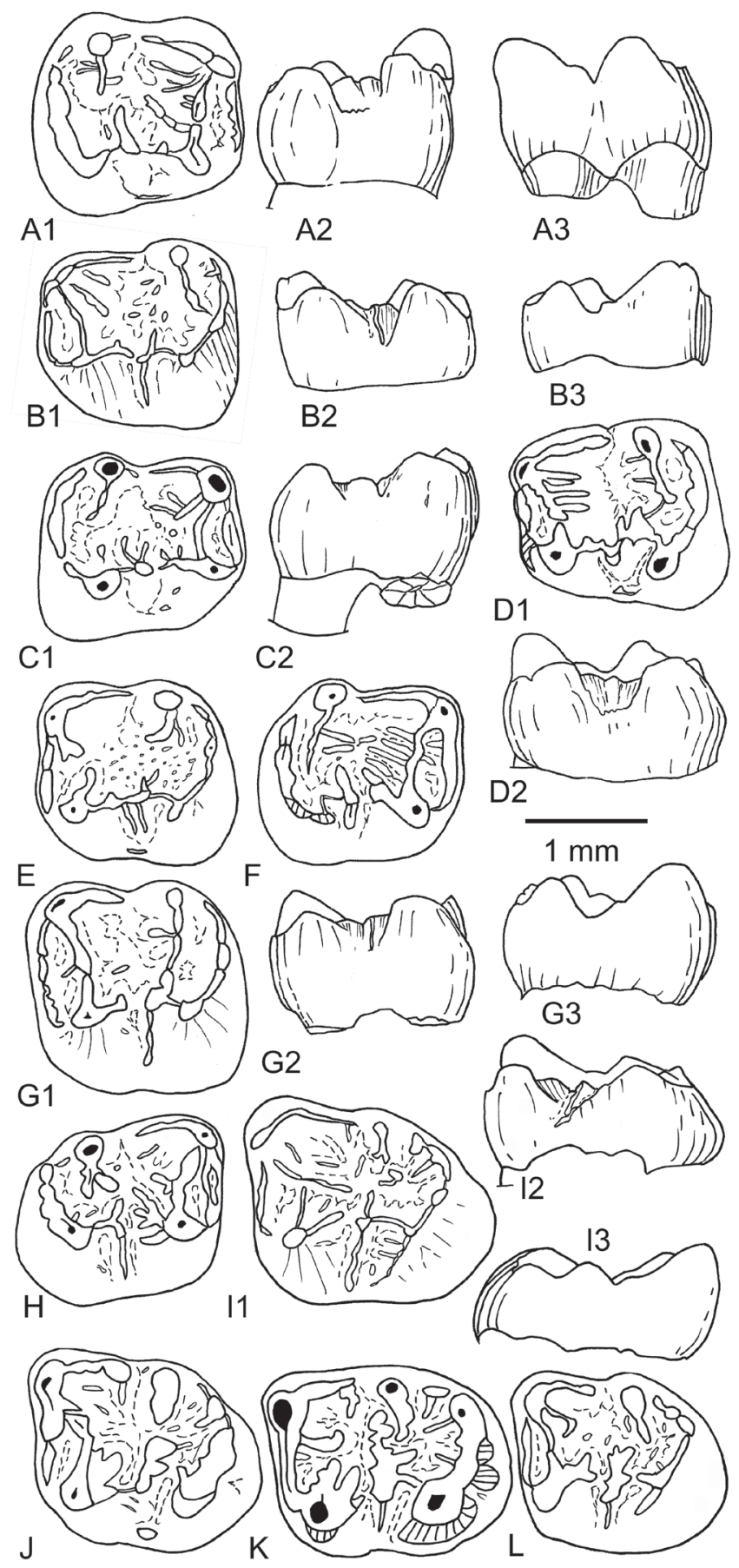

Figure 56. Lower $\mathrm{m} 1$ (A-D), $\mathrm{m} 2$ (E-G) and $\mathrm{m} 3$ (H-L) of Pantrogna russelli (Michaux, 1964) from Avenay (Ypresian, MP8-9, Bassin de Paris). A. AV$764 \mathrm{~L}$, right $\mathrm{m} 1$; A1, occlusal view, A2, buccal aspect, A3, lingual aspect. B. AV-490 L, left $\mathrm{m} 1$; B1, occlusal view, B2, buccal aspect, B3, lingual aspect. C. AV-533 L, right $\mathrm{m} 1$; C1, occlusal view, C2, buccal aspect. D. AV314 L, left m1; D1, occlusal view, D2, buccal aspect. E. AV-520 L, left m2: occlusal view. F. AV-601 L, right m2: occlusal view. G. AV-524 L, left m1; G1, occlusal view, G2, buccal aspect, G3, lingual aspect. H. AV-250 L, right m3: occlusal view. I. AV-247 L, left m3; I1, occlusal view, I2, buccal aspec t, I3, lingual aspect. J. UM-AV-699 BN, left m3: occlusal view. K. AV-353 L, left m3: occlusal view. L. AV-495 L, left m3: occlusal view. Scale bar, 1 mm. 
more on the other $\mathrm{m} 2$ than on the $\mathrm{m} 1$. Discrete granules are sometimes present on the enamel surface of the talonid and posterosynclinid (e.g., AV-490 L, -503 L, and -520 L). The enamel of the outskirts of the crown is rarely rough.

$\boldsymbol{m} 3$. The $\mathrm{m} 3$ are only slightly narrower and longer than $\mathrm{m} 2$ (Fig. 52B). They differ from $\mathrm{m} 1$ and $\mathrm{m} 2$ in their reduced posterolophid. Their other features are the same as those characterizing $\mathrm{m} 1-\mathrm{m} 2$, with a more frequent occurrence of extra-ridges. The metaconid is more mesial than on $\mathrm{ml}$ $\mathrm{m} 2$; therefore, the lingual metalophulid I often starts closer to the linguobuccal premetacristid. The distal end of the postmetacristid is more often (10/17) swollen or prolonged by a short linguobuccal extraridge, like a lingual mesolophid. The unworn AV-247 L (Fig. 56I) allows distinguishing the main features of this species:

- Strong thick oblique postprotocristid (stronger and longer than on Sparnacomys);

- Metalophulid I with its oblique lingual and transverse buccal parts converging to the middle of the tooth;

- Low and short ectolophid (mesial part very low, broken at the occlusal surface; distal part higher, before the short and slightly higher prehypocristid);

- Mesoconid prolonged by a long ectomesolophid (the buccomesial spur of the hypoconid, long in this case);

-Wrinkled enamel buccal surface of the crown. For this tooth, and for all $\mathrm{m} 3$, the postmesoconid ridge coincides in position with the mesolophid. Here, it is distinct from the discontinuous ridges marking the position of the entolophid: two short ridges slope transversely from the entoconid, another is mesiodistal and directed towards an extra-ridge from the hypoconulid.

\section{Genus Hartenbergeromys Escarguel, 1999}

Type species. Hartenbergomys hautefeuillei Escarguel, 1999.

Type locality. Prémontré (Aisne, Bassin de Paris; late early Eocene, MP10).

Referred species. Hartenbergeromys marandati (Escarguel, 1999) comb. nov., previously referred to as Pantrogna marandati Escarguel, 1999, from Prémontré.

Original diagnosis (Escarguel, 1999: 201; Translation from French). "Microparamyini of medium size. Dental pattern between Pantrogna and primitive Theridomyidae. Protrogomorph infraorbitary foramen. Tendency to hypsodonty. P4 with anteroloph reduced or absent, but paracone well-developed. Upper molars of primitive type, with hypocone smaller than the protocone; lingual sinus variable; protoconule present, stretched mesiodistally, before the protoloph; metaconule massive; mesostyle well-developed. Hypocone and sinus generally absent on M3. Lengthened p4; continuous ectolophid, sometimes lined buccally; m1-3 with low anterolophid, weakly or not cuspate; anterior arm of the protoconid (= buccal metalophulid) not joining the metaconid; strong postprotocristid, joining the mesoconid and prolonged in a complete hypolophid; hypoconulid reduced but present".

Remarks. The dental features of this original diagnosis included features of other assemblages than that of Premontré, i.e., that of the Hérault localities Mas-de-Gimel and Naples. However, these show strong differences with the type locality. Moeover, as we do not keep the species parvus from Messel in the genus Hartenbergeromys, the dental features of these assemblages are therefore no more taken in account for the genus diagnosis.
Emended diagnosis. Basal Theridomorpha, with protoconid strongly reduced to absent on $\mathrm{p} 4$.

Small sized rodent, larger than Pantrogna.

Differs from Pantrogna:

- In its slightly higher unilateral hypsodonty and in the extraridges often more numerous.

- On upper molars, in its paraconule strongly protruding from the protoloph. In the hypocone slightly more developed, and in the presence of a higher endoloph. In the anterostyle higher than the anteroloph, generally developed at the end of the preprotocrista (= protostyle). In the metaconule(s) often separated or connected variably to the postprotocrista or to the endoloph, exceptionally to the hypocone.

- On lower teeth in the higher and stronger metalophulid I and entolophid, with lingual part of metalophulid I frequently joining its buccal part, and bearing long mesiodistal extraridges; the entolophid more often complete, its buccal part connected to the postmesoconid spur-ridge, or to the junction distal ectolophid-prehypocristid; the sinusid slightly deeper.

Morphological, size analysis and comparative description of Hartenbergeromys marandati (Escarguel, 1999) and Hartenbergeromys hautefeuillei (Escarguel, 1999) from Prémontré (Aisne, Bassin de Paris; late early Eocene, MP10).

Holotypes. H. hautefeuillei: UMPRE-138, left m2 (Fig. 67H); Hartenbergeromys marandati: SLP29PR-498, right m2 (Fig. 69A).

Remarks. These two species have been defined from the same locality, Prémontré (Escarguel, 1999), but differential diagnoses based on discrete features are lacking (see below). In order to stress the similarities and differences between these two species from Prémontré, we compare and describe successively the assemblages previously referred to each. Then, we establish new diagnosis for the two species, also providing a differential diagnosis.

Maxillary. (Plates 1-2)Two maxillaries bearing teeth have been referred to Hartenbergeromys hautefeuillei (SLP29PR-1312: right, incomplete, bearing M1 to M3; and SLP29PR-1211, left, incomplete, with M3). One right maxilla bearing M1 to M3 (SLP29PR-960) and a more fragmentary right one with M1 were originally determined as Pantrogna marandati. There are also two toothless maxillary fragments, undetermined (MSPRE-17 and -67).

All the specimens in which the infraorbitary region is preserved show an enlarged i.o.f. It is the case for SLP29PR-1312 (H. hautefeuillei), for which the bottom of the i.o.f. appears widely open, contra Escarguel (1999, p. 205) who supposed it was reduced and protrogomorphous; it is the same on SLP29PR-1211, where the i.o.f. is slightly more complete. Similarly, the i.o.f. of SLP29PR-960 (H. marandati) is widely open at its base. It is likely that a significant portion of the masseter medialis was passing through such a large i.o.f. The two species are considered here as hystricomorphous.

On the bases of these fragmentary maxillae, the differences between the two taxa are actually weak. On both fragments of $H$. hautefeuillei, the edge limiting the shallow fossa for the insertion of the masseter superficialis ends at the mesial border of the (D3?)P3 alveolus. It is partially broken on $H$. marandati, but it seems to be the same. The masseteric fossa, on the ventral surface of the zygomatic arch, is well marked on both, its outer 
edge ending against the front of the P4 alveolus (Plate 2). The arch is slender (narrower?) in $H$. hautefeuillei than in $H$. marandati: these observations suggest that the SLP29PR-960 specimen was an elderly adult, whereas SLP29PR-1312 documents an older individual (with much more worn teeth).

The toothless MSPRE-17 and -67 maxillaries are probably specimens of $H$. hautefeuillei, given their size and the slenderness of the zygomatic arch, and the closely appressed P4 buccal roots alveoli on MSPRE-67, whereas these are more separated in $H$. marandati. The wide and high i.o.f. is more complete on MSPRE-67 than on the other maxillary specimens.

The occurrence of (D3?)P3 is not a differential diagnostic character between the two species inasmuch as this tooth is present on both.

Dentary. (Plate 2) Only three fragments of right dentary are documented. The SL29PR-2012 specimen was originally identified as Pantrogna marandati with an anterior tooth considered as a p4. We identify this tooth as a d4 (not a p4) inasmuch as the roots are divergent and the protoconid is present. Because of the morphology of this $\mathrm{d} 4$, we suggest that this dentary is better documenting Hartenbergeromys hautefeuillei. The two other SLP29PR-1278 and SLP29PR-1185 dentaries are $H$. hautefeuillei (Escarguel, 1999). If we compare the size of the alveoli of $\mathrm{m} 1$, the position of the foramen mentale (in front of the anterior root of the teeth), the distance between the symphysis and the anterior alveolus of $\mathrm{p} 4$ or $\mathrm{d} 4$, the pinched ridge underlining the edge of the diastema curving mesiolingually, these dentaries are very similar. SL29PR-2012 differs from SLP29PR-1278 and SLP29PR-1185 in its slender horizontal ramus, and narrower incisor alveolus. SLP29PR-1185 is slightly more complete than -1278. It displays the same features. Moreover, it is possible to see on its buccal face that the junction of the two masseteric crests stands below the separation between $\mathrm{m} 1$ and $\mathrm{m} 2$; the ramus ascendens uplift above the alveolar level begins at the m2-m3 contact.

The differences between SL28PR-2012 and the two other dentaries could be ontogenetic, the slender being the juvenile with $\mathrm{d} 4$, the strongest, the adults with $\mathrm{p} 4$ or with $\mathrm{m} 1$. All could belong to the same species, Hartenbergeromys hautefeuillei, and no one seems to document $H$. marandati. The snout appears short with divergent lower jaws, and strong, high (ventrodorsally) incisors.

Size variations of teeth (Figs. 57-58); Table 8.

Length and width of the different loci of teeth of the two species have been compared via an ANOVA: The P4, M1, M2, M3 and the $\mathrm{m} 1, \mathrm{~m} 2, \mathrm{~m} 3$ of $H$. marandati are highly significantly larger than those of $H$. hautefeuillei ( $\mathrm{p}$ value $<0.01$ ). The average size of D4, d4 and p4 of $H$. marandati is larger than the average size of $H$. hautefeuillei, but the data are not numerous enough to apply ANOVA (Table 8).

\section{Morphological variations of dental features.}

Upper teeth. (Figs. 59-61)

DP3-P3. The alveolus only is preserved on the maxillary fragments.

D4. Hartenbergeromys marandati. The only D4 referred to H. marandati from Prémontré (SLP29PR-418) is pristine; therefore, buccal cusps and conules are sharp, and the ridges narrow. It is wider than the P4, but its length corresponds to the average of the P4 lengths (Fig. 58A; Table 8). The parastyle is a slender arcuate ridge, from the buccal base of the paracone to the anteroloph, leaving a wide anteroflexus, as wide as the mesoflexus. Its bottom is finely wrinkled. The anteroloph is made of three aligned small swellings that would fuse on more worn teeth. A shallow and narrow antesinus underlines the lingual swelling, the anterostyle. Then it connects lingually to a long and oblique (buccomesial to distolingual) preprotocrista. The latter, compressed and stretched, is on the same line as the protocone and the short postprotocrista. The small hypocone has a similar oblique direction. The protocone and hypocone are linked by a short endoloph. A shallow sinus underlines this endoloph lingually. The paracone is acute and the buccal protoloph thin and transverse. It bifurcates, giving a short low mesiodistal ridge ending at the bottom of the mesoflexus, this low ridge being doubled buccally by two lower extra-ridges. The main part of the buccal protoloph turns forward to a protruding strong paraconule, which occupies the wide anteroflexus: it has the same position as the preparaconule seen in Sparnacomys chandoni; it is strong, elongated distomesially, and linked to the anteroloph by a short anterolophule. There is a very low lingual protoloph directed to the base of the preprotocrista. The postparacrista, which has the same shape as in $P$. russelli or $S$. chandoni, runs distally to reach a protruding mesostyle buccally, which is linked lowly with the metacone through the premetacrista. The apex of the metacone and buccal metaloph make an arcuate ridge, which then angles mesially, and runs parallel to the buccal protoloph up to the strong metaconule. The mesiodistal flank of the metaconule is lowly connected to the mid-protocone through the lingual metaloph. The long buccolingual posteroloph joins the distal end of a short postparacrista. The posteroflexus is narrow. There is rare and very low extra-ridges.

Hartenbergeromys hautefeuillei. (Fig. 59B-E). There are seven D4 referred to $H$. hautefeuillei, one of them being rolled and worn. PL670 is a D4 germ (unerupted deciduous premolar); therefore, its shape differs slightly from the others, with slender lophs, and more acute cusps and conules. They differ from the D4 of H. marandati in their size well inferior (Fig. 57A, Table 8 ) and distinct occlusal crown outline. This is due to the less arcuate and less protruding parastyle, and to the less lingual hypocone than in $H$. marandati. Most of them are triangular, the less being the figured D4 (SLP27PR-343 in Escarguel, 1999: pl. 22i). The parastyle is not, or weakly, swollen, and generally ends at the base of the paracone; on PLPRE-670 and SLP27PR- 533, it turns slightly buccally and much more on SLP27PR-343, where it makes a weak para-ectocingulum nearly reaching the mesostyle. The latter is stronger than on D4 of $H$. marandati. The anteroflexus is narrower than on $H$. marandati, like in $P$. russelli, and the mesoflexus is wider than on $H$. marandati. The paracone and metacone are slightly bulged. A weak and short postparacrista is present on PLPRE-785 and SLP29PR-187, and absent on the others. This is a difference with Pantrogna russelli, H. marandati and $S$. chandoni, on which the postparacrista is stronger. The path of the buccal protoloph is transverse, like on $H$. marandati, but its end is not bifid; one or two very low extra-ridges are present like in $H$. marandati; one runs parallel to the buccal protoloph on PLPRE-785.

The buccal protoloph joins mesially a well-protruding paraconule (however slightly less mesial than in $H$. marandati), which is not stretched but rounded, and generally not attached to the anteroloph. On SLP27-PF-343 and PLPRE-785, there is a weak and low anterolophule. The lingual part of the protoloph is heading towards, or fused to, the preprotocrista; once to the apex (PLPRE-670) of the protocone. The latter is less stretched than in $H$. marandati. The mesostyle is generally swelling, connected distally to the premetacrista and lingually 
to a more or less short buccal mesoloph; this is not distinct on the worn and damaged SLP29PR-1817 specimen. On the latter, the mesostyle is duplicated. The metacone is not arcuate and the premetacrista is short. The buccal metaloph joins a rounded metaconule on the whole teeth, except on PLPRE-896, where there is a shallow break between them. The metaconule lowly attaches to the postprotocrista or to the protocone. The hypocone, lesser developed than the protocone, is more or less lingual than the latter, but in any cases less than on the D4 of H. marandati, and not more as it was previously thought (Escarguel, 1999). The short posthypocrista turns to the posteroloph less abruptly than in $H$. marandati. This posteroloph is long and reaches the corner of the tooth, at the mesiobuccal base of the metacone. The posteroflexus is narrow.

P4. (Fig. 60) Among the material considered in Escarguel (1999) as documenting $H$. hautefeuillei, one (UMPRE-119) is smaller than all the others are; it is described separately, as a possible different species. One other small P4 is much damaged (PLPRE-938), and it cannot be considered. The distribution of the larger P4 of $H$. hautefeuillei overlaps that of the smaller $\mathrm{P} 4$ of $H$. marandati. The previous descriptions of the P4 of these two species do not provide significant morphological differences, except the "anterior cingulum" sometimes absent in H. marandati and "rarely absent" in H. hautefeuillei, the hypocone more developed in $H$. marandati, the mesostyle not
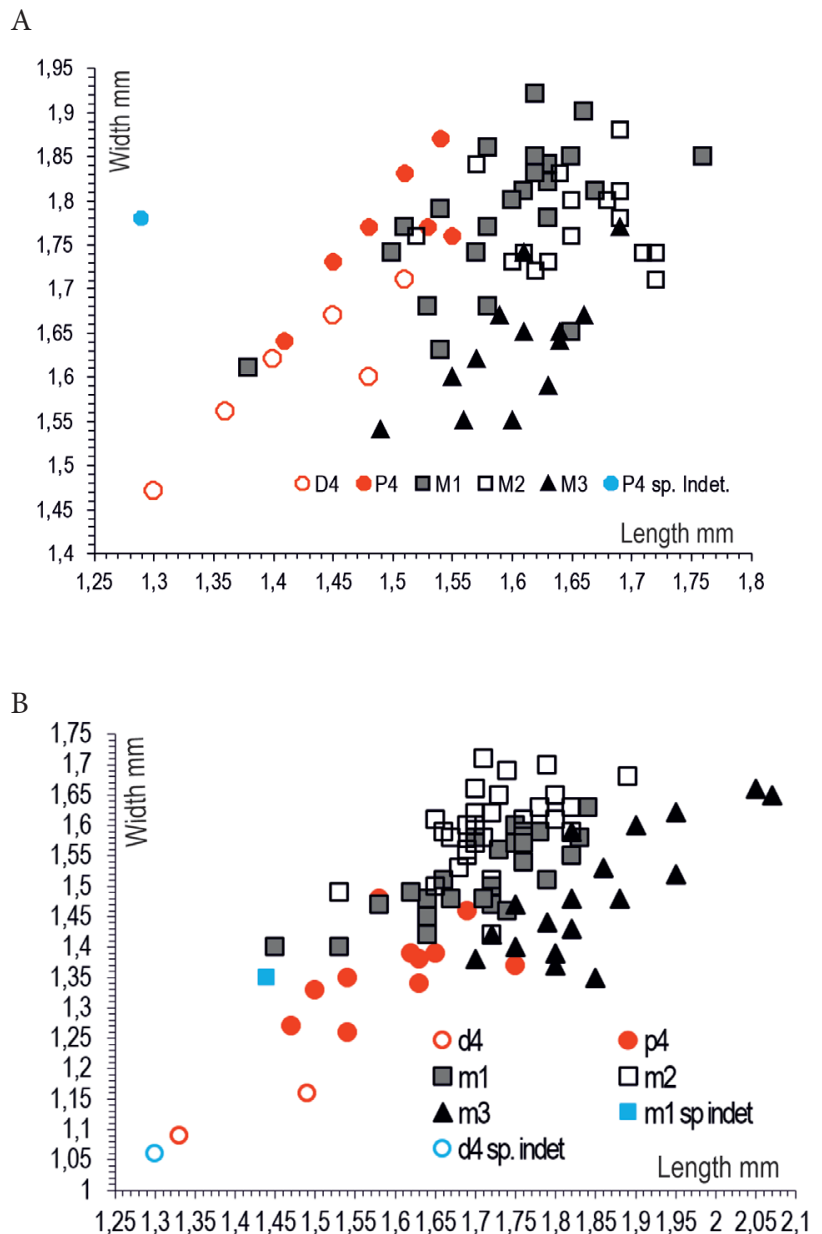

Figure 57. Bivariate graphs (Length $x$ Width) of upper teeth (A) and lower teeth (B) of Hartenbergeromys hautefeuillei Escarguel, 1999 (black marks) and sp. indet. (red marks) from Prémontré (late Ypresian, MP10, Bassin de Paris). Graduations as millimetres. well-developed in H. hautefeuillei. Here, we can improve the description and provide some different features for each.

The buccal roots of $\mathrm{P} 4$ of $H$. marandati are well separated from the base of the crown (except one, SLP29PR-118) and then are divergent. This appears also on the maxillaries (SLP29PR-960 and -2000). Even if the tooth is absent, it is clear that the buccal alveoli are well separated by a thick bony partition, whereas this wall is thin between the mesiobuccal alveolus of $\mathrm{P} 4$ and the (D3)P3 alveolus. It is the reverse on the maxillaries of $H$. hautefeuillei (SLP29PR-1312, MSPRE-17, and -67): the partition is thin between the buccal roots and thick between the (D3)P3 alveolus and the mesiobuccal alveolus of P4. The buccal roots of $H$. hautefeuillei are fused or very close near the base of the crown (cervix), then diverge slightly. Only SLP29PR-1445 has the two buccal roots separated from their base, and then the buccodistal one is oblique. We have observed this root fusion in $P$. russelli and $S$. chandoni, but not in $H$. marandati.

Hartenbergeromys marandati. (Fig. 60F-J). On the 18 P4, the parastyle is not discernible; the anteroloph, always present, nearly reaches the buccomesial corner of the paracone on 14; it turns bucco-postwardly on SLP29PR-1715 (Escarguel, 1999: Pl. 21, fig. i) towards a short para-ectocingulum at the buccal base of the paracone. It is shorter on the three others. This anteroloph generally fuses with the mesiobuccal extremity of

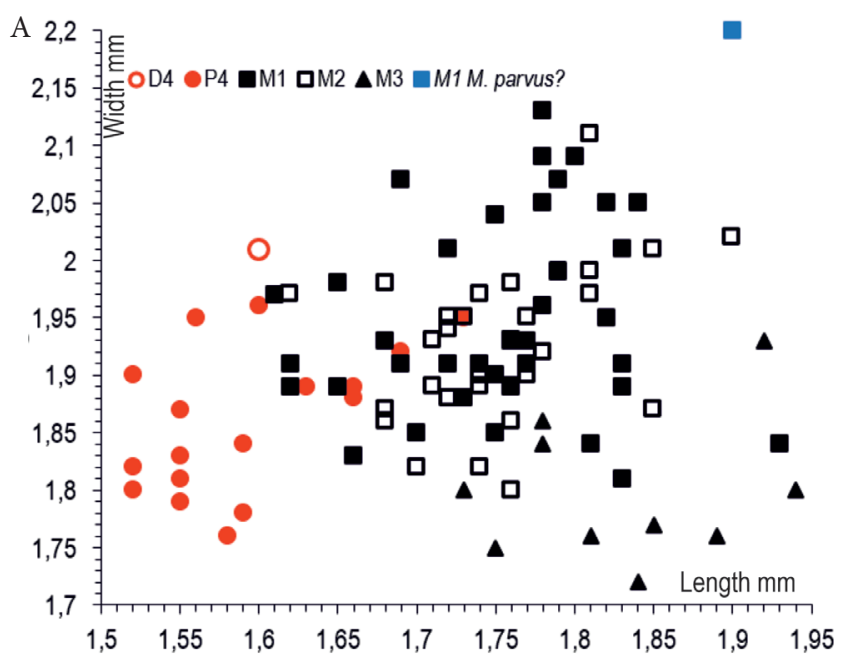

B

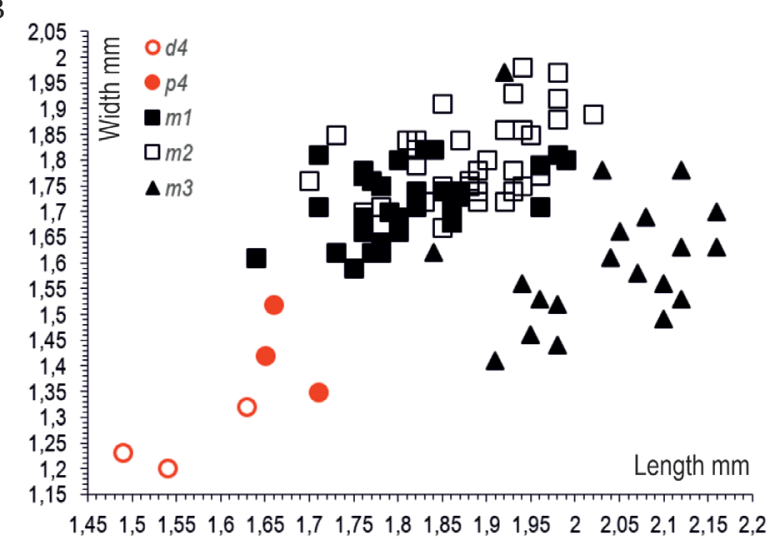

Figure 58. Bivariate graphs (Length $x$ Width) of upper teeth (A) and lower teeth (B) of Hartenbergeromys marandati (Escarguel, 1999) (black marks) and ?Masillamys parvus (blue mark for $\mathrm{m} 1$ ) from Prémontré (late Ypresian, MP10, Bassin de Paris). Graduations as millimetres. 


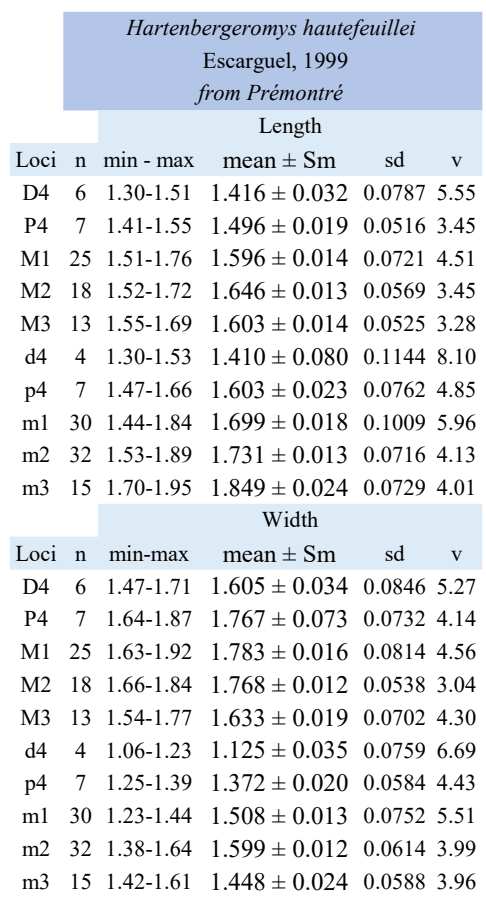

Table 8. Size variations of the different loci of teeth of Hartenbergeromys hautefeuillei Escarguel, 1999 and Hartenbergeromys marandati (Escarguel, 1999) from Prémontré (MP10; Bassin de Paris). Comparisons of the size (Length $\mathrm{x}$ Width) of the different loci of teeth between these two species through ANOVAs, in association with a test $\mathrm{F}$ of significance $(\mathrm{P}<0.01)$. the preprotocrista. The anteroflexus is rarely complete at the level of the protocone (SLP29PR- 307, -366, and PLPRE-540). It may be broken in two parts when a forwardly oriented buccal protoloph joins it (SLP29PR-194, -269, -900, and -1607). More often, it is shortened by the mesial position of the paraconule (as a preparaconule), which becomes fused buccally to the anteroloph and lingually to the terminus of the preprotocrista. The paraconule is placed on the protoloph and well distinct from the anteroloph on PLPRE-540, SLP29PR-366 and -1609. The paracone is thicker than $(11 / 18)$ or equal to $(7 / 18)$ the metacone. This is because the paracone is prolonged in a short, high and thick buccal protoloph, whereas the buccal metaloph is thinner and lower, often divided in two short metalophules (I, mesial; II, distal); the buccal metalophule II is postwardly oriented, and sometimes joins the posteroloph (SLP29PR-71, $-269,-900,-1607$, and -1609). A short postparacrista is generally present, rarely joining the mesostyle. The premetacrista is shorter, rarely joining the mesostyle (SLP29PR-269). This is stretched mesiodistally, sometimes it is double (SLP29PR-194, $-366,-1584$, and -2046) or triple (SLP29PR-1607). It is often $(14 / 18)$ prolonged in a short buccal mesoloph. There are sometimes short ectocinguli (SLP29PR-1609 and -2046) or long (SLP29PR -1715).

The hypocone is small and frequently not bulged at the lingual end of the posteroloph. Therefore, the endoloph is short (absent on the unworn SLP29PR-609), and the sinus absent or weakly marked. The posteroloph is generally long from the hypocone to the base of the mesial flank of the metacone. The posteroflexus is narrow. There are extra-ridges in the mesoflexus, often two main from the protoloph, and more from the metaloph and the metaconule. The floor of the mesoflexus is narrow on a few teeth (SLP29PR-194, -304, and -900), slightly wider on the others.

Hartenbergeromys hautefeuillei. (Fig. 60A-E). Six P4 are referred to this species among the material from Prémontré (one other is too much worn to be described), triangular and smaller than $H$. marandati. As there are six teeth only, the morphological variability is lesser characterized.
Like in $H$. marandati, the parastyle is not swollen and the anteroloph is rarely long (PLPRE-783). The paraconule can be along the protoloph, distinct from the anteroloph (PLPRE-783). More often, it fuses with the anteroloph mesially and with the preprotocrista lingually, like a preparaconule. The metaconule is stronger than the paraconule. The premetacrista is short, ending close to the mesostyle; the latter is unique or divided (SLP29PR-493), prolonged in a short buccal mesoloph on the whole teeth; the mesostyle is less stretched mesiodistally than in $H$. marandati. There are two to three extra-ridges from the metalophule I to the basin, but they are rare on the metalophule II; the latter can be oriented towards or connected to the posteroloph $(3 / 6)$ or to the metaconule, and the buccal metalophule I ends free. The posteroloph is more or less long. The protocone is slightly shorter mesiodistally than in $H$. marandati. The hypocone is weak and lower than the protocone.

M1 - M2. The occlusal crown outlines of M1 compared to M2 of the two species $H$. marandati and $H$. hautefeuille $i$ are quite similar. On M1 and M2 of both species, the paracone is more buccal than the metacone, but the latter is even more lingual on the M2. The parastyle is thicker and more elongated or curved buccally on M1; the protocone is more reduced and buccal on M2, and the posteroloph is shorter.

The M1-M2 previously referred (Escarguel, 1999) to $H$. hautefeuillei and $H$. marandati are slightly re-distributed. Measurements are plotted on a bivariate graph, and their statistical parameters calculated (Figs. 57-58; Table 8): M1 are slightly wider than M2 for both species; and the teeth of $H$. marandati are significantly larger than that of $H$. hautefeuillei, even if their distribution areas overlap. A few teeth appear out of the main distribution. Three M1 (PLPRE-806, SLP29PR-817, and -784) and one M2 (SLP29PR-379) are smaller than that of $H$. hautefeuillei: their pattern is close to that of $H$. hautefeuillei, but the extra-ridges are slender, and the pre- and post-protocristae are less aligned mesiodistally for PLPRE-806. The SLP29PR-2000 M1 is out of the distribution of the M1 of the two species, as it is as wide as long, whereas all the other M1 (and M2) are wider than long; however, its 
morphological features are not much different. SLP43PR-56 is a M1 not wider than the others of $H$. marandati are, but longer, as SLP29PR-1124 is the longest M2. The SLP43PR-287 M1 is the largest, clearly out of the distribution of $H$. marandati; it will be compared to Masillamys parvus.

Hartenbergeromys marandati. (Figs. 61 and 63A-D). Fourtyone M1 are considered, among them seven were previously considered as M2, and one fall out of the distribution (SLP29PR-2000, smaller than both species H. hautefeuillei and $H$. marandati), and $45 \mathrm{M} 2$, among them two were previously considered as M1.

The description of the SLP29PR-960 specimen, a fragment of maxillary bearing M1 to M3 (Plate 2A and Fig. 61B; Text-fig. 14B, in Escarguel, 1999), will be a starting point for describing the morphological variation of this species. This specimen is among the largest $H$. marandati. The parastyle of M1 is well defined, and turns buccally, whereas it is shorter and slender on M2. The paracone is slightly swollen and merged in the buccal protoloph. As seen on the buccal region, paracone and metacone

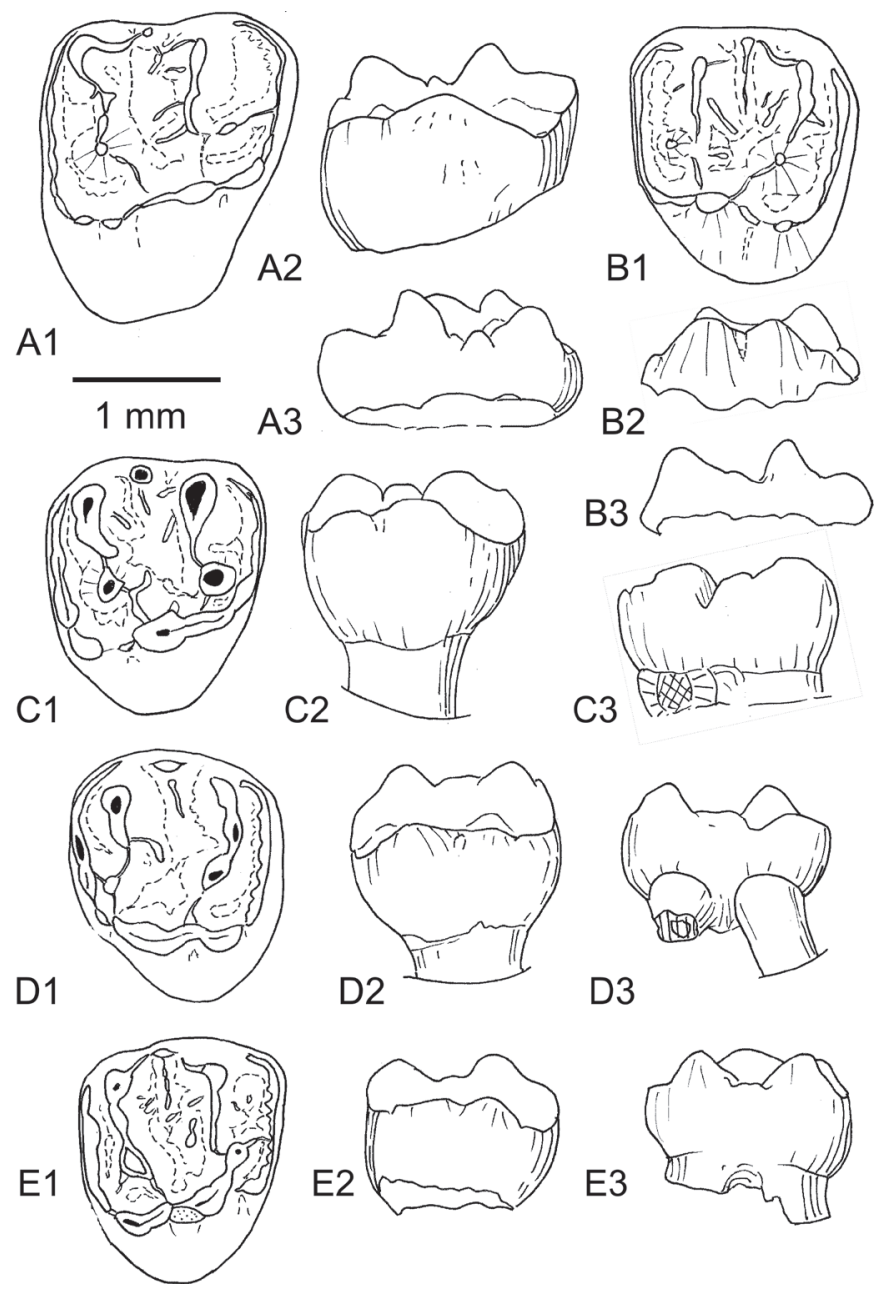

Figure 59. Upper D4 of Hartenbergeromys marandati (Escarguel, 1999) (A1-A3) and H. hautefeuillei Escarguel, 1999 (B1-E3) from Prémontré (late Ypresian, MP10, Bassin de Paris). A. SLP29PR-418, right D4; A1, occlusal view, A2, lingual aspect, A3, buccal aspect. B. PLPRE-670, unworn right P4; B1 occlusal view, B2, lingual aspect, B3, buccal aspect. C. PLPRE-896, right $\mathrm{P} 4$ : $\mathrm{C} 1$, occlusal view, $\mathrm{C} 2$, lingual aspect, $\mathrm{C} 3$, buccal aspect. D. SLP27PR-343, left D4; D1, occlusal view, D2, lingual aspect, D3, buccal aspect. E. PLPRE-785, right P4; E1, occlusal view, E2, lingual aspect, E3, buccal aspect. Scale bar, $1 \mathrm{~mm}$. are nearly equal in size. The anteroloph (and posteroloph) are less high than protoloph and metaloph, mainly in their buccal halves. The anteroloph is markedly wrinkled posteriorly; it fuses with a strong anterostyle (protostyle?), ending the preprotocrista, as high as the preprotocrista and higher than the anteroloph. This character represents a difference with $P$. russelli, on which the anterostyle ending lingually the anteroloph is well defined from the preprotocrista on unworn teeth and it is lower. The anteroflexus is wide mesiodistally, and wider than the posteroflexus. The buccal protoloph bears mesially and distally two main extra-ridges, buccal to the paraconule, which protrudes mesially, nearly joining a wrinkle of the anteroloph. At the beginning of the lingual protoloph, following the paraconule, another extra-ridge, distally oriented, is present on M1 but not on M2. The protoloph connects to the apex of the protocone.

The mesostyle is buccal to the paracone-metacone axis; it is slightly stretched mesiodistally, and underlined buccally by two short notches. It prolonges in a short buccal mesoloph. A short postparacrista descends the distal flank of the paracone towards the mesostyle from which it is separated by a cleft; another narrow notch separates the mesostyle from the strong premetacrista, same arrangement occurs in P. russelli and $S$. chandoni. From the mesial end of the premetacrista, there is a thin extra-ridge parallel to the mesoloph on M2. The premetacrista + the metacone make an arch with the buccal metaloph, more arcuate on M2 than on M1. Two extraridges more (on M2) or less (M1) well-defined descend distomesially from the buccal metaloph. On M1, the bulbous metaconule is isolated from the lingual metaloph by a shallow and narrow valley. It bears on its mesial side a thick extra-ridge. On M2, this extra-ridge is longer, extending mesially and distally, making a kind of second metaconule. The lingual metaloph joins the postprotocrista on M1; they are isolated on M2, the lingual metaloph being very low.

The protocone is bulbous, with a wide base and apex nearly mesiodistally oriented with its high long pre- and postprotocristae. The endoloph is lower than these arms and very short. It caps a narrow sinus, pinched between the distal flank of the protocone and the mesial flank of the hypocone, which ends at mid-height of the crown. The hypocone is smaller and slightly lower than the protocone. It has short anterior and posterior arms; the posterior attaches to the posteroloph on M1, which is relatively worn at this level; a break appears on the less worn M2. The anteroflexus is less narrow than the posteroflexus, whereas the mesoflexus of M2 appears slightly wider mesiodistally.

Wear affects the cusps and sloping lophs to make a mesiodistal gutter at mid-width of the teeth, whilst the buccal and lingual cusps remain higher. The strong extra-ridges converge to the middle of the basined mesoflexus. On this specimen (SLP29PR-960), moderately worn, the enamel of the vertical lingual flanks of the crown appears smooth; whilst it is generally rough and sometimes wrinkled on less worn or unworn teeth. The lingual root is strong and vertical. The small buccal roots, well-separated here, diverge slightly: on M1 the mesial buccal root is inclined mesially whilst the distal one is vertical; on M2 the distal buccal root is inclined, whilst the mesial one is vertical.

All teeth display similar features as to SLP29PR-960 described above, peculiarly the number and position of extraridges is remarkably constant. Variations occur for a few features: 


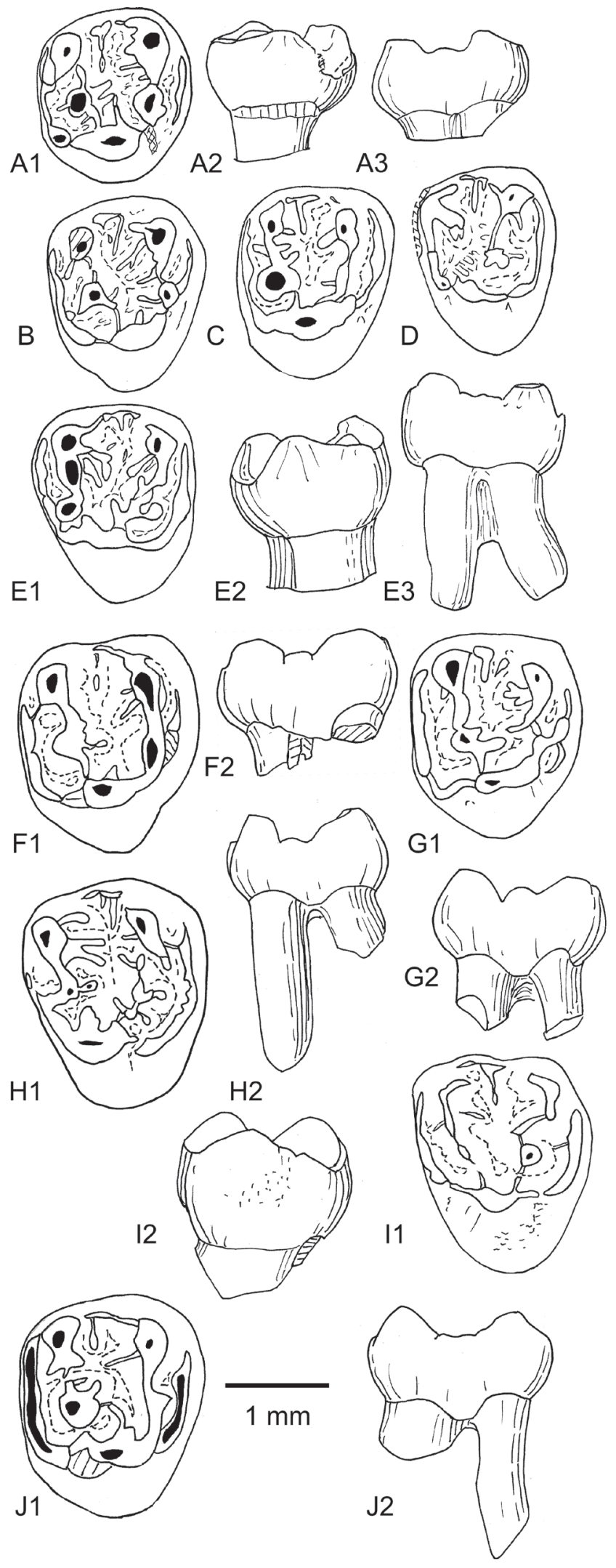

- The parastyle is generally well distinct from the paracone: the elevation closing buccally the anteroflexus bears rarely a preparacrista connecting the parastyle to the apex of the paracone (SLP29PR-471, -858, -1050, and PLPRE-128);

- The sinus is rarely pinched, mainly shallow and open, limited in the upper area of the crown;

- The extra-ridges are more or less thick;
Figure 60. Upper P4 of Hartenbergeromys hautefeuillei Escarguel, 1999 (A-E) and H. marandati (Escarguel, 1999) (F-J) and from Prémontré (late Ypresian, MP10, Bassin de Paris). A. PLPRE-743, right P4; A1, occlusal view, A2, lingual aspect, A3, buccal aspect. B. UMPRE-121, right P4: occlusal view. C. UMPRE-121, right P4: occlusal view. D. UMPRE-119, left P4: occlusal view. E. SLP29PR-493, left P4; E1, occlusal view, E2, lingual aspect, E3, buccal aspect. F. SLP29PR-71, right P4; F1, occlusal view, F2, buccal aspect. G. SLP29PR-1584, right P4; G1, occlusal view, G2, buccal aspect. H. SLP29PR-194, left P4; H1, occlusal view, H2, buccal aspect. I. SLP29PR-307, left P4; I1, lingual aspec, I2, occlusal view. J. SLP29PR-269, right P4; J1, occlusal view, J2, buccal aspect. Scale bar, $1 \mathrm{~mm}$.

- The protruding paraconule generally connects to the buccal protoloph, rarely separates; it is more or less bulged, or stretched;

- There is generally a single mesostyle; there are one or two small meso-ectocinguli, buccal to it, on a few teeth (SLP43PR-56, -287, PLPRE-395, -558, -1053, SLP29PR-858, -1598, -2250, and -2366);

- The buccal mesoloph can be double or triple;

- The metaconule is primarily single, rarely double;

- The endoloph is rarely thickened (SLP29PR-482 and PLPRE-542). PLPRE-542is among the largest M1 and is somewhat peculiar: its buccal roots are fused, whilst they are distinct and divergent in all others; its short endoloph is swollen in a conule, and the metaconule is double.

Hartenbergeromys hautefeuillei. (Fig. 63) If we exclude the smallest teeth (App. S. 3), 19 M1 and 20 M2 are tentatively referred to $H$. hautefeuillei. They are significantly smaller than the teeth of $H$. marandati (Table 8).

As for $P$. marandati, the description of a fragment of maxillary with M1 to M3 (SLP29PR-1312; Plate 2A and Fig. 61B and in Escarguel, 1999; fig. 14A), will be the starting point for describing the morphological variation of this species. This specimen stands in the average of teeth length and width of the assemblage (Fig. 62). Its features are close to that of $H$. marandati, but the extra-ridges are less numerous and weaker along the lophs. The conules are more rounded, especially the strong paraconule, which lies in front of and against the protoloph, like a preparaconule. It is isolated from the anteroloph by a narrow cleft, and a strong anterostyle (protostyle?) is present at the mesiobuccal extremity of the preprotocrista like on $H$. marandati. The buccal protoloph bears mesially and distally two main low and sloping extra-ridges. Like $H$. marandati, at the beginning of the lingual protoloph, following the paraconule, another weak extra-ridge, distally oriented, is present on M1 but not on M2. The protoloph weakly connects to the apex of the protocone on M1, slightly mesially on M2, on which a short protocrista is present.

The mesostyle is like in $H$. marandati, buccal to the paracone-metacone axis; it is slightly stretched mesiodistally, and underlined buccally by two short notches; it is extended in a short buccal mesoloph. A short postparacrista descends the distal flank of the paracone towards the mesostyle from which it is isolated by a narrow pinched notch. Another narrow notch separates the mesostyle from the strong premetacrista. The metaconule is not much stronger than the paraconule. It connects to the buccal metalophule I, on M1 and M2, whereas the short distal metalophule II ends free. Unlike $H$. marandati, there is no lingual metalophule on M1: the metaconule is isolated from the protocone. It joins the postparacrista on M2.

The protocone is bulbous with relatively long pre- and post- 

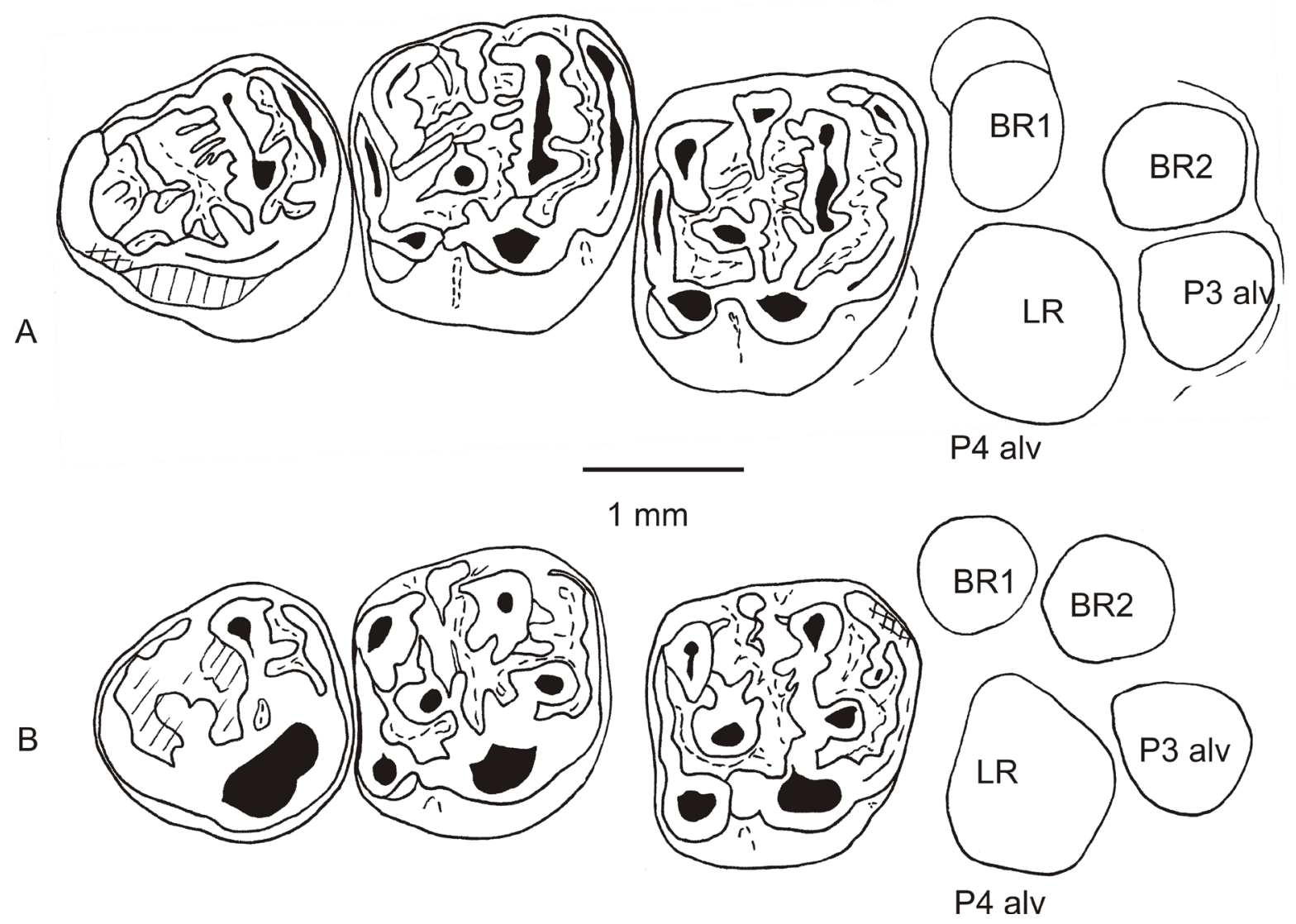

Figure 61. Right hemi-maxillaries of Hartenbergeromys from Prémontré (late Ypresian, MP10, Bassin de Paris). Occlusal view, showing M1 to M3, and roots alveoli of P4 (BR1 and BR2, buccal roots; LR, lingual root) and P3 (P3 alv). A. SLP29PR 960, H. marandati, showing the P3 alveolus closely appressed with the mesial buccal root of P4, BR2), whereas the two buccal roots of P4 are well separated. B. SLP29PR 1312, H. hautefeuillei, showing the two close buccal roots of $\mathrm{P} 4$, whereas the BR2 alveolus is more separated from the P3 alveolus root than on H. marandati. Scale bar, $1 \mathrm{~mm}$.

protocristae, like on $H$. marandati. The endoloph is very short, closing a shallow sinus lingually. The hypocone is smaller than the protocone. Its anterior and posterior arms are very short; the posterior joins the posteroloph on M1 and M2, probably due to wear. On this specimen (SLP29PR-1312) moderately worn, the enamel of the vertical lingual flanks of the crown appears smooth, whereas it is generally rough, and sometimes wrinkled on less worn or unworn teeth, like in H. marandati. The lingual root is strong and vertical. The small buccal roots are closer to each other than in H. marandati. The mesiodistal gutter at midwidth of the teeth, resulting from wear in $H$. marandati, is less marked; wear produces a horizontal surface on the lingual main cusps.

Variations of the morphology are generally the same as for H. marandati. If on SLP29PR-1312 the extra-ridges are faint or absent along the protoloph, they are present on the main part of the specimens of $H$. hautefeuillei. The mesoloph is generally present (absent on SLP29PR-1027) and single, rarely double (PLPRE-668 and SLP29PR-1763). The protruding paraconule more generally links to the buccal protoloph and is rarely isolated. The mesostyle is generally unique, once double (the M2 SLP29PR-1776); the meso-ectocingulae are often absent. The metaconule is single, and on the SLP29PR-1763 specimen, it subdivides in two aligned metaconules. It can be isolated on unworn or weakly worn teeth, connected to the metalophule I, and rarely to the metalophule II: the latter is often free, directed to or fused with the posteroloph (Fig. 63B1). On pristine/ unworn teeth, the small hypocone is lower than the protocone.
The endoloph, connecting the postparacrista to the anterior flank of the hypocone, is frequently thick on M1.

M3. Hartenbergeromys marandati. (Fig. 64H, J) Thirteen M3 are identified as $H$. marandati. The unworn SLP29PR-821 specimen falls out the distribution of the others, because it is narrower than the others, but it is as long. It is longer than the M3 of $H$. hautefeuillei and its features match with those of $H$. marandati, notably the complete and relatively high pericingulum.

Their occlusal crown outlines vary from triangular to ovoid (posteriorly round). The strong buccodistal root is inclined distally, and the small lingual root being parallel to it. The buccomesial root is the smallest. The extra-ridges are numerous. The paracone is the highest cusp, followed in height by the protocone. The reduced hypocone joins the postparacrista through a short and lower endoloph. The sinus is sometimes marked but shallow (7/13). The paraconule is stretched and often thin, extending closely to the anteroloph. The lingual protoloph merges with the thick protocrista. The unique $(6 / 13)$ or double (7/13) mesostyle is stretched mesiodistally, closing more or less completely the buccal opening of the mesoflexus. There are one, two or more short and low mesolophs, sometimes reduced to faint extra-ridges (SLP29PR-355, -1959, and PL666). The metacone connects to the posteroloph, which joins the posterior arm of the hypocone, making an arcuate distal cingulum, which expands the tooth posteriorly. The metaconule lies in this arch, sometimes connected at different levels, from the metacone to the posteroloph, sometimes being isolated. It can fuse lingually 


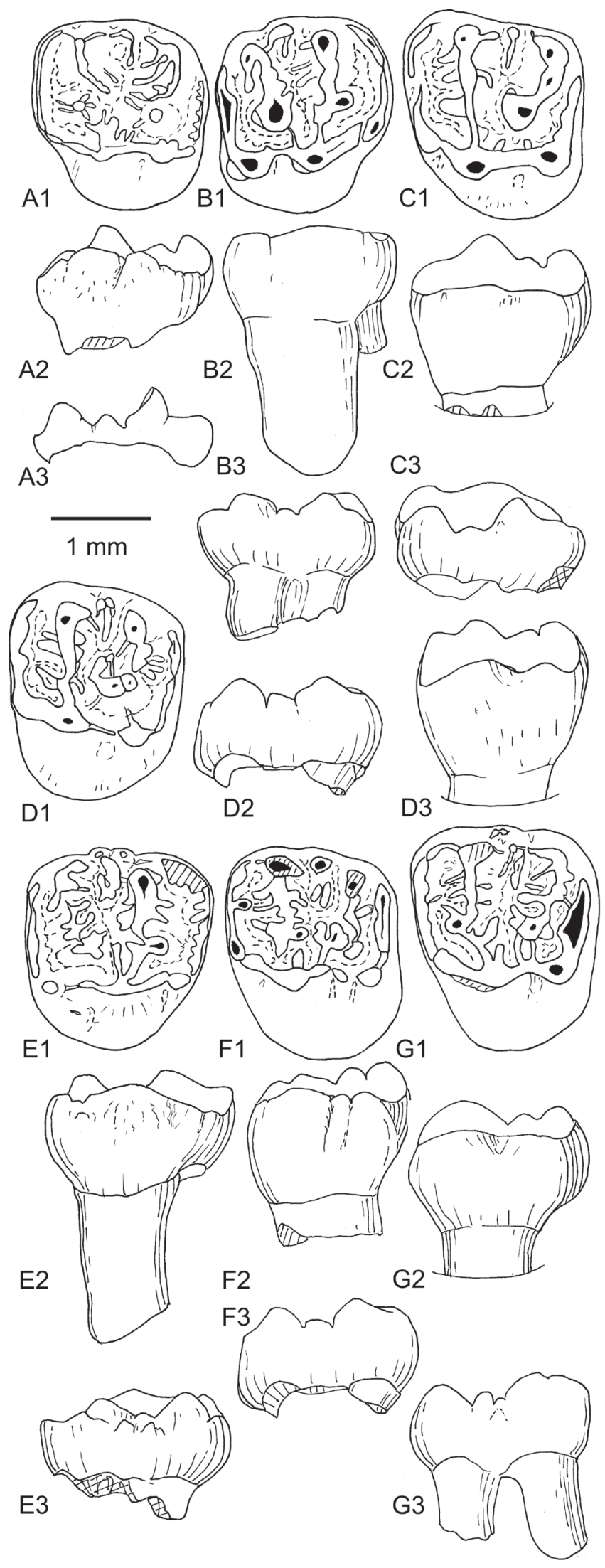

Figure 62. Upper M1 of Hartenbergeromy marandati (Escarguel, 1999) (typical H. marandati: A-D; remarkable variants of H. marandati: E-G) from Prémontré (late Ypresian, MP10, Bassin de Paris). A. SLP29PR-471, left M1; A1, occlusal view, A2, lingual aspect, A3, buccal aspect. B. SLP29PR-1578, right M1; B1, occlusal view, B2, lingual aspect, B3, buccal aspect. C. PLPRE-1022, left M1; C1, occlusal view, C2, lingual aspect, C3, buccal aspect. D. SLP29PR-1642, left M1; D1, occlusal view, D2, lingual aspect, D3, buccal aspect. E. SLP43PR-56, right M1; E1, occlusal view, E2, lingual aspect, E3, buccal aspect. F. PLPRE-542, left M1; F1, occlusal view, F2, lingual aspect, F3, buccal aspect. G. SLP43PR-287, left M1; G1, occlusal view, G2, lingual aspect, G3, buccal aspect. Scale bar, 1 mm. 

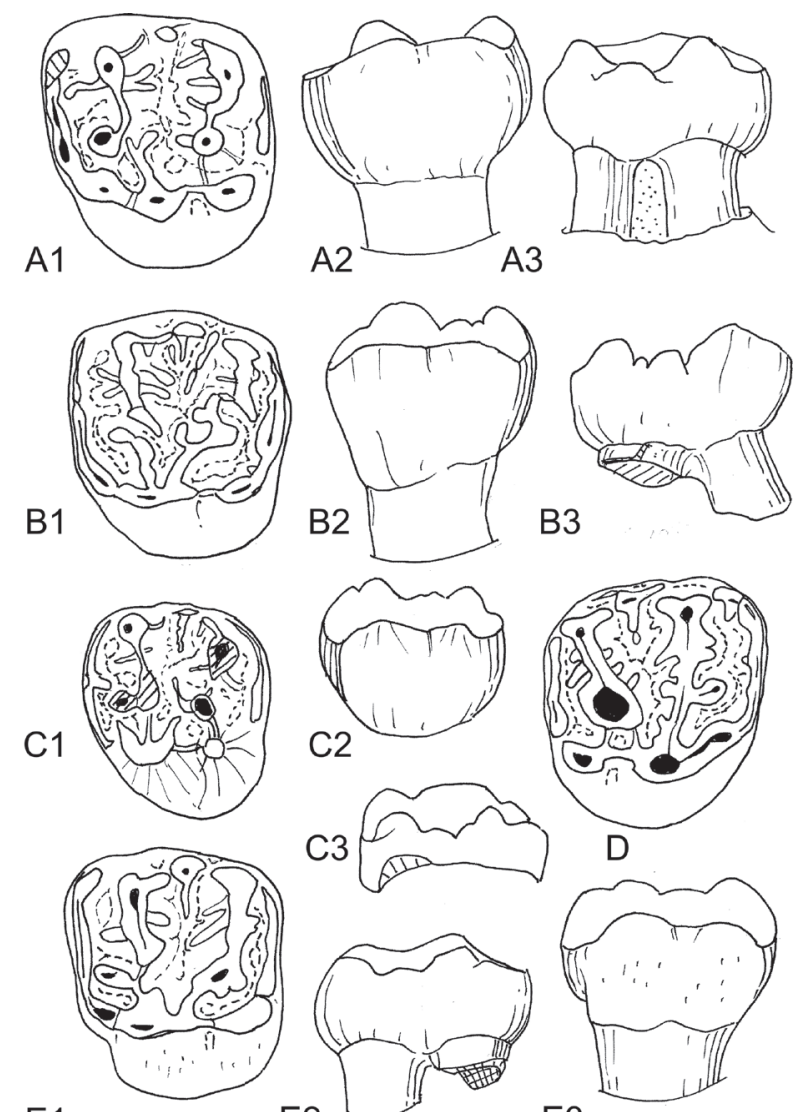

E1

E2
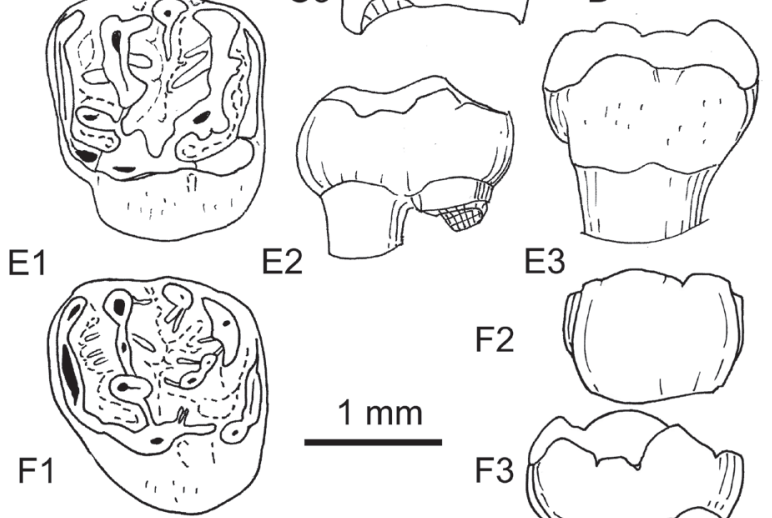

E3

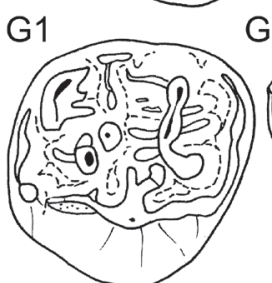

$\mathrm{G} 2$

F2<smiles>C1#CCCC=CCCC=C1</smiles>

F3

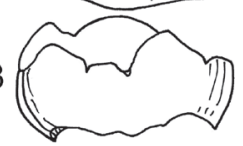

G3

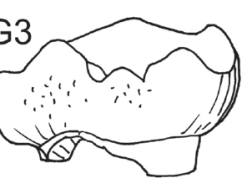

H3

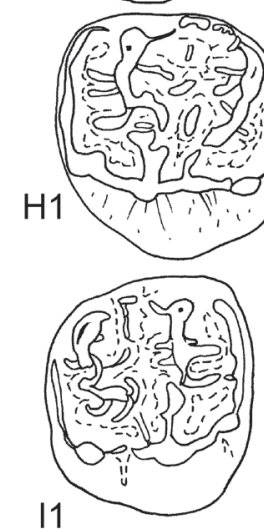

11
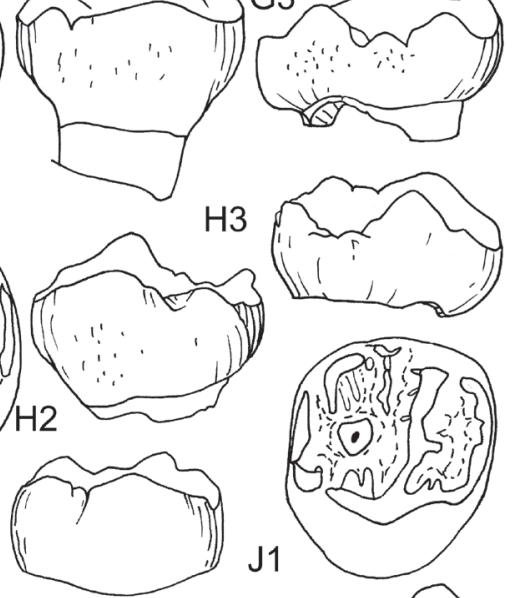

12
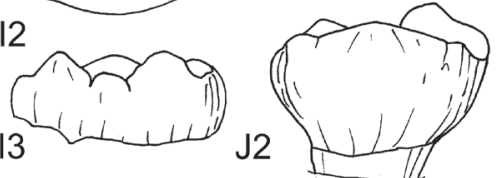

Figure 63. Upper molars of Hartenbergeromy hautefeuillei Escarguel, 1999 (M1: A-F; M2: G-J) from Prémontré (late Ypresian, MP10, Bassin de Paris). A. SLP29PR-1027, left M1; A1, occlusal view, A2, lingual aspect, A3, buccal aspect. B. PLPRE-668, left M1; B1, occlusal view, B2, lingual aspect, B3, buccal aspect. C. PLPRE-806, left M1; C1, occlusal view, C2, lingual aspect, C3, buccal aspect. D. PLPRE-1003, right M1: occlusal view. E. PLPRE-1046, left M1; E1, occlusal view, E2, buccal aspect, E3, lingual aspect. F. SLP29PR-1763, left M1; F1, occlusal view, F2, lingual aspect, F3, buccal aspect. G. SLP29PR-2353, right M2; G1, occlusal view, G2, lingual aspect, G3, buccal aspect. H. SLP29PR-1776, left M2; H1, occlusal view, H2, lingual aspect, H3, buccal aspect. I. SLP29PR-937, right M2; I1, occlusal view, I2, lingual aspect, I3, buccal aspect. J. SLP29PR-651, right M2; J1, occlusal view, J2, lingual aspect. Scale bar, 1 mm. 

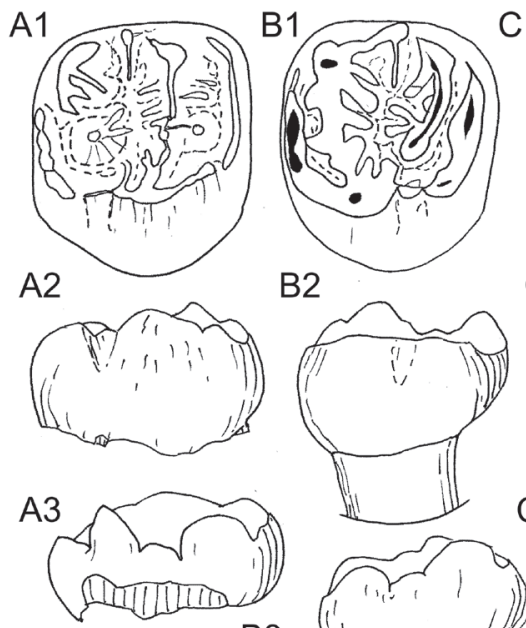

B2

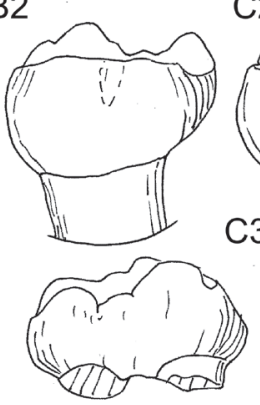

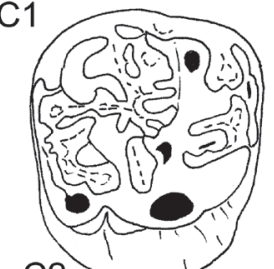

$\mathrm{C} 2$
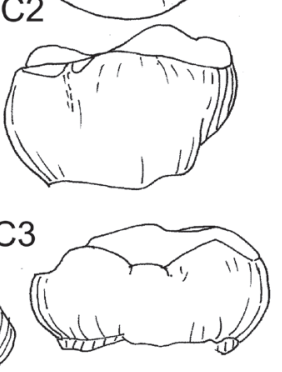
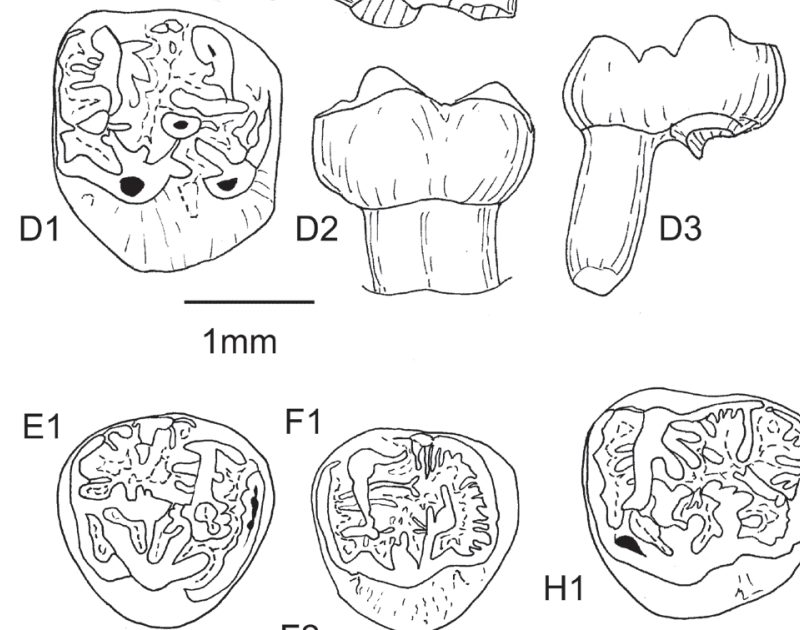

$\mathrm{F} 1$
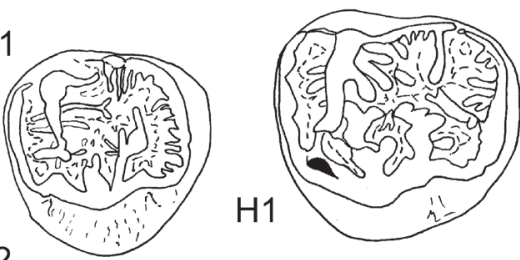

E2

F2

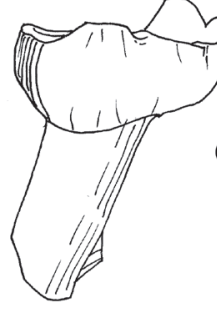

E3

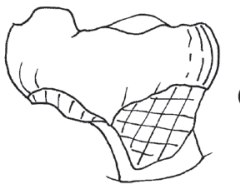

G1
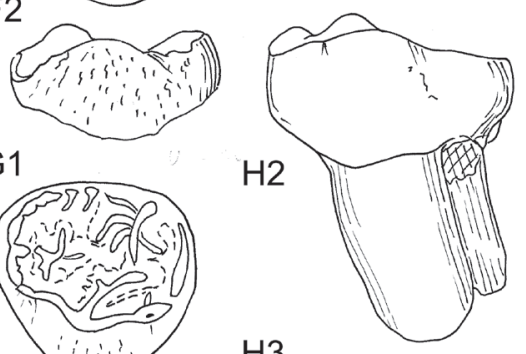

$\mathrm{H} 3$

$\mathrm{G} 2$
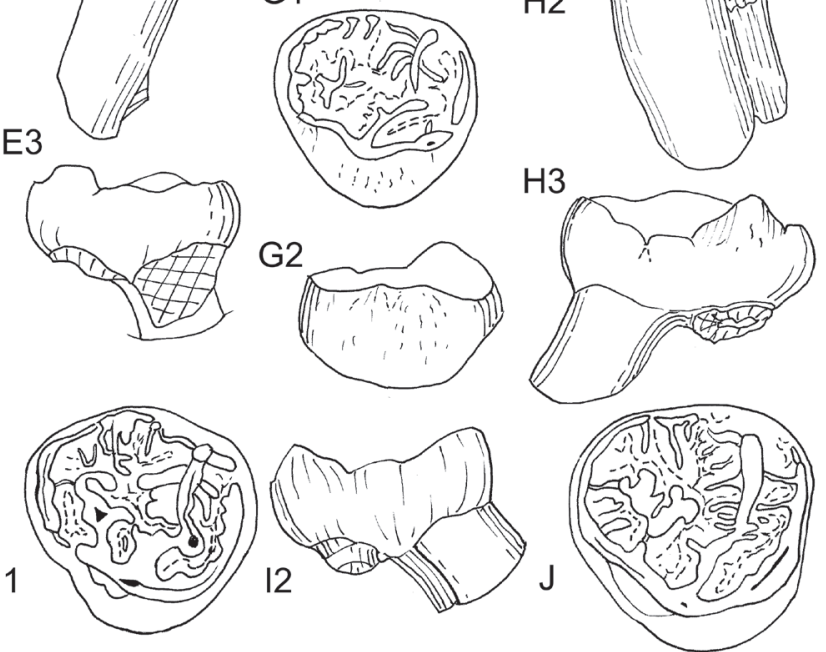

Figure 64. Upper M2 and M3 of Hartenbergeromy marandati (Escarguel, 1999) (M2: A-D; then M3: H-J); upper M3 of H. hautefeuillei: E-G) from Prémontré (late Ypresian, MP10, Bassin de Paris). A. PLPRE-1120, right M2; A1, occlusal view, A2, lingual aspect, A3, buccal aspect. B. SLP43PR-216, left M2; B1, occlusal view, B2, lingual aspect, B3, buccal aspect. C. SLP29PR-2242, right M2; C1, occlusal view, C2, lingual aspect, C3, buccal aspect. D. SLP43PR-53, left M2; D1, occlusal view, D2, lingual aspect, D3, buccal aspect. E. SLP29PR-675, right M3; E1, occlusal view, E2, lingual aspect, E3, buccal aspect. F. PLPRE-534, left M3; F1, occlusal view, F2, lingual aspect. G. UMPRE-126, left M3; G1, occlusal view, G2, lingual aspect, G3, buccal aspect. H. PLPRE-821, left M3; H1, occlusal view, H2, lingual aspect, H3, buccal aspect. I. SMPR-156, right M3; I1, occlusal view, I2, buccal aspect. J. SLP29PR-1131, right M3: occlusal view. Scale bar, 1 $\mathrm{mm}$. 
with the postparacrista or with the endoloph. The stretched mesostyle, the metacone, and the posteroloph make a long and relatively high pericingulum, together with the hypocone, the endoloph, the protocone + its arms and the anteroloph. The anterostyle (protostyle?) is present as a thickening of the mesial extremity of the preprotocrista.

M3. Hartenbergeromys hautefeuillei. (Fig. 64E-G) Fourteen M3 are identified as $H$. hautefeuillei. One (SLP29PR-379) was previously considered as a M2, but the metacone is cingular in the continuity of the posteroloph, and its size is out of the distribution of M1-M2 of $H$. hautefeuillei, but within that of M3. The extra-ridges are more numerous than on M1-M2, but lower than in $H$. marandati. The enamel borders of the crown are rough on some teeth, a feature we have not observed on M3 of $H$. marandati.

They are smaller than the M3 of $H$. marandati, and none expands posteriorly, therefore they are mostly triangular. The mesostylar area is lower than the metacone area, and the pericingulum not continuous. Paraconule and metaconule are smaller than on M1-M2; their connections are variable. Always at the end of the buccal protoloph, the small protruding paraconule variably joins the protocrista, the preprotocrista and/or the anterostyle. The metaconule can be isolated (SLP29PR-1110 and PLPRE-1048), connected to the postparacrista, the hypocone and/or the posteroloph. The hypocone is strongly reduced and the sinus faintly marked.

Lower teeth. (Figs. 65-70) For both species, the crowns of lower molars are overhanging the roots; the protoconid and hypoconid buccal flanks being bulbous. The differences are subtle between the morphologies of the different teeth, and the morphological variation within the two species can overlap. Therefore, as complete toothrows on jaws are unknown, the distribution between $H$. hautefeuillei and $H$. marandati remains only tentative.

d4. Among the three d4 from Prémontré referred initially to "Pantrogna" marandati by Escarguel (1999), only one (SLP29PR-912) must be considered as representing this species, the two others being close to the species $H$. hautefeuillei. Among the material considered as $H$. hautefeuillei, one (SLP29PR-1687) is simpler and smaller than all the others are. It could belong to the same species as the small and simple SLP29PR-2147 $\mathrm{m} 1$ and the P4 UMPRE-119. These three teeth are described separately, as they possibly belong to another species (p.139-140).

Hartenbergeromys marandati. Among the four d4 we referred to this species, the specimen SLP29PR-1615 was unfortunately lost after study. They differ from the $\mathrm{d} 4 \mathrm{of} H$. hautefeuillei in the presence of a stronger protoconid; thereby the metaconid is more lingual, and the sinusid less asymetrical. The anterolophid, developed mesially from the preprotocristid, is high; it reaches the end of the linguobuccal premetacristid (SLP29PR-1615) The buccal metalophulid I is postwardly oblique, as is the lingual metalophulid I; their extremities do not join on three (Fig. 65D-F). On these, the posmetacristid descends steeply, and a mesostylid is clearly distinct (worn on Fig. $65 \mathrm{G}$ ). Following the small protoconid, there is a strong postprotocristid, higher than the mesial ectolophid. The ectomesolophid starts on a mesoconid swelling, and descends to the base of the hypoconid. Ectostylids edge the base of the sinusid, of which the enamel surface is wrinkled. The mesoconid is bulbous and a short low mesolophid is seen on three teeth; the prehypocristid is low. The entolophid is high, regularly transverse, and attached at the distal ectolophid-prehypocristid junction on SLP29PR-912. It joins the hypoconulid on SLP29PR-2173 and -2012. It is widely interrupted at mid length on SLP29PR-1615. The bulging hypoconulid is strong; the posterolophid ends slightly buccally to the entoconid, making the posteroflexid shallowly open lingually. The mesoflexid is much deeper than the antero- and postero- flexids; there are rare granules on their enamel surface.

Hartenbergeromys hautefeuillei. Only four d4 are now attributed to $H$. hautefeuillei. All of them have their metaconid - the highest cuspid - more mesial than the protoconid. Both cuspids are relatively close buccolingually, so that the anterior part of the tooth is much narrower than the posterior one. A short anterolophid develops lingual to the preprotocristid (except on PLPRE-531: Fig. 65B). A transverse buccal metalophulid I starts from the apex of the protoconid, directed (SLP29PR-2012) or connected (SLP29PR-932) to the short lingual metalophulid I. It is absent on PLPRE-531. One main mesiodistal ridge is present on all teeth, together with lower wrinkles. The postmetacristid lowers gradually to the opening of the mesoflexid. The postprotocristid is thick, postwardly directed, bearing a short lingual extra-ridge on SLP28PR-2012. On the mesiodistal ectolophid, the mesoconid is moderately swollen; it bears an ectomesolophid (SLP29PR-932) or not (PLPRE-531), and no mesolophid. There is also a more or less long postmesoconid (spur or ridge). The prehypocristid is short. The sinusid is asymmetrical and wide, its distal part pinched between the hypoconid and the ectomesolophid. It is deeper buccolingually than on $S$. chandoni and P. russelli. The sinusid is flat at its base, bounded by an ectocingulid. The long posterior cingulid joins the flank of the entoconid. The hypoconulid swells slightly in this cingulid. The entolophid is complete only once (PLPRE-531), connecting the postmesoconid ridge. On the two other $\mathrm{d} 4$, it is short and postwardly oblique towards the hypoconulid.

p4. (Fig. 66) From Prémontré, 14 p4 were originally referred to "Pantrogna" marandati and eight to Hartenbergeromys hautefeuillei (Escarguel, 1999). Our revision of this material lead to a redistribution of this material between the two species: only four are referred to H. marandati (SLP27PR-4, SM 147, SLP29PR-19796, and -312) and among the 18 others, 15 to $H$. hautefeuillei; three are too much damaged to be identified with certainty. We have taken into account not only their size, but also their features, with reference to the p4 figured in Escarguel (1999: SLP27PR-4: pl.21b for Pantrogna and SLP29PR-1466: $\mathrm{pl} .22 \mathrm{~b}$ for Hartenbergeromys). However, like for $\mathrm{d} 4$, the differences are subtle, and the morphological variation can overlap.

Hartenbergeromys marandati. The posterior root is flat on its posterior face. The metaconid is less dominant than on $H$. hautefeuillei. It is more lingual than mesial, and the posmetacristid is shorter, descending less steeply to the narrow opening of the mesoflexid. On this lingual face, the entoconid appears relatively stronger than on $H$. hautefeuillei. The short premetacristid is transverse, making the mesial edge of the tooth relatively flat. It then connects to the generally crenulated anterocingulid, sloping mesiodistally along the buccal flank up to the buccomesial edge of the sinusid. This anterocingulid is stronger and longer than in $H$. hautefeuillei, joining the ectostylid ridge, which can link with a spur descending from the buccal flank of the hypoconid. At least two mesiodistal ridges descend from the metaconid apex to the center of the basin. More buccally, another and thicker low ridge descends posteriorly: it corresponds to a metalophulid I prolonged by the protocristid 
A1

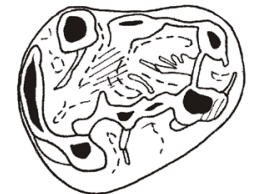

B1
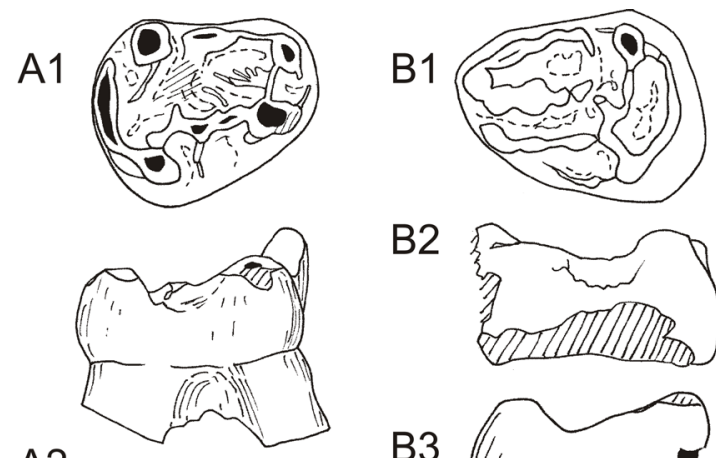

A2

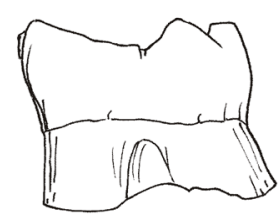

B2

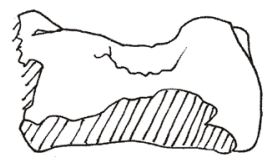

B3

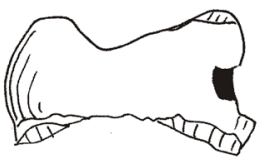

A3

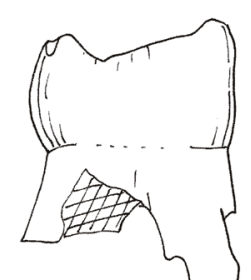

C1

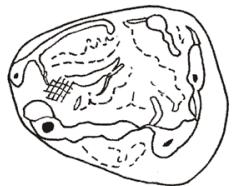

C3

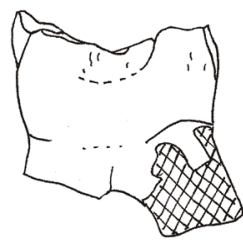

$1 \mathrm{~mm}$

D1

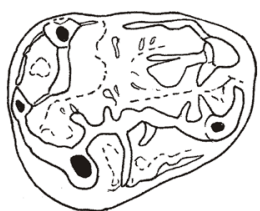

E1

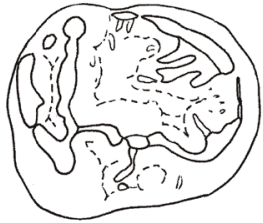

D2

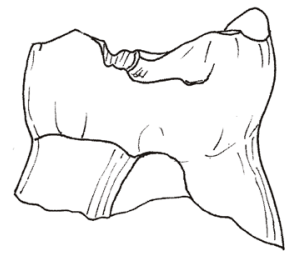

E2

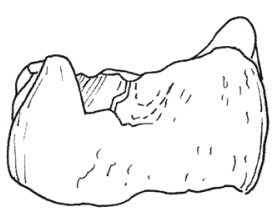

D3

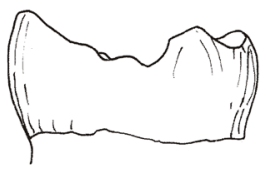

E3

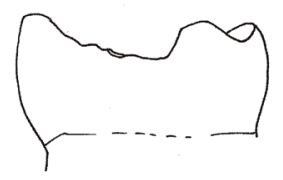

$\mathrm{F}$

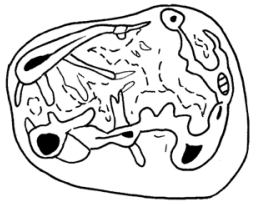

$\mathrm{G}$

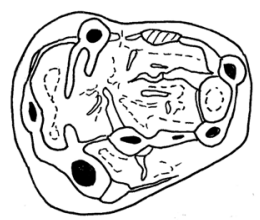

Figure 65. Lower d4 of Hartenbergeromys hautefeuillei Escarguel, 1999 (AC) and H. marandati (D-G) from Prémontré (late Ypresian, MP10, Bassin de Paris). A. SLP29PR-932, right d4; A1, occlusal view, A2, buccal aspect, A3, lingual aspect. B. PLPRE-531, left d4; B1, occlusal view, B2, buccal aspect, B3, lingual aspect. C. SLP29PR-1687, left d4; C1, occlusal view, C2, lingual aspect, C3, buccal aspect. D. SLP29PR-2012, right d4; D1, occlusal view, D2, buccal aspect, D3, lingual aspect. E. SLP27PR-912, right d4; E1, occlusal view, E2, buccal aspect, E3, lingual aspect. F. SLP29PR-2173, left d4: occlusal view. G. SLP29PR-1615, right d4: occlusal view. Scale bar, 1 $\mathrm{mm}$.

(reduced protoconid, not protruding) and the postprotocristid. They make an angle at the junction with the short mesiodistal ectolophid; the mesoconid is swollen. One mesolophid is present on SLP29PR-312 and two on SLP29PR-19796. There are two ectomesolophids, from a premesoconid swelling and from the mesoconid, and one more from the preprotocristid on MSPRE-147. The entolophid is rarely complete: on SLP27PR4 (Fig. 66D), its lingual part is short and separated from the buccal one, connected to the prehypocristid/ectolophid junction. This part is worn on SLP29PR-312 (Fig. 66C), on which the lingual entolophid is directed to the hypoconulid area. On SLP29PR-19796, the lingual entolophid is long and does not join the short prehypocristid. It is much incomplete on MSPRE-147. The hypoconulid is not salient, being subsumed within the posterolophid. The posterolophid is well defined from the entoconid on SLP27PR-4 and SLP29PR-312; its merges with the entoconid on the two others. The buccal enamel surface is strongly wrinkled, mainly in the sinusid.

Hartenbergeromyshautefeuillei. The posterior rootiscircular to oval in section (it is flattened posteriorly in $H$. marandati). The metaconid is mesiomedian, high and voluminous and the entoconid relatively small, therefore the posmetacristid is long and high; it ends generally in a short lingual mesolophid; the mesoflexid opening is often narrow, once it is blocked by a mesostylid (SLP29PR-550). A premetacristid is not distinct from the oblique sloping anterocingulid that is shorter and simpler than on $H$. marandati. Like on the latter, at least two mesiodistal ridges descend from the metaconid to the center of the basin, the protocristid (mesiodistal ridge, at the place of the protoconid) + postprotocristid is slightly longer, the ectolophid and mesoconid, have similar shapes, with a generally short mesolophid, pre- and post- mesoconid spurs or ridges. An ectomesolophid, sometimes two or three, are present. The anterocingulid, low, descends from the mesiobuccal border of the metaconid, the premetacristid being absent; it is crenulated on the less worn teeth. It ends at the level of the beginning of the ectostylid, at the flattened buccal edge of the sinusid. A short ectolophid can be differenciated. The sinusid is not deep, and the crown still high below. The variation of the entolophid is like in H. marandati. It is rarely complete (SLP29PR-109, Fig. 66B1, on which it connects to the posterior arm of the hypoconid). It is generally incomplete with a short lingual part, free and directed to the postmesoconid spur/ridge or sometimes linked to the posterolophid. This ends at the distal flank of the entoconid; the hypoconulid being stretched along this posterior lophid. There are some extra-ridges or wrinkles in the basin, or in the sinusid, less strong than in $H$. marandati.

m1-m2. (Figs 67-69) The m1-m2 previously referred to Hartenbergeromys hautefeuillei and to "Pantrogna" marandati are only slightly re-distributed, but 10 of the lower molars of marandati determined as $\mathrm{m} 2$ are in fact for us identified as $\mathrm{m} 1$ (see below our justification). Two of the largest teeth (SLP29PR-2235 and SLP43PRPR-110) belong to another taxon, as are the three teeth among the smallest. The two other smallest teeth (SLP29PR-1686 and PL909) are much worn, and their pattern difficult to evaluate. UMPRE-134 was referred (Escarguel, 1999) to a $\mathrm{m} 2$ of $H$. hautefeuillei; it is rather a $\mathrm{m} 1$ of $H$. marandati; the same is true for SLP29PR-423 and -1105 . The specimen SLP29PR-560 is not a $\mathrm{m} 3$ but a $\mathrm{m} 2$. There are also worn or damaged teeth difficult to identify (PL2169, PL745, SLP29PR-139, -330, -340, -396, -547, -953, and -2381).

Hartenbergeromys marandati. (Figs 68-69) We cannot find substantial morphological differences between the lower 
molars of $H$. marandati and those of $H$. hautefeuillei. On both species, on $\mathrm{m} 1$, the trigonid basin is only slightly higher than the talonid, whereas they are about at the same level on $\mathrm{m} 2$ and $\mathrm{m} 3$. The talonid basin is flatter on $H$. marandati than on $H$. hautefeuillei, for which it appears smaller and more concave; in both, lophids and relatively thick extra-ridges fill this basin.
A1
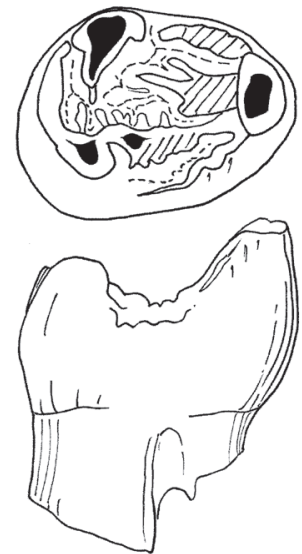

$\mathrm{A} 2$

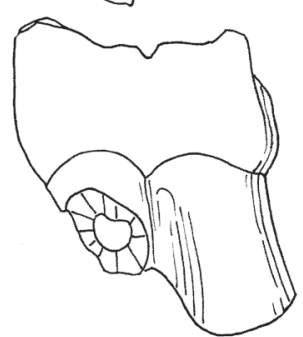

A3

C1

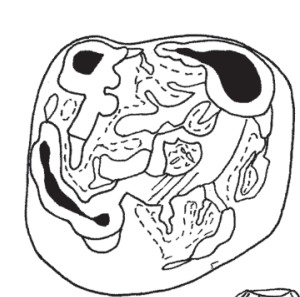

C2
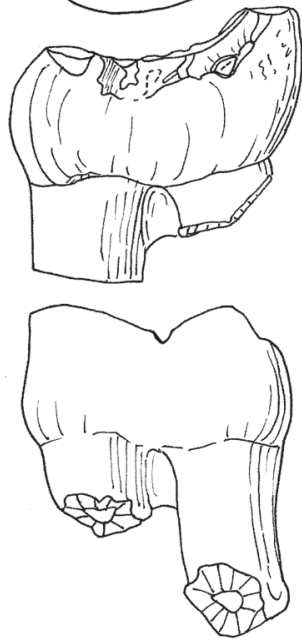

B1

B3

B2
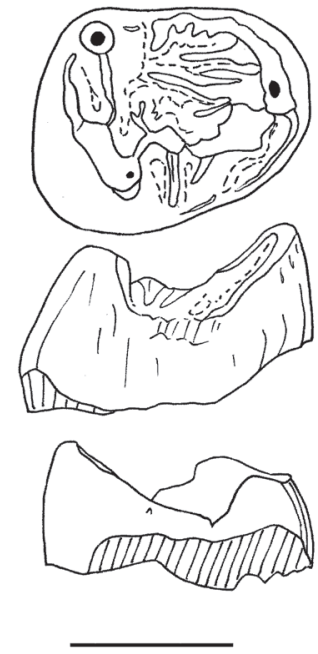

$1 \mathrm{~mm}$
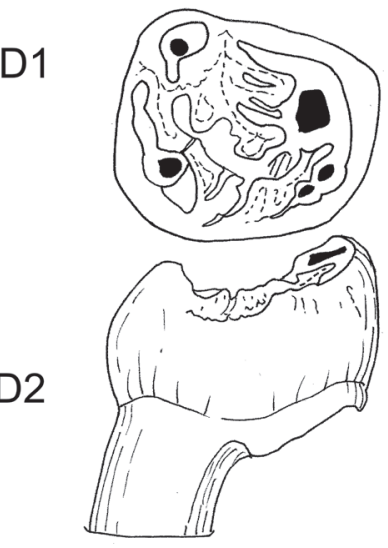

D3

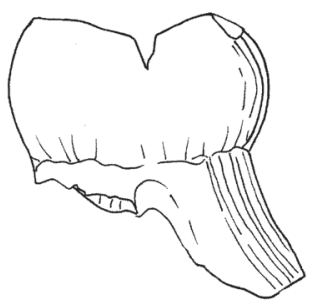

Figure 66. Lower p4 of Hartenbergeromys hautefeuillei Escarguel, 1999 (A, B) and H. marandati (C, D) from Prémontré (late Ypresian, MP10, Bassin de Paris). A. SLP29PR-1569, right p4; A1, occlusal view, A2, buccal aspect, A3, lingual aspect. B. SLP29PR-109, right p4; B1, occlusal view, B2, buccal aspect, B3, lingual aspect. C. SLP29PR-912, right p4; C1, occlusal view, C2, buccal aspect, C3, lingual aspect. D. SLP27PR-4, right p4; D1, occlusal view, D2, buccal aspect, D3, lingual aspect. Scale bar, $1 \mathrm{~mm}$.
Hartenbergeromys marandati differs mainly in its more robust teeth (Figs. 57A, 58A, table 8 and Figs. 67-69), and in showing molars bearing a metaconid relatively less dominant. However, the latter remains the highest cuspid, and its postmetacristid sharply interrupts at its distal end, from where a short linguobuccal ridge develops (lingual mesolophid) on nearly all m1-2. The mesostylid (? metastylid) is absent, indistinct from the extremity of the posmetacristid, except for the $2 / 38 \mathrm{~m} 1$ and $3 / 41 \mathrm{~m} 2$. The anteroconid swells slightly on eight $\mathrm{m} 1$ and three $\mathrm{m} 2$; it is more salient and curved on six $\mathrm{m} 1$. The occurrence of a short anterocingulid on $2 / 38 \mathrm{ml}$ and $4 / 41 \mathrm{~m} 2$, and of a weak shallow antesinusid on 12/38 and 19/41 m2 are the only notable differences with $H$. hautefeuillei.

The linguobuccal premetacristid is rarely doubled distally with à short mesial lingual metalophulid I (two $\mathrm{ml}$ and one $\mathrm{m} 2$ ), whereas this characteristic is more frequent on $H$. hautefeuillei. There is generally one main lingual metalophulid I, rarely two, and the second, when present, is lower and weak. The buccal metalophulid I is connected (or isolated only by a narrow break) to the lingual metalophulid I on $\mathrm{m} 1$ (18/38) and $\mathrm{m} 2$ (17/41); they are separated on $14 \mathrm{~m} 1$ and $20 \mathrm{~m} 2$. The lingual metalophulid I is oriented toward the basin and does not join the buccal metalophulid I on a few teeth (SLP29PR-199, PLPRE-954, and -1055). The protoconid is generally slightly distal to the metaconid, rarely facing the metaconid; the thick oblique posprotocristid always bears a premesoconid swelling/ spur. The ectolophid + mesoconid are either mesiodistally oriented $(11 / 38 \mathrm{~m} 1$ and $10 / 41 \mathrm{~m} 2)$ or, more frequently, oblique $(17 \mathrm{~m} 1$ and $31 \mathrm{~m} 2)$. The mesoconid is like in H. hautefeuillei; it is generally moderately bulged or slightly mesiodistally or obliquely stretched. Short mesolophids are present. This buccal "wall" is more lingual than on $P$. russelli, like on $H$. hautefeuillei. Nearly all teeth $(24 / 38 \mathrm{~m} 1,35 / 41 \mathrm{~m} 2)$ display one long ectomesolophid; it is worn on nine $\mathrm{m} 1$; rarely there are two ectomesosolophids $(5 / 38 \mathrm{~m} 1 ; 6 / 41 \mathrm{~m} 2)$. As for the premolars, the sinusid is not deep, and the crown relatively high below; as seen on unworn teeth, the sinusid is slightly deeper buccolingually than on $P$. russelli. Like on $H$. hautefeuillei, the sinusid is edged buccally by one or two ectostylid(s). Wrinkles or extra-ridges along its enamel flanks are frequent, as well as a mesiobuccal spur of the protoconid and a distobuccal spur of the hypoconid.

The entolophid is thin, but its base appears thicker when it is worn; it is often complete $(26 / 38 \mathrm{~m} 1 ; 32 / 41 \mathrm{~m} 2)$, less frequently interrupted $(12 / 38 \mathrm{~m} 1 ; 9 / 41 \mathrm{~m} 2)$. It connects to the mesolophid or postmesoconid ridge or swelling $(13 / 38 \mathrm{ml}$; $27 / 41 \mathrm{~m} 2$ ), the end of the prehypocristid or the distal ectolophid $(19 / 38 \mathrm{~m} 1 ; 1 / 41 \mathrm{~m} 2)$. When interrupted, the buccal part is directed postwardly towards the posterolophid; the lingual part is sometimes double: one to the postmesoconid spur, one to the prehypocristid. The posterior lophid (posthypocristid + hypoconulid + short posterolophid) is always long, rarely isolated from the postentocristid by a shallow and narrow gap, as seen on unworn teeth. The hypoconulid is always stretched buccolingually, merged in the posterior lophid, and only slightly salient on a few unworn teeth.

From the metalophulid I area to the center of the basin, there can be one mesiodistal or slightly oblique extra-ridge, longer than the others are $(19 / 38 \mathrm{~m} 1 ; 25 / 41 \mathrm{~m} 2)$ or two $(19 / 38$ $\mathrm{m} 1 ; 15 / 41 \mathrm{~m} 2)$. Extra-ridges and granules in the flexids are generally thinner than the main ridges. A few teeth have more numerous thin extra-ridges and granules (SLP29PR-1622, -2227, PLPRE-399, -421, and -940) and two teeth that could be $\mathrm{m} 3$ (SLP29PR-2316 and PLPRE-141: the posterior root is 
rounded in section, but their posterior half is far less reduced than on the $\mathrm{m} 3$ described below). The enamel of the outskirts of the crown is frequently rough.

Hartenbergeromys hautefeuillei. (Fig. 67) The metaconid is the highest cuspid, but the difference in height is less than in $P$. russelli and a fortiori, in $S$. chandoni; its base is voluminous, stocky, therefore the anteroflexid is limited lingually. The posmetacristid is sharply broken at its distal end (lowering less steeply on two $\mathrm{m} 1$ and two $\mathrm{m} 2$ ); it ends in a short linguobuccal ridge (mesolophid). The lingual opening of the mesoflexid is generally narrow at its base; it is wider only on two $\mathrm{m} 1$ and two $\mathrm{m} 2$. The mesostylid is absent, indistinct from the extremity of the posmetacristid, except for the two $\mathrm{m} 1$ and two $\mathrm{m} 2$.

The anteroconid merges in the long anterolophid (46/48); it is salient and short only on two specimens. This anterolophid is higher than the bottom of the basin, and higher than the entolophid. It is not lower or thinner than in $H$. marandati (contra Escarguel, 1999: 207).

A linguobuccal premetacristid, aligned with the anterolophid, is always present. One distal lining of this lophid is frequent (on $21 / 26 \mathrm{ml}$ and $15 / 23 \mathrm{~m} 2$ ), more rarely two $(5 / 26 \mathrm{ml}$ and $7 / 23 \mathrm{~m} 2$ ), and absent for one $\mathrm{m} 1$ and two $\mathrm{m} 2$. The buccal metalophulid I, developed from the apex of the protoconid, is transverse and always present. It is connected (or separated only by a narrow break) to the lingual metalophulid I on $\mathrm{m} 1$ $(15 / 26)$ and $\mathrm{m} 2(11 / 23)$; they are separated on $11 \mathrm{~m} 1$ and 12 $\mathrm{m} 2$. In some of these cases, the lingual metalophulid I is more mesiodistal, directed to the basin, parallel to the mesiodistal ridge from the anterolophid (Fig. 67B-C). The buccal metalophulid I is fused to the mesial lingual metalophulid I only in one case (Fig. 67A).

The protoconid is generally slightly distal to the metaconid, rarely facing this $(3 / 49)$. The thick oblique postprotocristid characterizes all specimens. A premesoconid swelling/ spur is frequent $(22 / 26 \mathrm{~m} 1$ and $18 / 23 \mathrm{~m} 2)$. The ectolophid + mesoconid are mesiodistally oriented $(22 / 26 \mathrm{~m} 1$ and $17 / 23 \mathrm{~m} 2)$ or rarely more oblique $(4 / 26 \mathrm{~m} 1$ and $6 / 23 \mathrm{~m} 2)$. The mesoconid is generally moderately bulged or slightly mesiodistally to obliquely stretched. One, generally, or two, rarely (7/26 m1 and $5 / 23 \mathrm{~m} 2$ ), low short mesolophids are present. More often, one starts from the mesoconid (14/26 m1 and 17/23 m2); it is long on PLPRE-135. One can develops from the premesoconid spur $(9 / 26 \mathrm{~m} 1$ and $3 / 23 \mathrm{~m} 2)$ or from the postmesoconid spur $(10 / 26$ $\mathrm{m} 1$ and $5 / 23 \mathrm{~m} 2)$. One ectomesolophid is frequent $(22 / 26$ $\mathrm{m} 1$ and $18 / 22 \mathrm{~m} 2$ ). It is generally long but in one case, short (SLP29PR-101). The occurence of two ectomesosolophids $(3 / 26 \mathrm{ml}$ and $3 / 23 \mathrm{~m} 2)$ as the absence of ectomesolophid (1/26 $\mathrm{m} 1$ and $1 / 23 \mathrm{~m} 2$ ) are rare. As for the premolars, the sinusid is not deep, and the crown relatively high below. As far as the enamel is moderately worn, one can see that one or two ectostylid(s) limits buccally the sinusid, and rare wrinkles or extra-ridges sculpt its enamel flanks. On one specimen, two long distobuccal spurs are visible on the buccomesial slope of the hypoconid (SLP29PR-101). The mesial ectolophid is short (longer on $\mathrm{m} 2$ than on $\mathrm{m} 1$ ), and low as seen primarily on pristine teeth. The distal ectolophid is also short and low, and bulged on one specimen.

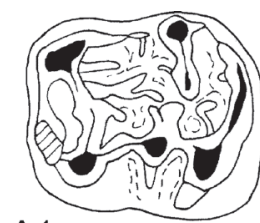

A1

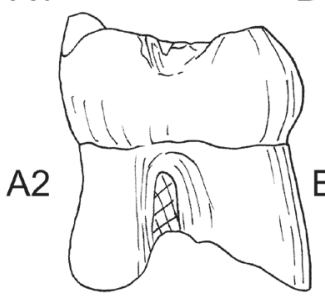

B1

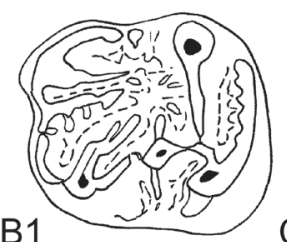

C1
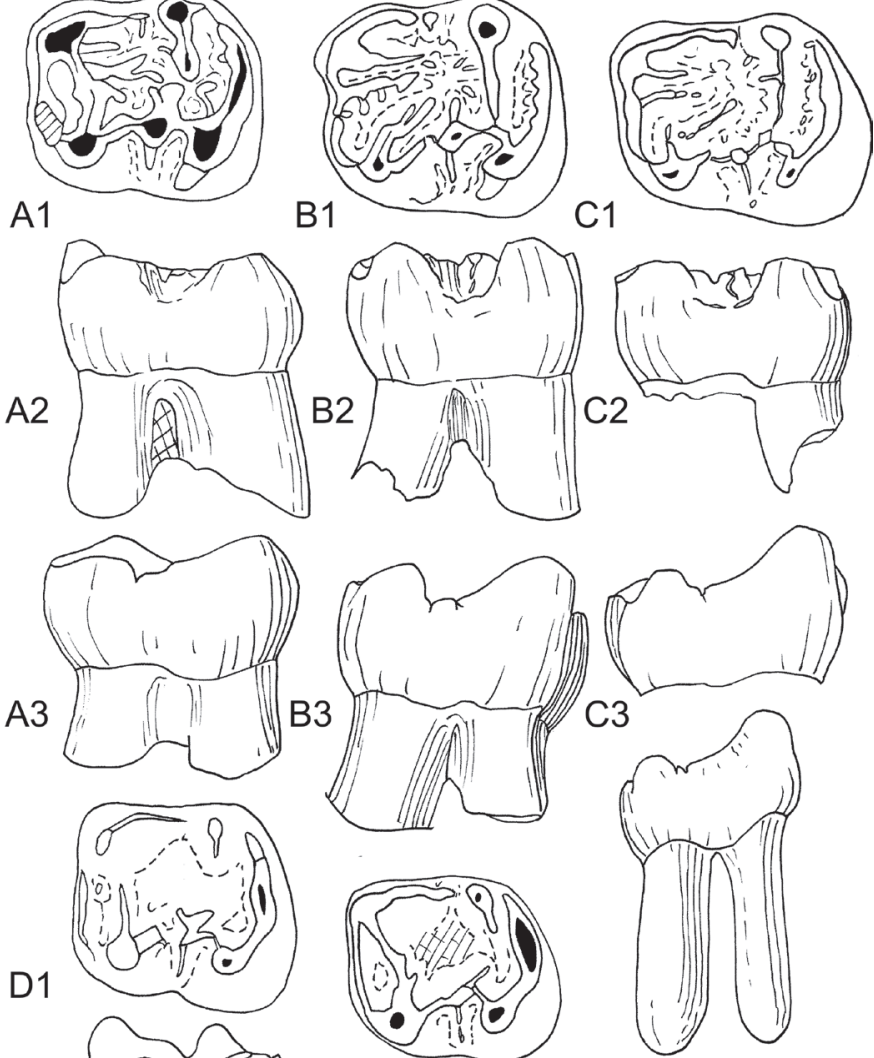

D1

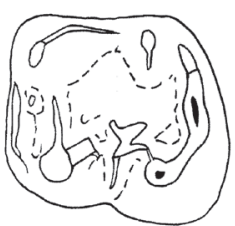

$\mathrm{D} 2$
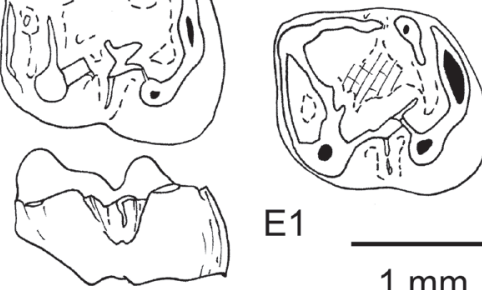

E2

$1 \mathrm{~mm}$
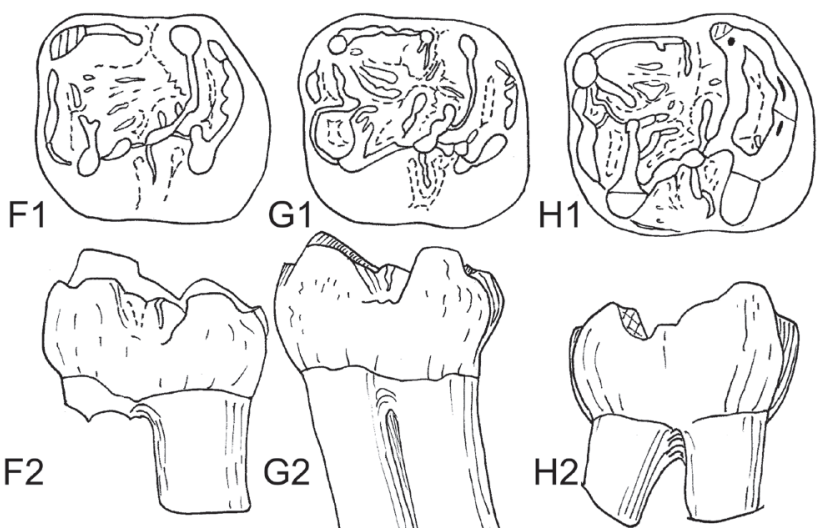

F2

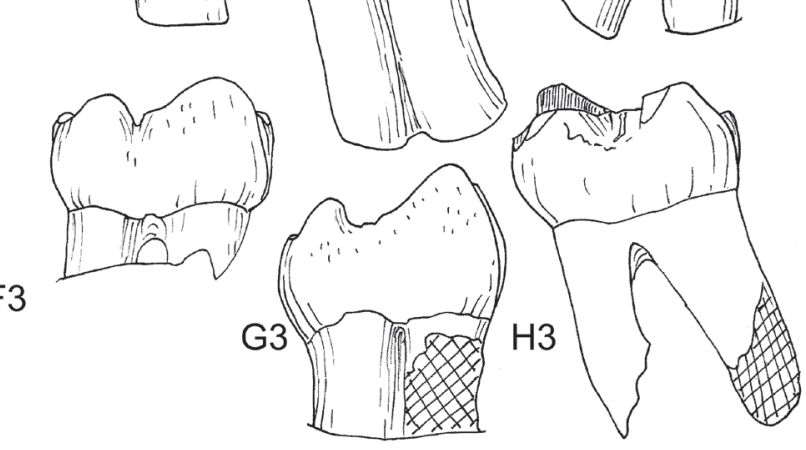

F3

Figure 67. Lower m1 (A-E) and m2 (F-H) of Hartenbergeromys hautefeuillei Escarguel, 1999 from Prémontré (late Ypresian, MP10, Bassin de Paris). A. SLP29PR-1185, left m1; A1, occlusal view, A2, buccal aspect, A3, lingual aspect. B. PLPRE-1105, left m1; B1, occlusal view, B2, buccal aspect, B3, lingual aspect. C. SLP29PR-214, left m1; C1, occlusal view, C2, buccal aspect, C3, lingual aspect. D. PLPRE-947, left m1; D1, occlusal view, D2, buccal aspect. E. SLP29PR-2147, left m1; E1, occlusal view, E2, lingual aspect. F. SLP29PR-1809, left m2; F1, occlusal view, F2, buccal aspect, F3, lingual aspect. G. PLPRE-565, left m2; G1, occlusal view, G2, buccal aspect, G3, lingual aspect. H. UMPRE-138, Holotype, left m2; H1, occlusal view, H2, lingual aspect, H3, buccal aspect. Scale bar, $1 \mathrm{~mm}$. 
The prehypocristid is always short. The hypoconid faces the entoconid on three $\mathrm{ml}$ only; it is generally slightly distal to the entoconid. This entoconid is the smallest cuspid, as for H. marandati. The entolophid is low and much lower in its buccal half. It is often complete $(18 / 26 \mathrm{~m} 1$ and $15 / 23 \mathrm{~m} 2)$, or interrupted $(8 / 26 \mathrm{~m} 1$ and $8 / 23 \mathrm{~m} 2)$. It can connect variably: - to the postmesoconid spur ridge or swelling (7/26 m1 and 18/23 $\mathrm{m} 2)$; - to the posterior arm of the hypoconid $(2 / 26 \mathrm{~m} 1)$; - to the apex of the hypoconid $(2 / 26 \mathrm{~m} 1$ and $1 / 23 \mathrm{~m} 2)$; - to the end of the prehypocristid; - to the distal ectolophid (13/26 $\mathrm{m} 1$ and $2 / 23 \mathrm{~m} 2$ ); - even connected or directed to the middle of the posterolophid at the hypoconulid $(2 / 26 \mathrm{~m} 1$ and $1 / 23 \mathrm{~m} 2)$. The posterior lophid is always long, high and thick, nearly reaching the apex of the entoconid. The hypoconulid is rarely salient $(8 / 26 \mathrm{~m} 1$ and $2 / 23 \mathrm{~m} 2)$, on the others, it is subsumed within the posterior cingulid.

From the metalophulid I area to the center of the basin, there can be one mesiodistal or slightly oblique extra-ridge, longer than the others $(12 / 26 \mathrm{~m} 1$ and 4/23 m2), or two $(9 / 26 \mathrm{~m} 1$ and $13 / 23 \mathrm{~m} 2$ ). Some teeth are too much worn for distinguishing these ridges. Extra-ridges and granules in the flexids are rare and generally as thick as the main ridges $(22 / 26 \mathrm{ml}$ and 17/23 $\mathrm{m} 2$ ); they are probably present on the others but too much worn to be distinguished. The enamel of the periphery of the crown is rarely rough $(10 / 26 \mathrm{ml}$ and 10/23 $\mathrm{m} 2)$.

m3. The m3 of H. hautefeuillei figured in Escarguel (1999:

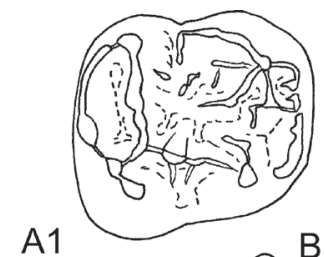

A1
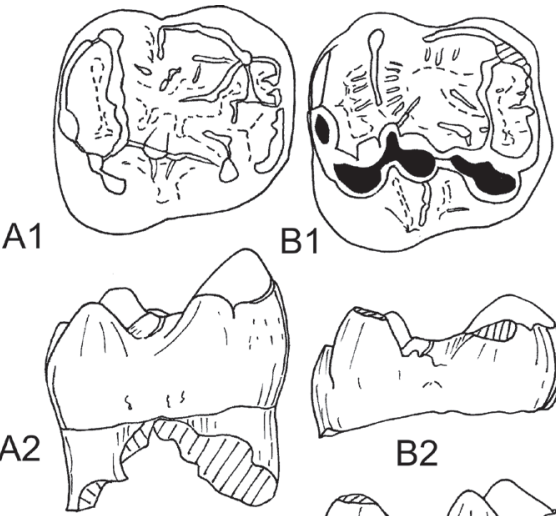

B1

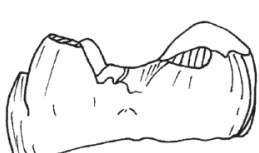

B2
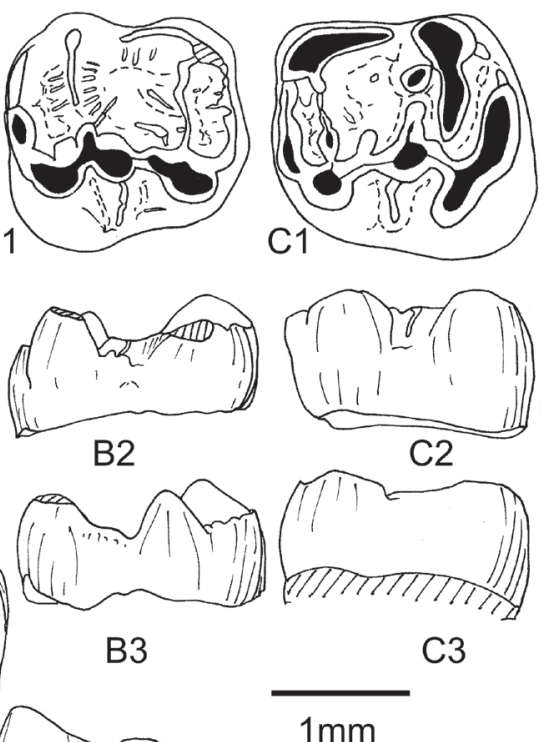

A3

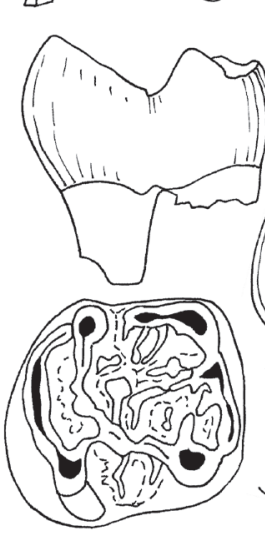

D1

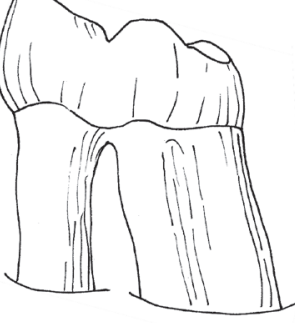

D2

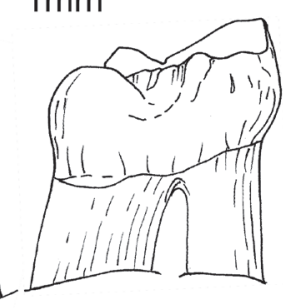

D3
Figure 68. Lower $\mathrm{m} 1$ of Hartenbergeromys marandati (Escarguel, 1999) from Prémontré (late Ypresian, MP10, Bassin de Paris). A. SLP29PR-571, right $\mathrm{m} 1$; $\mathrm{A} 1$, occlusal view, $\mathrm{A} 2$, buccal aspect, $\mathrm{A} 3$, lingual aspect. B. UMPRE-134, right $\mathrm{m} 1$; B1, occlusal view, B2, buccal aspect, B3, lingual aspect. C. PLPRE-1107, left m1; C1, occlusal view, C2, buccal aspect, C3, lingual aspect. D. SLP29PR-199, right m1; D1, occlusal view, D2, buccal aspect, D3, lingual aspect. Scale bar, $1 \mathrm{~mm}$.
Pl. 22h; SLP43PR-119) is described and compared to that of H. marandati (P1. 23g, SLP29PR-552), in order to formalize the differences between the two species. This comparison is necessary because the original descriptions did not use the same terminology; therefore, it is difficult to find singularities for each in Escarguel's descriptions and diagnoses. Then, we analyze the variability of the $\mathrm{m} 3$.

The metaconid is only slightly higher than the entoconid in both species (SLP43PR-119 as in SLP29PR 552). The posterior lobe is less reduced for $H$. hautefeuillei. On both, the mesostylid is hardly distinct at the distal end of the posmetacristid. It is extended in a very short lingual mesolophid; the anteroconid is subsumed within the anterolophid, which is in the continuity of the mesiolingual metalophulid; from the latter starts one short mesiodistal ridge on SLP29PR-552 and two on SLP46PR-119; the buccal metalophulid, developed from the apex of the protoconid, is transverse; it is separated from the lingual metalophulid. The latter is shorter on SLP43PR-119.

On both: the anterolophid is slightly lower than the mesial and buccal metalophulid I; its joins the mesial edge of the protoconid, closing buccally the anteroflexid. The postprotocristid lowers gently to the short mesial ectolophid.

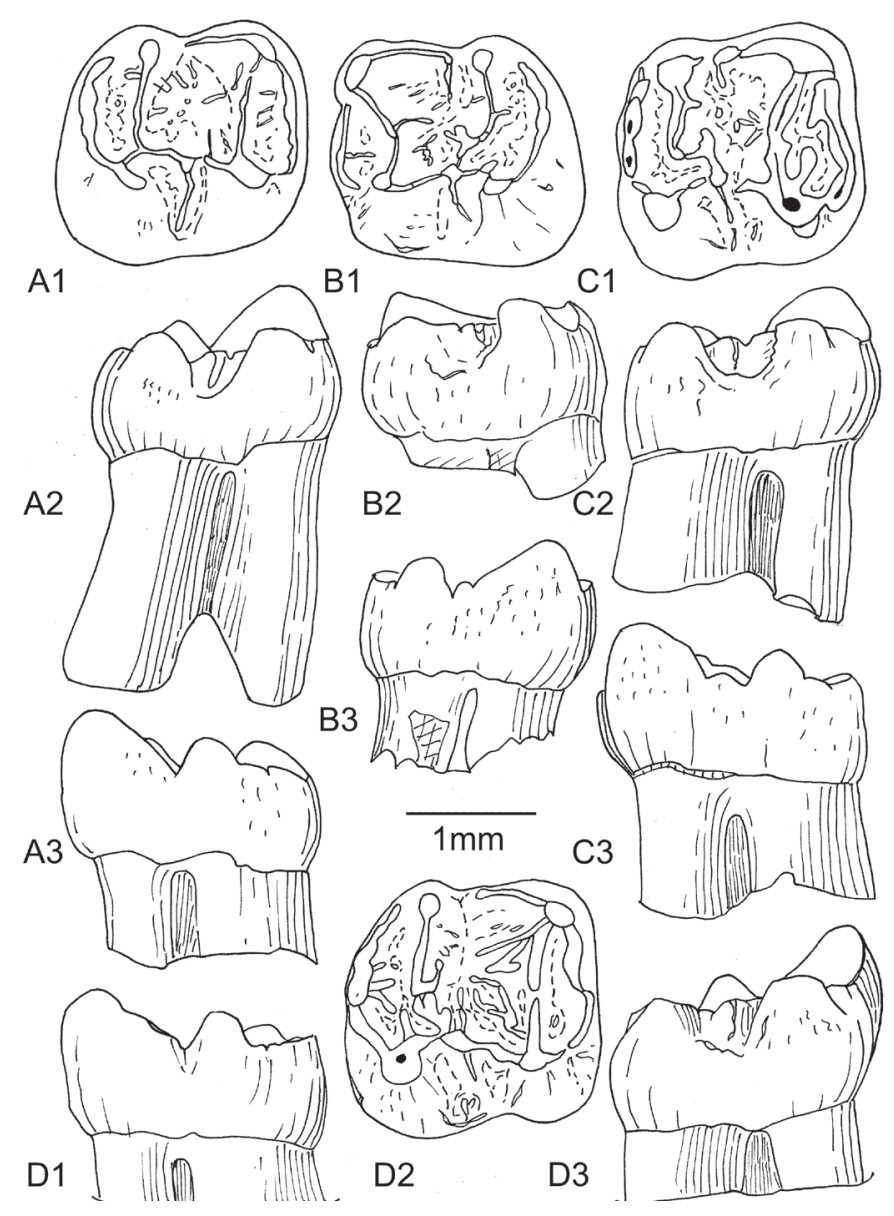

Figure 69. Lower m2 of Hartenbergeromys marandati (Escarguel, 1999) from Prémontré (late Ypresian, MP10, Bassin de Paris). A. SLP29PR-498, right $\mathrm{m} 2$, Holotype: A1, occlusal view, A2, buccal aspect, A3, lingual aspect. B. SLP29PR-902, left m2; B1, occlusal view, B2, buccal aspect, B3, lingual aspect. C. SLP29PR-1454, right m2; C1, occlusal view, C2, buccal aspect, C3, lingual aspect. D. SLP29PR-1695, right m2; D1, lingual aspect, D2, cclusal view, D3, buccal aspect. Scale bar, $1 \mathrm{~mm}$. 


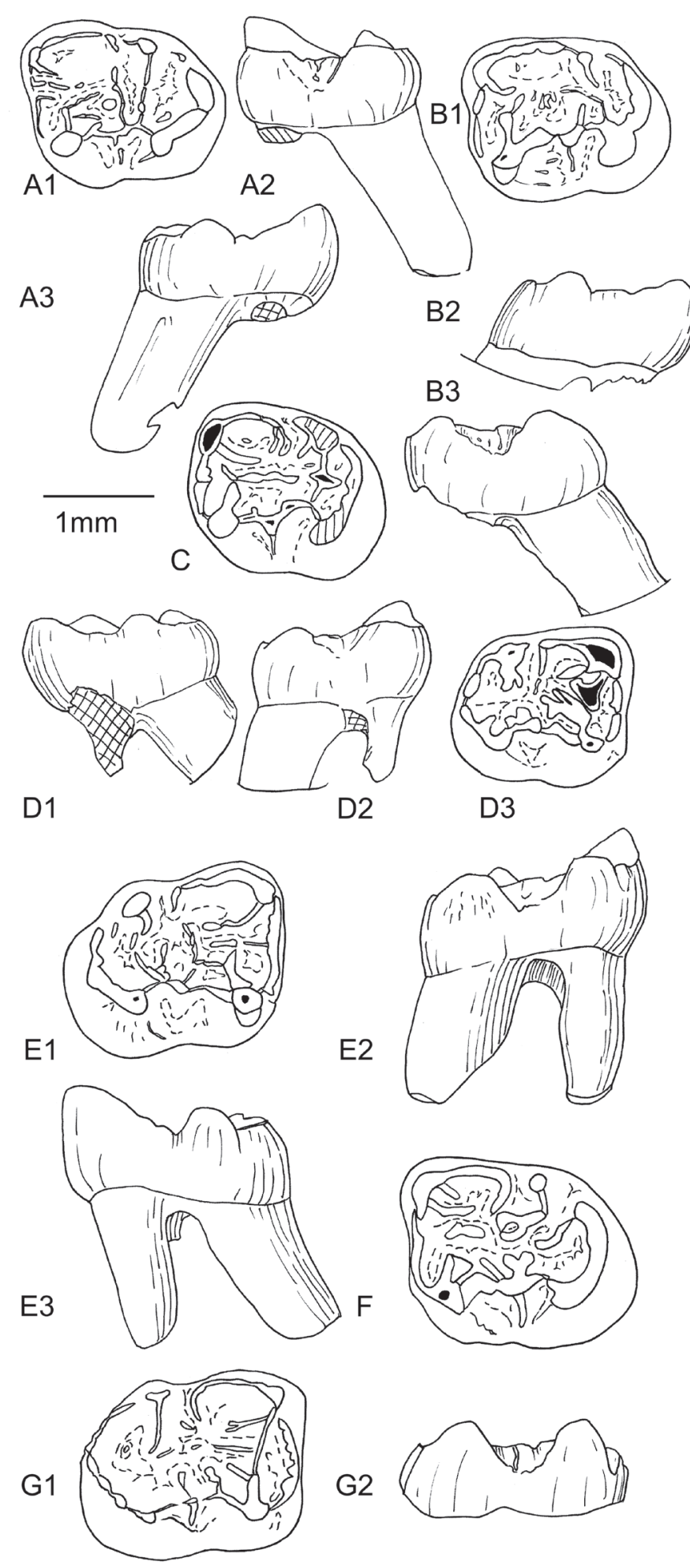

Figure 70. Lower m3 of Hartenbergeromys hautefeuillei Escarguel, 1999 (A-D) and of H. marandati (Escarguel, 1999) (E-G), from Prémontré (late Ypresian, MP10, Bassin de Paris). A. SLP43PR-119, left m3; A1, occlusal view, A2, buccal aspect, A3, lingual aspect. B. SLP29PR-794, left m3: occlusal view. C. SLP29PR-1128, left m3; C1, occlusal view, C2, buccal aspect, C3, lingual aspect. D. SMPRE-153, right m3; D1, occlusal view, D2, buccal aspect, D3, lingual aspect. E. SLP29PR-552, right m3; E1, occlusal view, E2, buccal aspect, E3, lingual aspect. F. SLP29PR-930, right m3; F1, occlusal view, F2, buccal aspect. G. SLP29PR-473, left m3: occlusal view. Scale bar, $1 \mathrm{~mm}$.
The mesoconid is moderately bulged, and slightly stretched, more mesiodistal in $H$. hautefeuillei, more oblique in $H$. marandati, and this possibly related to the reduction of the posterior lobe in the latter. The mesolophid and ectomesolophid on the mesoconid are faint on both. There is another mesolophid, which is longer, as a postmesoconid ridge. In the center of the basin, there is a buccolingual low ridge, related to the mesoconid in $H$. marandati, and to the postmesoconid ridge in $H$. hautefeuillei. The entolophid is low in both cases, straight, transverse and continuous in $H$. hautefeuillei, and connected to the distal ectolophid, very discontinuous in $H$. marandati with a short lingual ridge, two small extra-ridges punctuating the curved mesial border of the posteroflexid and another linked to the postmesoconid ridge. The posterior lophid is thick, and the hypoconulid not visible in both; a deep notch separates the posterolophid from the entoconid in $H$. marandati, not in $H$. hautefeuillei. In the latter, a postentocristid prolonges the posterolophid to the entoconid, and closes the posteroflexid lingually.

Finally, we can summarize the differences in a few characters: the anterolophid has the same height and shape in both; the metalophulid I is incomplete for both, and has the same shape and orientation; the mesiodistal buccal lophid (oblique postprotocristid + ectolophid + mesoconid + prehypocristid) has the same organization; the hypoconulid is not protruding. The main difference lies in the reduction of the posterior lobe. Due to this character, the orientation of the mesoconid is slightly different; the posterolophid is shorter, and more separated from the entoconid. Moreover, the figured $\mathrm{m} 3$ of $H$. marandati is larger than the figured $\mathrm{m} 3$ of $H$. hautefeuillei.

Concerning the variability of the $\mathrm{m} 3$ of $H$. hautefeuillei and H. marandati from Prémontré: (cf. Figs. 57B and 58B): these teeth are about as wide and slightly longer than the m1-m2 in $H$. hautefeuillei, and rather narrower in $H$. marandati. The number of $\mathrm{m} 3$ previously referred as to $H$. ("P.") marandati (27) was much higher than for the $\mathrm{m} 3$ of $H$. hautefeuillei (13). Among the smallest $H$. marandati, some display features similar to $H$. hautefeuillei, the posterior lobe is not reduced and the posteroflexus is higher and closed lingually (PLPRE-131, -803, -1049, SLP29PR-126, -367, -495, -2299, and SLP27PR-320), and as such they may belong to $H$. hautefeuillei. In contrast, PLPRE-144 previously referred as to $H$. hautefeuillei is better attributable to $H$. marandati: it shows a deep notch between the extremity of the posterolophid and the entoconid. Moreover one (SLP29PR-815), determined as a m3 of $H$. ("P.") marandati, is more probably a $\mathrm{m} 2$. Therefore, there are $22 \mathrm{~m} 3$ of $H$. hautefeuillei and 21 of $H$. marandati.

Their anterolophid does not vary a lot around the characteristics described above. If we consider unworn teeth, on one the anterolophid is isolated from the mesial flank of the protoconid, and the anteroflexus is superficially open buccally (Fig. 70), whereas it is closed on the others (14/16). The mesiodistal extra-ridges start from the mesiolingual premetacristid on SLP43PR-PR119 and seven other isolated teeth. On the others, the mesiodistal extra-ridges start from the lingual metalophulid I and from the lingual end of the buccal metalophulid I. The lingual metalophulid I joins the buccal metalophulid I on one specimen (PLPRE-663). Two specimens have the latter characters isolated by a cleft and on the other teeth by a less narrow groove. One lingual mesolophid is generally present at the extremity of the posmetacristid, it is double on SLP29PR-794 and absent on SLP29PR-481. At the extremity of the postprotocristid, the premesoconid is always a swelling. The mesoconid bears one $(12 / 16)$, two $(2 / 16)$ or none $(2 / 16)$ ectomesolophid. The flat at the base of the sinusid is not edged 
by an ectocingulid on three teeth only. The central low ridge is rarely continuous, more often short and divided in short extraridges. The long entolophid, as described for SLP43PR-119, is rare $(5 / 16)$; it is generally made of a relatively regular lingual part alone on $3 / 16$, with a discontinuous buccal one. When present, the entolophid connects to the mesoconid $(1 / 16)$, the postmesoconid (5/16), the ectolophid or the posterior arm of hypoconid (5/16). The posterior lophid is always long and the posterosynclinid closed. The extra-ridges and granules, out of these described above, are small and rare in the basins.

Diagnoses of Hartenbergeromys hautefeuillei (Escarguel, 1999) and Hartenbergeromys marandati (Escarguel, 1999)

\section{Hartenbergeromys hautefeuillei Escarguel, 1999}

Original diagnosis. (Escarguel, 1999: 202; translation from French). "Microparamyini of medium size. Dental pattern between Pantrogna and primitive Theridomyidae. Protrogomorphous infraorbitary foramen. Strong mandible, wide and robust, with thick incisor, very straightened. P3 present. P4 with anteroloph reduced or absent, but paracone well-developed. M1-3 of primitive type: hypocone welldeveloped; protoconule present, stretched mesiodistally, and placed in front of the protoloph; metaconule bulbous, massive; mesostyle buccal and well-developed, often connected to the paracone and metacone. Lower cheek teeth: with posterior root large, inclined and with a flat distal flank. p4 monocuspidate; complete ectolophid; frequent starts of mesolophid and hypolophid; short buccal crest lining the ectolophid. m1-3 with low anterolophid, sometimes cuspate labially; anterior arm of the protoconid (= buccal metalophulid) sometimes absent, never joining the metaconid, frequently turning towards the talonid basin; strong postprotocristid continuous, joining a mesoconid minute but present; mesoconid with a short "ectomesolophid", frequent start of a mesolophid and complete hypolophid; mesoconid-hypoconid connection weak to absent; hypoconulid weak but present and well-defined".

Emended diagnosis. Small species of the genus Hartenbergeromys: smaller (M1: L mean x W mean: $1.578 \mathrm{~mm}$ $\mathrm{x} 1.785 \mathrm{~mm}$ ) than $H$. marandati, larger than Pantrogna russelli (M1: L mean x W mean: $1.087 \mathrm{~mm}$ x $1.305 \mathrm{~mm}$ ), (Tables 7, 8). Lower jaw: short snout, with divergent jaws. Strong and high ventrodorsally incisors. Junction of the two masseteric crests standing below the separation between $\mathrm{m} 1$ and $\mathrm{m} 2$. Ramus ascendens uplift beginning at the $\mathrm{m} 2-\mathrm{m} 3$ contact.

Teeth differ from $H$. marandati in the extra-ridges less strong and less numerous, D4 without protruding parastyle and with anteroflexus narrower, P4 slightly larger than D4, and narrower than M1, with narrow anteroflexus and hypocone reduced to absent; on P4, buccal roots closer, and (D3)P3 more reduced (farther from the P4 mesiobuccal small root). On p4, metaconid mediomesial, anterolophid absent and ectocingulid shorter. Lingual metalophulid I more often less complete. Ectolophid more often mesiodistal than oblique. Posterior width of $\mathrm{m} 3$ more reduced.

Hartenbergeromys marandati (Escarguel, 1999)

Pantrogna sp. 1 Hooker, 1996, p. 148, pl. 1, figs 8-9.

Pantrogna marandati Escarguel, 1999: 196-197.
Original diagnosis. (Escarguel, 1999: 196-197; translation from French). "Species of the genus Pantrogna larger than $P$. russelli. Cheek teeth massive and bulbous, with wide cups; ridges (lophs and lophids?) better developed than on P. russelli, deeper valleys. Wrinkled enamel surface. Well-molarized D4, with two massive conules. $\mathrm{P} 4$ with anteroloph strongly reduced or absent; hypocone generally present, frequent start of a low mesoloph. M1-3 more massive and bulbous than in P. russelli: conules and hypocone more developed, complete protoloph; frequent start of a mesoloph. Frequent $U$ shaped trigon on M1-2. Marked lingual sinus, and complete metaloph on M3. p4 stocky, with a labial ridge lining the ectolophid. m1-2 with complete and strong anterolophid and metalophulid (= metalophulid I); short postprotocristid (= buccal metalophulid); mesoconid strongly stretched buccolingually; hypolophid generally complete and high; deep lingual sinusid; connection mesoconid-hypoconid well-developed; massive posterolophid; hypoconulid merged. $\mathrm{m} 3$ with metalophulid rarely complete; strong ectolophid and hypolophid."

Emended diagnosis. Species of the genus Hartenbergeromys. Differs from $H$. hautefeuillei in its larger size (M1: L mean x W mean: $1.739 \mathrm{~mm} \times 1.941 \mathrm{~mm}$ ), and in its extra-ridges stronger and more numerous. D4 with protruding parastyle, wide anteroflexus; protocone and pre- and post- protocristae stretched obliquely; with small hypocone. P4 slightly smaller than M1, with narrow anteroflexus and hypocone reduced to absent. On P4, buccal roots better separated, and (D3)P3 less reduced (alveolus closer to the mesiobuccal P4 small root). On p4, metaconid more lingual; anterolophid reduced and ectocingulid long. On molars, lingual metalophulid, more often complete. Frequently oblique ectolophid. Posterior width of $\mathrm{m} 3$ less reduced.

\section{Hartenbergeromys species indet.}

P4. The tooth UMPRE-119 (Fig. 60D) is smaller and narrower than the P4 of $H$. hautefeuillei. The anteroloph and anteroflexus are absent: the mesialmost ridge is the protoloph, joining the beginning of the preprotocrista. There is a strong postparacrista, which reaches the mesiodistally stretched mesostyle. The mesostyle is prolonged lingually as a short mesoloph. Two oblique extra-ridges converge with its lingual end, in the mesoflexus. The bulged metacone, stronger than the paracone, is prolonged lingually in two buccal metalophs, the mesialmost (metalophule I) joins the strong metaconule, which is attached through the lingual metaloph to the apex of the protocone. The buccal metalophule II does not attach to the distal extra-ridge from the metaconule.

d4. The SLP29PR-1687 (Fig. 65C) tooth is the smallest and simplest among the $\mathrm{d} 4$ stored with $H$. hautefeuillei. Its crown is relatively higher on both lingual and buccal sides, the metaconid being only slightly higher than the other cuspids; thereby the long postmetacristid is weakly sloping. There is no connection between the metaconid and the protoconid. The entolophid is limited to a short lingual entolophulid.

m1-2. The SLP29PR-2147 (Fig. 67E) left molar is also smaller than the molars of $H$. hautefeuillei. It has a complete metalophulid I. The mesoconid is stretched in line with the posprotocristid; it bears a short ectomesolophid. The entolophid is limited to a short lingual entolophulid. 


\section{Family Masillamyidae nov.}

Remarks. As the different species of this genus Masillamys make a well-defined clade (node M, Fig. 4) at the base of the classical Theridomyoidea superfamily (cf. Lavocat, 1951: 47; Thaler, 1966: 23-27) differentiated at the node L, they are raised to a familial level, like the Euromyidae and the Plesiarctomyidae. Like Pseudoparamys, Hartenbergeromys, Sparnacomys and probably Pantrogna, and the Pseudosciuridae and Theridomyidae for the more recent taxa, the species of the genus Masillamys are all hystricomorphous. Masillamys displays the derived features of the basal Theridomorpha (e.g., the high and oblique postprotocristid; the metalophulid I present only) and like Sparnacomys, Pantrogna and Hartenbergeromys, the protoconid absent on $\mathrm{p} 4$ and constant sloping extra-ridges along the main lophs and lophids.

\section{Genus Masillamys Tobien 1954}

Type species. Masillamys beegeri Tobien, 1954.

Referred species. M. krugi Tobien, 1954; M. parvus Tobien, 1954; M. mattaueri Hartenberger, 1975.

Remarks. The different species referred to this genus have been recently revised (Vianey-Liaud et al., 2019), in order to score their dental and i.o.f. features. The main results of this revision is that at least $M$. beegeri and $M$. krugi are hystricomorphous (Ruf \& Lehmann, 2018; Vianey-Liaud et al., 2019), and valid species. Their dental features used for the present phylogenetic analyses, confirm that all species of Masillamys, including $M$. parvus, the smaller species from Messel (MP11) and the older species $M$. mattaueri, defined from Mas-de-Gimel and also known from a few MP10 Bassin de Paris localities (Grauves and St-Agnan) make a clade (node $\mathrm{M}$ ).

Diagnosis of the genus. (From Vianey-Liaud et al., 2019) Basal Theridomorpha. Enamel rough to strongly wrinkled on the periphery of the crown; wrinkles and granules numerous in the mesoflexus. Preparacrista absent on M1-M2; parastyle moderate on M2; ectocingulum variably present on M1-M2; one to two mesolophs on M1-M2; one to two mesostyles on M3; metalophule II variably connected to the posteroloph; posthypocrista variably present on M1-M2; paracone strongly higher than the protocone on M3. On $\mathrm{m} 2$, trigonid only slightly higher than the talonid; buccal mesolophid distinct from a postmesoconid ridge; more than three mesiodistal extra-ridges along the distal slope of the trigonid on molars; ectomesolophid present on dp4 and p4; buccal entolophid connected/directed to the postmesoconid ridge; buccal anterolophulid absent on molars; entoconulid variably present.

\section{Differential diagnosis.}

The genus Masillamys differs from:

- Pantrogna and Hartenbergeromys in its less reduced p4, its metaconid less high than the other cuspids, the hypocone larger compared to the protocone on molars, although remaining smaller

- Protadelomys in its larger size, the occurrence of an ectolophid bearing a mesoconid (cf. original diagnosis of Stehlin \& Schaub, 1952), the lingual metalophule (or metaconule lingual connection) lower and more mesial (to the postprotocrista or the endoloph, exceptionnally to the hypocone).
Masillamys parvus Tobien 1954

Masillamys parvus Tobien, 1954: 23-26, Pl. 1, fig. 4, Pl. 2, fig. 4.

Microparamys parvus (Tobien): in Hartenberger, 1968: 1817, 1820.

Microparamys (Sparnacomys) parvus (Tobien): in Hartenberger 1971: 108.

Hartenbergeromys parvus (Tobien): in Escarguel, 1999: 211213

Holotype. Poorly preserved skeleton with teeth extracted: upper M1-M3 and lower p4-m3 left, m3 right. Hessisches Landmuseum $\mathrm{n}^{\circ} \mathrm{Me} 625$.

Type locality. Messel (Hesse, Germany; early middle Eocene, MP11)

Other locality. ? Prémontré (Aisne, France; late early Eocene, MP10).

Original diagnosis. (Tobien 1954: 23-24; translation adapted from German). "Definitely smaller (Holotype: p4, 1.75 x 1.42; $\mathrm{m} 2,1.93 \times 1.84 ; \mathrm{m} 3,2.02 \times 1.75$ ) than M. beegeri (Holotype: $\mathrm{p} 4,2.23 \times 2.00 ; \mathrm{m} 1,2.59 \times 2.41 ; \mathrm{m} 2,2.72 \times 2.45 ; \mathrm{m} 3,2.87 \times$ 2.13) and M. krugi (Holotype: p4, 2.36 x 2.10; m1, 2.30 x 2.36; $\mathrm{m} 2,2.38 \times 239 ; \mathrm{m} 3,2.69 \times 2.26)$. On the lower molars, the anterior cingulid is separated from the protoconid by a deep incision; there is only a short anterior arm of the protoconid (=buccal metalophulid; posterior arm of the protoconid in the translation by Escarguel, 1999: 212). The lingual metalophulid is absent. The entolophid is more sharply defined than in the two other species, proceeding from the entoconid, and joining the ectolophid between the mesoconid and the hypoconid. Entoconid opposite to the hypoconid on the p4; whereas it is distinctly more mesial on the lower molars."

Emended diagnosis. Relatively small sized rodent, larger (M2: $1.74 \mathrm{~mm} \times 2.00 \mathrm{~mm}$ ) than H. hautefeuillei. On lower molars, lingual main cuspids more mesial than buccal ones; p4 with protruding metaconid, mediomesial, and protoconid absent; posterior lobe of $\mathrm{m} 3$ not strongly reduced. On molars, lingual metalophulid I incomplete, buccal metalophulid I ending at midwidth; entolophid complete, attached to the distal ectolophid/prehypocristid junction; ectomesolophid present and hypoconulid reduced. On upper M2 and M3, mesostyle present and positioned only slightly more buccally than the paracone and metacone; hypocone well-developed, with strong pre- and post- hypocristae; shallow sinus present on both.

\section{Differential diagnosis.}

\section{Differs from}

- Masillamys beegeri and M. krugi in its smaller size; the absence of mesiobuccal cingulid and the reduction of the protocristid on $\mathrm{p} 4$; the entolophid always complete, attached to the distal ectolophid junction with the anterior arm of the hypoconid; from M. krugi in the lack of a mesostylid flat on lower molars.

- Hartenbergeromys hautefeuillei: on p4, in the absence of mesiobuccal cingulid, the reduction of the protocristid, and the metaconid lower relative to the entoconid; on lower molars, the buccal end of the anterolophid more distinct from the mesiobuccal flank of the protoconid; the entolophid more regularly continuous; on $\mathrm{M} 2$ and $\mathrm{M} 3$, in the presence of a larger hypocone. 
Masillamys aff. parvus Tobien, 1954

Figure $62 \mathrm{G}$

One M1 from Prémontré could be close to Masillamys parvus. The SLP43PR-287 M1 $(1.90 \mathrm{~mm} \times 2.20 \mathrm{~mm})$ is the largest among the M1 referred by Escarguel to Pantrogna marandati. If its general pattern ressembles that of $H$. marandati, some morphological features can be stressed. The most striking is the crestiform arcuate and high parastyle connected to the preparacrista. The mesostyle is small and acute, double on its mesiobuccal face by a low and short meso-ectocingulum, and attached to the postparacrista and the premetacrista by thin ridges. The protocone bears a protocrista. The metaconule is lined buccally by a short distomesial swollen ridge (? metalophule I). The lingual connection of the metaconule is double with the endoloph (extremities of the postparacrista and of the prehypocrista). The distal flank of the metaconule connects to the posteroloph via a short ridge. These characters evoke Masillamys parvus from Messel, but the latter is larger. It could be also a large variant of $H$. marandati.

\section{Basal THERIDOMYOIDEA, Family indet.}

Remarks. Until recently, the middle Eocene radiation of the superfamily Theridomyoidea was limited to four species of the genus Protadelomys. In a phylogenetic analysis of the theridomorphs (Vianey-Liaud \& Marivaux, 2017: fig. 7A), the topology of the first branches suggested that the genus is paraphyletic. Elsewhere, the species considered until now as the most primitive ( $P$. nievesae Pelaez-Campomanes, 1995 and $P$. maximini Escarguel, 1998) were resolved as a clade in the terminal branching of the genus. The results of the current analyses, are more consistent with the stratigraphic context. The late Lutetian species (P. cartieri, the type species of the genus, and P. lugdunensis; MP14) appear as the youngest clade. However, the other species recognized as belonging to the genus Protadelomys (P. alsaticus, P. maximini, and P nievesae; successively N, N' and N" on Fig. 4) are not resolved as closely related to the two latter species ( $P$. cartieri and P. lugdunensi; node O, Fig. 4). They emerge successively from the node L (Fig. 4), the Masillamys clade being their sister group. From these results, the genus Protadelomys appears paraphyletic, thereby requiring the revision and reevaluation of the generic attribution of the basal successive species, from "P." 'alsaticus (MP13) to "P." maximini (MP13) then "P." nievesae (MP12?).

\section{Genus Protadelomys Stehlin \& Schaub, 1951}

Type species. Protadelomys cartieri (Stehlin \& Schaub, 1951). Remarks about the diagnosis of the type species. Hartenberger has defined the genus Protadelomys for the species cartieri from Egerkingen, previously referred to as the genus Adelomys (type: right P4-M3; in Stehlin \& Schaub, 1951: fig. 25). Stehlin \& Schaub (1951) have provided some dental features in their diagnosis of the species: some of them (as the lack of the mesoconid on lower teeth) have not even been considered in the later definition of the genus, until Hooker and Weidmann (2000), who recognized the lack of mesoconid as an important taxonomic character. Thaler (1966), in order to clarify the systematics of the catch-all genus Adelomys, placed cartieri within the genus Masillamys, together with two species then referred to other genera: the species louisi (= Meldimys louisi
Michaux, 1968) and tobieni (= Elfomys tobieni Hartenberger, 1971). The original diagnosis of Protadelomys by Hartenberger (1969) was very succinct: “Adelomyinae de l'Eocène moyen de petite taille à dents jugales primitives". Later, Escarguel (1998) provided dental features in its emended diagnosis, taking into account the several species included in the genus (cartieri, alsaticus, lugdunensis, nievesae, and maximini). The observations and analyses of the species other than cartieri from their type locality and other provenances led us to reconsider and discuss their inclusion in the same genus. Moreover, the definition of the different species appears questionable because of the likely presence of several taxa in the assemblage of several of them (cartieri, lugdunensis, and alsaticus) and the fact that important characters have been omitted.

In addition to these ambiguities in the definition of the genus and of the species placed in Protadelomys, the genus appeared paraphyletic in our two phylogenetic analyses (Vianey-Liaud \& Marivaux, 2017, and the present one). For these reasons, a review of all species included in the genus Protadelomys will be undertaken. Due to the great amount of new data, which notably implies the reevaluation of previous species, as the identification of new taxa, the descriptions and analysis will be the subject of another paper to be published separately.

\section{Family Pseudosciuridae Zittel, 1893}

Definition and discussion. See Comte et al., 2012: 183-184.

\section{Genus Auroremys gen. nov.}

Type species. Auroremys subita (Comte et al., 2012).

Remarks. We define this new genus for the only species subita formerly referred to the genus Ailuravus (Comte et al., 2012). If this species shows upper teeth having few features looking those of Ailuravus, like a well-developed ectocingulum and the presence of acute cusps, the pattern of lower teeth is very different. We have seen that the development of an ectocingulum and the presence of acute cusps are widely homoplasic. They are notably found in a few pseudosciurids, like Tarnomys or Pseudosciurus. For Auroremys these features go with characters more developed than in Ailuravus, like the large hypocone as high as the protocone, or the deeper sinus, limited by convergent postprotocrista and prehypocrista, as it is the case for Tarnomys (late Eocene, early Oligocene) (Hartenberger \& Schmidt-Kittler, 1976). The sinus is deeper in Tarnomys, together with a longer prehypocrista and the development of a mure. The lower teeth pattern is close to that of Tarnomys and very distinct from Ailuravus, displaying notably a strong antesinusid, a complete transverse entolophid and, above all the strong oblique postprotocristid typical of Theridomorpha and not found in Ailuravinae. The features of the species as provided in the original diagnosis as well as observed on the original material, show clear differences with Ailuravus. The present parsimony phylogenetic analyses clearly separate this species from ailuravids: it gathers Auroremys with Tarnomys (Fig. 4; node $\mathrm{O}$, with 22 not ambiguous synapomorphies and 11 ambiguous), within the Pseudosciuridae. Because of the morphological differences, especially for upper molars, between this species and the species referred to Tarnomys (see below), and the long gap of time between them (Lower Bartonian for subita, and late Priabonian to early Rupelian for Tarnomys), we have chosen to create a new taxon for subita. 
Derivatio nominis. From Aurore Comte, the daughter of late $\uparrow$ Bernard Comte.

Original diagnosis of "Aluravus" subita. (Comte et al., 2012: 178; translation from French). "Species slightly smaller than Ailuravus michauxi. Differs morphologically in its M1-2, with a developed hypocone, a clear tendency to lophodonty, and the large mesostyle notably on M2. p4 with continuous ectolophid, strongly bulged at the mesoconid level. Trigonid basin closed distally by the metalophulid I; linked to the anteroconid by a mesiodistal ridge (anterolophulid). Metalophulid I complete on $\mathrm{m} 1$, incomplete on $\mathrm{m} 2$. Metalophulid II always absent on the observed m1-2; transverse ridges developing from the ectolophid; hypoconulid doubled on $\mathrm{m} 2$ and $\mathrm{m} 3 . "$

\section{Differential diagnosis (new).}

Differs from Ailuravus: on upper molars in having the metacone at the same buccal level as the paracone, the hypocone nearly to as strong and high as the protocone; the complete high protoloph attached to the protocone apex; the sinus relatively deep linguobuccally, limited by the junction of the relatively long postprotocrista and prehypocrista, like for instance in Pseudosciurus.

On lower molars, in the well-developed anterolophid, anterolophulid and large antesinusid; in the development of the metalophulid I, instead of metalophulid II, with the postprotocristid strong and oblique buccomesial to linguodistal, connecting to the mesial ectolophid; the entolophid better developed and connected to the distal ectolophid

Differs from Tarnomys: On upper molars: in having a sinus linguobuccally shorter, with a shorter prehypocrista, and especially the absence of mure. On lower molars: in the less strong lophids and in the absence of strong extra-ridges from the metalophulid area to the talonid basin.

\section{Auroremys subita (Comte et al., 2012)}

Figure 71

Ailuravus subita, Comte et al., 2012: 178-182.

Holotype. CHC-14, left M1 (Comte et al., 2012: Pl.1, fig. b). Type locality. Chéry-Chartreuve (Aisne, Bassin de Paris; late middle Eocene, "MP15").

Diagnosis. As that (emended) of the genus.

Description. (See also Comte et al., 2012: Pl. 1, figs. b-g). Despite the limited number of teeth ( 8 complete upper teeth, 8 complete lower teeth), there are loci enough for characterizing the species, and establishing distinctive features. The original detailed description is here completed.

\section{Upper molars. (Fig. 71A-C)}

$M 1$ and $M 2$ differ in the presence of a stronger parastyle on $\mathrm{M} 1$; on M2 the hypocone is more buccal, the ectocingulum elements are absent (except the meso-ectocingulum distal to the stretched mesostyle), the mesoloph reduced, the lingual metaloph indistinct on this unworn M2.

On the holotype (the only M1), the conical paracone bears a preparacrista, oblique linguomesially and connecting the junction of the strong parastyle with the para-ectocingulum. The buccal slope of the paracone is shallowly notched between the para-ectocingulum and the mesostyle. The latter connects to the buccal end of the premetacrista (slightly notched buccally). The mesostyle is stretched mesiodistally in a short ridge (meso-ectocingulum). It bears a short buccal mesoloph. The posteroloph is long, prolonged buccally by a short metaectocingulum, on which the postmetacrista is attached to it. On M1 and M2, the protoloph is well defined, sinuous at the level of the paraconule, which is projected forward in the wide anteroflexus. Three thick low extra-ridges descend from the paracone-buccal protoloph, filling the buccal half of the anteroflexus, buccally to the paraconule. The lingual protoloph is indistinct on the thick protocrista. The hypocone is as developed as the protocone on M1, slightly less on M2. Preprotocrista and postprotocrista make a wide V on M1, and a more open $\mathrm{V}$ on M2. The extremities of the postprotocrista and prehypocrista join relatively acutely: the endoloph is absent, and the sinus is well defined. There is a shallow antesinus underlying the junction between the anterostyle and the preprotocrista. A reentrant, stronger on M1 than on M2, underlines the junction between the posthypocrista and the posteroloph: here, there is a small posterostyle.

Diverging lingually from the conical metacone, two weak sloping ridges represent, for the more mesial the metalophule I, for the more distal and the higher, the metalophule II. The latter joins the more buccal metaconule on M1; it is weaker on M2. The former is longer on M2 than on M1. A second metaconule is slightly smaller than the first, and mesiolingual to it. A short, low lingual metaloph starts from the mesial edge of this second metaconule to join the buccal flank of the protocone, slightly behind the protocrista. This junction is not visible on the unworn M2.

On the only M3, wear affects the crown posterolingually, which appears nearly horizontal, abrading as well the mesostyle area, the metacone, metaconule and hypocone as the protocone; leaving an almost vertical plane of wear on the distal flank of the paracone + protoloph + paraconule, up to the level of the anterostyle at the mesial extremity of the long preprotocrista. The strong protocrista joins the protoloph at the level of the forwardly projected paraconule. There are three mesostyles and three mesolophs; the more distal is the longest, converging with the metaloph to the center of the tooth. The hypocone is well defined, even if small, and separated from the protocone by a marked sinus.

\section{Lower teeth. (Fig. 71D-G)}

On $p$, the metaconid is stronger with respect to the protoconid. A mesiodistal premetacristid descends from the high metaconid to a low swelling nearly to the base of the crown (anteroconid?). It weakly connects to the thin short and low anterolophid. From the latter, a thin mesiodistal ridge runs to the buccal part of the complete metalophulid I. The posprotocristid is not defined, whereas it is clearly visible from the buccal metalophulid on molars. The long sloping buccal part of the thin ectolophid starts at mid-length of the metalophulid I; more lingually, a thick and low ridge descends to the floor of the talonid basin parallel to the ectolophid. Two sloping buccal spurs, one from the protoconid along its distal flank, the other from the hypoconid along its mesial flank, reach the strong ectostylid at the buccal edge of the sinusid. The ectolophid, oriented mesiodistally, joins the long and swollen mesoconid. From the latter, three short ridges "ectomesolophids" descend to the floor of the large sinusid; one thinner and short ridge runs lingually towards the talonid basin; on $\mathrm{CHC}-86$, a premesoconid spur and a short mesolophid are present. The width of the sinusid is nearly equal to that of the talonid basin (ectolophid at mid- 
width). The hypoconid is slightly elongated and pinched lingually, making a short (buccal) hypolophid on which the distal ectolophid and posthypocristid are confluent. The posthypocristid runs obliquely distally to join the mesiodistally stretched hypoconulid, moderately salient. At this level, a weak posterosinusid marks this junction. The posterolophid, aligned on the former, ends at the distal corner of the entoconid. An angulated entolophid joins the mesial flank of the hypoconulid, closing a small linguo-posteroflexid. This is reduced on the CHC-86 p4, on which a low element of a short buccal entolophid is present as a postmesoconid ridge.

The three molars (m 1-3) are characterized by a short anterolophid (shorter on $\mathrm{m} 1$ ), swollen in a small anteroconid.
It extends buccally, as a sloping anterocingulid, which limits a weak antesinusid mesiobuccally. Lingually a strong anterolophulid turns at right angle with the anterolophid, to join the buccal metalophulid. Therefore, the anteroflexid is very short. On $\mathrm{m} 1$, the anteroflexid is closed distally as the lingual metalophulid joins the buccal one to make the complete metalophulid I. It is likely the same configuration for the $\mathrm{m} 3$, but it is too much worn to ascertain. The two parts of the metalophulid are separated by a groove on the $\mathrm{m} 2$. The postmetacristid ends with a distinct metastylid, in front of the mesoflexid opening (Fig. 71E3). The postprotocristid is long, strong and oblique, joining the mesiodistal ectolophid in which the mesoconid is bulged, its wear surface being triangular. We

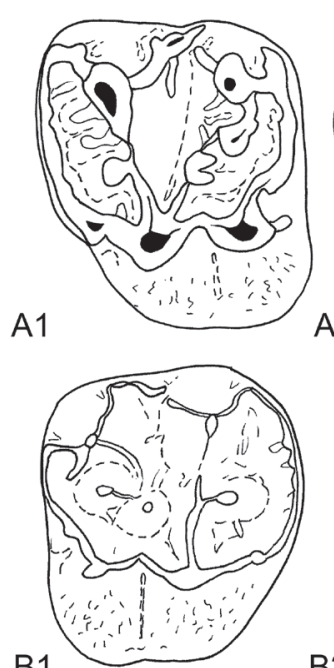

B1

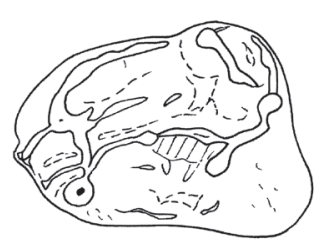

D1

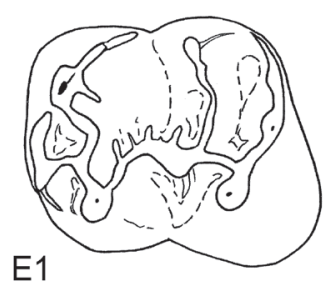

E1

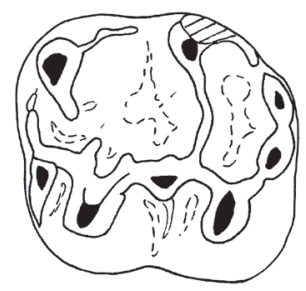

F1
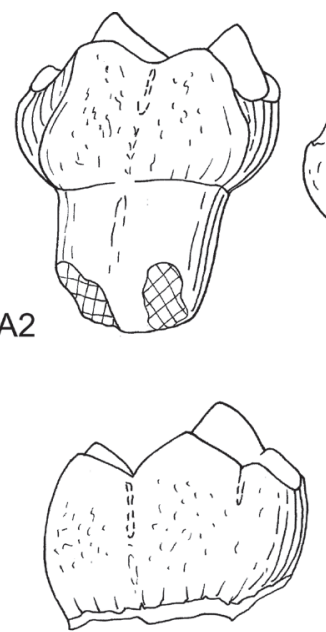

B2

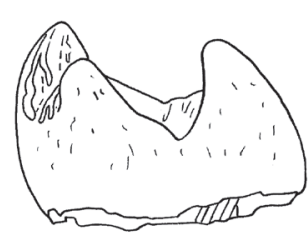

D2

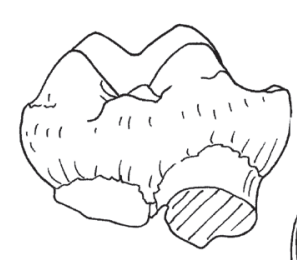

A3

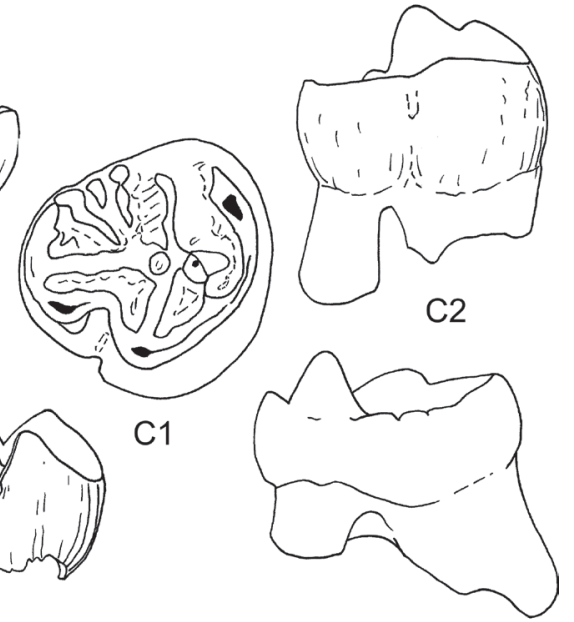

C3
B3

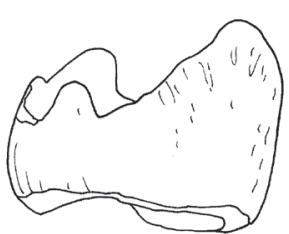

D3

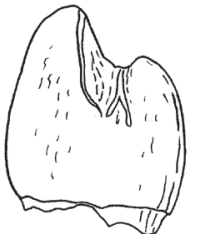

D4

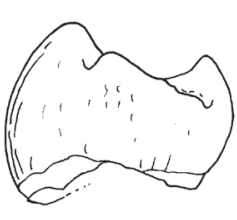

D5

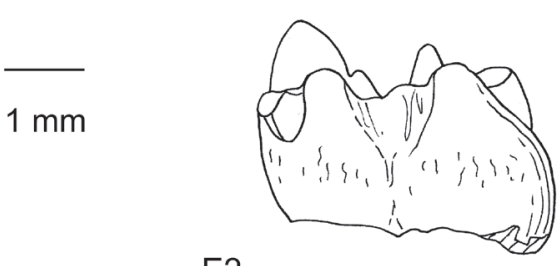

E2

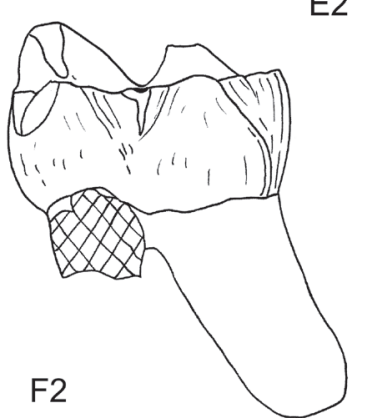

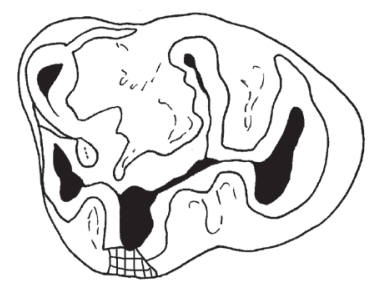

G1

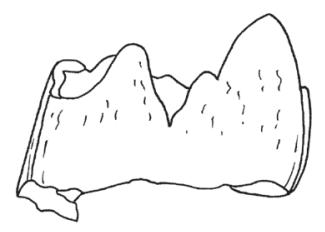

E3

Figure 71. Upper (A-C) and lower (D-G) teeth of Auroremys nov. gen. subita (Comte et al., 2012) from Chery-Chartreuve (early Bartonian, MP15, Bassin de Paris). A. CHC 14, left M1, Holotype: A1, occlusal view, A2, lingual aspect, A3, buccal aspect. B. CHC 17, right M2: B1, occlusal view, B2, lingual aspect, B3, buccal aspect. C. CHC 23, right M3; C1, occlusal view, C2, lingual aspect, C3, buccal aspect. D. CHC 24, left p4: D1, occlusal view, D2, buccal aspect, D3, lingual aspect, D4, mesial aspect, D5, distal aspect. E. CHC 27, left m1: E1, occlusal view, E2 buccal aspect, E3, lingual aspect. F. CHC 24, left m2 F1, occlusal view, F2, buccal aspect. G. CHC 33, left m3: G1, occlusal view, G2, lingual aspect. Scale bar, $1 \mathrm{~mm}$. 
distinguish a curved prehypocristid attached to the hypolophid part of the hypoconid, from which starts the posthypocristid, directed obliquely postwards. Then, there are two successive bulged hypoconulids, followed by a thin posterolophid.

On the three teeth, a complete entolophid, relatively high, connects the entoconid to the postmesoconid area, thereby individualizing a posteroflexid separated from the mesoflexid. The development of these transverse lophids prevents the oblique wear pattern observed on Ailuravus. The lingual cuspids are more mesial than the buccal ones, much more on $\mathrm{m} 3$. On the latter, the posterolophid and hypoconulid are reduced.

\section{GENERAL DISCUSSION AND CONCLUSIONS}

This study has shown how it is essential to use a detailed and formalized terminology for describing dental structures of the Eocene rodents, in order to be precise and to avoid subjectivity in the description of the global forms, and to characterize their variability. This is all the more necessary as homoplasies are numerous, and the relevant and diagnostic morphologies are not clearly identifiable in species emerging from adaptive radiation. The analyses of morphological and size variability led us to identify new taxa among the assemblage from Avenay, like the small Reinomys rhomboides, or to recognize Ailuravus features for the species inexpectatus from Prémontré.

The present morphological and phylogenetic analyses allowed to highlight critical features for defining the endemic European Theridomorpha; and to separate them from the ischyromyoids. As a result, the content of the Theridomorpha clade has been enlarged, thereby extending the first theridomorph radiations back to the mid-early Eocene (MP89). In this paper, the systematics chapter has been structurated following the results of the phylognetic analyses.

\section{Features of Theridomorpha}

The Theridomorpha Lavocat, 1955, illustrate a case of endemic evolution in Europe (e.g., Lavocat, 1955: 81). Until now only one superfamily, the Theridomyoidea Alston, 1876 (Lavocat, 1955; Thaler, 1966) was known, and two valid families, the Pseudosciuridae Zittel, 1893 and the Theridomyidae Alston, 1876. The Theridomyoidea are characterized by a hystricomorphous skull, sciurognathous mandible and dental formula encompassing 1/1 I, 2-1/1 D, 2-1/1 P, 3/3 M. The dental pattern was defined as initially tetralophodont on upper teeth and trilophodont on lower teeth evolving towards pentalophodonty (Stehlin \& Schaub, 1951) with main cusps and cuspids merged in lophs and lophids, notably in the Theridomyidae family, following various modes and rates (e.g., Hartenberger, 1970; Schmidt-Kittler, 1971; VianeyLiaud, 1979). This lophodonty goes with the deepening of the sinus and sinusid and the development of the mure, and with the flattening of the occlusal surface. They were supposed to appear during the middle Eocene, with the genus Protadelomys (Hartenberger, 1968). Most of Eocene species are brachydont to weakly unilaterally hypsodont (mainly Pseudosciuridae), whereas the main part of the late Eocene and Oligocene Theridomyidae have developed a more or less strong unilateral hypsodonty.

The definition of diagnostic dental features has been refined (Vianey-Liaud \& Marivaux, 2017, this paper). In addition to the development of the hypocone in the upper teeth, the lingual wall evolved from a mesiodistal endoloph to a mure (with sinus opening), but not before late middle Eocene species (e.g., Comte et al., 2012). In Eocene species, the endoloph is still mesiodistal, without a well-marked sinus. Transverse lophs and lophids are variably developed, and the semi-hypsodonty is weak. But the dental characters that appear now critical to define Theridomorpha are features of the lower teeth. They are notably the metalophulid I present only, its buccal part transverse and attached to the summit or to the mesial side of the protoconid, the strong oblique postprotocristid, the short ectolophid, the developed entolophid, and the hypoconulid reduced or absent stretched in the posterolophid (e.g., PeláezCampomanes, 1995; Vianey-liaud, 1998; Marivaux et al., 2004).

Taking into account the early Eocene taxa, we have found such features, or their initiations, like weak unilateral hypsodonty, with little protruding cusps and cuspids above the crown edge, protoloph and metaloph more or less complete, the mesoloph variably present and variably long, the endoloph first high, the hypocone present, the metalophulid I only or predominent, the postprotocristid oblique and thick, making an angle with the weak and short mesial ectolophid, from which it is distinct. These changes in lower teeth correspond to a lowering and reduction of the initial high trigonid, with the reinforcement and functional integration of the postprotocristid to the talonid. At the same time as the longitudinal "walls" develop, the transverse crests strengthen, initially incomplete, then variably developed, and in different ways depending on the taxa and their degree of hypsodonty, leading to the diversification of the groups.

\section{Systematics and phylogenetic results}

Among the Ischyromyoidea, the Ischyromyidae, which are mainly North-American Paleogene rodents, have been defined as protrogomorphous rodents. These rodents have pauciserial incisor enamel microstructure, have basically bunodont rather than lophodont teeth, which are low-crowned (brachydont); upper premolar formula $2 / 1$; size of P4 variable, but not as large as the molars; hypocone variable, small (smaller than the protocone) on upper molars; conules and styles present; protoloph and metaloph convergent to the protocone apex. Lower molars with small and high trigonid with metaconid the highest cupid; talonid shallow with marginal cuspids; hypolophid (= entolophid) and hypoconulid variable (e.g., Wood, 1962; Korth, 1994; Anderson 2008).

Most of these features are common to early Ischyromyiformes (sensu Marivaux et al., 2004) and primitive, together with the pauciserial incisor enamel (Martin, 1992), cuspate teeth, the orientation of the protoloph and metaloph, the elevated trigonid etc. The development of a hypocone, as well as an ectocingulum on upper molars are non-exclusive synapomorphies of the group, and found in several other unrelated coeval or subsequent rodent groups (e.g., Marivaux et al., 2004; Marivaux and Boivin, 2019). Features of lower teeth correspond to various developments of the main transverse lophids: metalophulids and entolophid. In the ischyromyoids, the entolophid is variably present; when present the metalophulid is a metalophulid II (transverse connection from the metaconid to the postprotocristid). In ischyromyoids, this postprotocristid generally makes the metalophulid II and the distal border of the trigonid, overhanging the talonid basin and separated from the ectolophid. Rarely for early Ischyromyoidea, a low thin mesiodistal ridge slopes from the postprotocristid distal 
flank to join the level of the mesial ectolophid, found here in small Corbarimys and the large Ailuravinae (nov. rank). The Ailuravinae species are brachydont, with acute cusps and cuspids much protruding above the crown edge; they keep a buccolingually narrow and high trigonid, with the anterolophid higher than the metalophulid II. Therefore, the mesiodistal cristid is weak and strongly sloping to the very short or indistinct mesial ectolophid. The entolophid generally reduces to a short lingual part, connected distally to the large and acute hypoconulid. In ailuravids, this lingual entolophid overhangs a trench, allowing oblique masticatory movements. A short anterior arm of the hypoconid results from a lingual stretching of the hypoconid. On upper teeth, the hypocone, always present, is weaker and lower than the protocone, and the endoloph is absent to low.

The first clade following the Ailuravinae is that of the medium sized Euromyidae (Meldimys and Euromys). They display dental apomorphies of Theridomorpha (weak unilateral hypsodonty, with faintly protruding cusps and cuspids above the crown edge, protoloph and metaloph developed, mesoloph variably present, endoloph high, hypocone present, metalophulid I only or predominent, postprotocristid oblique and thick, making an angle with the weak and short mesial ectolophid). These features have spread among most of the early Eocene European rodents at least since mid-early Eocene (MP8-9). They are associated with the enlargement of the i.o.f., related to lengthening and strengthening of the masseter medialis, and we found this for several basal Theridomorpha. They may correspond to a masticatory innovation, together with the development of hypsodonty, flattening and enlargement of occlusal surfaces with increase in size of premolars, as well as that of the hypocone on upper teeth, and transverse lophs in several lineages, and would explain the success of Theridomorpha during the Paleogene in Europe.

Euromys thaleri shows a wear pattern of lower molars close to that of Ailuravus. As all the basal Theridomorpha, the transverse lophs and lophids are often incomplete, the enamel surface is ornamented (extra-ridges or granules). The large species Euromys woodi previously referred with doubt to ?Paramys appears closely related to Euromys thaleri, in the same strongly supported clade.

The Plesiarctomyidae are within the basal Theridomorpha, closer to Sparnacomys than the Euromyidae. Convergently to the Ischyromyoidea, the large Plesiarctomys has also a mesiodistal postprotocristid, but the latter is stronger and higher than in ischyromyids. It becomes slightly oblique on the late Eocene species of Plesiarctomys; and the metalophulid II is variably present, whereas the metalophulid I predominates. Therefore, in Plesiarctomys, the trigonid basin reduces to a shallow and mesiodistally short anteroflexus, between the low anterolophid and the high metalophulid I, whereas the part of the trigonid posterior to the metalophulid I makes the relatively low anterior slope of the talonid basin. The latter is straightened at its bottom due to the large bases of the main cuspids. For this, this genus is different from Pseudoparamys, on which the talonid basin is widely open and cup-shaped, with flat floor surrounded by steep edges. Pseudoparamys has a mesiobuccally to distolingually oblique postprotocristid and a predominant metalophulid I, as well as a large i.o.f. In Plesiarctomys, the i.o.f. is smaller and considered to be protrogomorphous by Wood (1970), even if we show that it is relatively enlarged (Plate 1) in Plesiarctomys savagei.

Between the Plesiarctomyidae and the first Theridomyoidea (node L, Fig. 4), three branches of small sized Theridomorpha differentiate (node J, Fig. 4), successively: Sparnacomys, Pantrogna and the Hartenbergeromys clade. They show basal theridomorph features, their unilateral hypsodonty being weakly developed: on upper molars, complete protoloph and metaloph connecting the protocone apex, the hypocone being still smaller than the protocone, the endoloph nearly as high as the protocone and hypocone, and the sinus absent or shallow. For the species arranged until this node $\mathrm{J}$, the protoconid is strongly reduced or absent on $\mathrm{p} 4$, whereas it is present and well developed among basal Theridomorpha. The morphological and size analyses of the numerous samples from Avenay (mid-early Eocene, MP8-9) (Sparnacomys chandoni and Pantrogna russelli), and from Prémontré (late early Eocene, MP10) (Hartenbergeromys hautefeuillei and $H$. marandati) allowed us to characterize the variability of size and features. Their integration in the phylogenetic analyses, suggests that there is no reason to refer the two species of Prémontré to different genera, but both to the genus Hartenbergeromys. Moreover, we preserve the monophyly of Pantrogna, the type of which is $P$. russelli, the sister species of them. The species georgei Hooker (2010), here doubtly maintained in the genus Sparnacomys is hystricomorphous, as well as the two species of Hartenbergeromys from Prémontré. This cranial apomorphy of Theridomorpha, is characteristic of subsequent clade, i.e., the Masillamyidae, the Protadelomys clade and the Pseudosciuridae, and inferred for the paraphyletic branches of Protadelomys. These results, based on detailed morphological analyses, upon which was assembled the taxon/character matrix for the phylogenetic analyses, indicate the paraphyly of the genus Protadelomys. The taxonomic revision of this genus is in progress and will be published separately and subsequently given the already extensive length of this present paper.

Auroremys subita, was previously referred to Ailuravus on the bases of morphological features of upper molars, that appear to be homoplastic, like the occurrence of the ectocingulum, the protoloph and metaloph (when present) convergent on the protocone. However, in A. subita, the hypocone is as developed as the protocone and situated at the same lingual level, the sinus is well defined, deep and relatively long linguobuccally; the junction of the high strong postprotocrista and prehypocrista, making a V (as seen for example in Pseudosciurus or some teeth of Tardenomys or Tarnomys) replaces the endoloph. The lower molars are clearly Theridomyoidea, even Pseudosciuridae, with their low trigonid and thick oblique posprotocristid, their short anterolophid, anterolophulid, anterocingulid and antesinusid, like in Tarnomys, their high and complete entolophid, preventing the oblique wear pattern observed on Ailuravus.

\section{Prospects}

These results open up new prospects, through the many questions that have emerged following the analyses of the different taxa from their type localities. These questions will have to be addressed for other localities of the early and middle Eocene, notably from Southern France, like Mas de Gimel, Naples or Aumelas (Hérault).

If the first radiations in basal Theridomorpha involved only medium to large rodents, from Meldimys to Plesiarctomys (MP8-9 to MP10), the genera that emerged afterwards in our analyses (Sparnacomys, Pantrogna, and Hartenbergeromys) are contemporaneous small sized taxa. Their relationship with older taxa (MP7) remains to be established. This concerns notably the rodent fauna of Dormaal (Belgium). Among the Dormaal rodents, at least a maxillary fragment (CtM92), holotype of 
the species "Paramys" metacingularis Quinet, 1964, displays a wide i.o.f., whereas the m1 EFM501, of "Paramys" lemoinei (Teilhard de Chardin, 1922: fig. 1c), shows a metalophulid I, a buccal part of the metalophulid II, together with a mesiodistal posprotocristid sloping down to the mesial ectolophid. We have shown that the Theridomorpha characters, like the obliquely developed postprotocristid allied with the occurrence of the metalophulid I, have been found in genera previously considered as Ischyromyidae (Pseudoparamys, Euromys, Sparnacomys, Meldimys, Pantrogna, and Hartenbergeromys) as well as the large i.o.f., when preserved (Pseudoparamys, Hartenbergeromys, and Masillamys). It would be possible to even more enlarge the content of theTheridomorpha clade extending back the first theridomorph radiations in the early Eocene, since MP7.

\section{ACKNOWLEGDMENTS}

This work has benefited from the collections and facilities of the Senckenberg Research Institute and Natural History, Museum Frankfurt and of the Hessische Landesmuseum in Darmstadt, for the material of Masillamys from Messel. Thanks to the Senckenberg teams in Frankfurt, and to Torsten Wappler from the Hessischen Landesmuseum in Darmstadt for their efficient and warm welcome. Many thanks also to Loïc Costeur for the warm welcome and facilities for the studies of Protadelomys from Egerkingen at the Naturhistorisches Museum, Basel and to Emmanuel Robert, who welcomed us at the Université de Lyon and allowed us to study the Protadelomys from Lissieu. Other material of this species has been loaned to us by Didier Berthet, from the Musée des confluences, Lyon. We are endebted to Guillaume Billet from the Muséum national d'Histoire naturelle in Paris for the loan of a part of the rodents from Avenay and Mutigny, and to Jerry Hooker, from the Department of Earth Sciences of Natural History Museum, in London, who kindly sent us casts and pictures of Sparnacomys georgei and Pseudoparamys sp. from Abbey Hood. We are greatly endebted to the Société Laonnoise et Axonaise de Paléontologie, especially for the fossil rodents from Prémontré, which have been collected by Emmanuel and Michel Dégrémont, Pierre Louis, Michel Laurain, Maurice Sabatier, Frédéric Hautefeuille, Raoul Tété, François Duchaussois, and David Zuccola. Overall, this work would not have been possible without the important collections stored in the Institut des Sciences de l'Evolution de Montpellier (Université de Montpellier) for the other localities mentioned. Finally, this manuscript has been improved thanks to the pertinent remarks of an anonymous reviewer for the English language and some questions of systematics, and Vincent Lazzari (PALEVOPRIM, Poitiers), who pushed us to integrate some elements of statistics in this work. We are also extremely indebted to Rodolphe Tabuce, who had the difficult task of editing this work, at the expense of his own research activities. We thank him warmly for this.

This is ISE-M publication $\mathrm{n}^{\circ} 2021-224$.

\section{BIBLIOGRAPHY}

Aguilar, J.-P., Legendre, S., Michaux, J., 1997. Biochronologie mammalienne du cénozoïque en Europe et domaines reliés. In: Aguilar, J.-P., Legendre, S., Michaux, J. (Eds.), Actes du Congrès BiochroM'97. Mémoires et Travaux de l'Institut de Montpellier de l'Ecole Pratique des Hautes Etudes, Montpellier, 1-818.
Alston, E.R., 1876. On the classification of the order Glires. Proc. Zool. Soc. London 44, 61-98. https://doi. org/10.1111/j.1096-3642.1876.tb02543.x

Anderson, D., 2008. 18. Ischyromyidae. In: Janis, C.M., Gunnell, G.F., Uhen, M.D. (Eds.), Evolution of Tertiary Mammals of North America. Cambridge University Press, Cambridge, pp. 311-325. https://doi.org/10.1017/CBO9780511541438.019

Bravard, A., 1850. [Notes sur les ossements fossiles de la Débruge] in Gervais, 1850: légendes des planches 46, 47 et 48, 2-3.

Bremer, K. 1988. The limits of amino acid sequence data in angiosperm phylogenetic reconstruction. Evolution 42, 795-803. https:// doi.org/10.1111/j.1558-5646.1988.tb02497.x

Comte, B., Sabatier, M., Marandat, B., Vianey-Liaud, M., 2012. Les rongeurs de Chery-Chartreuve et Rocourt-saint-Martin (Est du Bassin de Paris ; Aisne, France). Leur place parmi les faunes de l'Eocène supérieur d'Europe. Palaeovertebrata 37, 169-270. https://doi.org/10.18563/pv.37.4-5.167-271

Escarguel, G., 1998. Protadelomys maximini nov. sp. (Rodentia, Mammalia) : apport à la connaissance du genre Protadelomys et implications biochronologiques. Geobios 31, 371-383.

Escarguel, G., 1999. Les rongeurs de l'Eocène inférieur et moyen d'Europe Occidentale. Systématique, phylogénie, biochronologie et paléobiogéographie des niveaux-repères MP7 à MP14. Palaeovertebrata 28, 89-351.

Estravis, C., 1992. Estudo dos mamiferos do Eocénico itiferior de Silveirinha (Baixo Mondego). Ph.D. Dissertation, New University of Sciences and Technology, Lisboa.

Godinot, M., Crochet, J.-Y.. Hartenberger. J.-L., Lange-Badré, B., Russell. D.E., Sigé, B., 1987. Nouvelles données sur les mammifères de Palette (Eocène inférieur, Provence). Münchner Geowissenschatliche Abhandlungen A 10, 273 288.

Harrison D.L., 2006. A new genus and species of 'paramyid' rodent (Rodentia: Ischyromyidae) from the Creechbarrow Limestone Formation (late Middle Eocene) of Dorset, England. Cainozoic Research 4, 51-60.

Hartenberger, J.-L., 1968. Les Pseudosciuridae (Rodentia) de l'Eocène moyen et le genre Masillamys Tobien. C. R. Acad. Sci. Paris $267,1817-1820$.

Hartenberger, J.-L., 1969. Les Pseudosciuridae (Mammalia, Rodentia) de l'Eocène moyen de Bouxwiller, Egerkingen et Lissieu. Palaeovertebrata 3, 27-61. https://doi.org/10.18563/pv.3.2.2764

Hartenberger, J.-L., 1970. Les mammifères d'Egerkingen et l'histoire des faunes de l'Eocène d'Europe. Bulletin de la Société géologique de France, S7-XII, 886-893. https://doi. org/10.2113/gssgfbull.S7-XII.5.886

Hartenberger, J.-L., 1971. La systématique des Theridomyoidea (Rodentia). C. R. Acad. Sci. Paris 273, 1917-1920.

Hartenberger, J.-L., 1975. Evolution des rongeurs primitifs de l'Ancien monde. Colloque international CNRS - Problèmes actuels de paléontologie (Evolution des vertébrés) 218, 777-791.

Hartenberger, J.-L., 1993. New rodents from the Middle Eocene of Europe and remarks about the early history of the group. Kaupia, 3, 165-171.

Hartenberger, J.-L., 1995. Place des Ailuravinae dans la radiation initiale des rongeurs en Europe. C. R. Acad. Sci. Paris 321, 631-637.

Hooker, J.J., 1986. Mammals from the Bartonian (middle/late Eocene) of the Hampshire Bassin, southern England. Bulletin of the British Museum of Natural History 39, 191-478.

Hooker, J.J., 1996. Mammals from the Early (Late Ypresian) to Middle (Lutetian) Eocene Bracklesham Group, southern England. Tertiary Research 16, 141-174.

Hooker, J.J., 1998. Mammalian faunal change across the PaleoceneEocene transition in Europe. In: Aubry, M.P., Lucas, S.G., Berggren, W.A. (Eds.), Late Paleocene - early Eocene climatic and biotic events in the marine and terrestrial records. Columbia University Press, New York, pp. 428-450.

Hooker, J.J., Weidmann, M., 2000. The Eocene mammal faunas of Mormont, Switzerland: systematic revision and resolutions 
of dating problems. Schweizerische paläontologische Abhandlungen 120, 1-143.

Hooker, J.J., 2010. The mammal fauna of the early Eocene Blackheath Formation of Abbey Wood, London. Monograph of the Palaeontographical Society 164, 1-159.

Hooker, J.J., Cook, E., Benton, M.J., 2005. British Tertiary fossil mammal GCR sites. In: Benton, M.J., Cook, E., Hooker, J.J. (Eds.), Mesozoic and Tertiary Mammals and Birds of Great Britain. Geological Conservations Review Series, 32, pp. 67-124.

Korth, W.W., 1988. The rodent Mytonomys from the Uintan and Duchesnean (Eocene) of Utah, and the content of the Ailuravinae (Ischyromyidae, Rodentia). ). Journal of Vertebrate Paleontology 8, 290-294. https://doi.org/10.1080/ 02724634.1988 .10011711

Korth, W.W., 1994. The Tertiary Record of Rodents in North America, Plenum Press, New York, London. https://doi. org/10.1007/978-1-4899-1444-6

Lavocat, R., 1951. Révision de la faune des mammifères oligocènes d'Auvergne et du Velay. Sciences et Avenir, Paris, 1-153.

Lavocat, R., 1955. Quelques progrès récents dans la connaissance des rongeurs fossiles et leurs conséquences sur divers problèmes de systématique, de peuplement et d'évolution. Colloque International du CNRS 60, 77-85.

Lenz, O.K., Wilde, V., Mertz, D.F., Riegel, W., 2015. New palynologybased astronomical and revised ${ }^{40} \mathrm{Ar} /{ }^{39} \mathrm{Ar}$ ages for the Eocene maar lake of Messel (Germany). International Journal of Earth Sciences 104, 873-889. https://doi.org/10.1007/s00531-014$1126-2$

Lewis, P.O., 2001. A likelihood approach to estimating phylogeny from discrete morphological character data. Systematic Biology 50, 913-925. https://doi.org/10.1080/106351501753462876

Louis, P., 1966. Note sur un nouveau gisement situé à Condé-en-Brie (Aisne) et renfermant des restes de mammifères de l'Eocène inférieur. Ann. Univ. Reims, A.R.E.S. 4, 108-118.

Louis, P., 1970. Note préliminaire sur un gisement de mammifères de l'Eocène inférieur situé Route de Broyes à Sézanne (Marne). Ann. Univ. Reims, A.R.E.S. 8, 48-62.

Louis, P., Laurain, M. (with the collaboration of C. Bolin and L. Barta), 1983. Nouveau gisement de vertébrés dans le Cuisien supérieur de Saint-Agnan (Aisne). Ses relations stratigraphiques avec les autres gisements yprésiens de Bassin Parisien. Bulletin d'Information des Géologues du Bassin de Paris 20, 3-20

Major, F., 1873. Nagerüberreste aus Bohnerzen Süddeutschlands und der Schweiz. Palaeontographica 22, 5-130.

Marivaux, L., Vianey-Liaud, M., Jaeger, J.-J., 2004. High level phylogeny of early Tertiary rodents. Zoological Journal of the Linnean Society 142, 105-134. https://doi.org/10.1111/ j.1096-3642.2004.00131.x

Marivaux, L., Boivin, M., 2019. Emergence of hystricognathous rodents: Palaeogene fossil record, phylogeny, dental evolution and historical biogeography. Zoological Journal of the Linnean Society 187, 929-964. https://doi.org/10.1093/zoolinnean/ $\underline{\text { zlz048 }}$

Marandat, B., 1989. Mammifères nouveaux de l'Ilerdien des Corbières et du Minervois (Bas Languedoc, France). Palaeovertebrata $19,161-167$

Marandat, B., 1991. Mammifères de l'Ilerdien moyen (Eocène inférieur) des Corbières et du Minervois (Bas-Languedoc, France). Systématique, biostratigraphie, corrélations. Palaeovertebrata 20, 55-144.

Martin, T., 1992. Schmelzmikrostruktur in den inzisiven alt-und neuweltlicher hystricognather nagetiere. Palaeovertebrata 21 , $1-168$.

Michaux, J., 1964. Diagnoses de quelques Paramyidés de l'Eocène inférieur de France. Comptes Rendus sommaires des Séances de la Société Géologique de France 1, 153-154.

Michaux, J., 1968. Les Paramyidae (Rodentia) de l'Eocène inférieur du Bassin de Paris. Palaeovertebrata 1, 135-193. https://doi. org/10.18563/pv.1.4.135-193
Miller, M.A., Schwartz, T., Pickett, B.E., He, S., Klem, E.B., Scheuermann, R.H., Passarotti, M., Kaufman, S., O'Leary, M.A., 2015. A RESTful API for access to phylogenetic tools via the CIPRES Science Gateway. Evolutionary Bioinformatics Online 11: 43-48 https://doi.org/10.4137/EBO.S21501

Peláez-Campomanes, P., 1995. Primates and rodents from the middle Eocene of Casa Ramón. Proceedings of the Koninklijke Nederlandse Akademie van Wetenschappen 98, 291-312.

Quinet, G.E., 1964. Morphologie dentaire des mammifères éocènes de Dormaal. Bulletin du Groupement international pour la Recherche scientifique en Stomatologie 7, 272-294.

Rambaut, A, Drummond, A.J., Xie, D., Baele, G., Suchard, M.A., 2018. Posterior summarization in Bayesian phylogenetics using Tracer 1.7. Systematic Biology 67, 901-904. https://doi. org/10.1093/sysbio/syy032

Rana, R.S., Kumar, K., Escarguel, G., Sahni, A., Rose, K.D., Smith, T., Singh, H., Singh, L., 2008. An ailuravine rodent from the lower Eocene Cambay Formation at Vastan, western India, and its palaeobiogeographic implications. Acta Palaeontologica Polonica 53, 1-14. https://doi.org/10.4202/app.2008.0101

Ronquist, F., Teslenko, M., Van der Mark, P., Ayres, D.L., Darling, A., Höhna, S., Larget, B., Liu, L., Suchard, M.A., Huelsenbeck, J.P., 2012. MrBayes 3.2: efficient Bayesian phylogenetic inference and model choice across a large model space. Systematic Biology 61, 539-542. https://doi.org/10.1093/ sysbio/sys029

Ruf, I., Lehmann, T., 2018. Rodents - Gnawing their way to success. In: Smith, K.T., Schaal, S.F.K., Habersetzer, J. (Eds.), Messel, An Ancient Greenhouse Ecosystem. Schweizerbart, Stuttgart, pp. 263-270.

Rütimeyer, L., 1891. Die Eocäne Saügethier-Welt von Egerkingen. Gesammtdarstellung und dritten Nachtrag zuden « Eocänen Saügethieren aus dem Gebiet des schweizerischen Jura (1862) ». Abhandlungen der Schweizerischen Paläontologischen Gesellschaft 18, 1-153.

Schmidt-Kittler, N., 1971. Odontologische Untersuchungen an Pseudosciuriden (Rodentia, Mammalia) des Alttertiärs. Abhandlungen (Bayerische Akademie der Wissenschaften. Mathematisch-Naturwissenschaftliche Klasse) 150, 1-133.

Schmidt-Kittler, N., 1987. International Symposium on Mammalian Biostratigraphy and Paleoecology of the European Paleogene. Münchner Geowissenschaftliche Abhandlungen.

Slowinski, J.B., 1993. "Unordered" versus "ordered" characters. Syst. Biol. 42, 155-165. https://doi.org/10.1093/sysbio/42.2.155

Smith, T., 1999. Les mammifères de la transition Paléocène-Eocène de Belgique (Formation de Tienen, MP7): systématique, phylogénie, paléoécologie, paléobiogéographie et biostratigraphie. Ph.D. Dissertation, Université de Louvain, Louvain.

Stehlin, H.G., Schaub, S., 1951. Die trigonodontie der simplicidentaten Nager. Schweizer. Paläontologische Abhandlungen 67, 1-385.

Swofford, D.L., 2002. PAUP*. Phylogenetic Analysis Using Parsimony (*and Other Methods). Version 4., 4 ed. Sinauer Associates, Sunderland, Massachusetts.

Teilhard de Chardin, P., 1922. Les mammifères de l'Eocène inférieur français et leurs gisements. Annales de Paléontologie 11, 9-116. https://doi.org/10.5962/bhl.title. 156400

Thaler, L., 1966. Les rongeurs fossiles du Bas-Languedoc dans leurs rapports avec l'histoire des faunes et la stratigraphie du Tertiaire d'Europe. Ph.D. Dissertation, Mémoires du Muséum National d'Histoire Naturelle, Paris

Tobien, H., 1954. Nagerreste aus dem Mitteleozän von Messel bei Darmstadt. Notizblatt des Hessisches Landesamt für Bodenforschung zu Wiesbaden 82, 13-29.

Vianey-Liaud, M., 1979. Evolution des rongeurs à l'Oligocène en Europe Occidentale. Palaeontographica A 166, 136-236.

Vianey-Liaud, M. 1998. La radiation des Theridomyinae (Rodentia) à l'Oligocène inférieur : modalités et implications biochronologiques. Geologica Paleontologica 32, 253-285.

Vianey-Liaud, M., Marivaux, L., 2017. Autopsie d'une radiation adaptative: Phylogénie des Theridomorpha, rongeurs 
endémiques du Paléogène d'Europe - histoire, dynamique évolutive et intérêt biochronologique. Palaeovertebrata 40, 1-68. https://doi.org/10.18563/pv.40.3.e1

Vianey-Liaud, M., Gomes Rodrigues H., Marivaux, L., 2010. A new Oligocene Ctenodactylinae (Rodentia: Mammalia) from Ulantatal (nei Mongol): new insight on the phylogenetic origins of the modern Ctenodactylidae. Zoological Journal of the Linnean Society 160, 531-550. https://doi.org/10.1111/ j.1096-3642.2010.00615.x

Vianey-Liaud, M., Marivaux, L., Lehmann T., 2019. A reevaluation of the taxonomic status of the rodent Masillamys Tobien, 1954 from Messel (Germany, late Lower to early Middle Eocene, 48-47 m.y.). Fossil Imprint 75, 454-483. https://doi. org/10.2478/if-2019-0028

Watrous, L.E., Wheeler, Q.D., 1981. The outgroup comparison method of character analysis. Systematic Zoology 30, 1-11. https://doi.org/10.1093/sysbio/30.1.1

Weitzel, K., 1949. Neue Wirbeltiere (Rodentia, Insectivora, Testudina) aus dem Mitteleozan von Messel bei Darmstadt. Abhandlungen der Senckenberg Gesellschaft fur Naturforschung 480, 1-245.
Wood, A.E., 1962. The early Tertiary rodents of the family Paramyidae. Transactions of the American Philosophical Society, Philadelphia 52, 1-261. https://doi.org/10.2307/1005914

Wood, A.E., 1970. The European Eocene paramyid rodent, Plesiarctomys. Verhandlungen der Naturforschenden Gesellschaft, Basel 80, 237-278.

Wood, A.E., 1976. The paramyid rodent Ailuravus from the Middle to Late Eocene of Europe, and its relationships. Palaeovertebrata 7, 117-149.

Yans, Y., Marandat, B., Masure, E., Serra-Kiel, J., Storme, J.Y., Schnyder, J., Marivaux, L., Adnet, A., Vianey-Liaud, M., Tabuce, R., 2014. Refined bio- (benthic foraminifera, dinoflagellate cysts) and chemostratigraphy $\left(\delta^{13} \mathrm{C}_{\mathrm{org}}\right)$ of the earliest Eocene at Albas-Le Clot (Corbières, France): implications for mammalian biochronology in Western Europe. Newsletters on Stratigraphy 47, 331-353. https://doi. org $/ 10.1127 /$ nos $/ 2014 / 0050$

Zittel, K.A., 1893. Handbuch der paleontologie. I Abteilung, Paleozoologie, IV Band, Vertebrata (Mammalia). R. Oldenbourg, Munchen und Berlin. 

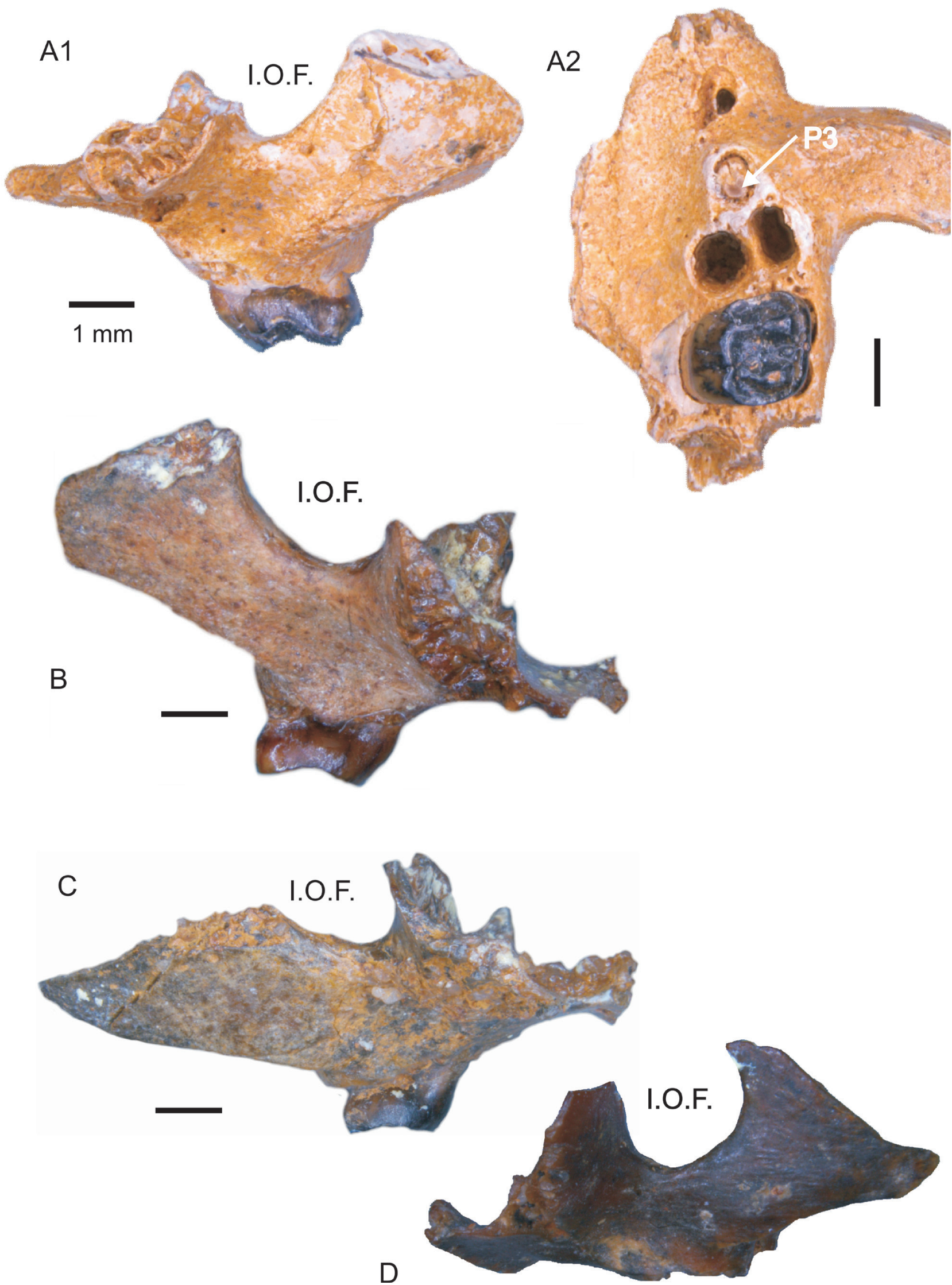

Plate 1. A. Plesiarctomys savagei (Michaux, 1964) from Prémontré (late Ypresian, MP10, Bassin de Paris). SLPZ 185, fragment of left maxillary. A1. Frontal view, showing the enlarged infra orbitary foramen (i.o.f.). A2. Palatal view, showing M1 and the alveoli of P3 and P4. B. SLP29PR 960, right maxillary of Hartenbergeromys marandati (Escarguel, 1999) from Prémontré (late Ypresian, MP10, Bassin de Paris); frontal view, showing the enlarged i.o.f. C-D. Hartenbergeromys hautefeuillei Escarguel, 1999, from Prémontré (late Ypresian, MP10, Bassin de Paris), frontal views showing the large i.o.f., C. SLP29PR 1312, right maxillary; D. MSPRE 67, left maxillary without teeth. 


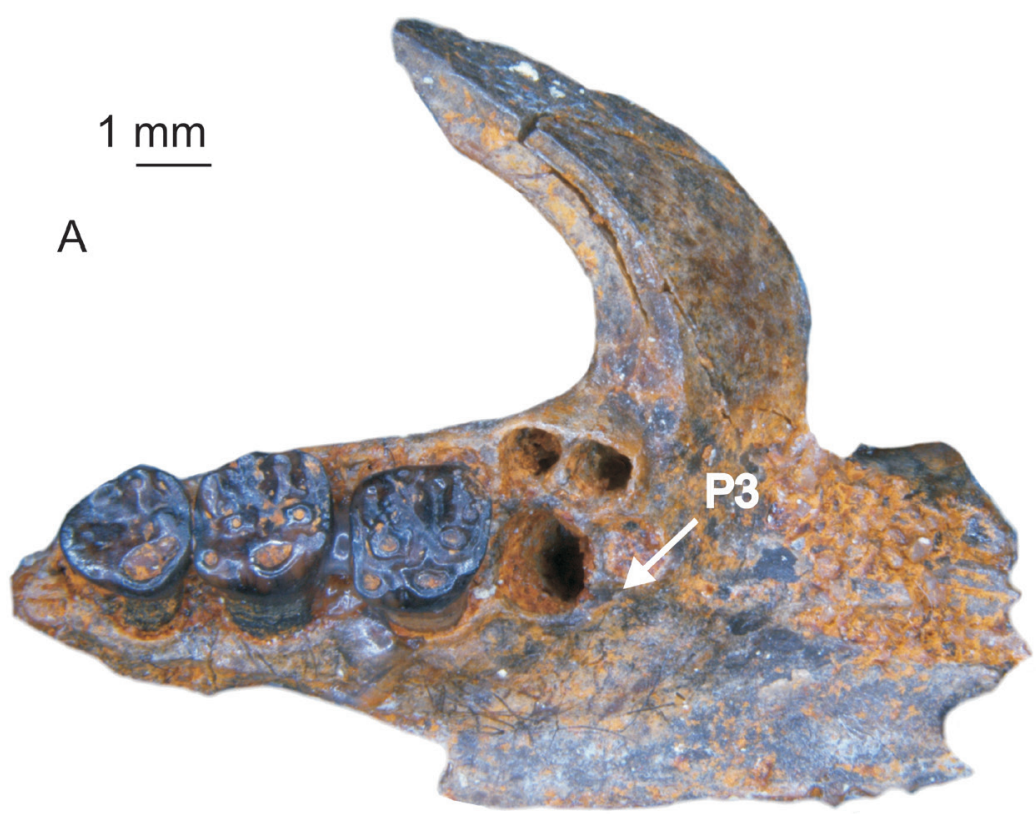

B
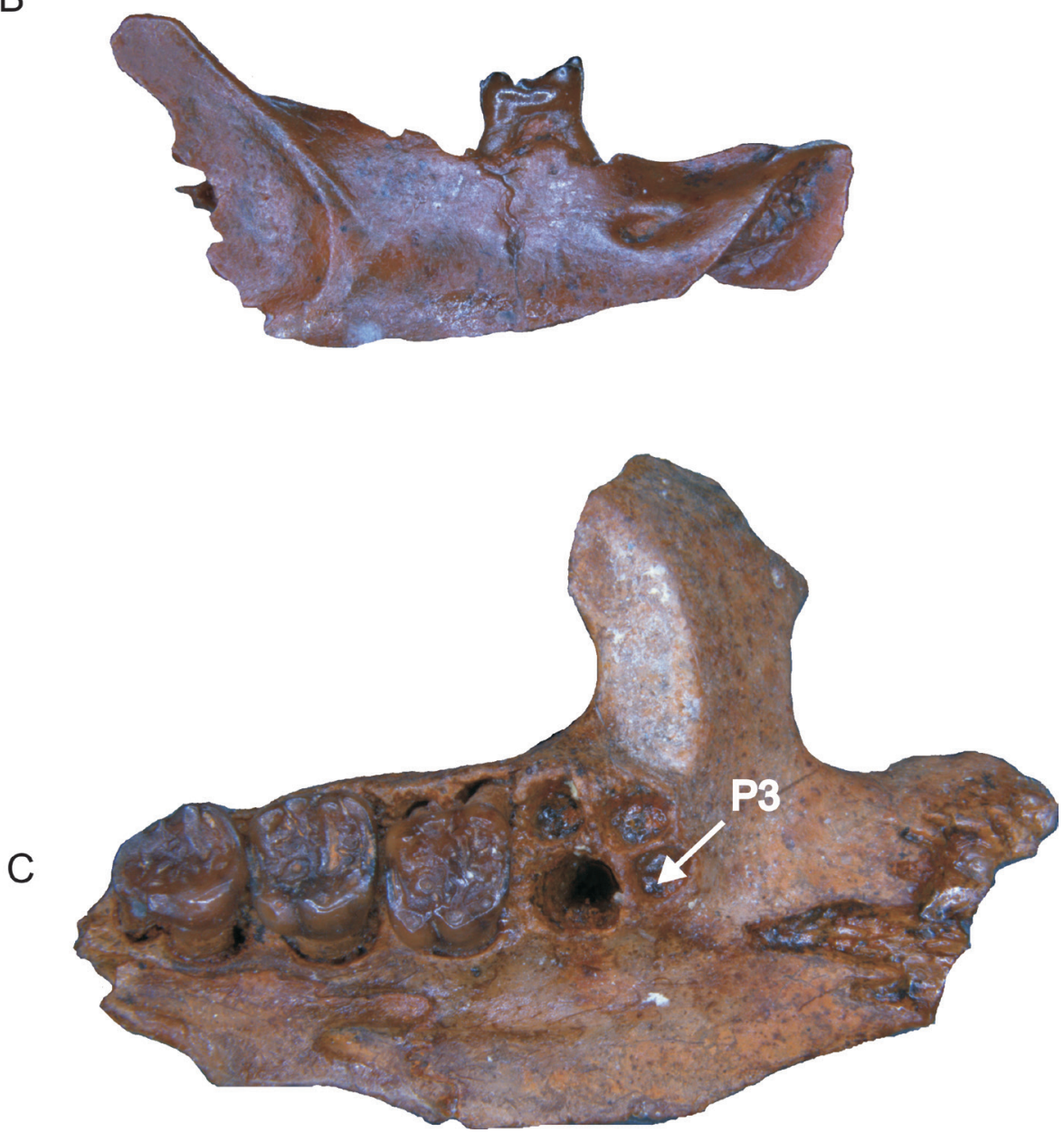

Plate 2. Hartenbergeromys from Prémontré (late Ypresian, MP10, Bassin de Paris). A-B. Hartenbergeromys hautefeuillei, Escarguel 1999; A. SLP29PR 1312, right maxillary bearing M1 to M3, and alveoli of P3 and P4, occlusal view. B. SLP29PR 2012, fragment of right juvenile lower jaw, buccal side, bearing d4. C. Hartenbergeromys marandati, Escarguel 1999. SLP29PR 960, right maxillary bearing M1 to M3, and alveoli of P3 and P4, occlusal view. 